\title{
Intestinal defense against bacterial toxins : role of LPS binding protein and lipoproteins
}

Citation for published version (APA):

Vreugdenhil, A. C. E. (2003). Intestinal defense against bacterial toxins : role of LPS binding protein and lipoproteins. [Doctoral Thesis, Maastricht University]. Universitaire Pers Maastricht. https://doi.org/10.26481/dis.20030509acv

Document status and date:

Published: 01/01/2003

DOI:

10.26481/dis.20030509acv

Document Version:

Publisher's PDF, also known as Version of record

\section{Please check the document version of this publication:}

- A submitted manuscript is the version of the article upon submission and before peer-review. There can be important differences between the submitted version and the official published version of record.

People interested in the research are advised to contact the author for the final version of the publication, or visit the DOI to the publisher's website.

- The final author version and the galley proof are versions of the publication after peer review.

- The final published version features the final layout of the paper including the volume, issue and page numbers.

Link to publication

\footnotetext{
General rights rights.

- You may freely distribute the URL identifying the publication in the public portal. please follow below link for the End User Agreement:

www.umlib.nl/taverne-license

Take down policy

If you believe that this document breaches copyright please contact us at:

repository@maastrichtuniversity.nl

providing details and we will investigate your claim.
}

Copyright and moral rights for the publications made accessible in the public portal are retained by the authors and/or other copyright owners and it is a condition of accessing publications that users recognise and abide by the legal requirements associated with these

- Users may download and print one copy of any publication from the public portal for the purpose of private study or research.

- You may not further distribute the material or use it for any profit-making activity or commercial gain

If the publication is distributed under the terms of Article $25 \mathrm{fa}$ of the Dutch Copyright Act, indicated by the "Taverne" license above, 


\section{iutrin}

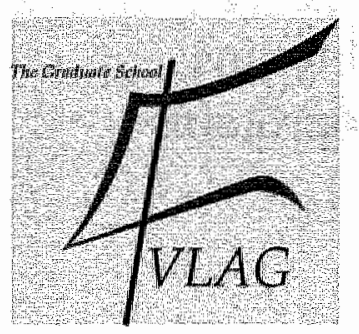

The study presented in this thesis was performed at the Nutrition and Toxicology Research Institute Mastricht (NUTRIM), which participates in the graduate school VLAG-2 (Food Technology, Agrobiotechnology, Nutrition and Health Sciences) accredited by the Royal Netherlands Academy of Arts and Sciences.

Productie: Datawyse, Maastricht

C. Anita C.E. Vreugdenhil, Maastricht, 2003

ISBN 90-901.6859-1 


\title{
Intestinal defense against bacterial toxins; role of LPS binding protein and lipoproteins
}

\section{PROEFSCHRIFT}

ter verkrijging van de graad van doctor aan de Universiteit Maastricht, op gezag van de Rector Magnificus, Prof. dr. A.C. Nieuwenhuijzen Kruseman, volgens het besluit van het College van Decanen, in het openbaar te verdedigen op vrijdag 9 mei 2003 om 16.00 uur

\author{
door
}

\section{Anita Corinne Eugenie Vreugdenhil}

geboren te Delft, 4 september 1971 


\section{Promotor}

Prof dr. W.A. Buurman

Co-promotor

Dr. J.W.M. Greve

Beoordelingscommissie

Prof dr. E.F.M. Wouters (voorzitter)

Prof. dr. R-J.M. Brummer

Prof. dr. R. Donckerwolcke

Prof. dr. C. Grunfeld (School of Medicine, San Francisco, USA)

Prof. dr. J. Verhoef (Universiteit Utrecht)

The work presented in this thesis was financially supported by a grant from the Dutch Digestive Diseases Foundation, The Netherlands and Numico Research, The Netherlands.

The financial support for publication of this thesis from Dr. Ir. van de Laar Stichting, Numico Research, Friso Kindervoeding and MeadJohnson is gratefully acknowledged. 
Aan mijn ouders,

Voor Jogchm, Stijn en ... 



\section{Contents}

Chapter 1 General introduction

The natural defense of the intestine against infection; a compass for future strategies in the battle against sepsis

Outline of the thesis

Chapter 2 Lipopolysaccharide Binding Protein and Serum Amyloid A secretion by human intestinal epithelial cells during the acute phase response

Chapter 3 Lipopolysaccharide Binding Protein is vectorially secreted and transported by cultured intestinal epithelial cells and is present in the intestinal mucus of mice

Chapter 4 Lipopolysaccharide Binding Protein circulates in association with apoB-containing lipoproteins and enhances endotoxinLDL/VLDL interaction

Chapter 5 Lipopolysaccharide Binding Protein mediates LPS detoxification by chylomicrons

Chapter 6 Enteral administration of high-fat nutrition before and directly after hemorrhagic shock reduces endotoxemia and bacterial translocation

Chapter 7 Phosphatidylcholine enhances apolipoprotein secretion by enterocytes during the acute phase response

Chapter 8 Summary and discussion

Samenvatting en discussie

Dankwoord

Curriculum vitae

Publications 



\section{Chapter 1 General introduction}

\section{The natural defense of the intestine against infection; a compass for future strategies in the battle against sepsis}

\section{Anita C.E. Vreugdenhil, Jan Willem M. Greve, Wim A. Buurman}

Natrition and Toxicology Research Institute Maastricht (NUTRIM). Department of General Surgery, Maastricht University, The Netherlands.

Manuscript submitted for publication 


\section{Introduction}

The clinical syndrome following invasion of Gram-positive and Gram-negative bacteria and their toxins, including hypotension and hypoperfusion of tissues, tachycardia, tachypnea, disseminated intravascular coagulation and organ dysfunction often resulting in death, is called the sepsis syndrome. The term "sepsis syndrome" suggests an unequivocal succession of events with well-defined signs and symptoms. However, the individual response initiated upon invasion of bacteria and their toxic metabolites is extremely whimsical and unpredictable. The course of sepsis can be fulminant with a fast clinicall deterioration and death within 24 hours in otherwise healthy persons, as seen for instance in meningoccocal sepsis. However, the course of sepsis and the systemic inflammatory response syndrome (SIRS) after major trauma and surgery may also occur late and can have a slow evolving course. The precise etiology and decisive factors in these distinct courses of sepsis are poorly understood, although a serious deterioration of the immune system is considered to be the leading cause of the live threatening multi organ failure (MOF). Paradoxically both, the selfdestructive effects of an overwhelming immune response as well as immunoparalysis are considered to be fundamental in the sepsis paradigm. After surgical procedures a plase of inflammation and hypo-inflammation do not only occur in sequence to each other but also in parallel, which complicates immunological monitoring and therefore also immunomodulation. Despite advances in intensive care, and decades of research, this notorious complication of surgery still lacks an effective treatment and consequently the mortality of sepsis is still estimated between $20-60 \%$ (1). The diversity of responsible pathogens, the complexity of the immunologic response and individual variation in the clinical course complicate the development of therapies. In the past, several interventions aimed at interrupting the inflammatory cascade, were studied and proven not successful. Inhibition of bacterial invasion and prevention of the initiation of this cascade are the ultimate goals of new treatment strategies aimed at intercepting the fatal effects of a deregulated immune response in the earliest stage. Most interestingly, the host is equipped with natural defense mechanisms extremely potent in deactivating bacterial toxin and preventing the initiation of an inflammatory response. In our vision, failure of these host defense mechanisms primarily causes the activation, deregulation and eventually inactivation of the immune system during sepsis. In search for new strategies aimed at reducing the fatal effects of sepsis, understanding the physiologic mechanisms that neutralize and clear bacterial toxin is of considerable importance.

Here the routes of entry for bacteria, the factors predisposing to bacterial invasion, and most important the host response to presence of bacterial compounds are described. In particular the natural defense mechanisms of the gut will be illuminated for two reasons. First, since the gut, being continuously exposed to high amounts of bacteria is an organ optimally equipped to prevent bacterial invasion and to defend against translocated bacteria and toxins. Second, the gut is a predominant source of bacteria and their toxic metabolites under pathologic conditions and is seen as the "engine" that drives sepsis. 


\section{Immune activation}

After entrance of bacteria and toxins into the host, cellular activation by bacterial toxins is an important initial step in the cascade of events that eventually results in sepsis and subsequent MOF. The principal pathogen-associated molecule of gramnegative bacteria, is lipopolysaccharide (LPS), a constituent of the outer membrane of all Gram-negative bacteria. Lipid A was identified as the biologically active part of LPS (2, 3). Lipoteichoicacid (LTA) and peptidoglycan (PGN) are important patllogenic compounds of gram-positive bacteria $(4,5,6)$. Cellular responses induced by these bacterial toxins are the net result of interaction with various plasma components such as complement, soluble CD 14 , LPS binding protein (LBP) and membrane receptors such as membrane bound CD 14, NOD1 and 2 and Toll-like receptors (TLR) (Figure 1). CD 14, a protein found on the surface of monocytes, macrophages and neutrophils (7), plays a crucial role in the cellular response to LPS, LTA and PGN $(8,9)$. CD14 is also found as a soluble protein in plasma, and complexes of LPS with soluble CD14 participate in responses of endothelial cells (10), epithelial cells (11) and possibly other cell types that do not express membrane CD14. Although CD14 is a glycosylphosphatidylinositol-anchored protein, which implicates that the receptor lacks an intracellular domain, binding of bacterial toxin to CD 14 initiates a response of cells $(12,13)$. Toll like receptors, a familly of transmembrane proteins, were recently identified to cooperate with CD14 and function as signal transducing molecules (14).

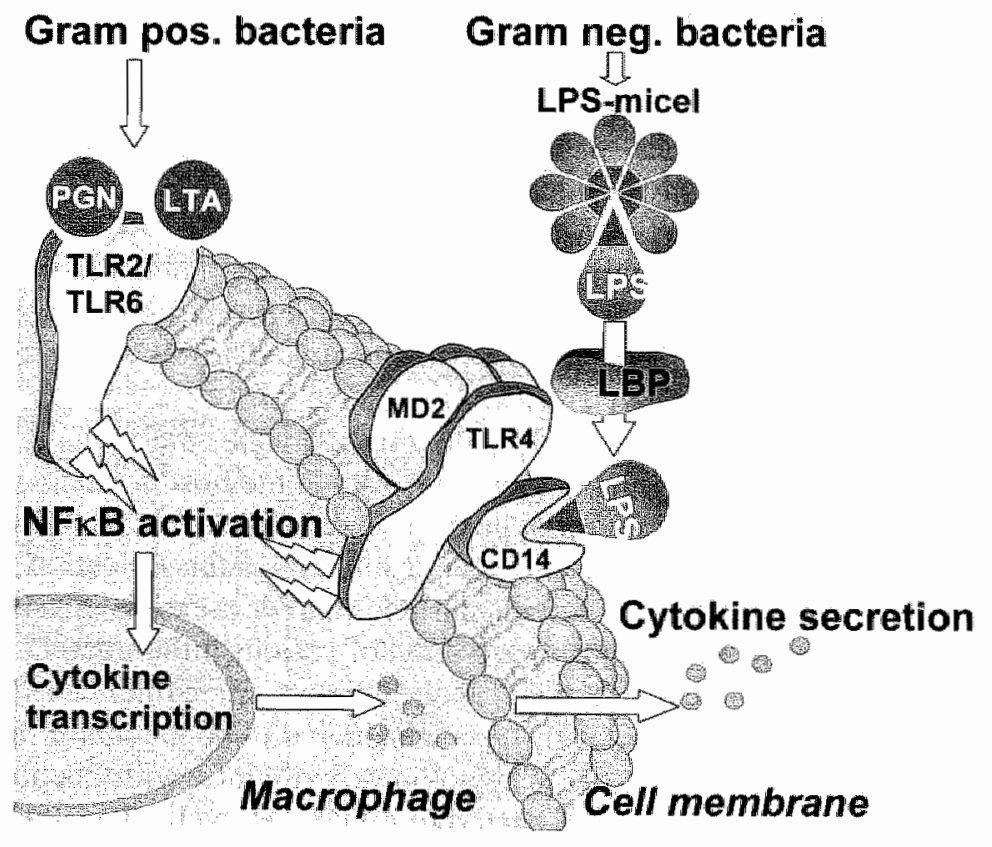

FIGURE 1. Celactivation by bacterial toxins. LPS derived from Gram-negative bacteria binds to CD14-TLR4-MD2 complexes on the cell membrane of macrophages. LPS binding protein (LAP) monomerizes LPS from micelles and catalyzes this binding. Peptidoglycan (PGN) and Lipoteichoicacid (LTA) derived from Gram-positive bacteria binds to TLR2/TLR6 complexes. Binding of bacterial toxin to these cell-membrane receptors activates $\mathrm{NF}-\mathrm{kB}$ in macrophages, thereby inducing eytokine transcription and release. 
LPS is reported to activate cells viat binding of TLR4 $(15,16)$, which requires the presence of the accessory protein MD2 (17). The toxins of gram-positive bacteria, PGN and LTA, activate cells via TLR2 (18). Findings of Bulut et al suggest that there is a functional interaction between TLR2 and TLR6 in the cellular response to these bacterial compounds (19). Other members of the TLR family are involved in the response to bacterial products as well; TLR9 was found to be responsible for mediating the recognition of bacterial DNA (20) and TLR5 is the Toll-like molecule that recognizes flagellin from both Gram-positive and Gram-negative bacteria (21). Binding of bacterial compounds to TLR activates $\mathrm{NF}-\mathrm{kB}(18,22)$ resulting in enlianced expression of cytokines, chemokines and adhesion molecules (Figure 1).

The acute phase protein, LBP, plays an important modulating role in cell activation by bacterial toxins. Although involvement of LBP in cell activation induced by LTA and PGN remains to be further evaluated, its role in LPS induced cell activation is indisputable (23). Once released from bacteria, LPS forms micelles. LBP is considered to monomerize LPS from micelles and subsequently transport LPS to membrane-bound CD14 on target cells (24) (Figure 1). Thereby LPS induced cell activation is strongly enhanced. Constifutive LBP circulates in low concentrations, whereas circulating LBP concentrations rise dramatically during infection for which the liver was held responsible for a long time. Recently, however, LBP secretion at extra-hepatic sites, amongst which the intestinal epithelium (25) and lung (26), was reported. In contrast to low concentrations of LBP, these acute phase concentrations have been shown to decrease endotoxin activity (27) and to protect against septic shock caused by Gramnegative bacteria $(23,27)$.

The immune response to microbial pathogens is initiated by recognition of pathogen components by host cells not only at the cell surface, also after phagocytosis a cellular response can be initiated in the cytosol. Recently NOD1 and 2 were identified as intracellular sensors of bacterial products. NODI and 2 are nucleotide-binding site leucine-rich repeat (NBS-LRR) proteins. This leucine rich repeated region (LRR) is homologues to that found in TLRs and was demonstrated to be required for LPSinduced NF-KB activation by NOD 1 and 2 (28).

Moreover, bacteria and microbial toxins directly activate the complement and coagulation system, which both play an important part in the host defensive response. The complement system is a multifactorial protein cascade system essentially involved in the early unspecific immune response. Its major function is the activation of cellular defense mechanisms, opsonisation of foreign particles and destruction of target cells.

Cell activation by bacterial toxins leads to secretion of various inflammatory mediators such as cytokines. The biological effects of bacterial toxins are mainly caused by these cytokines. Tumor necrosis factor- $\alpha$ (TNF- $\alpha$ ) is considered to be the major mediator of the pathogenesis of infection $(29,30)$. Chemokines, cytokines with chemoattractive capacity, are secreted in response to bacterial toxins, as well. Together with an increased expression of adhesion molecules, the presence of these chemokines results in chemotactic recruitment of neutrophils that are professional phagocytes, which take up bacteria and kill them by secretion of bactericidal substances and production of oxidative metabolites. 


\section{Hyper-and hypo-inflammation}

The initial systemic pro-inflammatory response to pathogenic components derived from invading bacteria is in particular caused by TNF- $\alpha$, interleukin-1 (IL-1), $I L-6$, and interferon- $\gamma$, which act synergistically and are considered to be "alarm" cytokines. Besides these mediators generated by activated cells, humoral cascades are activated directly in response to bacterial toxin or in response to cytokines, such as the complement- and coagulation-system that also release pro-inflammatory mediators. Although the release of these mediators is induced to promote survival of infection, an overwhelming response during fulminant sepsis becomes self-destructive and is responsible for induction of vascular leakage, hypotension and hypoperfusion of tissues, tachycardia, tachypnea, disseminated intravascular coagulation and organ dysfunction (Figure 2). The initial inflammation also induces a compensatory antiinflammatory response that prevents ongoing auto-destructive inflammation. The activation of these endogenous counter-regulatory systems may also predominate and cause the so-called immunoparalysis (Figure 2). This state of immunodeficiency is characterized by monocytic deactivation, marked by depressed HLA-DR antigen expression, the altered capacity of monocytes to induce antigen-specific $T$ cell stimulation and to release various cytokines (31). The multiplication and spread of bacteria and the toxic effects of their metabolites then becomes unanswered, resulting in nosocomial infections that cause late sepsis. There is evidence that inflammation and immunoparalysis do not only occur in sequence to each other but also in parallel early after extensive surgical procedures.

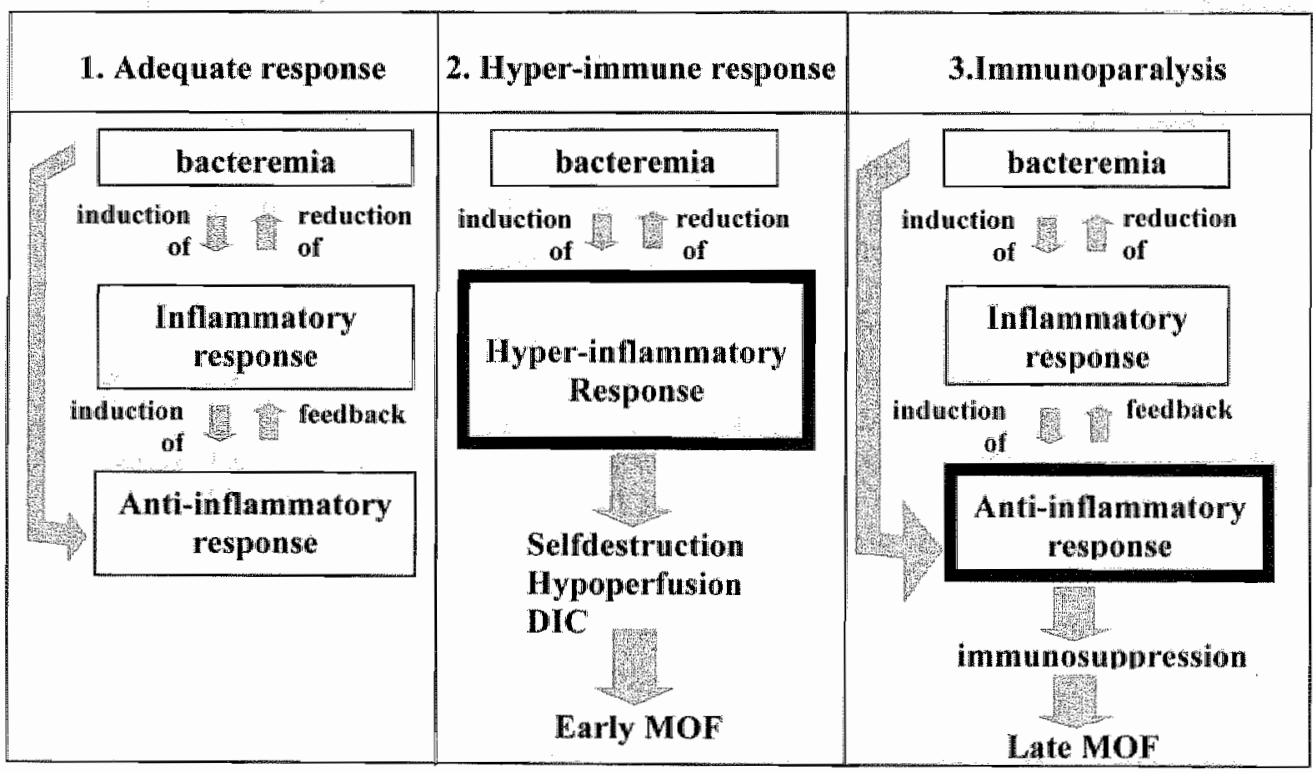

FIGURE 2. Inflanmatory responses during sepsis. 1. Adequate response; an early proinflammatory response adequately copes with circulating bacteria and endotoxin. The anti-inflammatory response initiated by the initial proinflammatory response prevents auto-destructive-hyperinflammation, 2 . Early MOF; the early proinflammatory response evolves into hyperinflammation which causes early MOF and shock 3. Late MOF; immediately after the release of inflammatory mediators an ant - $^{-}$ inflammatory response is initiated which paralyses the immune system and results in late MOF. 


\section{Lipoproteins, the natural antitoxins}

\section{Inactivation of bacterial toxins by lipoproteins}

of the known physiologic mechanisms for decreasing the stimulatory potency of bacterial toxins, the binding and detoxification by lipoproteins is most prominent. Already in the late seventies, high density lipoprotein (HDL) was demonstrated by Ulevitch et al to bind LPS as part of a two step process requiring serum (32,33). After binding to HDL, the ability of LPS to induce a cytokine response, fever, leucocytosis, and hypotension is strongly impaired $(32,33)$. Whereas Ulevitch et al focused on the interaction between HDL and LPS, nowadays all major lipoprotein classes have been demonstrated to bind LPS and reduce its activity as reflected by a diminished capacity of endotoxin to induce cellular cytokine production $(34,35,36)$. It was recently demonstrated that lipoproteins not only prevent LPS binding to cells, hence also promote the release of cell associated LPS thereby reducing cell activation (37) (Figure 3). This LPS detoxifying capacity of lipoproteins may underlie the in vivo observation that enhanced circulating concentrations of $\operatorname{LDL}(38,39)$, VLDL, chylomicrons and HDL (38) reduce the lethal effect of LPS in mice. Also in human, lipoproteins were demonstrated to be effective in attenuating the response to endotoxin (40). Besides binding of LPS, lipoproteins also bind toxins derived from gram-positive bacteria (41) and inhibit the ability of those toxins to activate macrophages $(42,43)$. Overall, these findings indicate that binding of bacterial toxins to lipoproteins prevents the initiation of the inflammatory cascade resulting from cell activation.

There is no consensus in the literature concerning the class of lipoproteins most relevant for LPS detoxification in vivo. Although several reports describe that LPS in human serum binds preferentially to LDL and VLDL $(34,44,45)$, work from other laboratories has shown that LPS binds to $\operatorname{HDL}(32,46,47,48)$. One reason for this discrepancy is that rabbits and rodents were used in the majority of the latter studies. The predominant binding of LPS to HDL in plasma from rabbits and rodents can be explained by the high levels of HDL and high HDL:LDL/VLDL ratio in the circulation of these animals as compared to human. The importance of this ratio in the fate of LPS in the circulation is derived from studies using New Zealand white rabbits in which LPS associates predominantly with HDL, while in Watanabe heritable hyperlipidemic rabbits LPS binds predominantly to LDL (34). The relevance of lipoprotein levels is also observed in human since persons with high HDL levels show higher binding of LPS to HDL as compared to persons with low HDL levels (45). HDL, LDL and VLDL might compete for LPS binding while in human serum the high LDL and VLDL concentrations result in predominant binding to these lipoproteins. However the preferential binding of LPS to HDL in humans is also described (49). These different observations are possibly caused by differences in separation techniques or by using EDTA plasma instead of serum to study interaction of LPS with lipoproteins or by presence of EDTA during the separation of lipoproteins. It has been shown that calcium chelation by EDTA increases binding of LPS to HDL $(50,51)$.

\section{Lipoprotein constiments involved in LPS-lipoprotein interaction}

Since endotoxicity can be prevented by cholesterol-rich as well as triacylglycerol rich lipoproteins, it is most likely that a lipid-lipid interaction is involved in the interaction between LPS and lipoproteins. Levine suggested a simple leaflet insertion model for 
binding and neutralization of lipopolysaccharide by phospholipids on the surface of lipoproteins (52). However, also apolipoproteins appear to be importantly involved in LPS binding and possibly also inactivation. We recently have shown LPS binding to apoB in a solid phase assay (44). In accordance, Victorov ef al demonstrated the association of LPS with predominantly apoB-100 on LDL (53). Enancipator found that both apoA-I and apoB reduce detection of endotoxin in the Limulus amebocyte lysate assay (54). Also, apoE was found to bind LPS (55). In line with this observation apoE-deficient mice display increased susceptibility to endotoxemia (56). In addition, hypertriglyceridemia induced by Intralipid was not effective in protection from endotoxemia (57) underlining the importance of apolipoproteins.

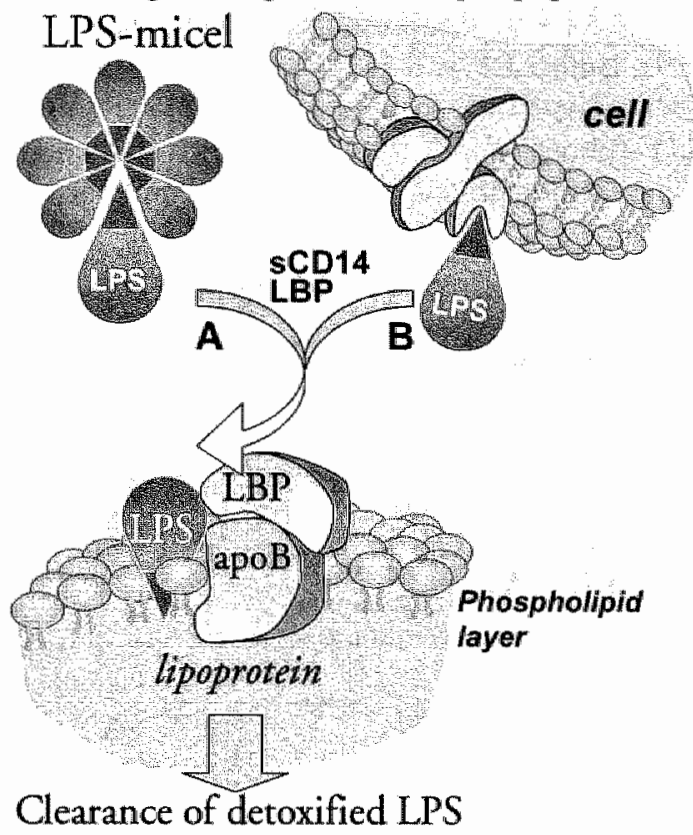

FIGURE 3. Deroxification of endotoxin by lipoproteins. LPS release from LPS-micelles (A) or cellmembranes (B) is catalyzed by circulating LBP and CDI4. LPS is then incorporated into the phospholipidlayer of lipoproteins (leaflet-insertion model). Also lipoprotein associated LBP enhances this incorporation. Lipid $A$, the biologic active part of LPS, is masked by lipoprotein binding and is not capable of cell activation. Subsequent lipoprotein bound LPS is cleared from the circullation.

\section{Plasma proteins involved in LPS-lipoprotein interaction}

It was demonstrated that plasma constituents other than lipoproteins or lipoprotein associated agents are required for lipoproteins to achieve maximal prevention of endotoxin-induced death in experimental animals (38), suggesting that a constituent of plasma is required for the binding of endotoxin to lipoproteins. Later studies identified various plasma proteins involved in the interaction of bacterial toxins with lipoproteins. The most essential protein in this respect is LBP. Besides its role in the transfer of monomerized LPS to CD14 on cells as described above, it also catalyzes binding of LPS (58) and LTA (42) to lipoproteins (Figure 3 route A). Subsequent, detoxification of these bacterial toxins by lipoproteins is strongly enhanced $(43,44$, 
58). Recently, using new techniques, we demonstrated that LBP circulates in association with apoB-containing lipoproteins. LBP associated with these lipoproteins effectively catalyzes LPS binding and detoxification $(43,44)$. These LBP and apoBcontaining lipoproteins were also identified as the predominant LPS transporting lipoproteins under healthy and septic conditions (44). Lamping et al demonstrated in a murine model that high levels of LBP in the circulation, as seen during an acute phase response, inhibit LPS effects and prevent mortality induced by endotoxemia (27). The latter observation strongly supports a physiological role for LBP dependent detoxification of LPS in host defense.

Another plasma protein involved in LPS binding to lipoproteins is SCD14. LBP catalyzed neutralization of LPS by lipoproteins is accelerated more than 30 -fold in the presence of $\mathrm{sCD} 14$ (59). Both LBP and $\mathrm{SCD} 14$, also diminish monocyte responses to LPS by transferring cell-bound LPS to lipoproteins (37) (Figure 3 route B). Besides LBP and SCD14, PLTP (phospholipid transfer protein), which shares $24 \%$ sequence similarity with LBP, was demonstrated to mediate the transfer of LPS to lipoproteins (60).

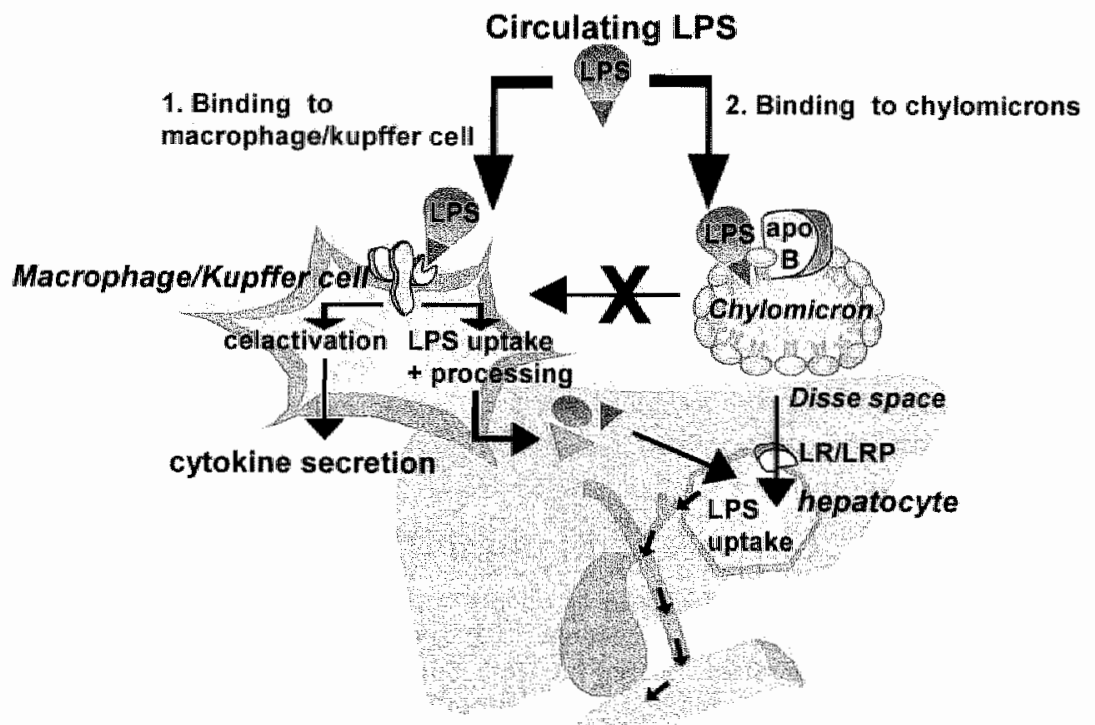

Secretion of inactivated LPS in bile/faeces

FIGURE 4. Hepatic processing and clearance of endotoxin. 1. LPS binds to membrane receptors on Kupfler cells, resulting in eell activation and subsequent cytokine release. LPS is internalized by Kupffer cells, processed and redistributed to hepatocytes and delivered to the bile and faeces. 2 . LPS associates with chylomicrons which enthance the plasma clearance and hepatic uptake of LPS. Chylomicrons shum LPS to hepatocytes and away from hepatic macrophages. The LDL receptor (LR) and LDL receptor related protein (LRP) participate in the rapid internalization of chylomicron-bound LPS by hepatocytes. Consequently, LPS is delivered into the bile, where it is inactivated by bile salts, and excreted with the faces. 


\section{Cleanance of bacterial toxins}

Besides detoxification of bacterial toxins, removal of toxins from the blood stream is an essential part of coping with bacterial infection. LPS is cleared from the bloodstream in a biphasic way. There is an initial rapid clearance followed by a phase with slower clearance rate (61). The liver is the main organ responsible for uptake of LPS from the circulation $(23,55,61)$. LPS internalized by Kupffer cells is redistributed to parenchymal cells and is delivered to the bile and faeces (61) (Figure 4). The TNF secretion by macrophages in response to LPS released by Kupffer cells is much lower then to native LPS, indicating that LPS is processed by Kupffer cells (62), Organ distribution studies of LPS demonstrate that several extra-hepatic binding sites exist.

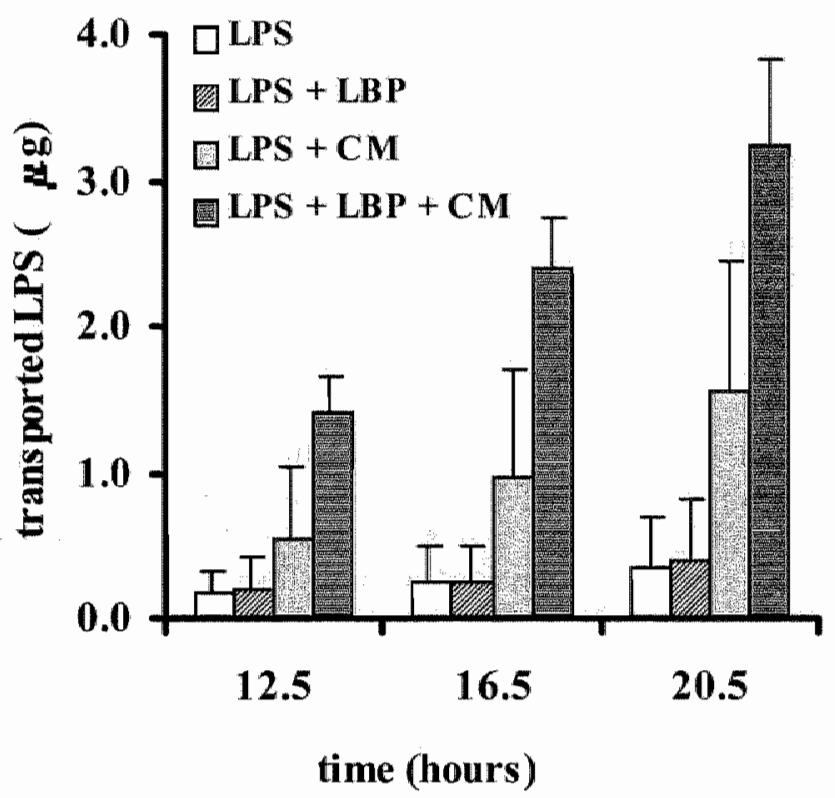

FIGURE 5. Chylonicrons and LBP cooperate in LPS clearance by enterocytes. lin vitro differentiated human colonic adenocarcinoma (Caco-2) cells were used as a model of normal human intestinal epithelial cells. Caco-2 cells were grown on collagen-coated membranes inserted in Transwells. After two weeks, Caco-2 monolayers display functional properties similar to those found in nonnal enterocytes and they form a polarized monolayer with tight junctions. Therefore, the experiments were conducted 14 days after seeding of the cells. At the start of the experiment, naintenance medium was removed, cells were washed and serum free medium containing $100 \mathrm{\mu g} / \mathrm{ml} \mathrm{LPS}-\mathrm{FITC}$ with or without chylomicrons (CM) isolated from human serum (10\% of circulating levels) and with or without 5 $\mu \mathrm{g} / \mathrm{ml}$ purified human LBP, was added at the basolateral side of the monolayers. After $12.5,16,5$ and 20.5 hours small amounts of the apical medium were removed and the fluorescence determined. LPS is transported from the basolateral towards the apical side of Caco-2 monolayers. This process is enhanced by presence of chylonicrons. LBP further enhanced the LPS transport across the monolayers in the presence of chylomicrons.

Recently evidence was found for uptake of circulating endotoxin by the intestinal epithelium followed by secretion of endotoxin into the intestinal lumen (63). These data suggest an important role for the intestine in the clearance of bacterial toxins in addition to the liver. 
The metabolic fate of LPS was shown to be strongly affected by complex formation with lipoproteins $(64,65,66)$. The association of LPS with HDL decreases its clearance from the circulation $(64,65)$. In contrast chylomicrons enhance the plasma clearance and hepatic uptake of LPS (Figure 4). Chylomicrons shunt LPS to hepatocytes and away from hepatic macrophages $(55,66)$. Harris et al recently presented data indicating that both the $\mathrm{LDL}$ receptor (LR) and LDL receptor related protein (LRP) participate in the rapid internalization of chylomicron-bound LPS by hepatopytes (67). Consequently, LPS is deliwered into the bile, where it is inactivated by bile salts (68). In addition, pilot experiments performed recently in our laboratory demonstrated that the clearance of LPS by intestinal epithelial cells is markedly enhanced by presence of both, chylomicrons and LBP (Figure 5).

\section{Lipoprotein metabolism during infection}

Lipoprotein metabolism is dramatically altered during infection, which alterations are mediated by cytokines. In human, circulating levels of total cholesterol, LDLcholesterol and HDL cholesterol decrease, whereas one of the earliest metabolic responses is an hypertriglyceridemia and concomitant enhanced hepatic secretion of the triacylglycerol rich VLDL (69), an effect caused by cytokines, in particular TNF (70). In contrast, in rodents and rabbits, endotoxemia induces hypercholesterolaemia instead of hypocholesterolemia $(71,72)$. In addition, in man alterations in apolipoprotein levels are observed $(69,73)$. ApoA-I concentrations drop and HDL becomes depleted in apoA-1 $(69,71)$. ApoB levels are not affected by either viral or bacterial infection (69). The rise in lipoprotein levels is postulated to reflect an endogenous mechanism to limit activity of bacterial toxin and thus is part of the host defense mechanism against bacterial toxin. The physiologic relevance of high lipoprotein concentrations appears from studies demonstrating that a low cholesterol concentration is associated with increased mortality due to a wide variety of chronic and acute disorders (74). Although the high concentration of circulating lipoproteins apparently has beneficial effects during acute infection, during chronic inflammation the enhanced presence of lipoproteins in the circulation is associated with the initiation of cardiovascular disease. Further enhancement of this efficient defense mechanism, i.e maximizing lipoprotein production in order to overcome the battle of man against sepsis, might from evolutional point of view be disastrous, since life threatening cardiovascular disease would then be a major complication of chronic inflammation at an early age.

\section{The intestine: the bacterial barrier that fails}

The gastrointestinal tract is considered the "motor" of the sepsis syndrome. Disruption of the gut mucosal barrier between the gastrointestinal content containing high amounts of bacteria and the sterile internal milien of the host and subsequent bacterial translocation has been identified as an integral part of the development of sepsis and MOF in critically ill, burn, trauma, and surgical patients $(75,76)$. Several studies support the concept that bacteria translocate from the gut to mesenteric lymph nodes, distant organs and systemic blood $(77,78)$ and are a potential source for lethal infections. Bacterial translocation is predisposed by conditions that 1) disturb the gastrointestinal microflora leading to bacterial overgrowth (75) such as antibiotic therapy and gastrointestinal stasis, 2) disnupt the physical barrier of the gut mucosa 
such as a reduced splanchnic blood flow, parenteral nutrition and starvation $(78,79)$ or 3) compromise the host immune system such as during the hypo-inflammatory phase of sepsis (Figure 6).

The mechanisms that underlie bacterial translocation are not well understood. Whether bacteria migrate transcellular, paracellular or both, remains unclear. In addition, most of the insights concerning bacterial translocation come from animal studies. Despite extensive evidence from animal studies, the number of publications concerning bacterial translocation involving human subjects is small. Human studies evaluating the role of bacterial translocation in pathogenic mechanisms are therefore urgently needed.

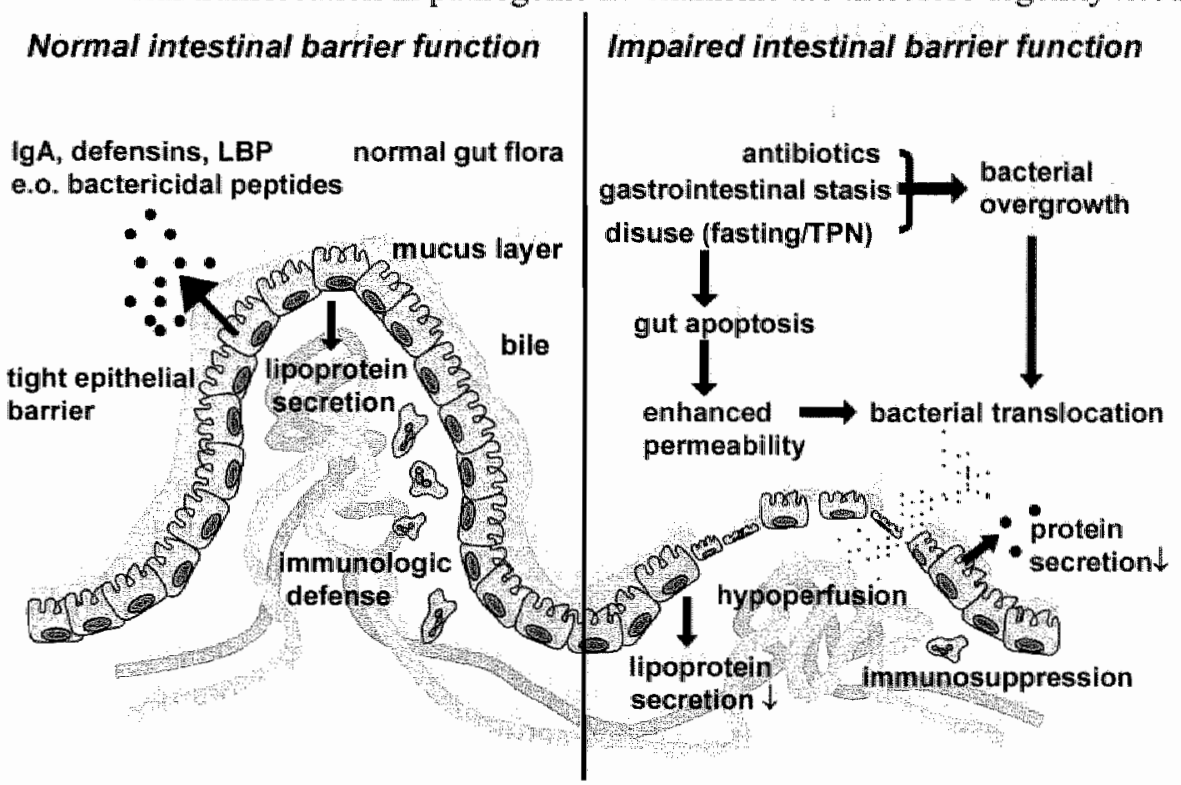

FIGURE 6. The intestinal barrier to bacteria and bacterial toxin. The physiologic epithelial barrier of the intestine against bacteria and bacterial toxin consist of a mechanical. epithelial barrier layered with mucus, the gut flora, anti-microbial peptides secreted by the epithelium and a cellular immunologic defense. Further, lipoproteins secreted by enterocytes are effective in detoxification of bacterial toxin. Under the extreme conditions of hemorhagic shock, major trama, severe burns, and complex surgicall interventions, the intestinal barrier often fails. Hypoperfusion of the splanchnic circulation and disuse of the gut (during fasting or TPN) results in atrophy of the intestinal mucosa, enhanced permeability and bacterial translocation. In addition, depletion of oral feeding and antibiotics disturbs the microfloren resulting in bacterial overgrowth. The conditions for intestinal lipoprotein secretion are strongly impaired. An initial hyperinflammatory response may result in local immunosuppresion.

\section{The self-perpetwating effect of translocated enteric bacteria}

The gut is seen as a source of bacteria, toxins and cytokines that initiates, aggravates and perpetuates the systemic inflammatory response in critically ill patients. Circulating bacterial toxins, and most likely inflammatory mediators produced in response to bacterial toxins, are thought to further disturb the integrity of the intestinal epithelium and enhance its permeabillity (80). This loss of integrity is considered to result in further bacterial translocation (80). In addition, gastrointestinal translocation of bacteria and endotoxin may induce immunosuppression after an initial local or 
systemic hyperinflammation. LPS-primed monocytes have a marked decreased HLAclass II antigen expression and were demonstrated to be greatly impaired in their capacity to induce antigen-specific $\mathrm{T}$ cell proliferation and cytokine production in vitro (immuno-paralysis) $(31,81)$. Such an induced immunoparalysis is considered to be an important predisposing factor for further bacterial translocation. This self-perpetuating capability of bacterial toxins, i.e. further destruction of the structure and function of the epithelium and undermining of the immunological defense of the intestinal mucosa, might be essential in the evolution of a simple infection into sepsis and MOF.

The phenomenon of impaired gut barrier function induced by circulating toxins, also suggests a possible role for enteric bacteria in infections initially caused by entrance of bacterial toxins via extra-intestinal sites such as wounds, respiratory airways, drains, arterial/venous catheters and the urinary tract.

Furthernore, PMNs primed in the intestine relocate to other organs where they can cause damage during a 'second hit' such as tissue injury or hemorrhagic shock. This second insult than causes these primed cells to react with an augmented response and cause increased endothelial injury within the target organs (82), in particular in the lungs. This explains the morphological changes observed in early sepsis-induced ARDS, i.e. pulmonary edema, vascular thrombosis and hemorrhages.

\section{Prevention of bacterial invasion by the intesiine}

The innate immune system of the intestinal mucosa consists of a physical barrier which functions to confine the intestinal microflora within the gut lumen and prevents colonization of the host with enteric bacteria. The first line of intestinal defense is formed by a thick mucus layer covering the epithelium of the intestine that prevents the attachment of microbes and helps to sweep bacteria away by peristalsis. Microbes are trapped in the mucus by sugar chains mimicking epithelial receptors for bacteria. The intestinal epithelium secretes antimicrobial substances in the mucus such as lysozyme (83) and defensins (84) (Figure 6). Furthermore, the presence of phospholipids in the mucus, derived from both the intestinal epithelium and bile, is thought to serve as surfactant preventing attachment of bacteria to the epithelium. Presence of bile in the intestinal lumen was demonstrated to be important in prevention of bacterial translocation (85). The microflora of the gut forms part of the nonspecific defense system of the gut as well, since the secretion of antibacterial substances by these microbes inhibits the growth of pathogenic bacteria (colonization resistance) $(86,87)$. In addition the microflora induces the intestinal production of bactericidal peptides (88).

\section{Defense against translocated bacteria and toxin}

Translocated bacterial toxins attract and activate strategically located macrophages and neutrophils and induce a cytokine response in the intestinal mucosa including production of the pro-inflammatory cytokines IL-1 $\alpha$ (89), IL-8 (90), TNF- $\alpha$ and IL-6 $(91,92)$. The function of the intestinal mucosa is regulated by epithelial cell-immune cell interactions mediated by these cytokines. Although activated macrophages are thought to be the predominant source for cytokines in the intestine, also endothelial cells, fibroblasts and even the epithelial cells in the intestine are involved in this cytokine response. The intestinal epithelium recognizes and responds to invading 
pathogens by secretion of various anti-mierobial and pro-inflammatory mediators ( 93 , 94). Recently, CD14 (95), TLR2 and TLR4 $(94,96,97)$, the receptors for bacterial toxins, were demonstrated to be present on intestinal epithelial cells: TLR expression by these cells is markedly upregulated under inflammatory conditions (94). Binding of LPS to TLR4 on intestinal epithelial cells activates NF-KB (96). In addition intestinal epithelial cells were demonstrated to release LBP, which is strongly upregulated by presence of cytokines (25). These data indicate that under non-inflammatory conditions, the low expression of TLR, MD-2 and LBP by intestinal epithelial cells protects against a dysregulated proinflammatory response to bacterial toxins. However, during inflammation, intestinal epithelial cells have all the necessary factors at their disposal to directly respond to bacterial toxin, implying that these cells may play a frontline role in the defense against bacteria and bacterial toxins (Figure 7).

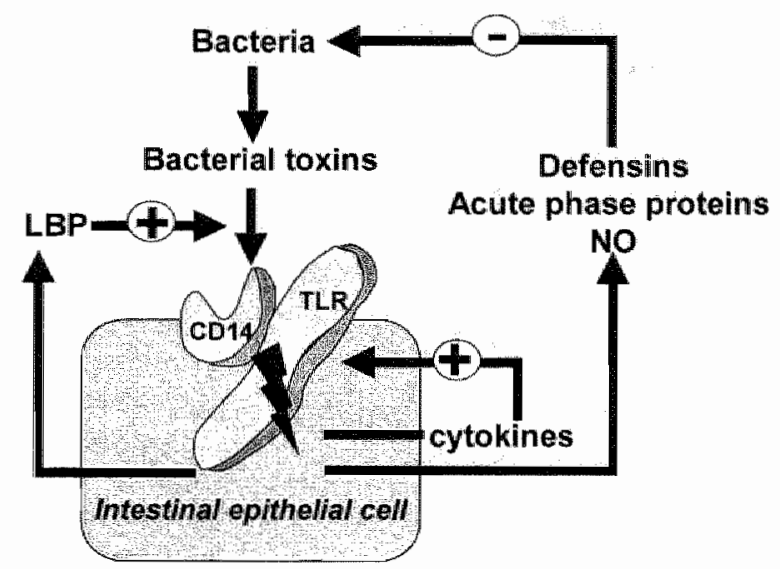

FIGURE 7. Acute phase response of intestinat epithelial cells. Receptors for bacterial toxins are upregulated during inflammation on intestinal epithelial cells. Subsequent, these cells are activated by binding of bacterial toxins to membrane receptors; CDI4 and TLR's. The secretion of LBP by intestinal cells is enhanced during inflammatory conditions. LBP catalyzes the binding of bucterial toxins to the epithelial cells, and as a result cell activation. The secretion of cytokines, acute phatse proteins, defensins and $\mathrm{NO}$ is enhanced by cell activation.

Cytokines produced in the intestine exert local effects on the regulation of the mucosal metabolism. The secretion of several anti-microbial agents such as the free radical nitric oxide (NO) (98) and defensins (83) are upregulated in response to cytokines. In addition the presence of cytokines induces the secretion of several acute phase proteins by the intestinal mucosa $(25,99,100)$ (Figure 7$)$ that are generally seen as important contributors to host defense.

Pathogenic antigens such as bacterial toxin also induce the activation of the gutassociated lymphoid tissue (GALT) among other things resulting in the luminal secretion of sIgA. slgA plays an important role in bacterial agglutination thereby preventing attachment and translocation of bacteria (101).

There is strong evidence that the intestine contributes to the lipoprotein induced detoxification and clearance of bacterial toxins. In response to nutrition, enterocytes produce chylomicrons, which bind endotoxins and accelerate their clearance from the 
circulation $(55,66)$. In addition chylomicron bound LPS is not able to elicit a cytokine response in cells (43). As a result, chylomicrons protect against endotoxin induced death and infusion of chylomicrons before or up to 30 min after the administration of endotoxin improved survival in rodents $(66,102)$. Moreover, LBP enhances the binding and detoxification of bacterial toxin by chylomicrons (43). In this context, the secretion of LBP by the intestinal mucosa is most interesting (25). Chylomicrons present in the circulation may cooperate with both, hepatic and gut derived LBP and detoxify circulating bacterial toxin. Besides detoxification of toxin in the circulation by LBP-chylomicron complexes; we hypothesize that this mechanism may be part of a local defense mechanism of the intestine against translocated bacterial toxins (Figure 8). Such a mechanism may oecur in the subepithelial space or in the lymphatics and possibly prevents further damage to the intestinal epithelial barrier caused by bacterial toxins and the entrance of biological active toxins into the circulation.

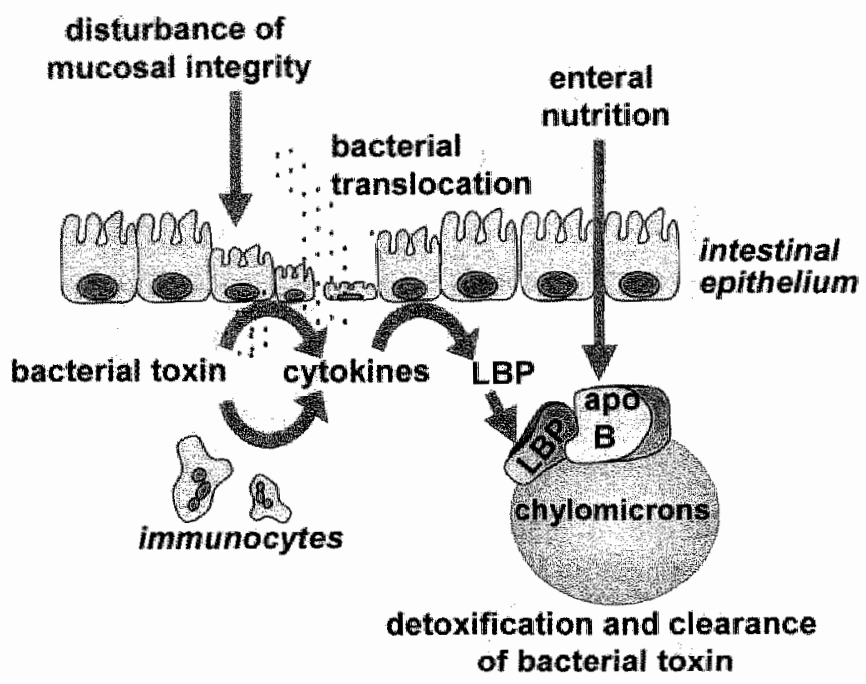

FIGURE 8. Proposed mechanism of detoxification of bacterial toxin in the gut. Bacteria translocate across an injured intestinal mucosa. Bacterial toxins released from bacteria induce the secretion of cytokines by intestinal epithalial cells and immunocytes. LBP secretion by the intestinal epithelium is enhanced in response to these cytokines. In response to enteral nutrition, the epithelial cells produce chylomicrons as well. Chylomicrons cooperate with LBP in the detoxification of bacterial toxins. Detoxification may take place in the subepithelial space or lymphatics. Hence, further damage to the intestinal barrier is prevented as well as entrance of biologically active bacterial toxin into the circulation. Moreover clearance of bacterial toxins is enhanced.

\section{Impaired intestinal defense in surgical patients}

The fatal effects of bacterial toxins are a rising surgical concern since the incidence of infectious complications, such as sepsis and SIRS, are increasing $(103,104)$ most probably due to aging of the population and as a result of more complex surgery. Although gram-negative bacteria have long been seen as the principle causative microbes, the incidence of sepsis caused by gram-positive bacteria has risen markedly the last few years (105). 
Trauma patients or patients undergoing major surgery have several predisposing factors making them at risk for developing enteric bacteraemia. These patients experience hypotensive periods and subsequent diminished perfusion of the splanchnic circulation resulting in intestinal and liver ischemia/reperfusion injury. The mucosal integrity is also impaired as a result of non- or parenteral feeding, which both cause atrophy of the intestinal mucosa. These injuries lead to a disturbed gut barrier function and are thought to promote the translocation of enteric bacteria and toxins into the portal circulation.

Also various drug treatments, i.e. antibiotics and antacids, disturb the normal ecology of the gut resulting in bacterial overgrowth. A reduction of gastrointestinal peristalsis due to intra-abdominal disease or injury resulting in stasis in the stomach and the intestines, also contributes to disturbance of the normal microbial ecology of the intestinal tract.

In conclusion, in patients undergoing extensive cardiovascular or abdominal surgery, the intestinal defense systems, which protect the host against invasion of bacteria, are severely impaired. Therefore the host depends on mechanisms that detoxify and clear bacterial toxin in an early stage, such as binding of toxin to lipoproteins. Ideally, toxins associate with lipoproteins directly after translocation across the intestinal mucosa by lipoproteins present in the submucosal space or the lymphatics. However, cytokines released in response to these bacterial toxins interact with enterocytes and diminish the secretion of intestinal lipoproteins. In this respect "TNF- $\alpha$ and I1-6 were demonstrated to reduce the synthesis of apoB and apoA-I and the secretion of lipids. and lipoproteins by intestinal epithelial cells $(106,107,108)$. In addition, TNF decreases the enteral absorption of fat (109). An additional effect of these circulating cytokines is anorexia (110). Moreover, critically ill patients admitted to an intensive care unit are in general initially starved or receive total parenteral nutrition (TPN). Hence, the main trigger for intestinal lipoprotein production, i.e. the presence of intraluminal nutrients, is strongly impaired during disease. This lack of enteral mutrition during critical illness also causes a profound reduction of bile flow and biliary phospholipid concentrations (111), which most probably further impedes intestinal lipoprotein secretion since presence of phospholipids in the intestinal lumen is required for secretion of lipoproteins by enterocyles $(112,113,114)$. Overall, during the acute phase response the conditions for intestinal lipoprotein secretion are poor, hence the capacity of the intestine to contribute to detoxification and clearance of bacterial toxins by means of lipoprotein secretion is limited. Improvement of the conditions required for intestinal lipoprotein secretion might interrupt this vicious circle and should be target of new strategies.

\section{Modulation of host defense against bacterial toxins}

\section{Interception of the inflammatory cascade}

There are distinct difficulties in the development of therapies for the prevention and management of sepsis. First of all an important point of dispute in the development of therapeutic strategies for sepsis is to either stimulate the immune system in order to enhance the defense against bacteria and toxin or to downregulate the response to prevent or reduce the self-destructive effects of a pro-inflammatory 'overshoot". Stimulation of the immune system may be useful during the anti-inflammatory 
response, for instance by activation of granulocytes and monocytes by IFN-gamma and collony stimulating factors, which indeed were demonstrated to have potential as adjunctive therapy in the treatment of infectious diseases (115). In contrast, during the hyperinflammatory phase anti-inflammatory therapy theoretically would be more effective. However, clinical trials with antagonists of I1-1 (116) and antibodies against TNF (117) have proved to be disappointing. The latter observation is in line with that of Echtenacher et al who demonstrated that $\mathrm{TNF}$ is required for survival of experimental septic peritonitis in a mouse model of cecal ligation and puncture (118). They hypothesize that during the early phase of peritonitis endogenous TNF may stimulate nonlymphoid cells such as granulocytes, macrophages, platelets, and fibroblasts to destruct bacteria and to localize inflammation. Most importantly, the current immunologic analyses are deficient in monitoring the biphasic pattern of hyperand hypo-inflammation during the course of sepsis. Such analyses are a prerequisite to decide which immuno-therapy to apply, as both hyper and hypo-inflammation are major determinants of an adverse clinical outcome.

Besides the lack of information concerning the immunologic stage of these patients, a major bottleneck concerning interventions is that once the sepsis cascade is initiated the diversity and complexity of the chain of events is enormous, including activation of the cytokine cascade, the complement cascade and the coagulation cascade. The inflammatory mediators produced form a network of interacting signals with overlapping activity. Attenuation of these complex effects by one therapeutic strategy once the acute phase response is initiated obviously is problematic.

Considering the apparent insuperable difficulties of interrupting the inflammatory cascade once it is started, prevention of bacterial translocation and detoxification of bacterial compounds responsible for the induction of an inflammatory response would hypothetically be more effective in preventing sepsis in the earliest stage.

\section{Prevention of bacterial inwasion}

In the past, strategies to prevent invasion of the host with bacteria and their toxic metabolites were investigated. The intestine has been an important target of these strategies. The absence of nutrients in the intestinall lumen, as occurs during starvation, malnutrition, or TPN, is associated with deleterious consequences to the intestinalbarrier function and, although not proven yet, is thought to predispose to bacterial translocation. Meta analysis have demonstrated that in a large variety of patients, including patients with acute pancreatitis, ulcerative colitis, Crohn's disease, multiorgan failure, and after major surgery and trauma, enteral feeding was associated with a lower risk of infection compared to starvation and parenteral nutrition (119). Early post-operative enteral feeding was found to reduce septic morbidity $(120,121)$ and hospital stay (122). Several mechanisms are proposed for this beneficial role of enteral feeding. First of all, early postoperative enteral nutrition was demonstrated to improve the maintenance of intestinal integrity as manifested by a reduced permeability (121). Certain nutrients in particular are thought to ameliorate the mucosal architecture by exertion of a trophic effect on the intestinal mucosa, such as glutamine (123), shortchain fatty acids (124) and fiber supplementation (125). However, thete is no strong evidence in the literature that supports the association of the ameliorated intestinal permeability with bacterial translocation. Second, evidence was found for an immune 
enhancing function of enteral feeding (126) and specific nutrients such as arginine or RNA supplementation (127). Furthermore, enteral nutrition stimulates the enteric nervous system, which enhances GALT and MALT function In addition, since we demonstrated that intestinal lipoproteins are efficient in detoxifying bacterial toxins (43) we hypothesize that intestinal lipoprotein secretion induced by enteral nutrition may reduce damage to the intestinal epithelium caused by bacterial toxin and thereby prevent further bacterial translocation. There are a number of other factors that might be involved in the beneficial effects of enteral feeding such as alterations in splanchnic bloodflow and gastrointestinal microflora, and stimulation of gastrointestinal protein production, peristalsis, mucus and acid secretion. Since the microflora of the gut is an important factor in the prevention of bacterial translocation, several studies focused on alteration of this microflora by dietary fibers and non-digestible oligosaccharides (prebiotics), by live micro-organisms (pro-biotics), and by selective gut decontamination using antibiotics.

\section{Prevention of immune activation}

In an attempt to intercept active toxins before interacting with responsive cells, antibodies directed against the LPS molecule have been developed, such as human antiserum to heat killed Escherichia coli $\mathrm{J} 5$ and murine (E5) and humanized (HA A ) antibodies directed against the lipid A component of endotoxin. Although initial results were encouraging in patients with gram-negative sepsis, larger clinical trials showed no benefit $(128,129)$. Other toxin antagonists were investigated for their clinical relevance in the treatment of sepsis. Polymyxim, the polycationic antibiotic most frequently added to neutralize effects of LPS in vitro, is of limited clinical use due to its high toxicity. Bacterial permeability-increasing protein (BPI) is a constituent of PMN primary granules, which is cytotoxic to gram-negative bacteria, binds endotoxin and inhibits LPS induced cytokine release in vitro. Although, BPI was described not to be effective in baboons (130), others found that administration of rBPI resulted in improved clinical outcome in patients undergoing major liver resection (131). In addition, the results of a recent study using $\mathrm{BPI}$ as adjunctive treatment for children with severe meningococcal sepsis indicate that BPI is beneficial in decreasing complications of meningococcal disease (132). Naturally occurring cationic peptides, as well as synthetic analogues block the ability of LPS to stimulate cytokine secretion by immune reactive cells in vitro (133). Clinical relevance of such peptides still has to be proven in clinical trials.

Another strategy studied in detail is the use of glucocorticoids during endotoxemia and bacteremia. Although in animal models large doses of corticoids improved survival (134), in human administration of high doses of glucocorticoids at the onset of sepsis was proven not successful (135). More recently. however, glucocorticoids in lower doses were shown to have a beneficial effect in patients with septic shock (136).

Recently a snowball effect in the progress of understanding the mechanisms underlying cell activation was made after recognition of the TLRs as signal transducers of bacterial toxins. This breakthrough raised hope for development of therapeutic interventions based on blocking the binding of toxin to its receptor or inhibiting receptor function. Although further research is required, unfortunately, these new insights in immune activation did as yet not result in new effective therapeutic 
strategies in the treatment of sepsis since inactivation of TLRs appeared to sensitize the host for specific bacterial infections $(137,138)$.

Since lipoproteins bund and inactivate endotoxin and have been shown to increase survival of endotoxemia, several investigators increased circulating lipoprotein concentrations artificially by infusion of exogenous lipoproteins in animal models of infection $(38,66,102)$. Modest increases in circulating chylomicron concentrations profoundly enhanced resistance to endotoxemia in vivo $(38,66)$. In contrast to studies using exogenous lipoproteins, Harris et al recently demonstrated that endogenous Hipoproteins, produced in response to feeding, reduce the toxic effects of bacterial foxins in human (40). In line with these findings we recently demonstrated that elevation of endogenous lipoproteins by administration of a high-fat enteral nutrition just before and after haemorrhage, reduces endotoxemia and bacterial translocation in a rat model (139). Others found that intravenous infusion of intralipid did not influence inflammatory responses to endotoxin (57), which emphasizes the importance of the structure and composition of endogenous lipoproteins and of apolipoproteins in the detoxification of bacterial toxins. In conclusion these studies suggest that induction of endogenous lipoprotein secretion may have an important potential as a therapy that anticipates on bacterial translocation and infection in case of extensive surgery and for instance in premature neonates. Besides prevention of the initiation of the inflammatory cascade, lipoprotein enhancing strategies may have a role as an adjuvant therapy after the onset of sepsis. Although it is unlikely that once circulating bacterial toxins have initiated the inflammatory cascade lipoproteins will reverse all the effects of this cascade, it was demonstrated that lipoproteins are able to detach LPS from macrophages and thereby prevent cytokine induction. Most interestingly in vivo infusion of chylomicrons up to $30 \mathrm{~min}$ after the administration of endotoxin improved survival in rodents $(66,102)$. Moreover, antibiotics given during sepsis, result in the rellease of enormous amounts of bacterial toxin, often causing an initial deterioration of the clinical condition. Enhancement of endogenous lipoprotein secretion might be effective in diminishing the excessive immune response to the release of those bacterial toxins.

In search for further improvement of the intestinal defense against bacteria we investigated conditions to raise the endogenous intestinal lipoprotein secretion and found evidence for an upregulation induced by oral administration of phosphatidy/choline under normal as well as under acute phase conditions (140). These results are in agreement with earlier observations demonstrating that luminal presence of dietary fat and biliary phospholipids are a prerequisite for intestinal lipoprotein secretion (112, 113, 114). Early post-operative feeding with phosphatidylcholine or phosphatidylcholine enriched enteral nutrition in patients at risk for translocation of enteric bacteria may be of clinical relevance. Enhancement of intestinal lipoprotein secretion by these feeding strategies hypothetically reinforces a biological defense mechanism of the intestine against bacterial toxins by enhanced neutralization and cllearance of circulating bacterial toxins and possibly, even more important, by direct neutralization of bacterial toxins translocated across a compromised intestinal mucosa. Harris et al found that preincubation of LPS with postprandial blood was required for attenuation of the immune response by the endogenous lipoproteins secreted in response to feeding (40). We hypothesize that the endogenous lipoproteins secreted by 
the intestine have the opportunity to interact and neutralize bacterial toxins already in the intestinal submucosa and lymphatics, hence before active toxins reach the blood stream (Figure 8).

\section{Diseussion}

Derangements in gut barrier function are in general considered to play a key role in the etiology of sepsis and MOF. However, there is still no hard evidence for the relevance of bacterial translocation across an mured intestinal barrier in the development of sepsis in human. For development of new interventions that prevent invasion of the host with bacteria, it is important to further define the pathophysiology of bacterial translocation.

Significant advances have been made unraveling defense mechanisms of the intestine against bacteria and their toxic metabolites. This new knowledge will form the foundation of new interventions. We anticipate that future studies will further optimize therapeutic concepts that maintain gut barrier function, for instance by reducing intestinal hypoperfusion and the effects of the subsequent ischaemiareperfusion damage, by prevention of cell apoptosis and enhanced mucosal permeability, by reducing the harmful effects of pro-inflammatory mediators, by stimulating the secretion of anti-microbial substances, and by controlling the bacterial flora of the gut. Until it is possible to prevent entrance of bacteria into the host, therapies supporting optimal host-microbial homeostasis are needed. Since extensive attempts to modify the inflammatory cascade after its onset has proven to be disappointing, attempts to prevent the initiation of this cascade might be a good alternative. The success of lipoprotein enhancement to overcome endotoxinemia in animal studies appears to be promising in the development of adjuvant therapies for the treatment of sepsis. Clinical trials should be initiated to verify that also in human enhanced circulating concentrations of lipoproteins alter the outcome of sepsis. We hypothesize that studying the effect of interrupting cholesterol lowering therapies in patients suffering from cardiovascular disease in the period before cardiovascular or abdominal surgery will in part answer this question. In addition, enhancement of endogenous intestinal lipoprotein production by enteral feeding of fat, in particular phospholipids, thereby reducing the toxic effects of microbial components direct after entering the host, might be an interesting focus for targeting the host response.

\section{References}

1. Sessler CN, Shepherd W. New concepts in sepsis. Curr Opin Crit Care 2002; 8:465-472.

2. Westphal $O$, Luderitz $O$. Chemische Erforschung von Lipopolysacchariden Gram-negatiever Bakterien. Angew Chem 1954; 66:407-417.

3. Galanos C, Luderitz O, Rietschell ET, et al. Synthetic and natural Escherichia coli free lipid A express identical endotoxic activities. Eur J Biochem 1985; 148:1-5.

4. Bhadki $S$, Klonisch T, Nuber $\mathrm{P}$, et al. Stimulation of monokine production by lipoteichoic alcids. Infect Immun 1991; 59:46 I 4-4620.

5. Gupta D, Wang Q, Vinson C, et al. Bacterial peptidoglycan induces CDJ4-dependent activation of transcription factors CREB/ATF and AP-1.J Biol Chem 1999; 274:14012-14020.

6. Mattsson E, Verhage $\mathrm{L}$, Rollof $\mathrm{J}$, et al. Peptidoglycan and teichoic acid from Staplyylococcus epidermidis stimulate human monocytes to release tumor necrosis factor- $\alpha$, interleukin-1 $\beta$ and interleukin-6. FEMS Immunol Med Microbiol 1993; 7:281-287. 
7. Goyert SM, Ferrero E. Biochemical analysis of myeloid antigens and CDNA expression of gp55 (CDw14). In: McMichad A, Berkley PCL, eds. Leucocyte typing III. New York: SpringerVerlag; pp 613 .

8. Kusunoki $\mathrm{T}$, Hailman $\mathrm{E}$, Juan TS, et al Molecules from Staphylococcus aureus that bind CDI4 and stimulate innate immune responses. IV Exp Med. 1995;182:1673-1682.

9. Gupta $\mathrm{D}$, Kirldland $\mathrm{TN}$, Viriyakosol $\mathrm{S}$, et al. CD14 is a cell-activating receptor for bacterial peptidoglyean. Biol Chem 1996;271:23310-23316.

10. Frey EA, Miller DS, Jahr TG, Sundan A, al. Soluble CD14 participates in the response of cells to lipopolysaceharide. J Exp Med 1992;176:1665-1671.

11. Pugin $J$, Schurer-Maly $C C$, Leturcq $D$, et al. Lipopolysaccharide activation of human endothelial and epithelial cells is mediated by lipopolysaccharide-binding protein and soluble CD 14. Proc Natl Acad Sci 1993; 90:2744-2748.

12. Wright $\mathrm{SD}$, Ramos $\mathrm{A}$, Tobias $\mathrm{PS}$, et al. CD/4 a receptor for complexes of lipopolysaccharide (LPS) and LPS binding protein. Science 1990;249:1431-1433.

13. Wright SD, Ramos RA, Hermanoski-Vosatka A, et al. Activation of the adhesiwe capacity of CR3 on neutrophils by endotoxin: dependence on lipopolysaccharide binding proten and CD14. J Exp Med 1991;173:1281-1286.

14. Kaisho T, Akira S. Toll-like receptors as adjuvant receptors. Biochim Biophys Acta. 2002; 1589:1-13.

15. Hirschfield $M_{3}, M_{a} Y$, Weis $J H$, et al. Cutting edge: repurification of Hipopolysaccharide eliminates signaling through both human and murine toll-like receptor. J Immunol 2000; $165: 618-622$;

16. Takeuchi $O$, Hoshino $K$, Kawai T, et al. Differential role of TLR2 and TLR4 in recognition of gram-negative and gram-positive bacteriall cell wall components. Immunity 1999; 11:443-451.

17. Shimazu R, Akashi S, Ogata $\mathrm{H}$, et al. MD-2, a molecule that confers lipopolysaccharide responsiveness on Toll-like receptor 4 . J Exp Med 1999;189:1777-1782.

18. Schwander R, Dziarski $\mathrm{R}$, Wesche $\mathrm{H}$, et al. Peptidoglycan- and lipoteichoic acid-induced cell activation is mediated by toll-like receptor 2. J Biol Chem 1999; 274:17406-17409.

19. Bulut Y, Faure E, Thomas L, et al. Cooperation of Toll-like receptor 2 and 6 for cellular activation by soluble tuberculosis factor and Borrelia burgdorferi outer surface protein $A$ lipoprotein: role of Toll-interacting protein and $\mathrm{IL}-1$ receptor signaling molecules in Toll-like receptor 2 signaling. J Immunol $2001 ; 167: 987-994$.

20. Takeshita F, Leifer CA, Gursel I, et al. Cutting edge: Role of Toll-like receptor 9 in CpG DNAinduced activation of human cells. J Immunol 2001; 167:3555-3558.

21. Hayashi F, Smith KD, Ozinsky A, et al. The innate immune response to bacterial flagellin is mediated by Toll-like receptor 5 . Nature 2001; 410:1099-1103.

22. Wang $Q$, Dziarski $R$, Kirsehning $C J$, et al. Micrococci and peptidoglycan activate TLR2-> MyD88 $\rightarrow$ IRAK $>$ TRAI $>$ NIK $>$ IKK $>$ NF-kappaB signal transduction pathway that induces transcription of interleukin-8. Infect Immun 2001; 69:2270-2276.

23. Jack RS, Fan $\mathrm{X}$, Bernheiden $\mathrm{M}$, et al. Lipopolysaccharide-binding protein is required to combat a murine Gam-negative bacterial infection. Nature 1997; $389: 742$.

24. Hailman E, Lichenstein HS, Wurfel MM, et al. Lipopolysaccharide (LPS) binding protein accelerates the binding of LPS to CDI4. J Exp Med 1994; 179:269-277.

25. Vreugdenhil ACE, Dentener $\mathrm{MA}_{\mathrm{w}}$ Snoek $\mathrm{AMP}$, et al. Lipopolysaccharide binding protein and serum amyloid $A$ secretion by human intestinal epithellal cells during the acute phase response. J Immunol 1999;163:2792-2798.

26. Dentener MA, Vreugdenhill ACE, Hoet PHM, et al. Production of the acute-phase protein lipopolysaccharidembinding protein by respiratory type III epithelial cells. Am J Resp CII Mol Biol 2000; 23:146-153.

27. Lamping N, Dettmer R, Schröder NMJ, et al. LPS-binding protein protects mice from septic shock caused by LPS or gram-negative bacteria. J Clin Invest 1998; 101:2065-2071.

28. Inohara $\mathrm{N}$, Ogura $\mathrm{Y}$, Chen $\mathrm{FF}$, et al. Human Nodll confers responsiveness to bacterial lipopolysaccharides. J Biol Chem 2001; 276:2551-2554.

29. Beutler B, Milsark IW, Cerami AC. Passive immunization against cachectin/tumor necrosis factor protects mice from lethal effect of endotoxin. Science $1985 ; 229: 869-871$. 
30. Tracey KJ, Beutler $\mathrm{B}$, Lowry $\mathrm{SF}$, et al. Shock and tissue injury induced by recombinant human cachectin. Science $1986 ; 234: 470-474$.

31. Wolk $\mathrm{K}$, Docke WD, von Baehr $\mathrm{V}_{3}$ et al. Impaired antigen presentation by human monocytes during endotoxin tolerance. Blood $2000 ; 96218-223$.

32. Ulevitch $\mathrm{RJ}$, Johnston AR, Weinstein DB. New function for high density lipoproteins. I Clin Invest 1979; 64:1516-1524.

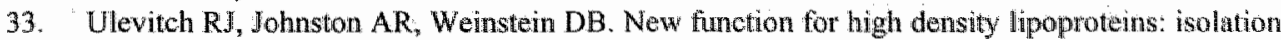
and characterization of a bacterial lipopolysaccharide-high density lipoprotein complex formed in rabbit plasma: J Clin Invest $1981 ; 67: 827-837$.

34. Van Lenten BJ, Fogelman AM, Haberland ME, et al. The role of tipoproteins and receptormediated endocytosis in the transport of bacterial lipopolysaccharide. Proc Natl Acad Sci USA $1986 ; 83: 2704-2708$.

35. Victorov AV, Medvedeva NV, Gladkaya EM, et al. Composition and structure of lipopolysaccharide-human plasma low density lipoprotein complex. Biochim Biophys Acta 1989; 984:119-127.

36. Netea MG, Demacker PNM, Kullberg BJ, et al. Bacterial lipopolysaccharide binds and stimulates cytokine producing cells before neutralization by endogenous lipoproteins can occur. Cytokine 1998; 10:766-772.

37. Kitchen RL Thompson PA, Viriyakosol S, et al. Plasna CDI4 decreases monocyte responses to LPS by transferring cell-bound LPS to plasma lipoproteins. J Clin Invest 2001; 108:485-493.

38. Harris $H W$, Grunfeld $C$, Feingold $K R$, et al. Human very low density lipoproteins and chylomicrons can protect against endotoxin-nduced death in mice. J Clin Invest 1990;86:696702 .

39. Netea MG, Demacker PN, Kullberg BJ, et al. Low-density lipoprotein receptor deficient mice are protected against lethal endotoxemia and severe gram-negative infections. J. Clin. Invest. 1996; 97:1366-1372.

40. Harris HW, Johson JA, Wigmore SJ. Endogenous lipoproteins inpact the response to endotoxin in humans. Crit Care Med 2002; 30:248-249.

41. Bhadiki $S$, Trabmum-Jensen $J$, Utermann $G$, et al. Binding and partial inactivation of Staphylococcus aureus $\alpha$-toxin by human plasma low density lipoprotein. The journal of biological chemistry. 1983; 258:5899-5904.

42. Grunfeld $\mathrm{C}$, Marshall $\mathrm{M}$, Shigenaga $\mathrm{JK}$, et al. Lipoproteins inhibit macrophage activation by lipoteichoic acid. J Lipid Res 1999;40:245-252.

43. Vreugdenhil ACE, Rousseau CH, Hartung T, et al. LPS-Binding Protein mediates LPS detoxification by chylomicrons. J Immunol 2003; 170:1399-1405.

44. Vreugdenhil ACE, Snoek AMP, van 't Veer C, et al. LPS-binding protein circulates in association with apoB-containing lipoproteins and enhances endotoxin-LDIL/VLDL interaction. J Clin Inwest 2001:107:225-233.

45. Eggesbo JB, Lyberg $T$,.Aspelin $T$, et al. Different binding of "125 I-LPS to plasmat proteins from persons with high or low HDL. Scand I Clin Lab Invest 1996; 56:533-543.

46. Tobias PS, Ulevitch RJ. Control of lipopolysaccharide-high density lipoprotein binding by acute phase protein(s). J Immunol 1983;131:1913-1916.

47. Munford RS, Andersen JM, Dietschy JM. Sites of tissue binding and uptake in vivo of bacterial lipopolysaccharide-high density lipoprotein complexes. J Clin Invest 198:; 68:1503-15॥3.

48. Munford RS, Hall CL, Dietschy JM. Binding of Salmonella typhimurium lipopolysaceharides to rat high-density lipoproteins. Infect Immun 1981;34:835-843.

49. Levels $\mathbb{J H}$, Abraham PR, van den Ende A, et al. Distribution and kinetics of lipoprotein-bound endotoxin. Infect Immun 2001; $69: 2821-2828$.

50. Kunitake ST, Carilli CT, Lau K, at al. Identification of proteins associated with apolipoprotein A-I-containing lipoproteins purified by selected-affinity immunosorption. Biochemistry 1994; 33:1988-1993.

51. Schlichting E, Aspelin T, Lyberg T. Interactions of endotoxin with human blood cells and serum proteins. Scand J Clin Lab Invest. 1996; 56:167-176.

52. Levine DM, Parker TS, Donelly TM, et al. In vivo protection against endotoxín by plasma high density protein. Proc. Natl. Acad. Sci. USA 1993;90:12040-1.2044 
53. Victorov $\mathrm{AV}$, Medwedeva NV, Gladkaya EM, et al. Composition and strueture of lipopolysaceharide-human plasma low density lipopiotein complex. Biochim Biophys Acta 1989;984:119-127.

54. Emancipator $K$, Csako $G$, Elin RJ. In vitro inactivation of bacterial endotoxin by human lipoproteins and apolipoproteins. Infection Imm 1992;60:596-601.

55. Rensen $P C N$, Van Oosten $M$, Van de Bilt $E$, et al. Human recombinant apolipoprotein $E$ redireets lipopolysaccharide from kupffer cells to liver parenchymal cells in rats in vivo. $J \mathrm{Clin}$ Invest 1997; $992438-2445$.

56. De Bont N, Nettea MG, Demacker PN, et all. Apolipoprotein E-deficient mice have an impaired immune response to Kllebsiella pneumoniae. Eur J Clin Invest. 2000;30:818-822.

57. Poll van der $\mathrm{T}$, Braxton $\mathrm{C}$, Coyle $\mathrm{SM}$, et al. Effect of hypertriglyceridemia on endotoxin responsiveness in lumans. Infection Imm. 1995;63:3396-3400.

58. Wurfel MM, Kunitake ST, Lichenstein H, et al. Lipopolysaccliaride (LPS)-binding protein is carried on lipoproteins and act as a cofactor in the neutralization of LPS. J. Exp. Med. 1994; $180: 1025-1035$

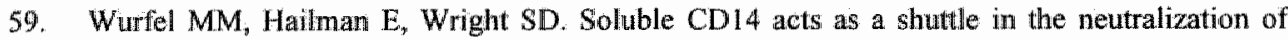
lipopolysaceharide (LPS) by LPS-binding protein and reconstituted high denisty lipoprotein. J Exp Med 1985:181:1743-1754.

60. Hailman $\mathrm{E}$, Albers $\mathrm{JJ}$, Wolfbauer $\mathrm{G}_{2}$ et al. Neutralization and transfer of lipopolysaccharide by phospholipid transfer protein. J Biol Chem 1996; 24:12172-12178.

61. Mathison JC, Ulevitch RJ. The clearance and tissue distribution, and cellular localization of intravenously injected lipopolysaccharide in rabbits. J Immunol 1979; 123:2133-2143.

62. Treon SP, Thomas P, Broitman SA. Lipopolysaccharide (LPS) processing by Kuptfer cells releases a modified L.PS with increased hepatocytes binding and decreased tumor necrosis factor-a stimulatory capacity. Proc. Soc. Exp. Biol. Med. 1993; 202:153-158.

63. Ge Y, Ezzell RM, Warren HS. Localization of endotoxin in the rat intestinal epithelium. J Infect Dis 2000,182:873-881.

64. Munford RS, Andersen JM, Dietschy JM. Sites of tissue binding and uptake in vivo of bacterial lipopolysaccharide-high density lipoprotein complexes. J Clin Invest 1981; 68:1503-1513.

65. Munford RS, Hall CL, Lipton M, et al. Biological activity, lipoprotein-binding behavior, and in vivo disposition of extracted and native forms of salmonella typhimurium lipopolysaccharides. J Clin Invest $\| 1982 ; 70: 877-888$.

66. Harris HW, Grunfeld C, Feingold KR, et al. Chylomicrons alter the fate of endotoxin, decreasing tumor necrosis factor release and preventing death. J Clin Invest 1993; 91: 10281034.

67. Harris $H W$, Brady SE, Rapp $J H$. Hepatic endosomal trafficking of lipoprotein-bound endotoxin in rats. I Surg Res: 2002; 106:188-195.

68. Read TE, Harris HW, Grunfeld C, et al. Chylomicrons enhance endotoxin excretion in Bile. Infect Immun 1993; 61:3496-3502.

69. Sammalkorpi $K$, Valtonen $V$, Kerttula $Y$, et al. Changes in serum lipoprotein pattern induced by acute infections. Metabolisen 1988; 37:859-865.

70. Feingold $\mathrm{KR}$, Grunfeld $\mathrm{C}$. Tumor necrosis factor-alpha stimulates hepatic lipogenesis in the rat in vivo. J Clin Invest 1987; 80:184-190.

71. Cabana VG, Siegel JW, Sabesin SM. Effects of the acute phase response to the concentration and density distribution of plasma lipids and apolipoproteins. J Lipid Res 1989; 30:39-49.

72. Lanza-Jacoby $S$, Tabares A. Triglyceride kinetics, tissue lipoprotein lipase and liver lipogenesis in septic rats. Am J Physiol 1990; 258:E678-685.

73. Alvarez C, Ramos A. Lipids, lipoproteins and apoproteins in serum during infection. Clin Chem 1986; $32 ; 142-145$.

74. Jacobs D, Blackburn H, Higgins $M$, et al. Report of the conference on low blood cholesterol: mortality associations. Circulation. 1992; 86:1046-1060.

75. MacFie J, O'Boyle $\mathrm{C}$, Mitchell $\mathrm{CJ}$, et al. Gut origin of sepsis: a prospective study investigating associations between bacterial translocation, gastric microflora and septic morbidity. Gut 1999; $45.223-228$ 
76. Woodcock NP, Sudheer V, El-Barghouti N, et al. Bacterial translocation in patients windergoing abdominal aortic aneurysm repair. Br J Surg $2000 ; 87,439,42$.

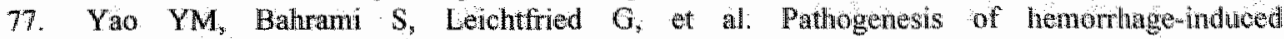
bacteria/endotoxin translocation in rats. Effects of recombinant bactericidal/permenbilityincreasing protein. Ann Surg 1995; 221:398-405.

78. Turnbull: RG, Talbot JA, Hamilton SM. Hemodynamic changes and gut bartier finotion in sequential hemorrhagic and endotoxic shock. J Tratma 1995;38:705-712.

79. Nettelbladt CG, Katouli M, Volpe A, et al. Starvation increases the number of coliform bacteria in the caecum and induces bacterial adherence to caecal epithelitim in rats. Eur I Surg $1997 ; 163: 135-142$.

80. Deitch EA, Berg RD. Endotoxin but not malnutrition promotes bacterial translocation of the gut flora in burned mice. J Trauma 1987;27:161-166.

81. Wolk $\mathrm{K}$, Docke W, von Baehr V, et al. Comparison of monocyte functions after LPS- or IL-10induced reorientation: importance in clinical immunoparalysis. Pathobiology 1999; 67:253-256.

82. Moore EE, Moore FA, Francoise RJ, et al. Postischemic gut serves as a priming bed for circulating neutrophils that provoke multiple organ failure. J Trauma 1994;37;881-887.

83. O'Neil DA, Porter EM, Elwaut D, et al. Expression and regulation of the human beta-defensins hBD- 1 and hBD-2 in intestinal epithelium. J Immunol 1999;163:6718-6724.

84. Selsted ME, Miller SI, Henschen AH, et al. Enteric defensins: antibiotic peptide components of intestine host defense. $J$ Cell Biol 1992; 118:929-936.

85. Ding JW, Andersson R, Soltesz V, et al. The role of bile acids in bacterial translocation in obstructive jaundice in rats. Eur Surg Res. 1993;25:1 1- 19 .

86. Sulivan A, Edlund C, Nord CE. Effect of antimicrobial agents on the ecological balance of human microflora. Lancet Infect Dis 2001; 1:101-114.

87. Tancrede C. Role of human microflora in health and disease. Eur J Clin Microbiol Infect Dis 1992;11:1012-1015.

88. Stolzenberg ED, Anderson GM, Ackermann MR, et al. Epithelial antibiotic induced in states of disease. Proc Natl Acad Sci U S A 1997; 94:8686-8690.

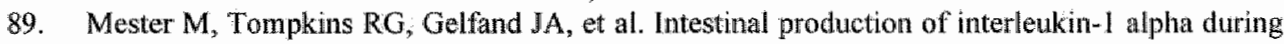
endotoxemia in the mouse. J Surg Res. 1993;54:584-591.

90. Schuerer-Maly CC, Eckmann L, Kagnoff MF, et al. Colonic epithelial cell lines as a source of interleukin-8: stimulation by inflammatory cytokines and bacterial lipopolysaccharide. Immunology 1994; 81:85-91.

91. Meyer TA, Wang J, Tiao GM, et al. Sepsis and endotoxemia stimulate intestinal interleukin-6 production. Surgery. 1995;118:336-342.

92. Wang Q, Wang JJ, Boyce $\mathrm{S}$, et al. Endotoxemia and $\mathbb{L L}-1$ beta stimulate mucosal $\| \mathrm{L}-6$ production in different parts of the gastrointestinal tract. J Surg Res 1998:76:27-31.

93. Mayer L, Eisenhardt $D$, Salomon $P$, et al. Expression of class II inolecules on intestinal epithellal cells in humans: differences between nomal and inflammatory bowel disetise. Gastroenterology $1991 ; 100: 3=12$.

94. Cario E, Podolsky DK. Differential alteration in intestinal epithelial cell expression of toll-like receptor 3 (TLR3) and TLR4 in inflammatory bowel disease. Infect Immun 2000; 68:70107017.

95. Funda DP, Tuckova L, Farre MA, et al. CD14 is expressed and released as soluble CD14 by human intestinal epithelial cells in vitro:lipopolysaccharide activation of epithelial cells revisited. Infect Immun 2001; 69:3772-3781.

96. Cario E, Rosenberg IM, Brandwein SL, et al. Lipopolysaccharide activates distinct signaling pathways in intestinal epithelial cell lines expressing toll-like receptors. J. Immunol. 2000 $164 ; 966-972$.

97. Abreu MT, Vora P. Faure E, et al. Decreased expression of Toll--like receptor-4 and MD-2 correlates with intestinal epithelial cell protection against dysregulated proinflammatory gene expression in response to bacterial lipopolysaccharide. J Immunol 2001; 167:1609-1616.

98. Ter Steege JC, van der Ven WC, Forget PP, et al. Regulation of lipopolysaccharide induced NO-synthase expression in the major organs in a mouse model. Eur Cytokine Netw. 2000; 1:39-46. 
99. Molmenti EP, Ziambaras T, Perlmutter DH. Evidence for an acute phase response in human intestinal epithelial cells. J Biol Chem 1993; 268:14116-14124.

100. Andoli $A$. Fujiyama $Y$, Bamba $T$, at al. Differential cytokine regulation of complement $c 3, c 4$ and factor B synthesus in human intestinal epithelial cell line Caco-2. I lmmunol 1993; 151: $4239-4247$.

101. Albanese GT, Smüt SD, Watkins S, et al. Effect of IgA on transepithelial passage of bacteria across the intact ileum in vitro. If Am Coll Surg 1994: 179:679-688.

102. Read TE, Grunfeld $C$, Kumwenda $Z$, et al. Triglyceride-rich lipoproteins improve survival when given after endotoxin in rats. Stirgery 1995; 117;62-67.

103. Parillo JE. Septic shock in humans: advances in the understanding of pathogenesis, cardiovascular dysfunction and therapy. Ann intern med 1990; 113:227-242.

104. Angus DC, Linde-Zwirble WT, Lidicker J, et al. Epidemiology of severe sepsis in the United States: analysis of incidence, outcome, and associated costs of care. Crit Care Med 2001; 29:1303-1310.

105. Bone RC. Gram-positive organisms and sepsis. Arch Intern Med. 1994; 154:26-34.

106. Hardardottir I, Sipe J, Moser AH, et al. LPS and cytokines regulate extra hepatic mRNA levels of apolipoproteins during the acute phase response in Syrian hamsters. Biochem Biophys Acta $1997 ; 1344: 210-220$.

107. Methran $M$, Seidman E, Marchand $R$, et all. Tumor necrosis factor- $\alpha$ inhibits lipid and lipoprotein transport by Caco-2 cells. Am J Physiol 1995; 269:G953-G960.

108. Murthy $\mathrm{S}$, Mathur $\mathrm{SN}$, Varilek $\mathrm{G}$, et al. Cytokines regulate apolipoprotein B secretion by Caco2 cells. Am J Physiol 1996;270:694-G102.

109. Feingold KR, Serio MK, Adli S, et al. The effect of diet on tumor necrosis factor stimulation of hepatic lipogenesis. Metabolism 1990; 39:623-632

1. 10. Plata-Salaman CR Cytokines and feeding. Int J Obes Metab Disord 2001;25:S48-52.

1.1. De Vree JML, Romijn $『 A$, Mok KS, et al. Lack of enteral nutrition during critical illness is associated with profound decrements in biliary lipid concentrations. Am J Clin Nutr 1999; $70: 70-77$

112. Field FJ, Born E, Chen $\mathrm{H}$, et al. Regulation of apolipoprotein $\mathrm{B}$ secretion by biliary lipids in Caco-2 cells. J Lipid Res 1994; 35:749:762.

113. Mathur SN, Born E, Murthy $S$, et al. Phosphatidylcholine increases the secretion of triacy lglycerol-rich lipoproteins by Caco-2 cells. Biochem J 1996;314:569-575.

114. Noh SK, Koo SI. Enteral infusion of phosphatidylcholine increases the lymphatic absorption of fat, but lowers alpha-tocopherol absorption in rat fed a low zinc diet. I Nutr Biochem $2001 ; 12: 330-337$

115. Hubel K, Dale DC, Liles WC. Therapeutic use of cytokines to modulate phagocyte function for the treatment of infectious diseases: current status of granulocyte colony-stimulating factor, granulocyte-macrophage colony stimulating factor, macrophage colony-stimulating factor, and interferon- $\gamma$. J Infeet Dis 2002; 185:1490-1501.

116. Opal SM, Fisher CJ Jr, Dhainaut JF, et al. Contirmatory interleukin-1 receptor antagonist trial in severe sepsis: a phase III, randomized, double-blind placebo-controlled, multicenter trial. The Interleukin-1 Receptor Antagonist Sepsis Inwestigator Group. Crit Care Med 1997; 25:1115124.

117. Fischer $\mathrm{CJ}$, Opal $\mathrm{SM}$, Dhainaut JF, et al. Anti-TNF $\lg \mathrm{G}$ monoclonal antibody (CB0006) in sepsis syndrome: pharmacokinetics, safety and role of pretreatment:Il-6 as a predictor of time or survival. Circ Shock 1991; 34:167-168.

118. Echtenacher B, Falk W, Mannel DN, et al. Requirement of endogenous tumor necrosis factor/cachectin for recovery from experimental peritonitis. J llmmunol 1990; 145:3762-3766.

119. Braunschweig CL, Levy $P$, Sheean PM, Wang X. Enteral compared with parenteral nutrition: a meta-analysis. Am J Clin Nutr 2001; 74:534-542.

120. Moore $\mathbb{F A}$, Moore EE, Jones TN, et al. TEN versus TPN following major abdominal trauma reduced septic morbidity. J Trauma 1989;29:916-922.

121. Kompan L, Kremzar B, Gadzijev E, et al. Effects of early enteral nutrition on intestinal permeability and the development of multiple organ failure after multiple injury. Intensive Care Med 1999; $25: 157-161$. 
122. Schilder JM, Hurteau JA, Look KY, et al. A prospective controlled trial of early postopetative oral intake following major abdominal gynecologie surgery. Gynecol Oncol 1997; $67: 235-240$.

123. Choi $\mathrm{SH}$, Lee $\mathrm{S}$, Lee $\mathrm{MD}$. Glutamine on the fuminal microbial enviroment after massive small bowel resection. J Korean Med Sci 2002; 17:778-783.

124. Koruda MJ, Rolandelli RH, Bliss DZ; et al. Parenteral nutrition supplemented with short-chain fatty acids: effect on the small-bowel mucosa in normal rats. Am J Clin Nutr 1990; $51,685-685$.

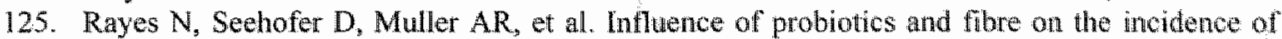
bacterial infections following major abdominal surgery - results of a prospective trial. Z Gastroenterol 2002;40:869-876.

126. Kudsk KA, Croce MA, Fabian TC, et al. Enteral versus parenteral feeding: effects on septic morbidity following blunt and penetrating abdominal trauma. Arn Surg 1992; 215:503-513.

127. Gianotti L, Braga $M$, Nespoli L, et al. A randomized controlled trial of preoperative onal supplementation with a specialized diet in patients with gastrointestinal cancer. Gastroenterology 2002; 122:1763-1770.

128. Zanetti $\mathrm{G}$, Glauser MP, Baumgartner J. Use of immunoglobulins in prevention and treatment of infection in critically ill patients: review and critique. Rew Infect Dis. 1991; 13:985-992.

129. MoCloskey RV, Straube RC, Sanders $C_{\text {s }}$ et al. Treatment of septic shock with human monoclonal antibody HA-1A. A randomized, double-blind, placebo-controlled trial. Ann Intern Med 1994; 121:1-5.

130. Rogy MA, Moldawer LL. Oldenburg HS, et al. Anti-endotoxin therapy in primate bacteremia with HA-IA and BPI. Ann Surg 1994;220:77-85.

131. Wiezer MJ, Boelens $P G$, Vuylsteke RJ, et al. Perioperative treatment with bactericidal/permeability-increasing protein (rBPI21) in major liver surgery; a concise summary. Ann Acad Med Singapore 2001; 30:226-233.

132. Levin $M$, Quint $P A$, Goldstein $B$, et al. Recombinant bactericidal/permeability-increasing protein (rBPI21) as adjunctive treatment for children with severe meningococcal sepsis: a randomised trial. rBPl2 I Meningococcal Sepsis Study. Lancet 2000;356:961-967.

133. Scott MG, Vreugdenhil. ACE, Butrman WA, et al. Cationic antimicrobial peptides block the binding of lipopolysaccharide (LPS) to LPS binding protein. J Immun 2000; 164:549-553.

134. Hinshaw LB, Beller BK, Chang $A C$, et al. Effects of prior administration of steroids upon recovery from lethal sepsis. J Am Coll Surg 1986; 163:335-344.

135. Lefering R., Neugebauer EA. Steroid controversy in sepsis and septic shock: a meta analysis. Crit Care Med 1995; 23:1294-1303.

136. Bollaert PE, Charpentier C, Levy B, et al. Reversal of Jate septic shock with supraphysiologic doses of hydrocortisone. Crit care med 1998; 26:645-650.

137. Wang M, Jeng KC, Ping Ll. Exogenous cytokine modultation or neutralization of interleukin-10 enhance survival in lipopolysaccharide-hyporesponsive $\mathrm{C} 3 \mathrm{H} / \mathrm{HeJ}$ mice with Klebsiella infection. Immunology 1999; 98:90-97.

138. Takeuchi $O$, Hoshino K, Akira S. TLR2-deficient and MyD88-deficient mice are highly succeptible to staphylococcus aureus infection. J Immunol 2000;165:5392-5396.

139. Luyer MDP, Jacobs JA, Vreugdenhil ACE, et al. Enteral administration of high-fit nutrition before and directly after hemorrhagic shock reduces endotoxemia and bacterial translocation. Submitted for publication.

140. Vreugdenhil ACE, Snoek AMP, Engelen EF, Phosphatidylcholine entances apolipoprotein secretion by enterocytes during the acute phase response. Submitted for publication. 


\section{Outline of the thesis}

The cellular effects induced by bacterial toxins are modulated significantlly by interactions with LPS Binding Protein (LBP) and lipoproteins. Prior studies described beneficial effects of LBP as well as lipoproteins on survival of infection. We hypothesized that local presence of LBP and lipoproteins in the intestine might be involved in the barrier function of this organ, which is continuously exposed to high concentrations of bacteria and bacterial toxin.

The main object of the experimental studies described in the first part of this thesis (Chapter 2 and 3 ) was to explore the local production and secretion of LBP by intestinal epithelial cells. The effects of proinflammatory cytokines on intestinal LBP production was evaluated as well as the polarization of LBP secretion by the intestinal epithelium. For this purpose both an in vitro model with human intestinal epithelial cell lines and an animal model of endotoxemia was used.

Earlier studies found evidence for an association of LBP with lipoproteins in plasma from healthy persons. We considered that the physical association of LBP with lipoproteins is of importance for the cooperation of LBP and lipoproteins in the detoxification of bacterial toxins. Tools were developed to further elucidate the interaction of LBP with lipoproteins and to study the effect of this interaction on binding and detoxification of bacterial toxins. By separation of lipoprotein classes under the mild conditions of agarose electrophoresis followed by westernblot analysis of LBP and apoproteins, we studied the association of LBP as wells as LPS with lipoproteins in serum of healthy persons and septic patients. Besides the evaluation of the interaction of LBP and LPS with liver derived lipoproteins, we focussed on LBP association with intestine-derived lipoproteins, i.e chylomicrons, and on the effect of this association on binding and detoxification of bacterial toxins.

The results of these studies indicated that LBP is produced by the intestinal epithelium and cooperates efficiently with chylomicrons in the deactivation of bacterial toxins. In addition, there is strong evidence that the conditions for secretion of chylomicrons are poor during infection, which hypothetically impairs this defense mechanism. These considerations have raised our interest in the development of an enteral formula that optimally induces endogenous intestinal lipoprotein secretion. Phospholipids were earlier found to be essential for secretion of intestinal lipoproteins and were demonstrated to be deficient in the intestinal lumen during critical illness. Therefore the effect of phosphatidylcholine on the production of intestinal lipoproteins was studied under quiescent and inflammatory conditions. In addition we studied the effect of a high-fat enteral diet on endogenous lipoprotein production, endotoxinemia and bacterial translocation in a rat model of non-lethal hemorrhagic shock. In this model a compromised gut function is thought to result in bacterial translocation and subsequent infectious complications.

With the studies described in this thesis we aimed to gain more insight in the natural defense of the gut against bacterial toxin. Based on the insights derived from these fundamental studies we found a new target for therapeutic intervention aimed at prevention of the deleterious effects of bacterial toxin in the earliest stage of the development of sepsis, under conditions in which the natural defense of the intestine is compromised. 


\section{Chapter 2}

\section{Lipopolysaccharide Binding Protein and Serum}

\section{Amyloid A secretion by human intestinal epithelial cells during the acute phase response}

Anita C.E. Vreugdenhil*, Mieke A. Dentener", A. M. Patricia Snoek*', Jan Willem M. Greve*, Wim A. Buurman*

Nutrition and Toxicology Research Institute Maastricht (NUTRIM), Department of * General Surgery and Pulmonology, Maastricht University, The Netherlands.

Published in: J. Immunol. 1999;163:2792-2798

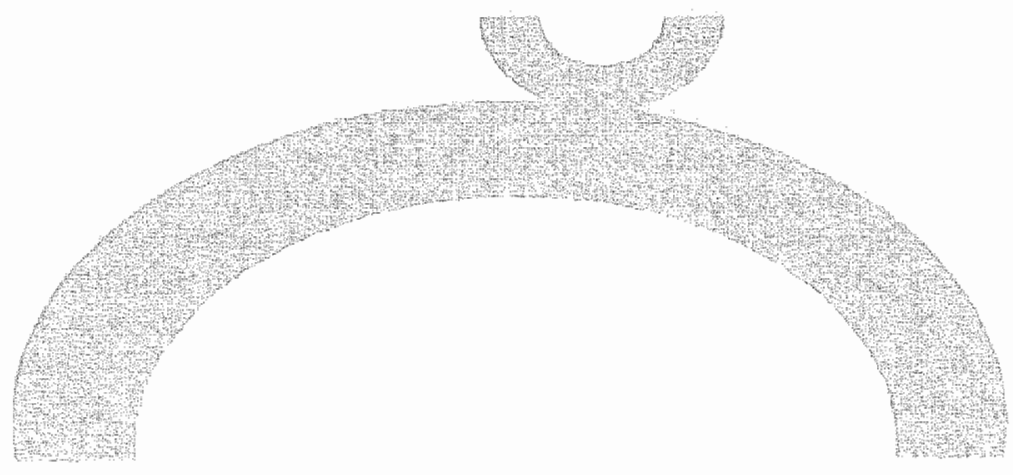




\begin{abstract}
The acute phase proteins LPS Binding Protein (LBP) and serum amyloid A (SAA) are produced by the liver and present in the circulation. Both proteins have been shown to participate in the immune response to endotoxins. The intestinal mucosa forms a large surface that is continuously exposed to these microbial products. By secretion of antimicrobial and immunomodulating agents, the intestinal epithelium contributes to the defense against bacteria and their products. The aim of this study was to explore the influence of the inflammatory mediators TNF- $\alpha, I L-6$ and $I L-1 \beta$ on the release of $L B P$ and SAA by intestinal epithelial cells (IEC). In addition, the induction of LBP and SAA release by cell lines of intestinal epithelial cells and hepatic cells was compared. The data obtained show that in addition to liver celis, IEC also expressed LBP mRNA and released bioactive LBP and SAA upon stimulation. Regulation of LBP and SAA release by IEC and hepatocytes was typical for class 1 acute phase proteins, although differences in regulation between the cell types were observed. Endotoxin did not induce LBP and SAA release. Glucocorticoids were demonstrated to strongly enhance the cytokine-induced release of LBP and SAA by IEC, corresponding to hepatocytes. The data of this study, which imply that human IEC can produce LBP and SAA, suggest a role for these proteins in the local defense mechanism of the gut to endotoxin. Furthermore the results demonstrate that tissues other than the liver are involved in the acute phase response.
\end{abstract}




\section{Introduction}

Lipopolysaccharide binding protein (LBP) is an acuite phase protein that strongly modulates the response to endotoxins, which are present in the outer membrane of Gram-negative bacteria. LBP enhances the recognition of endotoxin and bacterial surfaces by the immune system (1). Other studies demonstrated that an important function of LBP is to mediate the neutralization of endotoxin by lipoproteins $(2,3)$. Furthermore, it was demonstrated that ligh concentrations of LBP decrease endotoxin activity and protect against septic shock caused by Gram-negative bacteria (4).

The intestinal lumen contains high amounts of endotoxin, and the intestinal mucosa forms the interface between this potentially harmful material and the interior of the host. The intestinal epithelium contributes to the immunologic defense by secretion of proinflammatory cytokines (5) and microbicidal agents such as defensins (6). Although the liver has been held responsible for the production of circulating acute phase proteins, there is recent evidence for the synthesis of acute phase proteins in the intestinal mucosa as well $(7,8)$. This prompted us to study whether the release of LBP and the major acute phase protein serum amyloid A (SAA), which is involved in the routing and binding of high density lipoprotein (HDL) to inflammatory cells (9), is a part of the epithelial response to inflammation. In the current study we examined the regulation of LBP and SAA secretion by a number of intestinal epithelial cell lines in detail and compared it to the regulation in hepatocytes. The data obtained show that intestinal epithelial cells can release both LBP and SAA, which strongly implicates a role for these proteins in the local inflammatory processes in the gut.

\section{Materials and methods}

Reagents and Abs.

Human recombinant TNF- $\alpha$ was kindly provided by BASF/Knoll (Ludwigshafen, Germany); human recombinant IL-6 was provided by Prof. W. Sebald (PhysiologischChemisches Institut de Universität Würzburg, Germany); human rIL-1 $\beta$ was a gift from Dr. S. Gillis (Immunex, Seattle, WA); dexamethasone was a gift from Merck Sharp \& Dohme (Haarlem, The Netherlands); MTT and LPS (from Escherichia coli, serotype 055:B5) were purchased from Sigma (St. Louis, MO). Human recombinant LBP was produced by transfected Chinese Hamster Ovary (CHO) cells, kindly provided by Dr. P.Tobias (Research Institute of Scripps Clinic, La Jolla, CA). Polyclonal Abs to human rLBP were obtained by immunizing rabbits with human rLBP. After protein A purification, IgG was biotinylated. A specific anti-human LBP $\mathrm{mAb}$ HM14 was obtained by immunizing mice with human rLBP following classical procedures. The selection and properties of the mAb will be discussed in detail elsewhere. In short, this $\mathrm{mAb}$ was selected on basis of its reactivity with both free human LBP and human LBP that has formed a complex with LPS. The SAA immunoassay was kindly provided by Dr. P.C. Limburg (Department of Rheumatology, University Groningen, the Netherlands).

\section{Culture and stimulation of cells}

The cell lines Caco-2, Colo- 205 and T-84 cells were obtained from the American Type Culture Collection (Manasas, VA; ATCC HTB-37, CCL-222, CCL-248 respectively). Human colonic adenocarcinoma Caco-2 cells undergo in vitro differentiation and 
express structural characteristics and functional properties typical of small intestinal enterocytes. The Colo-205 and T-84 cell line are human colonic carcinoma cell lines. The small intestinal epithelial cell line Int- 407 was obtained from the European Collection of Cell Cultures (Wiltshire, UK, ECACC 85051004). Human hepatoma (HuH-7) cells were a generous gift of Dr. K.C.H. Fearon, department of Surgery, University of Edinburgh (Edinburgh, UK). Cells were cultured at $37^{\circ} \mathrm{C}$ with $5 \% \mathrm{CO}_{2}$. HuH-7 and Colo-205 cells were cultured in RPMI 1640 (Gibco, Paisley, UK) supplemented with 10\% fetal calf serum (Hyclone, Logan, UT). Caco-2 cells were cultured in DMEM (Life Technologies) supplemented with 10\% FCS (Hyclone), 1.0 $\mathrm{mM}$ sodium pyruvate (Life Technologies) and $0.1 \mathrm{mM}$ non-essential amino acids (Life Technologies). Int -407 cells were cultured in MEM with Earle's salts (Life Technologiles) supplemented with $10 \%$ fetal calf serum (Hyclone) and $0.1 \mathrm{mM}$ nonessential amino acids (Life Technologies). All culture media were supplemented with $100 \mathrm{IU}$ penicillin $/ \mathrm{ml}, 100 \mu \mathrm{g}$ streptomycin/ml (Life Technologies). Cell lines were maintained in $25 \mathrm{~cm}^{2}$ flasks (Costar, Cambridge, MA). Cultures were split when they reached $80 \%$ confluence. For experiments, designed to investigate the effect of cytokines on the release of LBP and SAA, cells were plated at a density of $1 \times 10^{4}$ cells/well on 96-well flat bottom tissue culture plates (Costar). Cells were cultured in complete medium as described above. The medium was changed $48 \mathrm{~h}$ after plating and then every other day. After $2 \mathrm{wk}, \mathrm{Caco}-2$ monolayers display morphologic and functional properties similar to those found in normal small intestinal enterocytes (10). Therefore, all experiments with Caco-2 cells were conducted between 14-17 days after seeding of the cells. Experiments with Colo-205, T-84, Int-407 and HuH-7 cells were conducted after confluence was established microscopically. At the start of each experiment, culture medium was removed and complete medium, supplemented with IL-1 $\beta, \mathbb{L L}-6$, TNF- $\alpha$, LPS or dexamethasone, as single agents or in combination as given in Results, was added. Stimulation with LPS was performed in the presence of human serum. At the end of the incubation period, the medium was removed and centrifuged to remove cells and cell debris. Cell number and viability were determined using the MTTmethod as described previously (11). In order to determine whether the presence of serum affected the cytokine induced LBP and SAA release, Caco-2 cells were stimulated under serum-free conditions in a protocol similar to stimulations conducted in the presence of serum.

For experiments, designed to determine whether endothelial cells also posses the capacity to release LBP and SAA, HUVEC were isolated from fresh umbilical cords by treatment with collagenase type I (Sigma). Cells were seeded into fibronectin-coated tissue culture flasks. For stimulation experiments cells were seeded in 96-well plates at a density of $1 \times 10^{4}$ cells/well and were cultured for 2-3 days to confluence. Cells were stimulated in a protocol similar to IEC and hepatocytes.

\section{Detection of LBP $M R N A$}

Total cellular RNA was isolated from quiescent and stimulated Caco-2 and HuH-7 cells using a Quick Prep Total RNA Extraction Kit (Pharmacia, Uppsala, Sweden). cDNA was obtained by reverse transcription of total RNA. PCR of B2-microglobulin was employed for standardization of the different RNA samples as described by Kloppenburg et al. (12). Human LBP-targeted PCR was performed in a $25-\mu l$ reaction 
mixture containing $100 \mu \mathrm{M}$ of each dNTP, $200 \mathrm{nM}$ printers and $0.5 \mathrm{U}$ of Taq DNA polymerase (Perkin Elmer/Cetus, Emeryville, CA). The primers were described by Su et al. (7): sense primer 5'-AGG-GCC-TGA-GTC-TCA-GCA-TCT-3'; and antisense primer 5'-CAG-GCT-GGC-CGT-GTT-GAA-GAC-3'. Thirty-five cycles were run under the following conditions: $95^{\circ} \mathrm{C}$ for $30 \mathrm{~s}, 57^{\circ} \mathrm{C}$ for $1 \mathrm{~min}$, and $72^{\circ} \mathrm{C}$ for $1 \mathrm{~min}$. The reaction product was analyzed on a $1.2 \%$ agarose gel containing ethidium bromide. A mock PCR (without CDNA) was included to exclude contamination.

\section{Immunoassays.}

LBP and SAA release was evaluated using sandwich ELISA's. LBP was determined as described previously (13). In short, plates (Nunc-Immuno Plate Maxisorp, Roskilde, Denmark) were coated with polyclonal anti-human LBP Abs. Supernatants of the cells and a standard dilution series of rLBP were added to the plate. Detection was performed with a biotinylated polyclonal rabbit anti-human $L B P \operatorname{IgG}$, followed by peroxidase-conjugated streptavidin (Zymed Laboratories Inc., San Francisco, CA) and tetramethylbenzidine (TMB) substrate (Kirkegaard \& Perry Laboratories Inc., Gaithersburg, MD). The detection limit was $200 \mathrm{pg} / \mathrm{ml}$.

SAA was quantified as described elsewhere (14). In short, SAA specific mAb Reu 86.5 was used as capture reagent. The amount of SAA bound to the wells was quantified by incubation with a horseradish peroxidase labeled monoclonal anti-SAA Ab (Reu 86.1) followed by TMB substrate. The detection limit for the SAA assay was $100 \mathrm{pg} / \mathrm{ml}$.

\section{Characterization of $L B P$ released by Caco- 2 cells}

To confirm the identity of LBP released by Caco- 2 cells, the protein was isolated from the medium by selective-affinity immunosorption, followed by determination of the molecular weight by Western immunoblotting. For this purpose the newly developed anti-LBP mAb HM14 was cross-linked to NHS-activated Sepharose (Pharmacia) according to the manufacturer's instructions. Conditioned culture medium of Caco-2 cells was applied to the anti-LBP column, and the unbound proteins were washed out with PBS. Glycine-HCL buffer ( $\mathrm{pH} 2.5)$ was used to elute bound LBP. For comparison, rLBP was isolated from the culture medium of transfected CHO-cells by the same method: Gel electrophoresis of Caco-2 derived LBP, rLBP and a prestained low molecular weight marker was performed using 10-15\% gradient polyacrylamide gels (Pharmacia) run in a Pharmacia Phast system followed by electrophoretic transfer onto a immobilon-P membrane (Millipore Corporation, Bedford, MA). LBP bands were detected using a biotin labeled polyclonal antibody to human LBP followed by peroxidase labeled streptavidin and 3,3' diamobenzidine substrate.

The bioactivity of LBP produced by Caco-2 cells was determined by measuring the LPS-binding-capacity. For this purpose Immuno-Maxisorp plates were coated with the monoclonal anti-human LBP Ab HM14. Next, dilution series of LBP produced by Caco- 2 cells and rLBP were added, followed by biotinylated LPS. For biotinylation of LPS a hydrazide-biotin reagent (Pierce, Rockford, IL) was used. Detection occurred with peroxidase-conjugated streptavidin and TMB substrate. The ODs obtained represent the LPS binding capacity of the LBP. 


\section{Statistical analysis:}

Data were analyzed using SPSS software (SPSS, Chicago, L). All values in the figures and text are expressed as mean $\pm \mathrm{SD}$ of $n$ observations. Groups were compared by Student's $t$ test. Results of experiments designed to study the effects of cytokines and dexamethasone on the secretion of LBP and SAA by Caco-2 and Hul- -7 cells were hierarchically analyzed by four-way-ANOVA, using dummy regression analysis after square root transformation of data. A $p$ value of 0.05 or less was considered statistically significant.

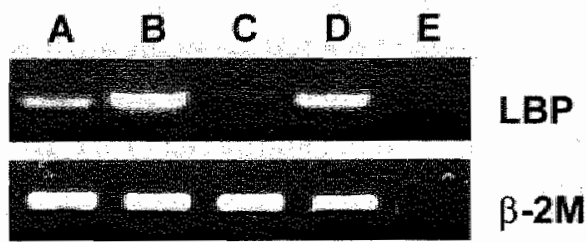

FIGURE 1. Human LBP targeted RT-PCR amplification of RNA from Caco-2 and HuH-7 cells. Cells were stimulated for $24 \mathrm{~h}$ with a nix of $\mathrm{IL}-1 \beta(5 \mathrm{ng} / \mathrm{ml}), \pi \mathrm{L}-6(100 \mathrm{ng} / \mathrm{ml})$ and TNF $-\alpha(100 \mathrm{ng} / \mathrm{ml})$. Controls consisted of unstimulated cells. PCR for $\beta-2$ microglobulin $(\beta-2 \mathrm{M})$ was employed for standardization of the samples. Lame $A$, Unstimulated HuH-7 cells; Lane $B$, HulH-7 cells after

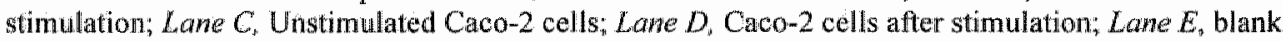

\section{Results}

\section{Cytokines induce the synthesis of LBP and SAA by Caco-2 cells}

First we investigated whether IEC express LBP mRNA. In vitro differentiated human colonic adenocarcinoma ( $\mathrm{Caco}-2)$ cells were used as a model of normal human intestinal epithelial cells. The monolayers were stimulated with a combination of IL-1 $\beta$ $(5 \mathrm{ng} / \mathrm{ml}), \mathrm{IL}-6(100 \mathrm{ng} / \mathrm{ml})$ and TNF $-\alpha(100 \mathrm{ng} / \mathrm{ml})$. For comparison, human hepatoma (HuH-7) cells were treated in a protocol similar to that used for Caco-2 cells. LBP mRNA was expressed in quiescent $\mathrm{Caco}-2$ and $\mathrm{HuH}-7$ cells in minor quantities. Subsequently, after culture of cells in the presence of cytokines LBP mRNA expression was up-regulated substantially (Fig.1). The PCR product was of predicted size ( $565 \mathrm{bp}$ ). These data are the first to demonstrate that intestinal epithelial cells express LBP $m R N A$, which strongly suggests synthesis of LBP by these cells.

Next, the induction pattern of LBP release by Caco-2 cells was studied. After incubation of the cells with cytokines, supernatants were harvested and analyzed. In the absence of cytokines low amounts of LBP were detectable in the supernatants. A significant $(\mathrm{p}<0.001)$ up-regulation of LBP release was induced by IL-6 (Fig.2A). LL$1 \beta$ and TNF- $\alpha$ alone did not induce a marked up-regulation of the LBP release, although both cytokines strongly enhanced the effect of IL-6 $(p<0.01)$ and each other ( $\mathrm{p}<0.001$ ) on LBP release. The strongest up-regulation was induced by the combination of IL-1 $\beta$, IL-6 and TNF- $\alpha(\mathrm{p}<0.01$; Fig.2A).

The capability of Caco-2 cells to express SAA mRNA was demonstrated by others (15). We investigated the induction pattern of SAA release by Caco-2 cells (Fig.2B). The SAA release of the cells was markedly up-regulated by IL-1 $\beta(p<0.001)$, while treatment with either IL-6 or TNF- $\alpha$ had no significant effect (Fig. 2B). However, IL-6 $(p<0.01)$ enhanced the IL-1 $\beta$ induced SAA synthesis, while TNF further up-regulated the effect of the combination of $11-1 \beta$ and $11-6(p<0.001)$. The necessity of IL- $1 \beta$ for 
apparent induction of SAA release by $\mathrm{Caco}^{-2}$ cells was evident and is typical for class 1 acute phase proteins. In conclusion, Caco- 2 cells have the capability to release both LBP and SAA in response to cytokines, while each protein has its own specific induction pattern.

In order to investigate whether the secretion of LBP and SAA is a general property of in vitro cultured cells, HUVEC were stimulated with proinflammatory cytokines. LBP and SAA was not detected in the supernatants (data not shown), which implicates that LBP and SAA secretion is not a common feature of cells in general or epithelial cells in particular.
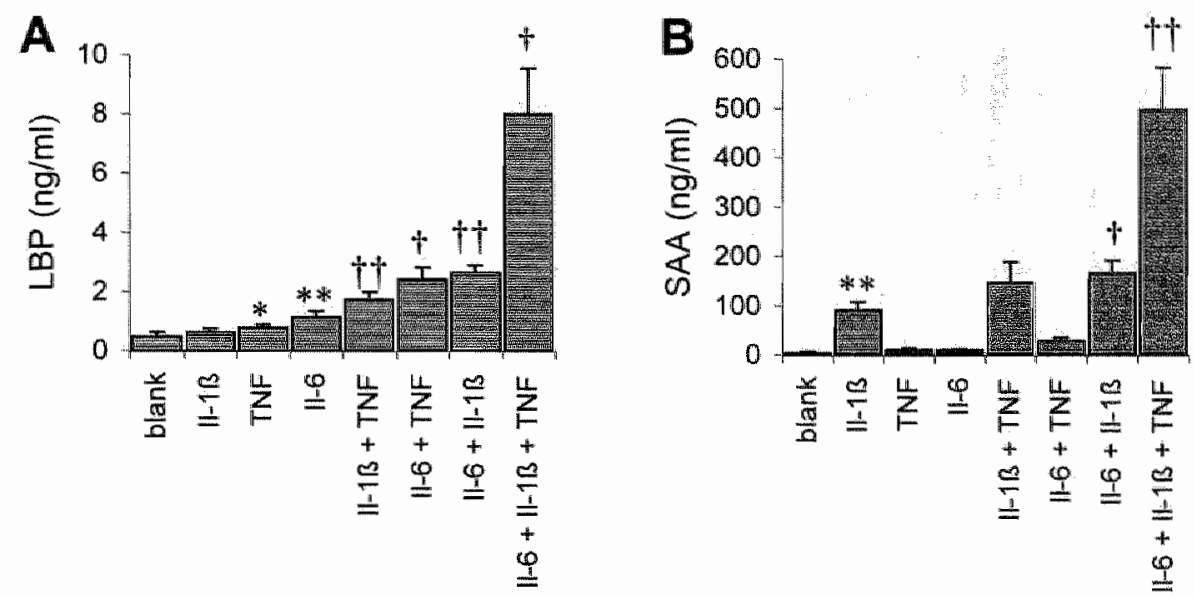

FIGURE 2. Cytokines induce LBP (A) and SAA (B) release by Caco-2 cells. Cells were incubated with IL-1B $(5 \mathrm{ng} / \mathrm{ml})$, IL-6 $(100 \mathrm{ng} / \mathrm{ml})$, TNF $-\alpha(100 \mathrm{ng} / \mathrm{ml})$ or combinations of these agents as indicated. Controls consisted of unstimulated cells. After $72 \mathrm{~h}$ incubation, supernatants were collected and LBP and SAA release were determined by ELISA. The data of a representative experiment are shown and expressed as mean $\pm S D(n=6)$. Significant effect of individual cytokines $(p<0.01)$; *** significant effect of individual cytokines $(\mathrm{p}<0.001)$; " significant positive interaction between cytokines $(p<0.01) ;{ }^{t T}$ significant positive interaction between cytokines $(p<0.001)$.

Next, the concentration-dependency of $I L-6$ and IL-1B on the induction of LBP and SAA release was studied (Fig. 3). A clear up-regulation of LBP release is mediated in Caco- 2 cells by $100 \mathrm{ng} / \mathrm{ml}$ Il-6. However, when cells were treated with II-6 plus $11-1 / 3$ simultaneously, the enhancement of LBP release was evident at concentrations as low as $1 \mathrm{ng} / \mathrm{ml} \mathbb{I L}-6$ (Fig. 3A). The data demonstrate that $0.5 \mathrm{ng} / \mathrm{ml} J \mathrm{~L}-1 \beta$ is enough to enhance SAA release. The synergistic effect of IL-6 on IL-1B mediated SAA release was clear at $5 \mathrm{ng} / \mathrm{ml}$ (Fig. $3 \mathrm{~B}$ ) Furthermore, synthesis of both proteins increased when concentrations of IL- $1 \beta$ and IL-6 were raised. The data of this experiment indicate that cytokine concentrations that has been previously reported in actively inflamed intestinal mucosa $(16,17)$ as well as in the mesenteric blood $(18)$ induce LBP and SAA secretion by IEC. 
The data obtained in the stimulation experiments were not caused by an effect of cytokines on cell numbers as determined by the MTT-method (data not shown): In addition, in absence of serum, identical induction patterns of LBP and SAA release were observed, although total amounts of LBP and SAA released were lower in serum deprived conditions (data not shown).
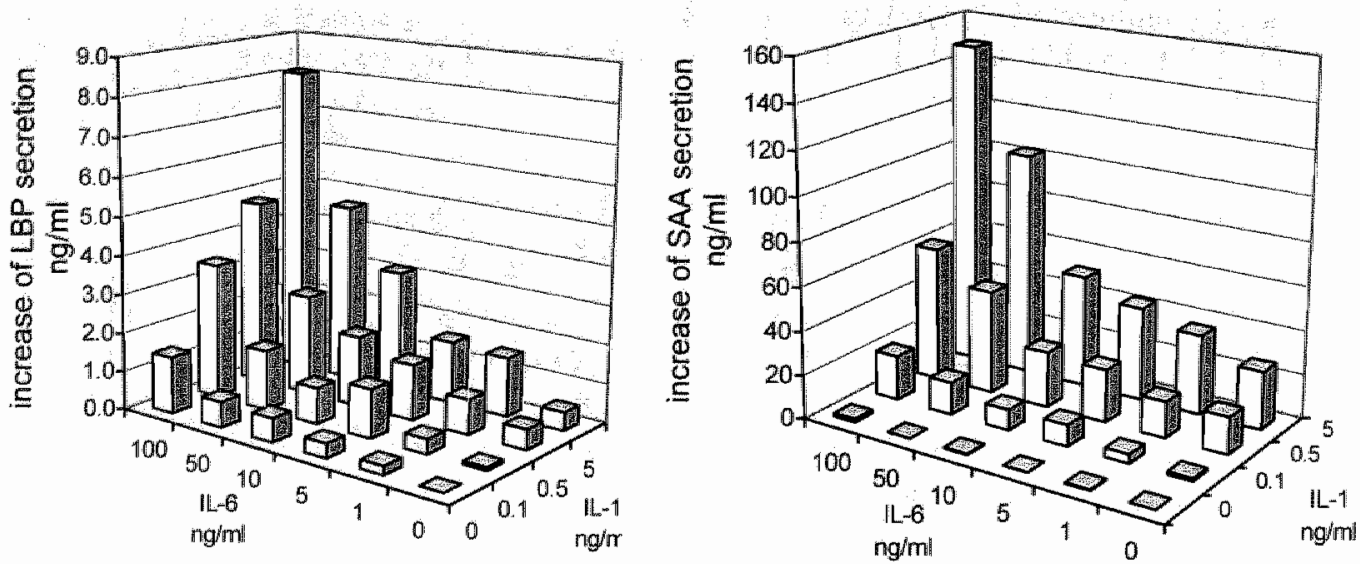

FIGURE 3. Cytokine induced enhancement of $L B P$ and SAA release by Caco-2 cells is concentration dependent. Caco-2 cells were incubated with increasing concentrations of $I L-1 \beta(0-5 \mathrm{ng} / \mathrm{ml})$ or IL-6 $(0-100 \mathrm{ng} / \mathrm{ml})$, or a combination of both. Controls consisted of unstimulated cells. Supernatants were collected after $72 \mathrm{~h}$ of incubation, and LBP and SAA release were determined by ELISA. The data from a representative experiment are shown and expressed as the increase of LBP released (ng/mi) compared to controls.

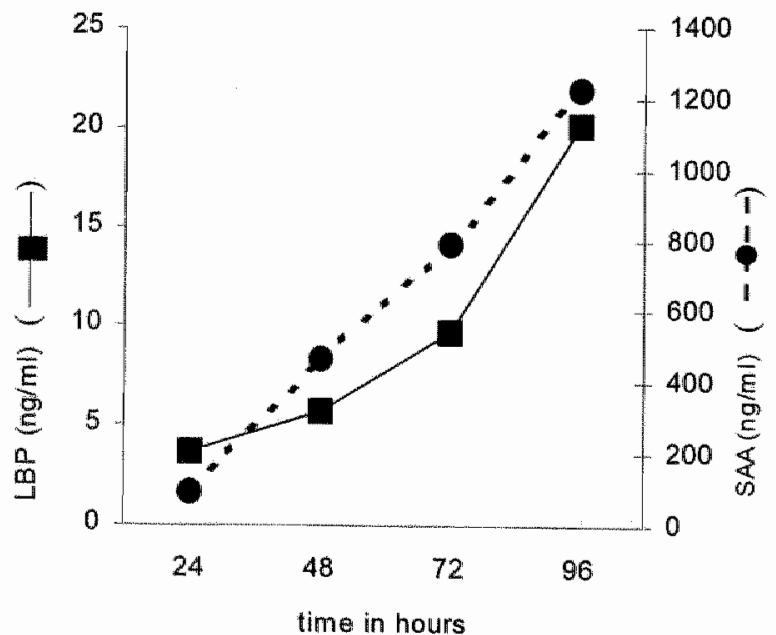

FIGURE 4. Time course of LBP and SAA release by Caco-2 cells after treatment with a combination of $I L-1 \beta(5 \mathrm{mg} / \mathrm{ml}), \Pi L-6(100 \mathrm{mg} / \mathrm{ml})$ TNF- $\alpha(100 \mathrm{ng} / \mathrm{ml})$ and dexamethasone $(1, \mu M)$. Supernatants $(\mathrm{n}=6)$ were collected after $24,48,72$ and $96 \mathrm{~h}$ incubation, and LBP and SAA release was determined by
ELISA. 
Time kinetics of LBP and SAA release by Caco-2 cells

Fig. 4 shows the time kinetics of LBP and SAA release. After an incubation period of $24 \mathrm{~h} \mathrm{LBP}$ and SAA concentrations in the supernatants where modest. A substantial increase was seen after $48 \mathrm{~h}$, and at 72 and $96 \mathrm{~h} \mathrm{LBP}$ and SAA release was further increased. These data are in agreement with the kinetics of LBP and SAA concentrations in the circulation during an acute phase response in man $(19,20)$,

\section{$L B P$ and SAA release by Caco- 2 cells is not induced by endotoxin}

The gastrointestinal tract contains high amounts of endotoxins that are important inducers of the acute phase response in vivo. To determine whether endotoxins can directly induce the release of LBP and SAA by IEC, endotoxin derived from Escherichia coli was added to Caco-2 cells cultured in the presence of human serum containing human LBP and soluble CD14, both necessary for non-immune cells to respond to endotoxins. Concentrations up to $10 \mu \mathrm{g} / \mathrm{ml}$ endotoxin did not lead to enhanced release of LBP or SAA by Caco-2 cells (data not shown).

To elucidate whether endotoxins are able to enhance the cytokine-induced release of LBP and SAA, Caco-2 cells were incubated with a combination of different concentrations of endotoxiin, IL-1 $\beta$ and IL-6. For all concentrations tested endotoxin did not affect the LBP and SAA release induced by IL-6 or IL-1 $\beta$ (data not shown). In conclusion these data indicate that LBP and SAA release by IEC is not influenced by endotoxins.
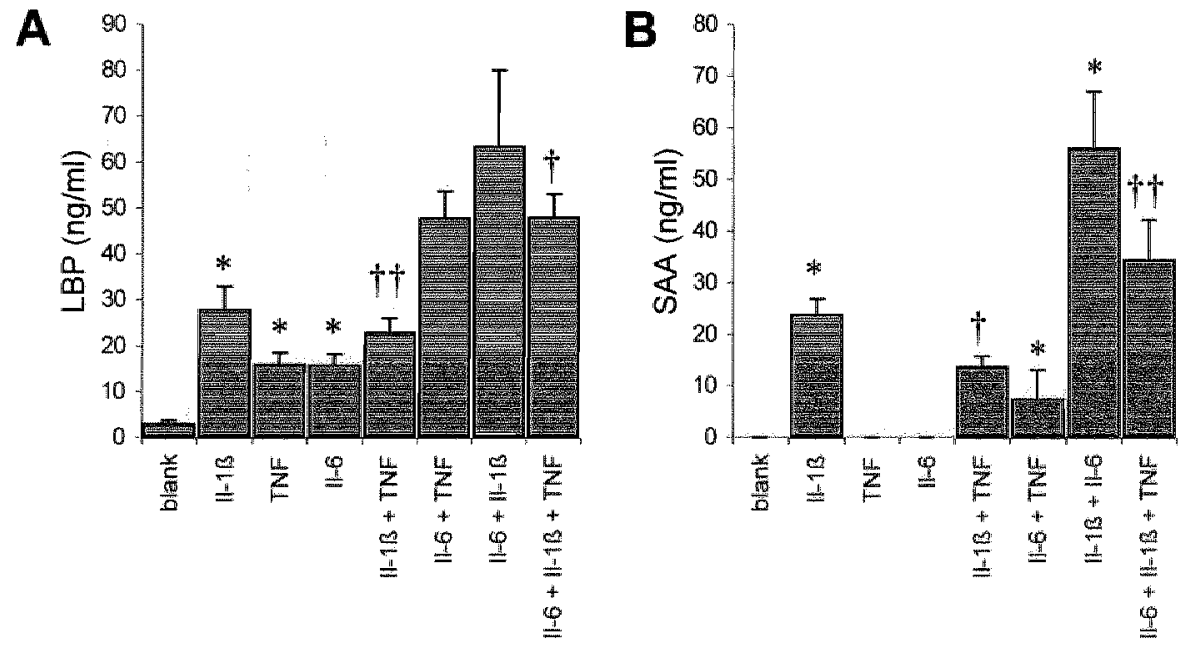

FIGURE 5. Cytokines induce LBP (A) and SAA (B) release by HuH -7 cells. Cells were inculbated with $\mathrm{IL}-1 \beta(5 \mathrm{ng} / \mathrm{ml}), \mathrm{IL}-6(100 \mathrm{ng} / \mathrm{ml})$, TNF $\alpha(100 \mathrm{ng} / \mathrm{ml})$, or combinations of these agents as indicated. Controls consisted of unstinulated cells. After 72-h incubation, supernatants were collected and LBP and SAA release was determined by ELISA. The data from a representative experiment are shown and expressed as the mean $\pm S D(n=6)$. * Significant effect of individual cytokines $(p<0.001)$ significant negative interaction between cytokines $(p<0.01) ;{ }^{\dagger \dagger}$ significant negative interaction between cytokines $(\mathrm{p}<0.001)$

Regulation of $L B P$ and SAA release by Caco-2 cells is different from $\mathrm{HuH-7}$ cells Acute phase proteins, such as LBP and SAA, are thought to be predominant liver 
derived. Therefore, the induction of LBP and SAA release in liver cells was investigated for comparison. To this end, HuH-7 cells were stimulated in a protocol similar to that used for Caco-2 cells (Fig. 5). These experiments revealed that with Hulf-7 cells, as with Caco-2 cells, LBP release is induced by IL-6 $(\mathrm{p}<0.001)$, whereas SAA release is induced by $L-1 B(p<0.001)$. Despite this conformity, several differences in the induction pattern of both proteins were notable between both cell types. The data demonstrate that IL- $1 \beta(5 \mathrm{ng} / \mathrm{ml})$ significantly $(\mathrm{p}<0.001)$ up-regulates the LBP release by HuH-7 cells, whereas no effect on LBP release was observed in Caco- 2 cells. Furthermore, TNF- $\alpha$ potentiated the LBP and SAA synthesis induced by the combination of $1 \mathrm{~L}-6$ and $\mathrm{IL}-1 \beta$ in Caco-2 cells $(p<0.01)$, whereas a down regulation of this induction was observed in Hull-7 cells $(p<0.05$; Fig. 5). In addition, the amount of SAA released by $\mathrm{Caco-2}$ cells exceeded the LBP release by these cells, whereas the opposite was found in HuH-7 cells. As in Caco-2 cells, endotoxin did not evoke a significant LBP and SAA release by HuH-7 cells (data not shown).
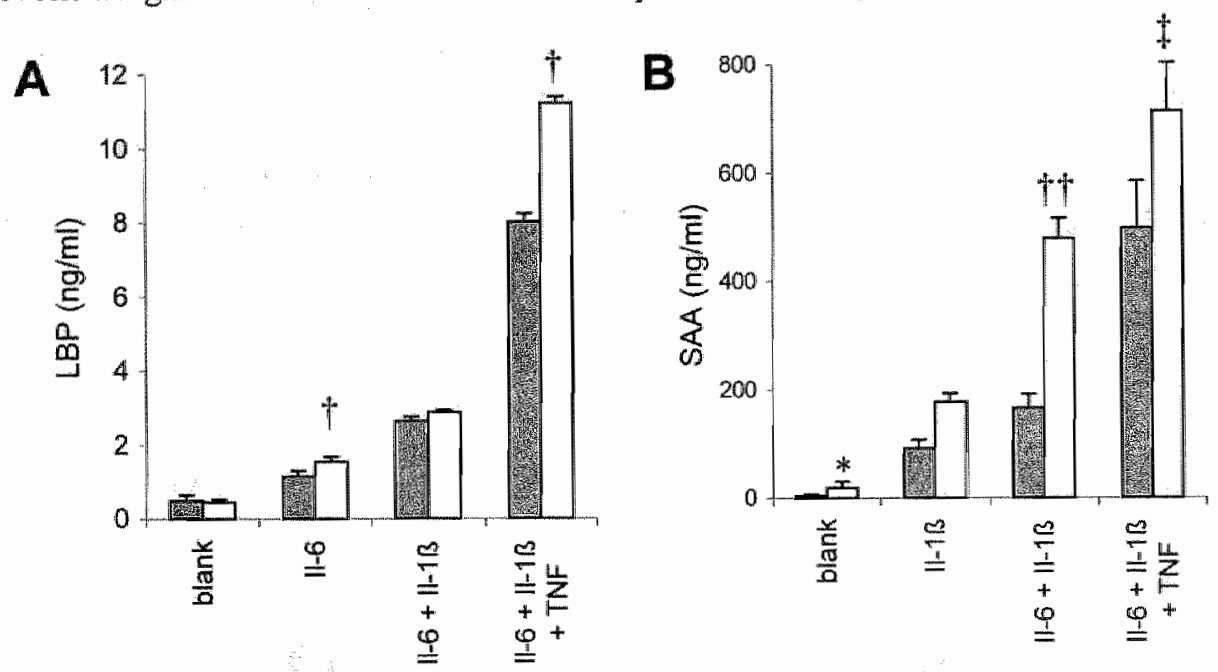

FIGURE 6. Dexanethasone thhances cytokine-induced LBP (A) and SAA (B) release by Caco-2 cells. Cells were stimulated for 72 h with IL- $1 \beta(5 \mathrm{ng} / \mathrm{ml}), \| \mathrm{L}-6(100 \mathrm{ng} / \mathrm{ml})$, TNF- $\alpha$ (100 $\mathrm{ng} / \mathrm{ml})$ or combinations of these agents in the presence (open bars) or the absence (filled bars) of $1 \mu \mathrm{M}$ dexamethasone. Controls consisted of unstimulated cells. After 72 h incubation, supernatants were collected and LBP and SAA release was determined by ELISA. The data from a representative experiment are shown and expressed as mean $\pm S D(n=6)$. Significant positive effect of the individual parameter dexamethasone $(\mathrm{p}<0.01)$; " significant positive interaction between dexamethasone and cytokines $(p<0.05)$; ${ }^{\text {ig }}$ significant positive interaction between dexamethasone and cytokines $(p<0.001) ;$; significant negative interaction between dexamethasone and cyokines ( $p$ $<0.001$ ).

Dexamerhasone enhances cytokine-induced LBP and SAA release by Caco-2 cells An important feature of the systemic acute phase response is the involvement of glucocorticoids. These glucocorticoids enhance the IL-1, TNF and IL-6 mediated induction of the acute phase response in the liver. To elucidate the effect of glucocorticoids on cytokine-mediated release of LBP and SAA by IEC, Caco-2 cells were stimulated in the presence of $1 \mu \mathrm{M}$ dexamethasone, a synthetic glucocorticoid. 
Dexamethasone enhanced the LBP synthesis induced by $I L-6(p<0.05)$ and markedly enhanced the induction by the combination of $11-6, \mathbb{1}-1 \beta$ and TNF- $\alpha(p<0.01$; Fig. $6 \mathrm{~A})$. Furthermore, spontaneous SAA release and SAA release induced by the combination of IL-1B and $\mathrm{L}-6$ were strongly enhanced by dexamethasone (Fig. $6 \mathrm{~B}$ ). The enhancement of LBP and SAA release by glucocorticoids was concentration dependent (data not shown). A negative interaction between dexamethasone and the combination of IL-1B, IL-6 and TNF- $\alpha$ was found $(p<0.001)$. These data indicate a role for glucocorticoids in the local acute phase response by regulation of the cytokine mediated LBP and SAA release in the gut.

Characterization of $L B P$ released by Caco- 2 cells

To characterize LBP produced by Caco-2 cells the $M_{\mathrm{r}}$ of the isolated protein was determined by western immunoblotting, and compared with that of rLBP. LBP produced by Caco-2 cells migrated as a single band with a $M_{\mathrm{r}}$ of approximately 60 $\mathrm{kDa}$, identical with that of rLBP (Fig.7).

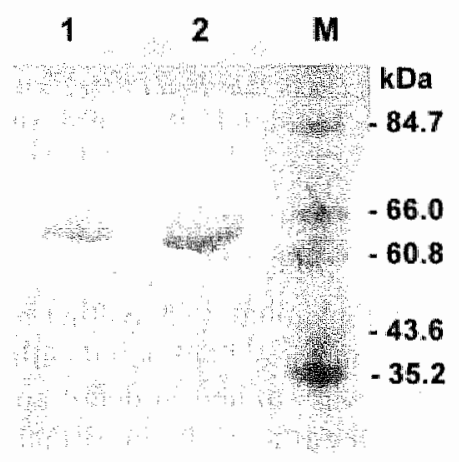

FIGURE 7. Westernblot of the Caco-2 derived LBP and rLBP. LBP was isolated from the supernatant of stimulated Caco-2 cells and CHO-cells. Gel electrophoresis of LBP was followed by electrophoretic transfer onto an Immobilon-P membrane. LBP was detecled by a polyclonal Ab to human LBP. Lane 1. rLBP; lane 2, LBP purified from supernatant of stimulated Caco-2 cells; lane $M_{n}$ molecular mass marker ( $\mathrm{kDa}$ ).

A characteristic of functional LBP is its capacity to bind LPS. Therefore, the capacity of Caco-2 derived LBP to bind LPS was established. The LBP produced by Caco-2 cells showed a dose dependent binding of LPS similar to that of rLBP (Fig. 8). These results ascertain the functional capacity of LBP produced by intestinal epithelial cells.

\section{LBP and SAA release by the intestinal cell lines Colo-205, T-84 and Int-407}

To elucidate whether the release of LBP and SAA is restricted to Caco-2 cells or is a common feature of IEC, the capacities of three other intestinal epithelial cell lines to release LBP and SAA were evaluated. For this purpose Colo-205 and T-84 cells, both derived from the human colon, and Int -407 cells, derived from human ileum/jejunum, were cultured in the presence of $I \mathrm{~L}-1 \beta(5 \mathrm{ng} / \mathrm{ml}), \Pi \mathrm{L}-6(100 \mathrm{ng} / \mathrm{ml}), \mathrm{TNF}-\alpha(100 \mathrm{ng} / \mathrm{ml})$ and $1 \mu \mathrm{M}$ dexamethasone. LBP release was inducible by cytokines in all tested cell 
lines. Non-stimulated cells produced only minute amounts of LBP. SAA was only detectable in the supernatant of stimulated Int-407 cells (Table I). These data confirm the capacity of human intestinal epithelial cells to synthesize and release LBP.

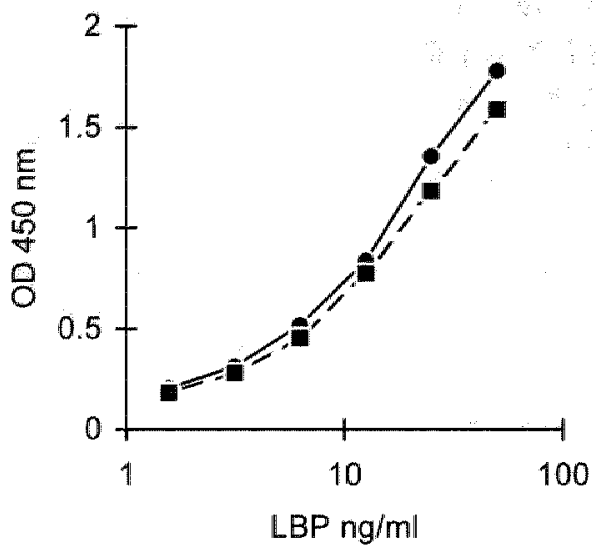

FIGURE 8. LPS binding capacity of Caco-2 derived LBP (-) and $R$ LBP $\mathbf{0}$, Concentration range of Caco-2 derived LBP and rLBP were added to plates coated with anti-LBP mAb HM14. Binding of biotinylated LPS to the immobilized LBP was determined. Data are expressed as OD $450 \mathrm{~nm}$.

\section{Discussion}

In the present study we demonstrated the synthesis and release of the endotoxin binding protein $L B P$ by human intestinal epithelial cells. Furthermore, the regulation of LBP and SAA release by IEC was studied in detail and compared to the regulation in liver cells. The results support the role of the intestinal mucosa as an active participant in the inflammatory response.

The results reveal that Caco-2, Colo-205, T-84 and Int-407 cells produce LBP. To our knowledge, this is the first evidence for the production of LBP by human IEC. Investigation of the induction of LBP release revealed that IL-6 induced LBP release by $\mathrm{Caco}-2$ cells, while $\mathbb{L L}-1 \beta$ and TNF- $\alpha$ showed a synergistic effect when used together with IL-6. Similarly, LBP synthesis was induced in liver cells by IL-6, whereas the effects of IL- $1 \beta$ and TNF- $\alpha$ on II- 6 induced LBP release were additive. TNF- $\alpha$ down regulated the LBP synthesis induced by a combination of IL-1 $\beta$ and IL-6 in liver cells, whereas the opposite effect was found for Caco-2 cells. The data concerning the release of LBP by liver cells are supported by others $(1,21,22)$.

SAA synthesis by Caco-2 cells was predominantly regulated by $I \mathrm{~L}-1 \beta$ and this induction was enhanced by IL-6. This regulation is consistent with the SAA synthesis in liver cells, which is also primary regulated by IL-1 $\beta$ and shows strong synergism with IL-6 (23). The regulation of SAA synthesis by TNF- $\alpha$ in Caco-2 cells was shown to differ substantially from the regulation of SAA release by liver cells. TNF- $\alpha$ downregulated the II- $1 \beta$ induced SAA release by HuH-7 cells, while in Caco- 2 cells IL- $1 \beta$ and TNF- $\alpha$ showed an additive effect on SAA release. Subsequently, parallel to the differences seen for LBP induction between these cell types, TNF- $\alpha$ suppressed the SAA release induced by the combination of IL-6 and IL-1 $\beta$ in liver cells, while a 
synergistic effect was seen in Caco-2 cells. In summary, both proteins behave like secretory class 1 acute phase proteins in IEC, similar to their regulation in bepatocytes $(19,21,23,24)$, although differences in the regulation of LBP and SAA release between both cell types were discernible. These differences possibly reflect a distinction between the regulation of systemic levels, controlled by the liver, and the regulation of local tissue levels in the intestine, for which epithelial cells are responsible. The high levels of cytokines found in the intestine during intestinal inflammation $(25,26)$ seem in line with our hypothesis of a localized regulation of acute phase protein synthesis in the gut. Furthermore, the ratio of SAA to LBP secreted by Caco-2 cells is high compared to $\mathrm{HuH}-7$ cells. It is not possible to conclude from the date that the absolute amount of SAA secreted by IEC exceeds the secretion of SAA by liver cells, because the number of Caco-2 and HuH-7 cells per well was not identical during experiments. However, these data clearly show a dramatic increase in SAA synthesis by Caco-2 cells in response to cytokines, which suggests that the intestinal mucosa is an important extrahepatic production site of SAA and which may reflect an immediate local requirement for this apolipoprotein during inflammation.

Table I: $L B P$ and SAA release by intestinal epithelial cell lines ${ }^{\prime}$

\begin{tabular}{lllc}
\hline & & LBP ng/ml & SAA ng/ml \\
\hline Colo-205 & Unstimulated & $1.05 \pm 0.06$ & ND \\
& Stimulated & $3.69 \pm 0.10^{*}$ & ND \\
T-84 & Unstimulated & $0.09 \pm 0.09$ & ND \\
& Stimulated & $0.69 \pm 0.13^{*}$ & ND \\
Int-407 & Unstimulated & $0.24 \pm 0.38$ & $\mathrm{ND}$ \\
& Stimulated & $0.85 \pm 0.04^{*}$ & $410.6 \pm 167.5 *$ \\
\hline
\end{tabular}

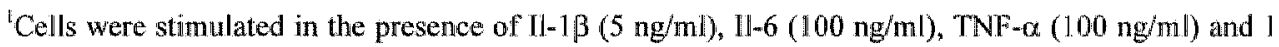
$\mu \mathrm{M}$ dexamethasone for $72 \mathrm{~h}$. Data are expressed as mean $\pm \mathrm{SD}$. ND; not detectable.

* Significantly different from unstimulated cells $(p<0.05)$.

In contrast to cytokines, endotoxin induced neither LBP nor SAA release by $\mathrm{Caco}-2$ cells in the presence of soluble CD14. The lack of response to endotoxin in Caco-2 cells is described for other acute phase proteins as well (8). Hypothetically this absence of response protects the host from an ongoing stimulation by endotoxins present in the gut lumen. Our data indicate that an inflammatory reaction leading to cytokine release is a necessary step for the induction of LBP and SAA release by IEC. Endotoxin enters under pathological circumstances the lamina propria, where it causes inflammation and the release of cytokines such as IL-6, IL-1 and TNF. We presume that these cytokines induce the release of acute phase proteins by the neighboring epithelium. However, it has been described that IEC themselves can generate cytokines in response to an endotoxin or bacterial challenge (27), although no consensus is achieved in the literature concerning this property of IEC (8).

Glucocorticoids were demonstrated to enhance the cytokine mediated induction of LBP and SAA release by IEC. This result is consistent with the enhancing effect of glucocorticoids on cytokine induced SAA $(24)$ and LBP $(19,21)$ synthesis by liver 
cells, as reported earlier and confirmed in this study (data not shown). The data indicate that the local synthesis of acute phase proteins in the gut is reinforced by glucocorticoids, which are synthesized by the adrenal glands in high amounts during a systemic acute phase response.

We hypothesize that the release of LBP by human intestinal epithellial cells is involved in the defense against endotoxins; which is pre-eminently important in the mucosa. Besides its role in neutralization and clearance of endotoxin, a basal concentration of LBP is known to enthance the sensitivity of the immune system to endotoxin by catalyzing the binding of endotoxin to macrophages. LBP produced by IEC may therefore also have a function in sensitizing the mucosal immune system to translocated endotoxins. However, high concentrations of LBP have been shown to decrease endotoxin activity (4). The ratio of LBP and endotoxin is reported to determine a number of essential processes; the monocytic response (4), the binding of LBP to HDL (28) and the inactivation of endotoxin by HDL (29). We suggest that a local production of LBP by epithelial cells during inflammation in the intestine may result in high local concentrations of LBP, and consequently to a reduced toxicity of endotoxin. The proposed importance of LBP in local defense against gram negative bacteria is supported by recent studies which demonstrate that intraperitoneal (i.p.) administration of bacteria is tolerated by wild type mice, although it results in an uncontrolled multiplication and spread of bacteria in LBP knockout mice (30). Moreover, i.p. injection of LBP can reduce mortality mediated by endotoxin and bacteria in mice (4).

Secretion of SAA by the intestinal epithelium refers to a role for SAA in the local inflammatory processes in the intestine. Although the primary function of SAA in the acute phase response is not fully understood, several immunological functions have been proposed. There is evidence that SAA enhances the binding of HDL, which possesses substantial endotoxin binding capacity (2), to macrophages (9). Furthermore, it was demonstrated recently that SAA has cytokine-like properties (31). Further studies are necessary to determine the biological role of SAA secretion by the intestinal mucosa.

In surnmary, we have demonstrated the release of LBP and SAA by intestinal epithelial cells in response to specific sets of cytokines and glucocorticoids. Endotoxin is shown not to incluce the release of LBP and SAA by IEC, indicating that cytokine release in the proximity of the epithelial cells is necessary for the induction of LBP and SAA release by these cells. The capability of IEC to release LBP and SAA suggests a role for the intestinal epithelium in the acute phase response and in the local defense of the gut against bacteria and endotoxin.

\section{Acknowledgement}

This work was supported by a grand of the Dutch Digestive Diseases Foundation, The Netherlands. The writers thank F. Nieman for performing the statistical calculations and J.A. Aben for expert technical assistance. 


\section{References}

1. Schumann, R.R., S.R. Leong, G.W. Flaggs, P.W. Gray, S.W. Wright, J.C. Mathison and R.d. Ulevitch. 1990. Structure and funetion of lipopolysaccharide binding protein. Sclence 249:1429.

2. Wurfel, M.M., E. Hailman, and S.D Wright. 1995. Soluble CD/4 acts as a shuttle in the neutralization of lipopolysaccharide (LPS) by LPS-binding protein and reconstituted high density lipoprotein. J. Exp. Med. 181:1743.

3. Ulevitch, R.J., A.R. Johnston ${ }_{*}$ D.B. Weunstein. 1979. New function for high density lipoproteins. J. Clin. Invest. 64:1516.

4. Lamping, N., R. Dettmer, N.W.J. Schröder, D. Pfeil, W. Hallatschek, R. Burger, and R.R. Schumann. 1998. LPS-binding protein protects mice from septic shock caused by LPS of gramnegative bacteria. J. Clin. Invest. 101;2065.

5. Michallsky, M.P., E.A. Deitch, J. Ding, Q. Lu, and Q. Huang. 1997. Unterleukin-6 and tumor necrosis factor production in an enterocyte cell model (Caco-2) during exposure to Escherichia coli. Shock. $7 ; 139$

6. Porter, E.M., L. Liu, A. Oren, P.A. Anton, and T. Ganz. 1997. Localization of human intestinal defensin 5 in Paneth Cell Granules. Infect. Immun. 65;2389

7. Su, G.L., P.D. Freeswick, D.A. Geller, Q. Wang, R.A. Shapiro, Y.H. Wan, T.R. Billiar, D.J Tweardy, R. L. Simmons, and S.C. Wang. 1994, Molecular cloning, characterization, and tissue distribution of rat lipopolysaccharide binding protein. J. Immunol. 153:743.

8. Molmenti, E.P., T. Ziambaras, and D.H. Perlmutter. 1993. Evidence for an acute phase response in human intestinal epithelial cells. J. Biol. Chem. 268:1411.6.

9. Kisilewsky, R., and L. Subrahmanyan. 1992. Serum amyloid A changes high density lipoprotein"s cellular affinity. Lab. Invest. $66 ; 778$

10. Hidalgo, I.J., T.J. Raub, and R.T. Borchardt. 1989. Characterization of the human colon carcinoma cell line $(\mathrm{CacO}-2)$ as a model system for intestinal epithelial permeability. Gastroenterology 96:736.

11. Hansen, M.B., S.E. Nielsen, and K. Berg. 1989. Re-examination and further development of a precise and rapid dye method for measuring cell growth/cell kill. J. Immunol. Meth. 19:203.

12. Kloppenburg, M., B.M.N. Brinkman, H.H. Rooij-Dijk, A.M.M. Miltenburg, M.R. Daha, F.C. Breedveld, B.A.C. Dijkmans, and C.L. Verweij. 1996. The tetracyeline derivative minocycline differentially affects cytokine production by monocytes and $T$ lymphocytes. Antimicrob. Agents Chemother. $40: 934$.

13. Froon, A.H.M,. M.A. Dentener, J.W.M. Greve, G. Ramsay, W.A. Buurman. 1995. Lipopolysaccharide toxicity-regulating proteins in bacteremia. J. Infect. Dis. $171: 1250$.

14. Hazenberg, B.P.C., P.C. Limburg, J. Bijzet, M.H. Rijswijk. 1990. Monoclonal antibody based ELISA for human SAA. In Amyloid and amyloidosis: VI ${ }^{\text {lite }}$ International Symposium on Amyloidosis, August 5-8, J.B. Natwig eds. Kluwer, Dordrecht, The Netherlands, p. 898.

15. Steel, D.M., F.C. Donoghue, R.M. O'Neill, C.M. Ulyar, and A.S. Whitehead. 1996. Expression and regulation of constitutive and acute plase serum aniyloid A mRNAs in Hepatic and nonhepatic cell lines. Scand. J. Immunol. 44:493.

16. Tateishi $H_{.}$K. Mitsuyama, A. Toyonaga, M. Tomoyose, K. Tanikawa. 1997. Role of cytokines in experimental colitis: relation to intestinal permeability. Digestion 58:27 I

17. Bertrand V., R. Guimbaud, M. Tulliez, C. Mauprivez, P. Sogni, D. Couturier, J-P. Giroud, S. Chaussade, and L. Chauwelot-Moachon. 1998. Increase in tumor necrosis factor-a production linked to the toxicity of indomethacin for the rat small intestine. British J. Pharm. 124;1385

18. Tamion, F., V. Richard, S. Lyouni, M. Daveau, g. Bonmarchand, J. Leroy, C. Thuillez, and J-P3. Lebreton. 1997. Gut ischaemia and mesenteric synthesis of inflammatory cylokines after hemortthagic or endotoxic shock. Am. J. Physiol. 273:G314

19. Schumann, R.R., C.J. Kirschning, A. Unbehaun, H. Aberle, H.P. Knopt, N. Lamping, R.J. Ulevitch, F. Herrmann. 1996. The lipopolysaccharide-binding protein is a secretory class I acutephase protein whose gene is transcriptionally activated by APRF/STAT-3 and other cytokineinducible nuclear proteins. Mol. Cell. Biol. 7:3490. 
20. McAdam, K.P.W.J, and J.D. Sipe. 1976. Murine model for human secondary amyloidosis: genetic variability of the acute-phase serum protein SAA response to endotoxins and casein. J. Exp. Med. $144: 1121$.

21. Grube, BJ, C.G. Cochane, R.D. Ye, C.E Green, M.E. McPhail, R. Ulevitch, and P.S. Tobias. 1994. Lipopolysaccharide binding protein expression in primary buman hepatocytes and HepG2 hepatoma cells. J. Biol. Chem. $269: 8477$.

22. Wan Y, P.D. Freeswick, L.S. Klyemlani, P.H. Kispert, S.C. Eang, G.L. Su, and T.R. Billiar 1995. Role of lipopolysatcharide (LPS), interleukin-1, interleukin-6, tumor necrosis factor, and dexamethasone in regulation of LPS-binding protein expression in normal hepatocytes and hepatocytes from LPS-treated rats. Infect. Immun. 63:2435.

23. Raynes, J.G., S. Eagling, and K.P.W.J. McAdam. 1991. Acute-phase protein synthesis in human hepatoma cells: differential regulation of serum amyloid $A$ (SAA) and haptoglobin by interleukin1 and interleukin-6. Clin. Exp. Immunol. 83:448.

24. Smith, J.W., and T.L. McDonald. 1992. Production of serum amyloid A and C-reactive protein by HepG2 cells stimulated with combinations of cytokines or monocyte conditioned media: the effects of predinisolone. Clin. Exp. Immunol. 90:293.

25. Viscardi, R.M, N.H. Lyon, C.C. Sun, J.R. Hebel, and J.D. Hasday. 1997. Inflammatory cytokine mRNAs in surgical specimens of necrotizing enterocolitis and normal newborn intestine. Ped. Path. Lab. Med. 17:547.

26. Youngman, K.R., P.L. Simon, G.A. West, F. Cominelli, D. Rachmilewitz, J.S. Klein; and C. Fiocchi. 1993. Localization of intestinal interleukin 1 activity and protein and gene expression to Jamina propria cells. Gastroenterology $104: 749$.

27. Ogle, C.K., X. Guo, P.O. Hasselgren, J.D. Ogle, and J.W. Alexander. 1997. The gut as a source of inflammatory cytokines after stimulation with endotoxin. Eur. J. Surg. 163:45.

28. Massamiri, T.,P.S. Tobias, and L.K. Curtiss, 1997. Structural determinants for the interaction of lipopolysaccharide binding protein with purified high density lipoproteins: role of apolipoprotein A-I. J. Lipid Res. 38,516-525

29. Wurfel, M.M., and S.D. Wright, 1997. Lipopolysaccharide-binding protein and soluble CDI4 transfer lipopolysaccharide to phospholipid bilayers. J.Immunol. 158;3925.

30. Jack, R.S., X. Fan, M. Bernheiden, G. Rune, M. Ehlers, A. Weber A, G. Kirsch, R. Mentel, B. Fürll, M. Freudenberg, G. Schmitz, F. Stelter, and C. Schütt, 1997. Lipopolysaccharide-binding protein is required to combat a murine Gam-negative bacterial infection. Nature 389:742.

31. Patel, H., R. Fellowes, S. Coade, and P.Woo. 1998. Human serum amyloid A has cytokine-like properties. Scand. J. Immunol. $48 ; 410$ 


\section{Chapter 3}

\section{Lipopolysaccharide Binding Protein is vectorially}

secreted and transported by cultured intestinal epithelial

cells and is present in the intestinal mucus of mice

Arita C.E. Vreugdenhi, A.M. Ratricia Snoek, Jan Willem M. Greve, Wim A. Buthman

Department of General Surgery, Mastricht University, The Netherlands,

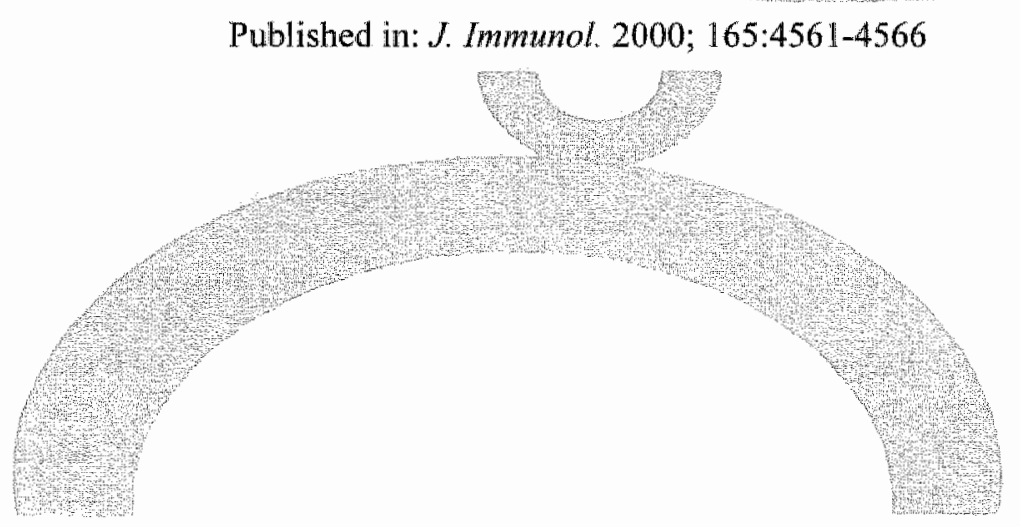




\begin{abstract}
Lipopolysaccharide-Binding Protein (LBP) is an important modulator of the host's response to endotoxin. In a previous study, we found evidence for the synthesis of LBP by intestinal epithelial cells. In this study, we explored the polarity of LBP secretion by these cells. Polarized monolayers of Caco-2 cells were used as intestinal mucosa model. Cells were stimulated apically or basally with cytokines, and LBP secretion was analyzed. Furtiermore, the presence of LBP in intestimal mucus of healthy and endotoxemic mice was studied using a mucus-sampling technique. The constitutive unipolar LBP secretion from the apical cell surface was markedly enhanced when celis were exposed to cytokines at their apical surface. However, bioactive LBP was secreted from both cell surfaces after basolateral stimulation of cells. Cytokines also influenced the secretion of the acute phase proteins serum amyloid $A$, apoA-I and apoB from both surfaces of Caco-2 cells. Furthermore, transport of exogenous LBP from the basolateral to the apical cell surface was demonstrated. In line with these in vitro data, the presence of LBP in intestinal mucus was strongly enhanced in mice after a challenge with endotoxin. The results indicate that LBP is present at the mucosal surface of the intestine, a phenomenon for which secretion and transport of LBP by intestinal epithelial cells may be responsible.
\end{abstract}




\section{Introduction}

The acute phase protein LPS-binding protein (LBP) strongly modulates the response to endotoxins, which are present in the outermembrane of Gram-negative bacteria. LBP has the paradoxical dual function of sensitizing the immune system to endotoxin (1), and on the other hand enhancing the neutralization of endotoxin by high density lipoprotein (HDL) (2,3). Furthermore, high concentrations of LBP have recently been shown to decrease endotoxin activity (4) and to protect against septic shock caused by Gram-negative bacteria $(4,5)$. The LBP concentration in the circulation increases enormously during inflammation, for which the liver has been held responsible. Previous in vitro studies from our laboratory, however, provided evidence for the extrahepatic synthesis of LBP by human intestinal epithelial cells (6). The intestinal mucosa serves as a boundary between the sterile interior of the host and the bacterial contents of the gut lumen. Therefore, the local release of LBP in the gut seems particularly important.

LBP secretion by intestinal epithelial cells was demonstrated to be dramatically upregulated by exposure to proinflammatory cytokines such as $\mathbb{L}-1$, IL-6 and TNF (6). Enhanced concentrations of these cytokines are present in the subepithelial tissue during inflammatory bowel diseases (7) and during systemic inflammation $(8,9)$. This implicates that epithelial cells are exposed to cytokines at their basolateral cell surface. However, inflammatory processes in the intestine take place at both poles of the epithelium, that is in the subepithelial tissue and at the luminal surface of the epithelium. Active inflammation of the intestine is histologically characterized by transmigration of neutrophils across the epithelial monolayer and subsequent collection of these cells in dilated crypts. Furthermore, there is evidence for the enhanced. presence of cytokines at the luminal surface of the mucosa during infection and inflammation of the gut $(10,11,12)$. Therefore, the intestinal epithelium may be exposed to cytokines at the apical pole as well. Moreover, receptors for IL-1 and IL-6 were described to be present at both the basolateral and the apical surface of intestinal epithelial cells (13). This prompted us to study whether intestinal epithelial cells synthesize LBP in response to cytokines administered to either the basolateral or the apical side of the cells. Furthermore, we studied from which surface of the cells LBP is secreted under various conditions.

\section{Material \& methods}

Reagents and Abs.

Human rTNF- $\alpha$ was kindly provided by BASF/Knoll (Ludwigshafen, FRG); human recombinant IL-6 by Prof. W. Sebald (Physiologisch-Chemisches Institut der Universität Würzburg, Germany); human rIL-1 $\beta$ was a gift from Immunex (Seattle, WA); dexamethasone was a gift from Merck Sharp \& Dohme (Haarlem, The Netherlands). Human rLBP was produced by transfected Chinese hamster ovary (CHO) cells, kindly provided by Dr. P.Tobias, Research Institute of Scripps Clinic (La Jolla, CA). Polyclonal Abs to human rLBP were obtained by immunizing rabbits with human rLBP. Murine LBP (mLBP) was produced by transfected Spodoptera frugiperda (SF9) cells. The baculovirus used for transfection as well as the rat antimurine LBP mAb clone 43 and a polyclonal rabbit anti-murine LBP Ab (14) was kindly provided by Dr. D. Heumann, department of Medicine, Lausanne, Centre 
Hospitalier Universitaire Vaudois. The Serum Amyloid A (SAA) immunoassay was kindly provided by Dr. P.C. Limburg, department of Rheumatology, University of Groningen, the Netherlands. The apoA-I and apoB immunoassay were a gift from Dr. Gavilondo, Center for Genetic Engineering and Biotechnology (Havana, Cuba).

\section{Culture and stimulation of $\mathrm{Caco-2}$ cells}

Caco-2 cells were obtained from the American Type Culture Collection (Manassas, VA; ATCC HTB 37). Caco-2 cells were cultured at $37^{\circ} \mathrm{C}$ with $5 \% \mathrm{CO}_{2}$ in DMEM (Life Technologies, Paisley, UK), supplemented with 10\% FCS (HyClone), $1.0 \mathrm{mM}$ sodium pyrtwate (Life Technologies), $0.1 \mathrm{mM}$ non-essential amino acids (Life Technologies), $100 \mathrm{IU}$ penicillin/ml and $100 \mu \mathrm{g}$ streptomycin/ml (Life Technologies), further defined as complete medium. Cells were maintained in $25-\mathrm{cm}^{2}$ or $75-\mathrm{cm}^{2}$ flasks (Costar, Cambridge, MA). Cultures were split when they reached $80 \%$ confluence.

For experiments, $5 \times 10^{5}$ Caco-2 cells $/ \mathrm{cm}^{2}$ were seeded onto a $1 \mathrm{~cm}^{2}$ or $4.7 \mathrm{~cm}^{2}$ collagen-coated membrane ( $3.0 \mu \mathrm{m}$ pore size) inserted in Transwells (Costar). Cells were cultured in complete medium, which was changed $48 \mathrm{~h}$ after seeding and every other day. After two weeks, Caco-2 monolayers display functional properties similar to those found in normal enterocytes (15) and they form a polarized monolayer with tight junctions and brush border microvilli at their apical surfaces (16). Therefore, in this study all experiments were conducted between 14 and 17 days after seeding of the cells. The formation and maintenance of a sealed monolayer of Caco-2 cells was monitored by measurement of the passage of the permeability probe phenol red ( 500 Da). Monolayers permeable for phenol red were not used (except for studies in which EDTA was added to disturb monolayer integrity).

For experiments designed to study the polarized release of acute phase proteins by Caco-2 cells, $1 \mathrm{~cm}^{2}$ filters were used. At the start of experiments, culture medium was removed from both compartments and complete medium, supplemented with IL-1 $\beta$, IL-6, TNF- $\alpha$ and dexamethasone, was added to the apical or basolateral compartment as given in the results. At the end of an $84 \mathrm{~h}$ incubation period, the apical and basolateral medium was removed, and apical derived medium was centrifuged to remove cells and cell debris. Acute phase protein concentrations in the medium were determined by ELISA.

To study the transport of LBP across Caco-2 monolayers, mLBP was used to prevent interference of human LBP synthesized by the Caco- 2 cells in the analysis. At the start of experiments, medium was removed from both compartments. Complete culture medium containing LBP-deficient human serum instead of FCS and containing MLBP was added to the basolateral or apical compartment. In many species, including humans, LBP is present in normal serum at a concentration of $0.1-5 \mu \mathrm{g} / \mathrm{ml}$ (17). Two concentrations in this range, 150 and $1500 \mathrm{ng} / \mathrm{ml}$, were used. After $72 \mathrm{~h}$ incubation, the mLBP concentration in the contralateral compartments was measured by a mLBP ELISA that lacks cross reactivity for human LBP.

\section{Immunoassays.}

Acute phase protein release by Caco-2 cells was evaluated using sandwich ELISA's. Human LBP was detected as described previously (18). In short, plates (Nunc-Immuno 
Plate Maxisorp, Roskilde, Denmark) were coated with polyclonal anti-human LBP Abs. The washing and reagent dilution buffer contained $40 \mathrm{mM} \mathrm{MgCl}_{2}$ to prevent disturbance of LBP recovery by LPS in the ELISA. LBP was detected using a biotinylated polyclonal rabbit anti-human $L B P \operatorname{IgG}$, followed by peroxidase-conjugated streptavidin (Zymed Laboratories Inc., San Francisco, CA) and tetramethylbenzidine (TMB) substrate (Kirkegaard \& Perry Laboratories Inc., Gaithersburg, MD).

SAA was quantified as described elsewhere (19). In short, SAA specific mAb Reu 86.5 was used as capture reagent. The amount of SAA bound to the wells was quantified by incubation with a horseradish peroxidase labeled monoclonal anti-SAA Ab (Reu 86.1), followed by TMB substrate.

For analysis of human apoA-I and apoB concentrations plates were coated with specific monoclonal $\mathrm{Abs}$ for $\mathrm{apoA}-\mathrm{I}$ and apoB, respectively. Peroxidase labeled mAbs were used for detection of immobilized apoA-I and apoB. Peroxidase activity was determined by addition of TMB substrate.

IL-6 concentrations were determined using sandwich ELISA for IL-6. In short, plates were coated with mAb $5 E 1$, specific for human IL-6. Immobilized IL-6 was detected using a biotinylated polyclonal rabbit anti-human IL-6 Ab, followed by peroxidaseconjugated streptavidin and TMB.

mLBP was quantified using sandwich ELISA. Rat mAb clone 43 was used as capture reagent. For detection of $\mathrm{mLBP}$ a polyclonal rabbit anti-murine $\mathrm{LBP} A \mathrm{~b}$ was followed by peroxidase-conjugated polyclonal goat-anti-rabbit IgG (Jackson ImmunoResearch, West Grove, PA) and TMB. Human LBP is not detected by the Abs used in this assay. For measuring murine $\operatorname{IgG}$, plates were coated with goat anti-murine $\operatorname{lgG}$ (Jackson ImmunoResearch). Peroxidase-conjugated polyclonal goat anti-murine IgG (Jackson ImmunoResearch), followed by TMB substrate, was used for detection of mIgG.

\section{Bioassay for $L B P$}

An important feature of LBP is its capacity to enhance the stimulation of PBMC by endotoxin. Therefore, the biologic activity of LBP secreted from either the apical or the basolateral cell surface was determined by assessing its effect on the endotoxininduced stimulation of PBMC. For this purpose $\mathrm{Caco}-2$ monolayers were cultured on $4.7 \mathrm{~cm}^{2}$ filters and basally stimulated as described before in the presence of complete medium containing $5 \%$ LBP-depleted human serum instead of FCS. This LBPPdepleted serum was produced by passing human serum $(15 \mu \mathrm{g} \mathrm{LBP} / \mathrm{ml})$ over an antiLBP column. To this end anti-hLBP mAb HM-14 was cross-linked to CNBr-activated Sepharose (Pharmacia) according to the manufacturer's instructions. LBP depleted serum, contained less then $3.5 \mathrm{ng} \mathrm{LBP} / \mathrm{ml}$ as assessed by LBP-ELISA. After an $85 \mathrm{~h}$ incubation period, the apical and basolateral supernatants were harvested and the concentration of LBP in the supernatants was determined by ELISA. To prevent LBP independent stimulation of PBMC caused by cytokines or other agents in the supernatants, a special method was developed. The apical and basolateral supernatants of stimulated cells, containing 66 and $33 \mathrm{ng} / \mathrm{ml} \mathrm{LBP}$, respectively, and of unstimulated cells, containing 2.5 and $0 \mathrm{ng} / \mathrm{ml} \mathrm{LBP}$, were added to a 96-well plate coated with a polyclonal $\mathrm{Ab}$ against $\mathrm{LBP}$. This $\mathrm{Ab}$ binds LBP without affecting its biological function. As a positive control complete stimulation medium containing $35 \mathrm{ng} \mathrm{rLBP} / \mathrm{ml}$ was added to the plates. Negative controls consisted of complete stimulation medium 
withou LBP. After 1.5 hour incubation the plates were washed extensively. PBMC were isolated from buffy coats of healthy volunteers, kindly provided by the local blood bank by density gradient centrifugation over Lymphoprep (Nycomed, Oslo, Norway). Cells were addel to the plates at a density of $1 \times 10^{5}$ cells/well and stimulated with $0.5 \mathrm{ng} / \mathrm{ml}$ LPS (from Escherichia coli, serotype $055 \mathrm{~B} 5$, Sigma) for $20 \mathrm{~h}$. The supernatants were harvested, and IL-6 concentrations in the culture supernatants were determined using ELISA. Enhanced IL-6 rellease was used as an indicator of biological activily of $\angle B B$.

\section{$L B P$ content of the intestinal mucus layer in mice}

Swiss mice were injected i.p. with $100 \mu \mathrm{g}$ LPS. Controls consisted of untreated mice. Mice were killed $24 \mathrm{~h}$ after injection of LPS and the small intestine was removed and spread open. The mucus on the luminal surface, was absorbed during 30 s using $0.5 \times 1$ cm filter paper (Whatmann no. 42; Maidstone, UK), a modified method described by Hendel et al. (12). Sections containing Peyer's patches were excluded. The filter papers were immediately transferred to a vial containing buffer solution (300 $\mu$ Tris buffer $0.1 \mathrm{M}, \mathrm{pH} 7.4 \mathrm{in}$ normal saline containing $0.3 \% \mathrm{BSA}, 0.01 \%$ azide and $0.002 \%$ Tween). Vials were placed on a rocker and agitated gently overnight at $4^{\circ} \mathrm{C}$. mLBP in the buffer was assessed using ELISA. To exclude the possibility that the LBP detected resulted from increased permeability of the mucosal membrane or contamination with blood, also the amount of IgG present in the buffer was analyzed.

\section{Statistical analysis}

Data were analyzed using SPSS (Chicago, IL) software. All values in the figures and texi are expressed as mean $\pm \mathrm{SD}$ of $n$ observations.

Comparison of acute phase protein levels in the supernatants of Caco-2 monolayers after different treatments was performed by the Mann-Whitney $U$ test. Data derived from the bioassay for LBP were analyzed by ANOVA with Dunnett's method as post hoc test, after $\log _{10}$ transformation of the data. The LBP and IgG concentration in the blood of healthy and endotoxemic mice was compared using the Mann-Whitney $U$ test. The data concerning LBP content of mucus in healthy and endotoxemic mice were conected for $\operatorname{IgG}$ content of mucus. For this purpose $\log _{10}$ transformation of mucus:serum ratios was performed. $\mathrm{u}=\mathrm{Log}$ (LBP ratio/IgG ratio) was counted for the untreated and LPS treated mice and Student"s t-test for unpaired values was performed to compare the means (u) of both groups. $10^{\text {u(uniteated)-u(L.LPS-treated) }}$ was counted to determine the relation of LBP in mucus of untreated and LPS treated mice. A probability of 0.05 or less was considered statistically significant. 


\section{Results}

Vectorial secretion of $L B P$ by Caco- 2 cells.

Furst, it was studied whether LBP is secreted from the apical or the basolateral plasma membrane surface of quiescent and apically or basally stimulated Caco-2 cells. To this end, Caco-2 cells were cultured on permeable filters which provide separation of apical and basolateral compartments. For stimulation of the monolayers, a mix of $U L$ $18(5 \mathrm{ng} / \mathrm{ml})$, IL-6 (100 $\mathrm{ng} / \mathrm{ml})$, TNF- $\alpha(100 \mathrm{ng} / \mathrm{ml})$ and 1 HM Dexamethasone was administered to the differentiated cells at either the apical or the basolateral side. In a previous study, this cytokine mixture was proven optimal for the induction of LBP secretion (6). After $84 \mathrm{~h}$ incubation the culture medium was harvested from both compartments and the LBP concentration was determined (Table I). It was found that LBP was secreted in minor amounts $(0.37 \mathrm{ng} / \mathrm{ml}$ absolute $0.19 \pm 0.12 \mathrm{ng})$ exclusively from the apical surface of unstimulated cells. When cytokines were added to the apical compartment, the secretion of LBP into the apical mediun was significantly enhanced $(2.23 \mathrm{ng} / \mathrm{ml}$ absolute $1.12 \pm 0.57 \mathrm{ng} \mathrm{LBP}, \mathrm{p}<0.05)$, while no LBP was detectable in the basolateral medium. Control experiments demonstrated that recombinant LBP traversed the naked filters and appeared in both compartments (not shown).

Table I: Vectorial secretion of LBP by intestinal epithelial cells

Stimulation

Apical LBP

Basolateral LBP

$\begin{array}{lll}\text { None } & 0.19 \pm 0.12 & \mathrm{ND}^{\ddagger} \\ \text { Apical } & 1.12 \pm 0.57^{*} & \mathrm{ND}^{*} \\ \text { Basolateral } & 2.03 \pm 0.42^{*} & 7.22 \pm 2.27^{* \dagger}\end{array}$

${ }^{\top}$ Cells were stimulated apically or basally with a combination of $\mathrm{IL}-1 \beta(5 \mathrm{ng} / \mathrm{ml}), \mathrm{IL}-6(100 \mathrm{ng} / \mathrm{ml})$, TNF- $\alpha(100 \mathrm{ng} / \mathrm{ml})$ and $1 \mu \mathrm{M}$ dexamethasone for $84 \mathrm{~h}$. Data are expressed as mean of total released ng $\mathrm{LBP} \pm \mathrm{SD}$ per compartment $(n=7)$. ND; not detectable. * Significant difference from unstimulated cells $(p<0.05) ;$ " significant difference from apical stimulated cells $(p<0.05)$; " significant difference from the concentration in the contralateral compartment $(\mathrm{p}<0.05)$.

This observation eliminates the possibility that the absence of LBP in the basolateral compartment results from its selective adsorption onto the filters supporting the monolayers.

In contrast to the unipolar secretion under neutral and apical stimulated conditions, basolateral administration of cytokines resulted in the secretion of LBP from both cell surfaces; LBP was secreted into the basolateral medium $(4.81 \mathrm{ng} / \mathrm{ml}$ absolute $7.22 \pm$ $2.27 \mathrm{ng}$ ) and the amount of LBP in the apical compartment increased markedly (4.06 $\mathrm{ng} / \mathrm{ml}$ absolute $2.03 \pm 0.42 \mathrm{ng}$ LBP). The permeability for phenol red during these experiments was not disturbed, indicating intact monolayer integrity. Taken together, these data indicate that both surfaces of Caco-2 cells interact with cytokines and that cells are able to secrete LBP from both surfaces. The intracellular targeting or delivery of LBP to either the apical or the basal cell surface, however, is influenced by the presence of cytokines at these surfaces. 
Table II: Vectorial secretion of SAA and apolipoproteins by intestinal epitheliai cells'

\begin{tabular}{|c|c|c|c|c|c|c|}
\hline \multirow[b]{2}{*}{ Stimulation } & \multicolumn{2}{|c|}{$\mathrm{SAA}$} & \multicolumn{2}{|c|}{$\operatorname{apoA}-1$} & \multicolumn{2}{|c|}{$\operatorname{apoB}$} \\
\hline & Apical & Basolateral & Apical & Basolateral & Apical & Basolateral \\
\hline None & $\mathrm{ND}$ & $\mathrm{ND}$ & $1.1 \pm 0.2$ & $3.3 \pm 1.3^{2}$ & $3.6 \pm 1.7$ & $13.9 \pm 4.0^{\frac{1}{2}}$ \\
\hline Apical & $184.2 \pm 69.8 *$ & $48.3 \pm 15.3^{*}$ & $0.9 \pm 0.1 *$ & $2.1 \pm 1.1^{2}$ & $2.2 \pm 0.7$ & $8.5 \pm 3.4^{\frac{t}{2}}$ \\
\hline Basolateral & $217.5 \pm 74.4$ & $583.3 \pm 132.3^{* 1}$ & $0.9 \pm 0.2$ & $1.3 \pm 0.5$ & $1.8 \pm 0.2 *$ & $5.7 \pm 3.0^{*}$ \\
\hline
\end{tabular}

Cells were stinulated apically or basally with a combination of $\mathrm{IL}-1 \beta(5 \mathrm{ng} / \mathrm{ml}), \mathrm{LL}-6(100 \mathrm{ng} / \mathrm{ml})$ TNF $-\alpha(100 \mathrm{ng} / \mathrm{ml})$ and $1 \mu \mathrm{M}$ dexamethasone for $84 \mathrm{~h}$. Data are expressed as the mean of total released ng $S A A$; $\mu \mathrm{g}$ apoA-I and $\mu \mathrm{g}$ apoB $\# \mathrm{SD}$ per compariment $(\mathrm{n}=7)$. ND; not detectable. * Significant difference from unstimulated cells $(\mathrm{p}<0.05)$; significant difference from apical stimulated cells $(p<0.05)$, significant difference from the concentration in the contralatera compariment $(\mathrm{p}<0.05)$.

\section{Vectorial secretion of SAA and apolipoproteins by Caco-2 cells}

During inflammation the concentration of several plasma proteins other then LBP are increased, such as SAA, which is one of the major positive acute phase proteins. Another important aspect of the acute phase response is the reduced presence of negative acute phase proteins in the circulation, such as the apolipoproteins apoA-1 and apoB $(20)$. The intestinal mucosa is a known producer of the apolipoproteins $S A A$, apoA-I and apoB. Previous work on the acute phase response in the intestine in vivo indicates that apoA-I decreases only in the duodenum, while SAA increases throughout the intestine (21). A common feature of these proteins and LBP is their association with lipoproteins. These lipoproteins contribute to the neutralization of endotoxin $(2,3)$. To study whether the polarized distribution, as observed for $L B P$, is a common feature of acute phase proteins or apolipoproteins in general, we investigated the polarized distribution of SAA, apoA-I and apoB by Caco-2 monolayers in parallel to LBP (Table II). SAA was not detectable in the supernatant of quiescent monolayers. After cytokine stimulation however, Caco-2 monolayers produced high amounts of SAA. In contrast to LBP, SAA was detectable at both surfaces in response to the addition of cytokines to either side of the monolayer. However, similar to LBP secretion, the secretion of SAA predominated in the compartment corresponding to the side of cyiokine stimulation.

The negative acute phase proteins apoA-I and apoB are produced in high amounts under normal culture conditions and are secreted from both cell surfaces, although the secretion into the basolateral compartment predominates. As expected, the total secreted amount of apoA-I and $a p o B$ decreased in response to cytokines. Apical addition of cytokines resulted in a 15\% decline in apical and a $35 \%$ decline in basolateral apoA-I concentration. Under these conditions, the apoB concentration decreased almost $40 \%$ in the apical and basolateral compartment. When cytokines were administered basolaterally the amount of apoA-I secreted into the apical compartment reduced with $20 \%$ and basolateral concentrations declined $60 \%$. Apical and basolateral apoB concentrations declined approximately $50 \%$ and $60 \%$ respectively under these conditions. 
These results indicate that the secretion of SAA, apoA-I and apoB from both surfaces of Caco-2 cells can be influenced by addition of cytokines to either pole of the cells. These results are consistent with those found for LBP secretion. However, the specific pattern of polarized LBP secretion under different conditions was not observed for the other tested acute phase proteins.

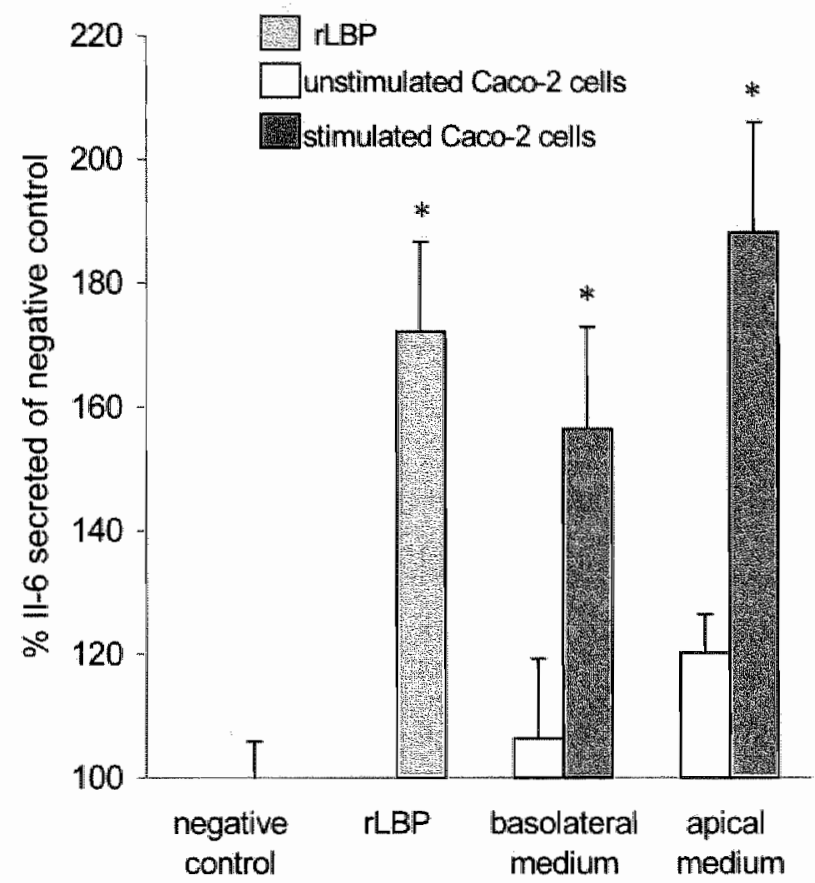

FIGURE 1. Bioactivity of apical and basolateral secreted LBP. Caco-2 cells were grown on Transwell-Col and stimulated basally with $I L-1 B(5 \mathrm{ng} / \mathrm{ml}), I L-6(100 \mathrm{ng} / \mathrm{ml})$, TNF $\alpha(100 \mathrm{ng} / \mathrm{ml})$ and $1 \mu \mathrm{M}$ Dexamethasone for $85 \mathrm{~h}$. The concentration of LBP in the supernatants was determined by ELISA. Apical and basolateral supernatants of stimulated cells, containing 66 and $33 \mathrm{ng} \mathrm{L/BP} / \mathrm{ml}$ respectively, and unstimulated cells, containing 2.5 and $0 \mathrm{ng} \mathrm{LBP} / \mathrm{ml}$, were added to 96 wells EL $\mathrm{LSA}$ plates coated with a polyclonal $\mathrm{Ab}$ against human LBP. A positive control containing $35 \mathrm{ng} \mathrm{rLBP} / \mathrm{m}$ ! and a negative control without LBP were included. After extensive washing of the plates, $1 \times 10^{5}$ PBMC and $0.5 \mathrm{ng}$ L.PS/ $/ \mathrm{ml}$ were added to the wells. Supernatants were harvested after $20 \mathrm{~h}$ and $\mathrm{IL}-6$ released into the supernatant was analyzed. Results shown represent percentage IL-6 secreted compared to negative controls, and are presented as mean $\pm \mathrm{SD}$ of 3 wells. * Significant difference from negative control $(\mathrm{p}<0.05)$.

Apical and basolateral secreted LBP enhances the endotoxin induced cell activation.

Next, the functional capacity of apical and basolateral secreted LBP was studied. Several functions of LBP have been described, among which its capacity to strongly enhance endotoxin induced cell activation (22). It was demonstrated that LBP binds to LPS and facilitates the interaction of endotoxin with membrane CD14 on monocytes, resulting in cytokine release (22). The capacity of the apical and basolateral released LBP to up-regulate the endotoxin induced IL-6 secretion by PBMC was studied. Using 
a new developed bio-assay, LBP in both apical and basolateral medium, was demonstrated to enhance the endotoxin-induced cell activation compared to LBP deprived conditions ( $<<0.05$ ) (Fig.1). Apical and basolateral media from untreated monolayers did not significantly affect the endotoxin induced cytokine release.

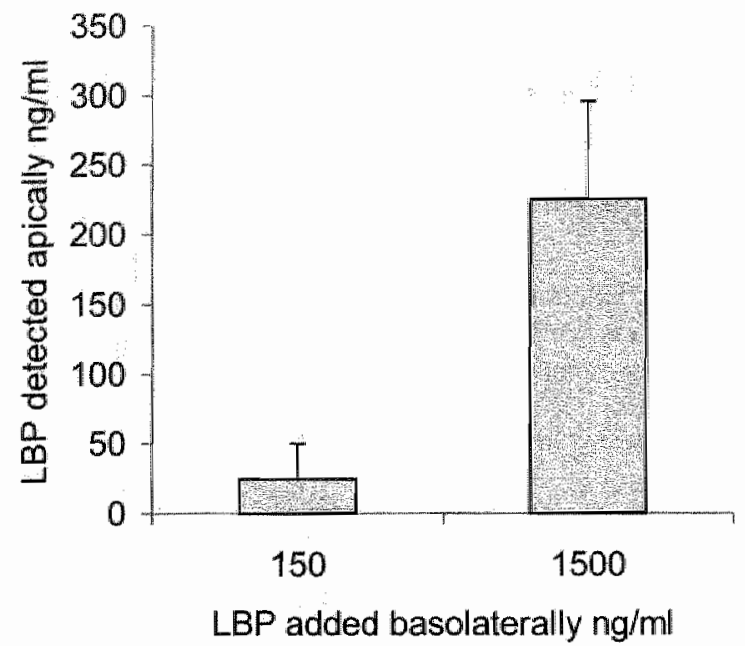

FIGURE 2. Transport of LBP across Caco-2 monolayers is directed towards the apical surface. 150 or $1500 \mathrm{ng} / \mathrm{ml} \mathrm{mLBP}$ was added to the basolateral compartment of cells that were grown on Transwell-Col ${ }^{\text {Th }}$ filters. mLBP was measured after $72 \mathrm{~h}$ incubation in the apical compartments. Presented are the means \pm SD of the mLBP concentration in the apical compartment of 3 welis.

LBP is transported across Caco-2 monolayers from the basolateral to the apical side. The data obtained in this study demonstrate that Caco-2 cells secrete LBP from their apical surface under all tested conditions. These findings suggest a putative importance of the presence of LBP at the apical surface of the intestinal epithelium. Therefore it was studied next whether besides the secretion of endogenous LBP towards the apical surface, Caco- 2 cells are also able to transport exogenous LBP from their basolateral to their apical surface. For this purpose, physiologic concentrations (150 and 1500 $\mathrm{ng} / \mathrm{ml}$ ) of murine LBP (mLBP) were added to the basolateral compartments. After $72 \mathrm{~h}$ incubation the amount of mLBP was measured in the apical compartments using an ELISA highly specific for mLBP. The data show that after administration of physiologic amounts of $\mathrm{mLBP}$ to the basolateral side of the cells, substantial amounts of mLBP were detected in the apical compartment (Fig.2). The passage of LBP across the monolayers was dose-dependent. To elucidate whether the passage of LBP across the monolayer was specific for the basolateral-apical direction, mLBP was also added to the apical compartment. No passage of mLBP across the Caco-2 monolayers could be detected in the apical-basolateral direction (data not shown). This restriction of passage required the integrity of the monolayers, since EDTA induced disruption of the integrity resulted in the traversing of LBP through the filter and cell layer (data not shown). These results are in line with experiments, which demonstrated the presence of LBP in the apical and not the basolateral medium after apical stimulation of the cells and in quiescent cells. 

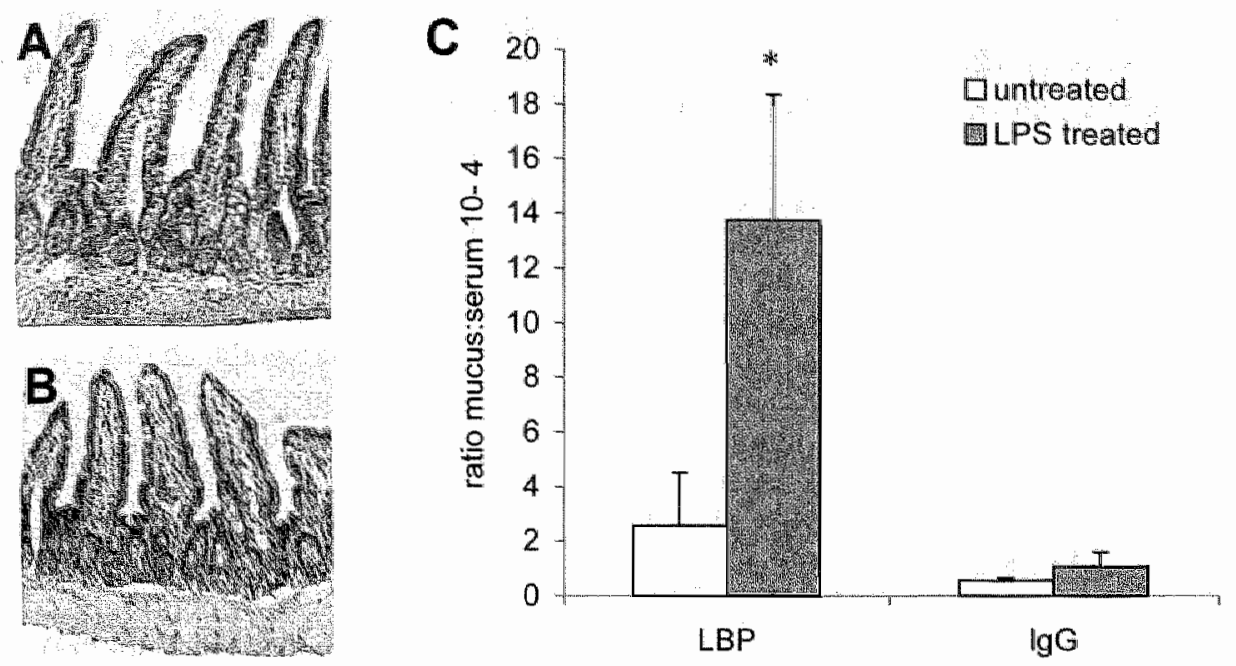

FIGURE 3. $L B P$ presence in mucus of mice is ewhanced during endotoxemia. Swiss mice were injected i.p. with $100 \mu \mathrm{g}$ LPS. Controls consisted of untreated mice. Mice were killed 24 h after injection of LPS. The mucus of the small intestine was absorbed using filter paper. Histological examination of the intestinal segment showed no damage to the epithelium attributable to the procedure in controls $(A)$ and endotoxin-challenged mice (B).

(C) Absorbed LBP and serum concentrations of LBP were assessed using ELISA. Absorbed IgG was used as a marker of plasma leakage. Results are presented as the mean \pm SD mucus:Serum ratio of LBP and $\operatorname{lgG}$ of 4 and 3 mice, respectively. * Significant enhanced compared to controls after correction for IgG leakage $(\mathrm{p}<0.05)$.

\section{The LBP content of mucus is enhanced during endotoxemia}

The data obtained in this study so far suggest that cytokines enhance the constitutive secretion of LBP towards the luminall surface of intestinal epithelial cells. Subsequent, the data implicate that transport of LBP toward the apical surface of the epithelium occurs. Therefore, we next studied whether the amount of LBP in the mucus overlaying the intestinal mucosa is enhanced during inflammation. In this model, mice were challenged with endotoxin. Endotoxemia induces inflammatory processes in the intestine, including intestinal production of cytokines $(8,9)$.

I.p. administration of endotoxin to mice resulted in a significantly increased serum concentration of LBP $(20.9 \pm 7.3 \mu \mathrm{g} / \mathrm{ml}, \mathrm{p}<0.05)$ as compared with the controls $(5.4 \pm 2.6$ $\mu \mathrm{g} / \mathrm{ml})$. The amount of LBP absorbed from $0.5 \mathrm{~cm}^{2}$ mucus increased from $1.4 \mathrm{ng}$ in controls to $30.6 \mathrm{ng}$ in the LPS treated mice. Histological examination of the intestinal segment showed no damage to the epithelial lining (Fig.3A/B). The integrity of the intestinal mucosa was further confirmed by investigating the leakage of $\mathrm{IgG}$ across the epithelium. The IgG concentration in serum was not significantly altered. The mean ratio of IgG in mucus to serum, was $6 \times 10^{-5}$ and $1 \times 10^{-4}$ in untreated and LPS treated mice respectively, indicating a slightly enhanced degree of leakage from the intestinal mucosa (Fig. $3 \mathrm{C}$ ). The ratio of LBP absorbed from $0.5 \mathrm{~cm}^{2}$ mucus to the concentration of LBP in serum of untreated mice was $2.6 \times 10^{-4}$ and of mice injected intraperitoneally with endotoxin $1.4 \times 10^{-3}$ (Fig.3C). In view of the mucus:serum ratios for IgG and LBP, 
the possibility that the detected LBP was a result of a disturbed intestinal integrity is not likely. In endotoxemic mice the ratio LBP in mucus to serum corrected for IgG leakage was significantly enhanced 5 times $(p<0.05)$ compared to controls.

\section{Discussion}

In previous studies we demonstrated that $\mathrm{Caco}-2$ and other intestinal epithelial cell lines, synthesize and secrete the endotoxin modulating proten LBP, and that this secretion is dramatically up-regulated by exposure to proinflammatory cytokines and dexamethasone (6). The data of this study demonstrate that the synthesis of LBP and other acute phase proteins by $\mathrm{Caco}-2$ cells is affected by the presence of cytokines at both the subepithelial and the luminal surface of the cells. These data are in line with the presence of $\mathrm{LL}-1$ and $\mathrm{IL}-6$ receptors on the basolateral and the apical surface of these cells as described by others (13). Local high concentrations of these cytokines can be found in both the subepithelium of the gut (7) and at the luminal surface of the mucosa during infection and inflammation of the gut $(10,11,12)$, which implies that both, the apical and the basolateral pole of enterocytes can be exposed to cytokines.

Constitutive LBP was secreted exclusively from the apical surface of Caco-2 cells and the amount of apical secreted LBP was strongly up-regulated by proinflammatory cytokines if present at either the apical or the basolateral surface of the cells. Remarkably, apical exposure of cells to cytokines resulted in unipolar secretion of LBP from the apical surface, whereas bipolar secretion of LBP from the basolateral and the apical surfaces of the cells occurred in response to cytokines present at the basolateral side of cells. The monolayer integrity was shown not to be disturbed and LBP was demonstrated not to passage the monolayers in the apical to basolateral direction. Therefore, it is not likely that the presence of LBP in the basolateral compartment resulted from a redistribution of cytokines or from LBP that was originally secreted from the apical surface. The data indicate that signals, induced by contact of cytokines with the basal cell surface, are necessary to direct LBP to the basolateral surface.

The data further indicate that LBP secretion is directed primarily toward the side of cytokine administration. This observation implies that the secretory response of intestinal epithelial cells is predominantly directed towards the cell pole at which inflammatory processes take place. These data are strongly supported by the vectorial secretion of cytokines by Caco- 2 cells and the ileal mucosa in response to a bacterial challenge $(11,23)$. Luminal secretion of cytokines will predominate when infection takes place at the apical surface of the mucosa such as during bacterial overgrowth (23). Cytokines are also present in high amounts at the apical surface of the mucosa during cryptabcesses, characteristic for inflammatory bowel disease. Therefore enhanced apical secretion of LBP may be of physiologic relevance during these conditions.

Surprisingly, Caco- 2 cells were also able to secrete the acute phase proteins SAA, apoA-1 and apoB from both surfaces. SAA was only secreted upon stimulation by cytokines. The secretion of the negative acute phase proteins apoA-I and apoB by Caco- 2 cells was reduced in response to cytokines, congruent with observations by others $(21,24,25)$. Although the reduction was most prominent when cytokines were added to the basolateral side, protein production was also diminished after apical 
cytokine administration. The reduced production of these negative acute phase proteins and the up-regulation of positive acute phase protein synthesis are consistent with the reprioritization of protein release described for hepatocytes during the acute phase response (26). The potential function of SAA, apoA-I and apoB at the apical surface of the intestinal mucosa is currently being explored.

In addition to the secretion of endogenous LBP from the apical surface, transport of exogenous LBP from the basolateral to the apical side of Caco-2 cells was observed. Remarkably, the passage of LBP in reversed direction did not occur. These data imply that LBP derived from the circulation can be transported toward the intestinal lumen and that the enhanced concentrations of LBP as found in the circulation during the acute phase response may result in increased transport of LBP.

The in vitro data obtained in this study were supported by in vivo data, which demonstrated the presence of LBP in mucus overlaying the small intestine, which was significantly enhanced during endotoxemia. The measured amounts of LBP in the mucus exceeded the levels that could be expected to result from passive leakage from the circulation. Based on the results obtained in this study we consider that the enhanced LBP concentration in mucus during systemic inflammation can be a result of both, enhanced local production of LBP induced by cytokines and enhanced transport of LBP from the circulation towards the lumen across the epithelial cells. The presence of LBP at the luminal surface of the intestinal mucosa is consistent with the presence of other acute phase reactants in the intestinal lumen during inflammation, such as cytokines $(10,11,12)$ and complement components (27).

The data of this study suggest that the intestinal epithelium can participate in inflammatory processes, which take place at the mucosal surface, by secretion of locally produced LBP and SAA and by transport of circulating LBP toward the lumen. It is tempting to speculate that the vectorial secretion and transport of LBP direct this endotoxin modulating protein to a location were its function can contribute to the defense of the gut, comparable to other proteins which contribute to host immunity at mucosal surfaces, such as $\operatorname{IgA}(28)$ and the microbicidal molecules lysozyme (29) and defensins (30). Several functions of LBP have been described, which can be applicable to processes taking place at the apical surface of normal and diseased epithelium. The secreted LBP may regulate the function of other cells in the local micro-environment. LBP is known to enhance the sensitivity of the immune system to endotoxin by catalyzing the binding of endotoxin to macrophages (22). High concentrations of LBP, however, have been shown to decrease endotoxin activity (4). In addition, evidence for a role for LBP in the sequestration of Gram-negative bacteria was supported by a recent study which demonstrated that an intraperitoneal administration of bacteria is tolerated by wild type mice, where it results in an uncontrolled multiplication and spread of bacteria in LBP knockout mice (5). Moreover, i.p injection of LBP can reduce mortality mediated by endotoxin and bacteria in mice (4). In view of these functions apical secreted LBP possibly contributes to the intestinal barrier against bacteria and their toxin by enforcement of the ability of mucus to impair bacterial translocation.

The observation that exposure of cytokines to the basolateral cell pole is necessary for LBP secretion from this cell surface, implies that in vivo basolateral LBP secretion occurs only when inflammatory processes take place at the subepithelium or during 
systemic inflammation. Basolateral secreted LBP may contribute to the handling of endotoxins that have penetrated into the subepithelium during conditions in which a disturbed mucosal integrity results in an enhanced permeability. This handling possibly concerns catalyzing the neutralization of endotoxin by lipoproteins; which are secreted in high amounts by the intestinal epithelium. Neutralization of bacterial toxin by LBP in the intestine might be important for the defense against gram-negative and gram-positive bacteria, since LBP was demonstrated to catalyzes the lipoprotein neutralization of LPS and lipoteichoic acid, a component of the cell membrane of gram-positive bacteria (31). Low non-harmful amounts of endotoxin are thought to leak continuously across the intact intestinal epithelium. LBP has a role in both, sensitizing the immunesystem for endotoxin and in the neutralization of endotoxin. Since this balance is concentration dependent, we hypothesize that the restriction of low concentrations of basolateral LBP in the absence of inflammatory processes taking place at the subepithelium may prevent hypersensitivity to endotoxin.

in conclusion, the results described in this paper provide evidence for the vectorial secretion of LBP and other acute phase proteins by the intestinal epithelium, a phenomenon that is not described before. Because LBP plays a significant role in the handling of endotoxin, the enhanced local presence of LBP at the apical surface of the intestinal mucosa and in the subepithelium, may be critical in host defense. The function of this intriguing phenomenon in events such as cryptabcesses, cellular infiltrates within the bowel wall and bacterial translocation demands further investigation.

\section{Acknowledgements}

The writers thank M.van de Watering for expert technical assistance. This work was supported by a grant of the Dutch Digestive Diseases Foundation, the Netherlands.

\section{References}

I. Schumann, R.R.,S.R Leong, G.W. Flaggs, P.W. Gray, S.W. Wright, J.C. Mathison, and R.J. Ulevitch. 1990. Structure and function of lipopolysaccharide binding protein. Science 249:1429

2. Wurfet, M.M., E. Hailman, and S.D. Wright. 1995. Soluble CD14 acts as a shuttle in the neutralization of lipopolysaccharide (LPS) by LPS-binding protein and reconstituted high density lipoptotein. II Exp. Med. 181:1743.

3. Ulevitch, R.J., A.R. Johnston, and D.B. Weinstein. 1979. New function for high density lipoproteins. J. Chin. Inwest. 64:1516.

4. Lamping, N., R. Detmer, N.W.J. Schroder, D. Pfeil, W. Hallatschek, R. Burger, and R.R. Schunann. 1998. LPS-binding protein protects mice from septic shock caused by LPS or gramnegatiwe bacteria. J. Clin. Imwest 101;2065.

5. Jack, R.S, X. Fan, M. Bemheiden, G. Rune, M. Ehlers, A. Weber, A. Kirsch, R. Mentel, B. Fürll, M. Freudenberg, G. Schmitz, F. Stelter, and C. Schüt. 1997. Lipopolysaccharide-binding protein is required to combat a murine Gam-negative bacterial infection. Narure $389: 742$.

6. Vreugdenhil, A.C.E. M.A. Dententer, A.M.P Snoek, J.W.M. Greve, and W.A. Buurman. 1999. Lipopolysaccharide binding protein and serum amyloid $A$ secretion during the acute phase response. J.lwmusol. 163:2792.

7. Tateishi, H., K. Mitsuyama, A. Toyonage, M. Tomoyose, and K. Tanikawa. 1997. Role of Cytokines in experimental colitis: relation to intestinal permeability. Digestion 58:271.

8. Mester, M., R.G. Tompkins, J.A. Gelfand, C.A. Dinarello, J.F. Burke, B.D. Clark. 1993. Intestinal production of Interleukin-l $\alpha$ during endotoxemia in the mouse. J. Surch. Res. 54:584. 
9. Meyer, TA., J. Wang, G.M. Twa, C.K. Ogle, J.E. Fischer, and P.O. Hasselgren. 1995. Sepsis and endotoxemia stimulate intestinal interleukin-6 production Sirgery. 118.336.

10. Riordan, S.M., C.J. McIver, D. Wakefield, V.M. Duncombe, T.D. Bolin, and M.C. Thomas. 1996. Mucosal cytokine production in small-intestinal bacterial overgrowth. Scand J. Gustroentenol. 31.977.

11. Grotz, M.R.W., E.A. Deitch, J. Ding, D. Ku, Q. Huang, and G. Regel. 1999. Intrestinal cytokine response after gut ischemia Am. Surg. 229:478.

12. Hendel, J, O.H. Nielsen, S. Madsen, J. Brynskow. 1996. A simple filter-paper technique allows detection of mucosal cytokine levels in vivo in ulcerative colitis. Dig. Dis. Scienc. 41:1775.

13. Molmenti, E.P., T. Ziambaras, and D.H. Perlmutter. 1993. Evidence for an acute plase response in human intestinal epithelial cells. J. Biol. Chem. 268:14116.

14. Le Roy, D., F. Di Padova, R. Tees, S. Lengacher, R. Landmann, M.P. Glauser, T. Calandra, and D. Heumarn. 1999. Monoclonal antibodies to murine lipopolysaccharide (LPS)-binding Protein (LBP) protect mice from lethal endotoxemia by blocking either the binding of LPS to LBP or the presentation of LPS/LBP complexes to CD 14.J. Immunol. 162:7454

15. Hidalgo, I.J., T.J. Raub, and R.T. Borchardt. 1989. Characterization of the human colon carcinoma cell line (Caco-2) as a model system for untestinal epithelial permeabjilty. Gastroenterology $96: 736$.

16. Pinto, M., S. Robine-leon, M. Appay, M. Kedinger, N. Triadou, E. Dussaulx, B. Lacroix, P. Simon-assmann ${ }_{x}$ K. Haffen, J. Fogh, and A. Zweibaum. 1983. Enterocyte-like differentiation and polarization of the human colon carcinoma cell line Caco-2 in culture. Biol Cell. 47,323.

17. Grube, B.J., C.G. Cochane, R.D. Ye, C.E. Green, M.E. McPhail, R.J. Ulevitch, and P.S. Tobias. 1994. Lipopolysaccharide binding protein expression in primary human hepatocytes and HepG2 hepatoma cells. J. Biol. Chem. 269:8477.

18. Froon, A.H.M., M.A. Dentener, J.W.M. Greve, G. Ramsay, and W.A. Buturman.1995. Lipopolysaccharide toxicity-regulating proteins in bacteremia. J. Mfect. Dis. $171: 1250$.

19. Hazenberg, B.P.C., P.C. Limburg, J. Bijzet, and M.H. Rijswijk. Monoclonal antibody based ELISA for human SAA. 1990. In Amyloid and amyloidosis: "Wh the International Sympositum on Amyloichosis, August 5-8, J.B. Natvig eds. Kluwer, Dordrecht, The Netherlands, p. 898.

20. Maury, C.P.J., K.J. Totterman, C.G. Gref, and C. Ehnholm. 1988. Serum amyloid A protein, apolipoprotein $\mathrm{A}-\mathrm{I}$, and apolipoprotein $\mathrm{B}$ during the course of acute myocardial infarction. $J . \mathrm{C} / \mathrm{in}$. Pathol. 41:1263.

21. Hardardottir, 1., J. Sipe, A.H. Moser, C.J. Fielding, K.R. Feingold, and C.Grunfeld. 1997. LPS and cytokines regulate extra hepatic mRNA levels of apolipoproteins during the acute phase response in Syrian hamsters. Bioch. et Bioph. Acta 1344:210.

22. Hetmann, D., P. Gallay, C. Barras, P. Zaech, R.J. Ulevitch, P.S. Tobias, M.P. Glauser, and I.D. Baumgartmer. 1992. Control of lipopolysaccharide (LPS) binding and LPS-induced numor necrosis factor secretion in human peripheral blood monocytes. J. Imminunol. 148:3505.

23. Michalsky, M.P., E.A. Deitch, J. Ding, Q. Lu, and Q. Huang. 1997. Interleukin-6 and tumor necrosis factor production in an enterocyte cell model (Caco-2) during exposure to Escherichica colli. Shock. $7 ; 139$.

24. Murthy, S., S.N. Mathur, W.P. Bishop, and F.J. Field. 1997. Inhibition of apolipoprotein B secretion by IL-6 is mediated by EGF or an EGF-like molecule in Caco-2 cells. $\%$ Lipid Res. 38:206.

25. Mehran, M., E. Seidman, R. Marchand, C. Gurbindo, and E. Lewy. 1995. Tumor necrosis factor-a inhibits lipid and lipoprotein transport by Caco-2 cells. Am. J. Physiol 269:G953.

26. Sganga, G., J.H. Siegel, G. Brown, B. Coleman, C.E. Wiles, H. Belzberg. S. Wedel, and R Placko. 1985. Repriorization of hepatic plasma protein release in trauma and sepsis. Arch. Surg. $120: 187$.

27. Alhrenstedt, O., L. Knutson, B. Nilsson, K. Nillsson-Ekdaha, B. Odlind, and R. Hallgren. 1990. Enhanced local production of complement components in the small intestines of patients with Crohn's disease N. Engl J. Med. 322:1345.

28. Albanese, G.T., S.D. Smith, S. Watkins, A. Kurkchubasche, R.L. Simmons, and M.I. Rowe. 1994. Effect of IgA on transepithelial passage of bacteria across the intact ileum in vitro. $\%$. Am. Coll Surg. 179:679. 
29. Bry, L.; P. FallK, K. Hutner, A. Ouelette, T. Midtvedt, and JI. Gordon. 1994. Paneth cell differentiation in the developing intestine of normal and transgenic mice. Proc. Narl. Acad. Sci. USA. $91: 10335$

30. Porter, E.M, L. Lit, A. Oren, P.A. Anton, and T. Ganz. 1997. Localization of human intestinal defersin 5 in paneth cell granulles. Infect. Immun. 652389

31. Grunfeld, C., M. Marshall, JK. shigenaga, A H. Moser, P. Tobias, and K.R. Feingold. 1999. Lipoproteins inhibit macrophage activation by lipoteichoic acid. $\mathcal{L}$ Lipid Res. 40.245 


\section{Chapter 4}

\section{Lipopolysaccharide Binding Protein circulates in}

association with apoB-containing lipoproteins and enhances endotoxin-LDL/VLDL interaction

Anita C.E. Vreugdenhil, A. M. Patricia Snoek, Cornelis van/t Veer, lan Willem M. Greve Wim A. Buurman

Department of General Surgery, Maastricht University, The Netherlands,

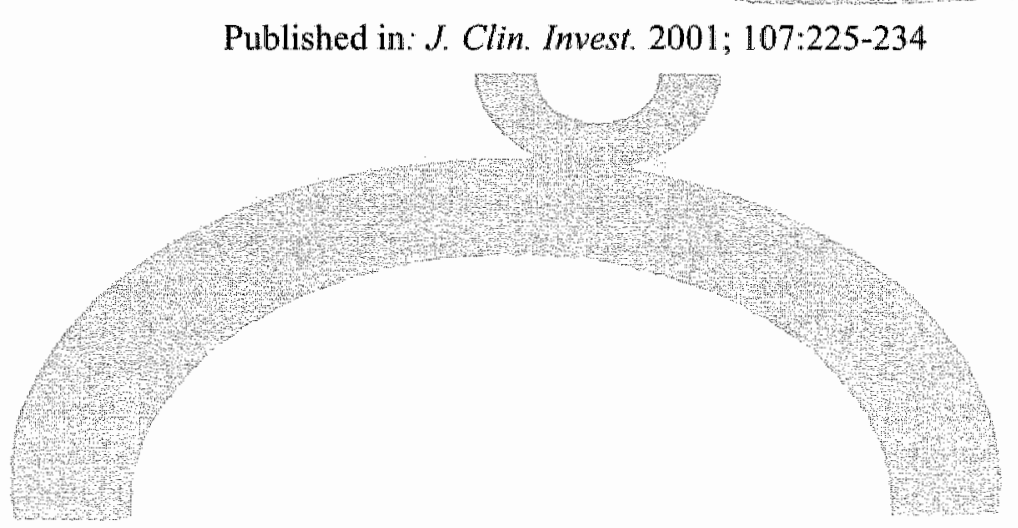




\begin{abstract}
Lipopolysaccharide (LPS) Binding Protein (LBP) and serum lipoproteins cooperate in reducing the toxic properties of LPS. In the present study we demonstrate that LBP circulates associated with $L D L$ and VLDL in healthy persons. ApoB was found to account at least in part for the interaction of LBP with LDL and VLDL. Although LBP interacted with purified apoA-I in vitro, no association of LBP with apoA-I or HDL was found in serum. Consistent with the observed association of LBP with LDL and VLDL, these lipoproteins were demonstrated to be also the predominant LPS binding lipoproteins. Most interestingly, the association of LBP with LDL and VLDL strongly enhanced the capacity of these lipoproteins to bind LPS. Since this function of LBP is of utmost importance during infection, the association of LBP and LPS with lipoproteins was also studied in serum from septic patients. In septic serum containing high LBP levels and a markedly altered lipoprotein spectrum, most of the LBP is associated with LDL and VLDL, although some LBP appeared to circulate free from lipoproteins. Also in serum from septic patients LPS was found to predominantly bind to LDL and VLDL. The observed binding of LBP and LPS to LDL and VLDL as well as the LBP dependent incorporation of LPS into these lipoproteins emphasize a crucial role for circulating LBP-LDL/VLDL complexes in the scavenging of LPS.
\end{abstract}




\section{Introduction}

Lipopolysaccharide (LPS), a constituent of the outer membrane of Gram-negative bacteria, evokes an inflammatory response by activation of monocytes and endothelial cells. LPS-induced cellular responses are the net result of the interaction of LPS with various plasma components such as soluble CD14, LPS binding protein (LBP) and membrane receptoss such as membrane bound CD14 and Toll-like receptors. This initiation of cellular responses is essential for the host defense against bacterial infections. However, if large amounts of endotoxin are present in the crroulation, an excessive cellular response can be deleterious for the host and therefore endotoxininactivating processes are of extreme importance.

LPS is detoxified in the circulation by incorporation into lipoproteins (reviewed in reference 1). Physiologic levels of lipoproteins protect against endotoxicity in vito and in wivo $(2,3)$. Early studies have demonstrated an interaction of LPS with high density lipoproteins (HDL) (4), albeit later also very low-density lipoproteins (VLDL) and low-density lipoproteins (LDL) were found to bind and inactivate LPS $(5,6,7)$. Consistent with this, LDL, VLDL, chylomicrons and HDL all have been observed to reduce the lethal effect of endotoxin in mice $(8,9,10)$.

Evidence for a physiologic role for LBP in inflammation is supported by studies which demonstrate enhanced mortality and uncontrolled multiplication and spread of bacteria in LBP knockout mice compared to wild type mice after intraperitoneal administration of bacteria (11). The results of these studies indicate that LBP is required to induce a rapid inflammatory response, which is essential for the resistance to bacteria. However, LBP has the paradoxical dual function of sensitizing the immune system to endotoxin and on the other hand enhancing detoxification of endotoxin. LBP catalyzes the transfer of LPS into lipoproteins, thereby enhancing LPS detoxification (12). Likewise, LBP catalyzes the lipoprotein neutralization of lipoteichoic acid, a component of the cell membrane of Gram-positive bacteria (13). Lamping et al demonstrated in a murine model that high levels of LBP in the circulation, as seen during an acute phase response, inhibit LPS effects and prevent mortality induced by endotoxemia (14). The latter observation strongly supports a physiological role for LBP dependent detoxification of LPS in the host defense.

Endotoxemia induces an acute phase response characterized by multiple physiologic adaptations. This response appears to play a role in host defense mechanisms, although its physiologic relevance needs further elucidation. One aspect of the acute phase response is a dramatic rise in circulating levels of LBP (15). Concomitantly, large changes in serum lipid and lipoprotein concentrations occur. Circulating levels of total cholesterol, LDL-cholesterol and HDL cholesterol decrease, while serum triglycerides and VLDL levels increase (16). In addition, alterations in apolipoprotein levels are observed $(16,17)$. ApoA-I concentrations drop and HDL becomes depleted in apoA-1 $(16,18)$. In contrast, apoB levels are not affected by either viral or bacterial infection (16).

Others found evidence for an association of LBP with apoA-I containing lipoproteins in plasma from healthy persons (12). We consider that the physical association of LBP with these lipoproteins may be important for the cooperation of LBP and lipoproteins in the detoxification of endotoxin. However, the strong reduction of apoA-I and HDL levels that coincides with the dramatic raise in LBP levels during endotoxemia seems 
in contrast with this cooperative function. Because it is firmly established that LDL and VLDL are critical in the survival of infection with Gram-negative bacteria (19) and that circulating lewels of these lipoproteins are relative high during inflammation compared to HDL levels, the present study was undertaken to investigate whether LBP associates with LDL and VLDL. To this end the distribution of LBP among lipoproteins was studied in serum of healthy and septic persons. Subsequent, we investigated the effect of the association of LBP with lipoproteins and apolipoproteins on the LPS bunding capacity.

\section{Material \& methods}

\section{Reagents}

L.PS from Escherichia coli, serotype 055:B5 was purchased from Sigma (St.Louis, MO). Purified apoA-I and apoB were derived from Calbiochem (La Jolla, CA) and ICN (Irvine, CA) respectively. Polyclonal Abs to human LBP were obtained by immunizing rabbits with purified human LBP. Protein A purified anti-LBP IgG was biotinylated following standard procedures. Anti-human LBP mAb HM14 was obtained by immunizing mice with LBP following classical procedures. Horseradish peroxidase labeled monoclonal $A b$ against apoA-I and apoB were gifts from $\mathrm{Dr}$. $\mathrm{L}$. Sorel1, Center for Genetic Engineering and Biotechnology (Havana, Cuba).

\section{Blood samples}

Blood was collected from healthy donors and from septic patients. Informed consent was obtained from healthy donors and relatives of septic patients. To prepare serum, blood was allowed to clot for 2 hours at room temperature. Serum was separated by centrifugation and stored at $-80^{\circ} \mathrm{C}$ until use. Fresh serum was used for isolation of lipoprotein fractions.

\section{Lipid electrophowesis and Western blot analysis}

Agarose electrophoresis was performed in barbital buffer $\mathrm{pH} 8.6$ using the Paragon Lipoprotein Electrophoresis kit P/N (Beckman Instruments, Brea, CA) according to the manufacturer's instructions. Agarose gel electrophoresis was followed by electrophoretic transfer onto an Immobilon-P membrane (Mi]lipore, Belford, MA) in blottingbuffer (25mM TRIS, $192 \mathrm{mM}$ Glycine, $10 \%$ methanol) using the Phast system (Pharmacia, Uppsala, Sweden). After transfer, the membranes were blocked with $1 \%$ $\mathrm{BSA}$ in PBS for 1 hour at $37^{\circ} \mathrm{C}$ and washed with $0.1 \%$ BSA $0.5 \%$ Tween in PBS. For detection of LBP, membranes were incubated with biotin-labeled polyclonal $\mathrm{Ab}$ specific for human LBP, washed and incubated with peroxidase-labeled streptavidin. After detection of LBP, apoA-I was probed on the same blot after elution of the LBP Abs by incubation with $0.1 \mathrm{M}$ Glycine- $\mathrm{HCl}$ buffer $(\mathrm{pH} 2.5)$ for 15 minutes at $37^{\circ} \mathrm{C}$. Localization of apoA-I was followed by detection of apoB in a similar protocol. For immunodetection of apoA-I and apoB, peroxidase labeled monoclonal Abs were used. Interactions of LPS with serum lipoproteins were studied by pre-incubation of biotin labeled LPS with human serum overnight at $37^{\circ} \mathrm{C}$. After pre-incubation, serum was subjected to electrophoresis, blotted and membranes were incubated with peroxidaselabeled streptavidin. For studying LPS binding to isolated (apo)lipoproteins human serum was first subjected to electrophoresis, blotted and membranes were incubated 
with biotinylated LPS, followed by incubation with peroxidase-labeled streptavidin (Zymed Laboratories Inc., San Francisco, CA). Peroxidase activity was detected by chemiluminescent substrates (SuperSignal Substrate, Pierce, Rockford, IL) according to the manufacturer's recommendation.

\section{Lipoprotein fractionation}

Lipoproteins were isolated from pooled fresh normal human serum ( 6 healthy donors) by a 22 hours single spin density gradient ultracentrifugation at $40.000 \mathrm{rpm}$ and $17^{\circ} \mathrm{C}$ according to Terpstra et al. (20), using a Beckman XL-80 ultra centrifuge with a SW40 rotor and ultra clear centrifuge tubes (Beckman Instruments). A step gradient was constructed from $2 \mathrm{ml}$ serum adjusted to density $1.250 \mathrm{~g} / \mathrm{ml}$ with $\mathrm{KBr}$ and sucrose, two $\mathrm{NaCl} / \mathrm{KBr}$ solutions with density 1.225 and $1.100 \mathrm{~g} / \mathrm{ml}$ respectively, and endotoxin free water density $0.998 \mathrm{~g} / \mathrm{ml}$. All solutions contained $0.1 \mathrm{mg} / \mathrm{ml}$ EDTA. The lipoprotein fractions VLDL, LDL, HDL2 and HDL3 were collected by aspiration and dialyzed extensively against PBS at $4^{\circ} \mathrm{C}$ and stored at $-80^{\circ} \mathrm{C}$ until use. Cholesterol concentrations in the isolated lipoprotein subfractions were determined using an enzymatic colorimetric test from Roche (Basel, Switzerland). The lipoprotein fractions used contained no detectable LBP as assessed by LBP specific ELISA (15).

\section{Purification of $\angle B P$ and production of $L B P$ depleted human serum.}

LBP was isolated from human plasma by selective affinity immunosorption as described before (21). Plasma from healthy volunteers was kindly provided by the local blood bank. In short, anti-hLBP mAb HM-14 was cross-linked to CNBr-activated Sepharose (Pharmacia) according to the manufacturer's instructions. Human plasma was applied to the anti-LBP column and unbound proteins were washed out with $0.5 \mathrm{M}$ $\mathrm{MgCl}$. Bound LBP was eluted with $0.1 \mathrm{M}$ Glycine-HCl buffer ( $\mathrm{pH} 2.5$ ). LBP depleted serum was produced by passing serum over the anti-LBP column. LBP depleted serum, contained less LBP then $0.05 \%$ of normal serum as assessed by LBP-ELISA.

\section{Preparation of biotin labeled LBP and LPS.}

LPS and LBP were biotinylated using hydrazide-biotin (Pierce). Briefly, LBP and LPS were oxidized with sodium periodate to generate aldehydes from vicinal diols present on the saccharide units. The products were then made to react with the hydrazide functionalities present on the biotin, forming stable hydrazone linkages. Linking biotin to the saccharide units in the LBP glycoprotein using hydrazide-biotin did not alter the biologic activity of LBP (data not shown).

\section{Assays for evaluating the association of $L B P$ and LPS to (apo) lipoprotein}

For detection of complexes of LBP and apoB containing lipoproteins in serum an assay was developed. 96 wells plates were coated with a monoclonal $\mathrm{Ab}$ against LBP (HM14). As controls non-coated plates or plates coated with an aspecific Ab (rat antimurine TNF-R75) were used. Aspecific binding sites were blocked for $1 \mathrm{~h}$ with $1 \%$ BSA in PBS. Dilution series of human serum were applied and incubated for 1 hour, followed by extensive washing of the plates. Captured apoB was detected using a peroxidase labeled monoclonal $\mathrm{Ab}$ against $\mathrm{apoB}$ followed by tetramethylbenzidine 
(TMB) substrate (Kirkegard \& Perry Laboratories Inc, Gaithersburg, MD). The absorbance at 450 nm was determined using an ELISA reader.

For studying the quantitative binding of LBP and LPS to lipoproteins an in vitro assay was used. Lipoprotein fractions isolated from pooled human serum were standardized for cholesterol concentration. 96 well plates were coated with lipoproteins or apolipoproteins for 2 hours at $37^{\circ} \mathrm{C}$. Aspecific binding sites were blocked for $1 \mathrm{~h}$ with $1 \%$ BSA in PBS. Plates were washed with PBS. Concentration ranges of biotin labeled. LBP or LPS diluted in $0.1 \% \mathrm{BSA}$ in PBS, were incubated for 1 hour at $37 \% \mathrm{C}$ with the immobilized lipoproteins or apolipoproteins. Bound LBP or LPS were detected using peroxidase-conjugated streptavidin and TMB.

To determine the effect of LBP association with LDL and VLDL on its capacity to interact with LPS, isolated LDL and VLDL were coated to plates in concentrations of 2 and $14 \mu \mathrm{g}$ cholesterol/ml respectively. After washing of plates and blocking of aspecific bindingsites with $1 \% \mathrm{BSA}$ in $\mathrm{PBS}$, a concentration range of $\mathrm{LBP}$ was incubated and allowed to associate with the lipoproteins overnight at $37^{\circ} \mathrm{C}$. Unbound LBP was washed out and biotin labeled LPS was incubated for 1 hour at $37^{\circ} \mathrm{C}$. After washing of plates bound LPS was detected by addition of streptavidin-peroxidase and TMB. The LPS binding capacity of the LBP-lipoprotein complexes was compared with that of lipoproteins free of LBP.

\section{Results}

$\angle B P$ circulates associated with apoB containing lipoproteins in healthy persons.

The distribution of LBP among lipoproteins in human serum derived from healthy volunteers was evaluated using agarose gel electrophoresis in combination with Westen blot analysis. Agarose gelelectrophoresis avoids the harsh conditions of several other techniques for separation of lipoproteins such as high salt concentrations and high gravitational forces encountered in ultracentrifugation or perturbation from polyanion precipitation, which cause loss of associated proteins (22). Accordingly, LBP was not detectable by ELISA (detection limit $200 \mathrm{pg} / \mathrm{ml}$ ) in the lipoprotein fractions separated by ultracentrifugation. In addition this technique enables to study interactions of serum constituents proportional to serum levels.

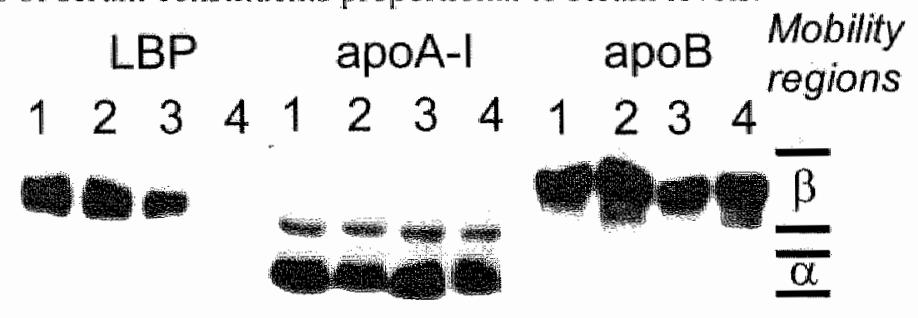

FIGURE 1. Distributiom profile of LBP among lipoproteins in serwm of healthy persons. Serum from three healthy persons (lane 1-3) and LBP depleted serum (lane 4) were subjected to agarose gel electrophoresis, blotted and probed with specific Abs to human LBP, apoA-I and apoB respectively. $\angle B P$ co-localizes with apoB in the B-mobility region and not with apoA-I.

Surprisingly, Western blot analysis with an LBP specific Ab shows that in all subjects investigated LBP is located only at the $\beta$ (LDL/VLDL) mobility region (Fig. 1). As a control, LBP depleted serum derived by selective affinity immunosorption was used, 
which lacked reaction with the anti-LBP Ab (Fig. 1). Immunoblotting for apoB demonstrates co-locallization of LBP with apoB (Fig. 1). LBP was not detected in the $\alpha$ mobility region and did not co-localize with apoA-I (Fig. 1).

Free LBP, purified from human plasma and devoid of lipoproteins, migrates between the $\beta$ and $\alpha$-region on agarose gel electrophoresis (Fig. 2). We studied whether the $\beta$ mobility of LBP in serum, is due to association of LBP with lipoproteins. To this end lipoproteins were fractionated by ultracentrifugation. The isolated lipoproteins were pre-incubated at approximately $50 \%$ of their plasma concentration overnight at $37^{\circ} \mathrm{C}$ with LBP $(30 \mu \mathrm{g} / \mathrm{ml})$, subjected to electrophoresis, and Westemblot analysis of LBP was performed. Pre-incubation of purified LBP with VLDL or LDL, restored the $\beta$ mobility of LBP (Fig. 2). This conversion in electrophoretic migration did not occur when LBP was pre-incubated with HDL. These results show that in serum the association of LBP with LDL and VLDL is responsible for its $\beta$ electrophoretic mobility.

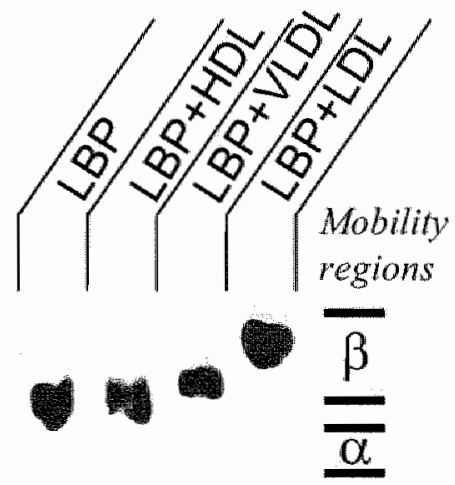

FIGURE 2. Effect of $L D L$ and VLDL on the electrophoretic mobility of purified $L B P$. Purified LBP was preincubated with PBS and isolated LBP-free HDL, VLDL or LDL (0.1, 0.035 and $0.5 \mathrm{mg}$ cholesterol/ml respectively). Agarose gel electrophoresis of purified LBP and the preincubated fractions was followed by Western blot analysis of LBP asing a specific Ab. Purified LBP migrates in between the $\beta$ and $\alpha$ mobility region. Pre-imcubation of LBP with isolated VLDL or LDL shifts the migration of LBP to the $\beta$ mobility region.

Further evidence for the association between LBP and apoB containing lipoproteins in human serum was found using an assay that specifically and quantitatively detects complexes of LBP and apoB containing lipoproteins in serum. In this assay LBP containing lipoproteins are captured from serum by solid phase anti-LBP Abs, followed by detection of apoB in the captured lipoproteins by peroxidase labeled antiapoB Abs. Consistent with our prior experiments, this assay demonstrates the association of LBP with apoB containing lipoproteins in serum (Fig. 3).

To characterize the association between LBP and the different lipoproteins in a more quantitative manner a binding assay was used. Binding of purified LBP to isolated lipoproteins standardized for cholesterol concentration was studied using this assay. Consistent with the results described above, a concentration dependent binding of LBP to LDL and VLDL is observed (Fig. 4). In contrast, the association of purified LBP with HDL is only minor. 


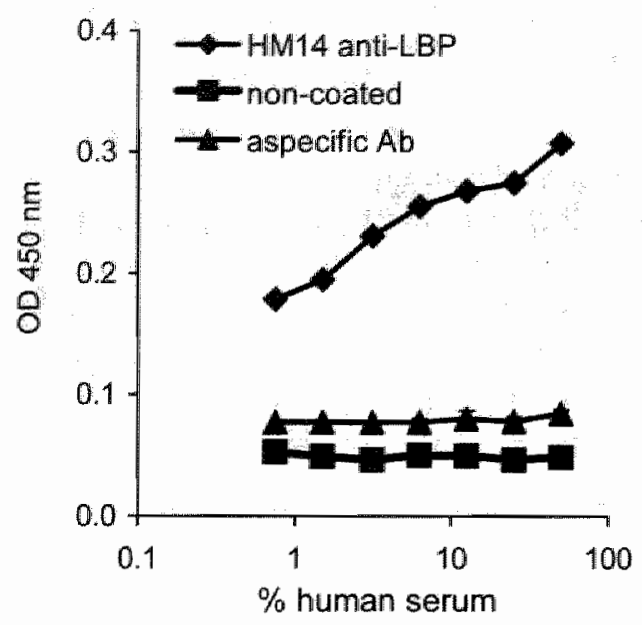

FIGURE 3. Presence of apoB in LBP-containing lipoproteins. LBP containing lipoproteins were captured from serum by applying serum to 96 -well plates coated with an $\mathrm{mAb}$ against LBP (diamonds) followed by extensive washing of the plates. As a control serum was also applied to non-coated plates (squares) or plates coated with an aspecific Ab (rat anti-murine TNF-R75) (triangles). Presence of apoB in the captured lipoproteins was detected by addition of a peroxidase labeled monoclonal Ab against apoB and is expressed as mean \pm sd of the $O D 450 \mathrm{~nm}$ of four wells.

In conclusion we now demonstrate that isolated LDL and VLDL display higher LBP binding capacity compared to HDL. This is fully in line with our observation that LBP circulates predominantly in association with apoB containing lipoproteins.

\section{LPS interacts predominantly with apoB containing lipoproteins.}

LBP binds LPS and catallyzes the transfer of LPS from micelles into lipoproteins (12). In the context of this function of LBP and our data demonstrating that LBP circulates as a complex with apoB containing lipoproteins we studied the relation between LBPlipoprotein interaction and LPS binding to lipoproteins. To this end, biotin labeled LPS was pre-incubated with human serum from healthy volunteers followed by separation of serum lipoproteins on agarose gels and Western blot analysis. Figure 5 reveals that LPS incubated in serum is recovered in the $\beta$ mobility region. This pattern is consistent with a predominant interaction of LBP with apoB containing lipoproteins. To test whether LPS binding to apoB containing lipoproteins is LBP-dependent, biotin labeled LPS was incubated with LBP depleted serum. Figure 5 demonstrates that LPS also binds to $\beta$-lipoprotein in the absence of LBP.

To study whether non-lipoprotein associated serum factors are responsible for the interaction of LS with LDL and VLDL, serum lipoproteins were separated by agarose gel electrophoresis followed by Western blot analysis. Biotinylated LPS was allowed to associate with the (apo)lipoproteins on the blot membrane. The distribution profile obtained was similar to the profile obtained as when LPS was pre-incubated with serum (data not shown). This suggests that $\beta$-lipoprotein associated factors account for the LPS binding and that other serum factors are not essentially affecting the distribution. 
The binding of LPS to lipoproteins was further characterized using an assay similar to that used above for studying LBP-lipoprotein interaction. Binding of LPS to isolated lipoproteins standardized for cholesterol concentration was studied. Also in this assay and fully in line with the results found by Western blot analysis, LDL and VLDL display high LPS binding capacity under LBP free conditions, whereas LPS binding to purified HDL is minor (Fig.6).

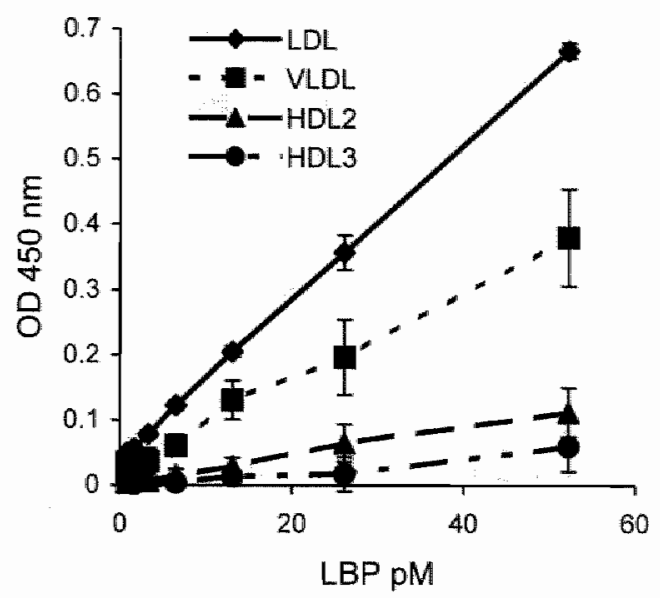

FIGURE 4. Association of LBP with different lipoprotein classes. Lipoproteins isolated from human serum by ultracentrifugation, free of LBP and standardized for cholesterol concentration were immobilized to 96 well plates and incubated with biotinylated LBP. Bound LBP was detected by peroxidase-conjugated streptavidin and TMB. Binding of LBP to the lipoproteins is expressed as mean $\pm S D$ of the OD $450 \mathrm{~nm}$ of four wells after correction for background. LDL and VLDL display high LBP binding capacity in contrast to HDL.

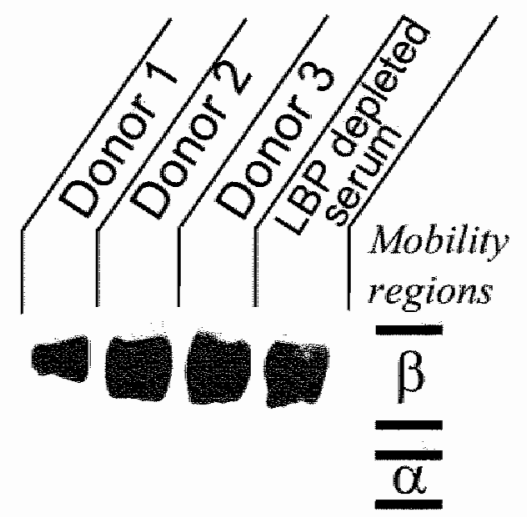

FIGURE 5. Distribution profile of LPS among lipoproteins in serum of healthy persons. Serum of three thealthy donors and LBP depleted serum were preincubated with biotinylated LPS. Agarose gel electrophoresis of the sera was followed by Western blotting. Biotinylated LPS was detected using peroxidase-conjugated streptavidin and a chemiluminescent substrate. LPS incubated with serum is recovered in the $\beta$ mobility region. 


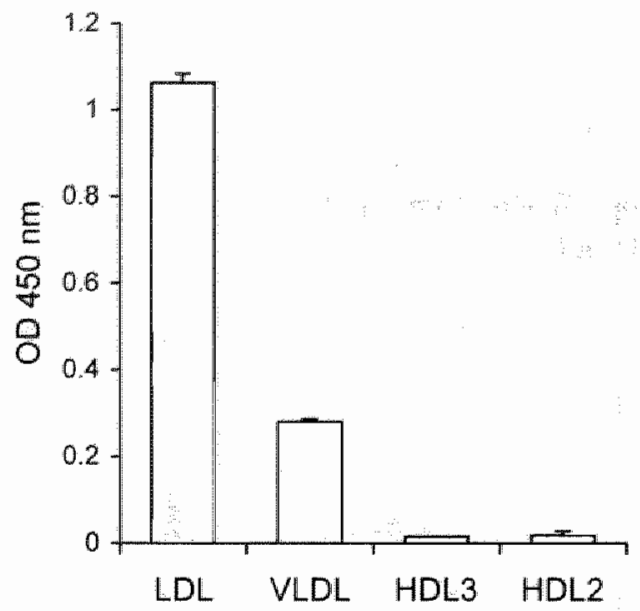

FIGURE 6. Association of LPS with differem lipopronein classes. Lipoproteins isolated from human serum by ultracentrifugation, free of $L B P$, and standardized for cholesterol concentration were immobilized to 96 well plates followed by incubation with biotinylated LPS. Binding of LPS to the lipoproteins was detected by peroxidase-conjugated streptavidin and TMB and expressed as mean \pm SD of the OD $450 \mathrm{~mm}$ of four wells after correction for background. LDL and to a lesser extend VLDL display high LPS binding capacity in contrast to HDL.

\section{LBP bound to lipoproteins enhances the interaction of LPS with lipoproteins.}

To elucidate whether LBP associated to LDL and VLDL is functionally active in transferring LPS to lipoproteins, we compared LPS binding to lipoproteins with binding of LPS to LBP-lipoprotein complexes. To this end LDL and VLDL were immobilized to 96 wells plates and a concentration range of LBP was allowed to bind to the lipoproteins for 18 hours at $37^{\circ} \mathrm{C}$. Plates were washed to remove unbound LBP before biotinylated-LPS was added to the preformed LBP-lipoprotein complexes. LBP associated with LDL and VLDL enhanced the binding of LPS to these lipoproteins dose dependently (Fig. 7). These data strongly indicate that LBP bound to LDL and VLDL displays functional properties and enhances the LPS binding capacity of LDL and VLDL.

Both, LBP and LPS associate with apolipoprotein B.

To elucidate whether binding of LBP and LPS to LDL and VLDL depends on interaction with apoB, present in both LDL and VLDL, we studied the binding of LBP and LPS to purified apoB. Contemporaneously, binding of LBP and LPS to purified apoA-I, the predominant apolipoprotein in HDL, was evaluated. Both LBP and LPS bind to apoB dose dependently (Fig. 8A,B). Binding of LPS to apoA-I was however not significant (Fig. 8A), which is in accordance with the minor binding of LPS to HDL. Surprisingly, LBP forms a complex with purified apoA-I (Fig. 8B).

Because circulating LBP is predominantly associated with lipoproteins containing apoB and not apoA-I (Fig.1), we compared the relative affinities of $L B P$ for apoB and apoA-I. To this end, plates were coated with apoB and a dilution series of apoA-I and apoB was added to the plates together with biotinylated LBP (Fig. 8C). The concentration necessary for $50 \%$ reduction of the signal was $50 \mathrm{nM}$ for apoB and 500 
$\mathrm{nM}$ for apoAI. These results can be due either to a difference in affinity for LBP or to the possibility that apoA-I and apoB have affinity for a different site of LBP. However, when plates where coated with apoA-I, comparable results were found (data not shown); apoA-I concentrations necessary for $50 \%$ reduction of the signal were tenfold higher then apoB concentrations. These data strongly suggest that apoA-I and apoB compete for the same binding site on LBP and that the affinity of LBP for apoB is tenfold higher then for apoA-I.

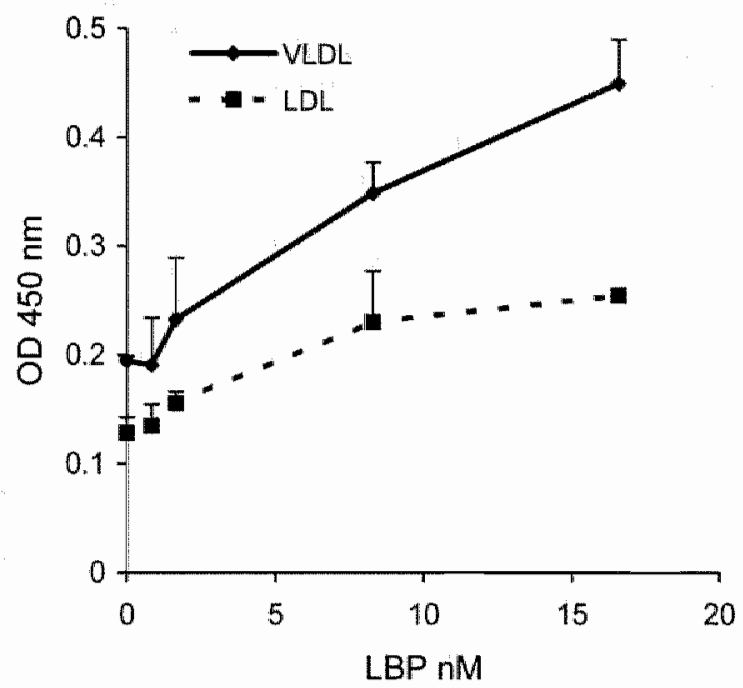

FIGURE 7. $L B P$ associated with $L D L$ and $V L D L$ enhances the interaction of $L P S$ with lipoproteins. Plates were coated with isolated LDL ( $2 \mathrm{mg}$ cholesterol/ $\mathrm{ml}$ ) or VLDL ( $14 \mathrm{mg}$ cholesterol/ml). The immobilized lipoproteins were preincubated with a concentration range of $\mathrm{LBP}$ overnight at $37^{\circ} \mathrm{C}$. Unbound LBP was removed by washing the plates and biotinylated LPS was added to the LBPlipoprotein complexes. Plates were washed to remove unbound LPS and bound LPS was detected using peroxidase-conjugated streptavidin and TMB. Binding of LPS to the lipoprotens is expressed as mean $\pm \mathrm{SD}$ of the OD $450 \mathrm{~nm}$ of four wells after correction for background. LBP associated to LDL and VLDL enhances the binding of LPS dose-dependently.

Since lipoprotein associated LBP enhances the binding of LPS to apoB containing lipoproteins, we evaluated whether LBP also catalyzes the binding of LPS to the purified apolipoproteins. To this end plates were coated with apoB and apoA-I and biotinylated LPS was added to the immobilized apolipoproteins together with $1.7 \mathrm{nM}$ LBP. This LBP concentration was demonstrated to enhance the binding of LPS to LDL and VLDL (Fig. 7). LBP enhanced the binding of LPS to apoA-I, whereas it decreased the binding of LPS to apoB (Fig. 9). These results suggest that the interaction of LBP with apoA-I enables the binding of LPS to this apolipoprotein, whereas LBP competes with LPS for binding to apoB.

Overall these data suggest that apoB contains a binding site for both LBP and LPS and it appears that this binding site account at least in part for the above described association of LBP and LPS with LDL and VLDL in serum. 
LBP and LPS associate with LDL and VLDL in serum of septic patients.

Lipoprotein metabolism as well as the composition of lipoproteins is altered during the acute phase response. In addition, serum levels of LBP rise dramatically during sepsis (15). Because the data so far indicate that the association of LBP with lipoproteins affect the functional properties of LBP and lipoproteins which is of utmost interest during endotoxemia, we evaluated in which form the plenitude of LBP produced
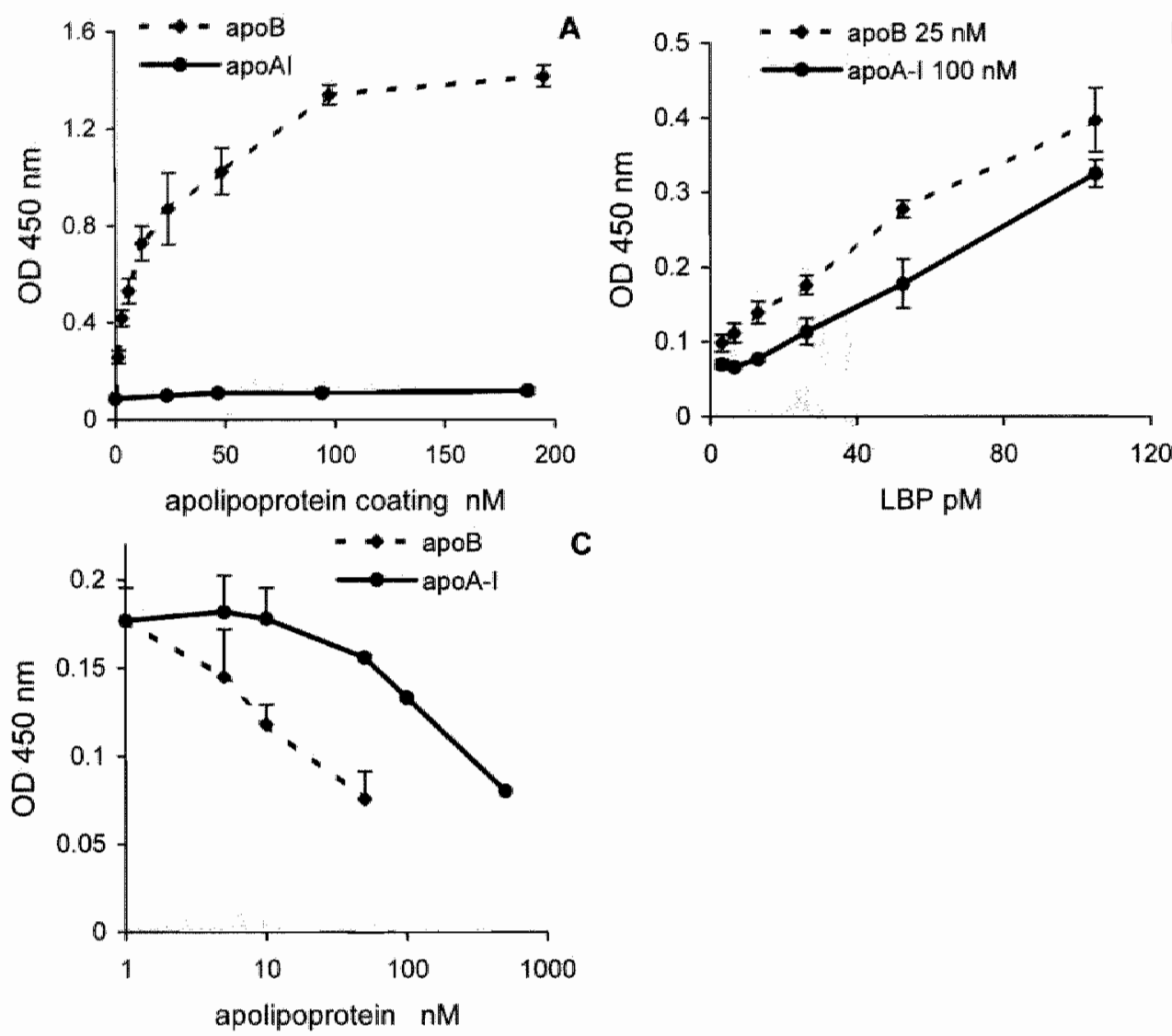

FIGURE 8. Association of LBP and LPS with apoB and apoA -1 . A) Binding of biotin-labeled LPS to apolipoproteins was evaluated. To this end plates were coated with a concentration range of apo $B$ and apoA-I and biotin labeled LPS was added. Bound LPS was detected by peroxidase-conjugated streptavidin and TMB and expressed as mean \pm SD of the OD $450 \mathrm{~nm}$ of four wells after correction for background. B) Binding of biotin labeled LBP to immobilized apoB (25 nM) or apoA-I (100 nM) was detected by peroxidase-conjugated streptavidin and TMB and expressed as mean \pm SD of the OD $450 \mathrm{~nm}$ of four wells after correction for background. C) The relative affinities of LBP for apoB and apoA-I were evaluated. Biotinylated LBP was added to plates coated with apoB ( $25 \mathrm{nM})$. Inlhibition of this interaction of $L B P$ with apoB by apoA-I and apoB was studied by adding concentration ranges of apoA-I and apoB together with LBP. Bound LBP was detected by peroxidase-conjugated streptawidin and TMB and expressed as mean \pm SD of the OD $450 \mathrm{~nm}$ of three wells after correction for background. 
during sepsis circulates. Serum derived from four septic patients (LBP serum concentration $121-589 \mu \mathrm{g} / \mathrm{ml}$ compared to $13-16 \mu \mathrm{g} / \mathrm{ml}$ in the healthy controls) were subjected to agarose gel ellectrophoresis followed by Western blot analysis. As observed for LBP in senm from thealthy persons, LBP circulates during septicemia. predominantly associated with LDL and VLDL (Fig.10). However, an additional LBP band is observed between the $\beta$ and the $\alpha$ region, indicative for the presence of free LBP. As expected, apoA-I levels dropped markedly in the septic patients (Fig. 10). Also in septic patients no association of LBP with HDL was observed.

In addition, we investigated whether the alterations in the composition of lipoproteins during infection and the presence of free LBP did affect the distribution of LPS among lipoproteins. Biotinylated-LPS pre-incubated with serum from septic patients was found to migrate with $\beta$ electrophoretic mobility and to co-migrate with apoB. These findings are in accordance to the data obtained from healthy persons and suggest that also during an acute phase response LPS binds predominantly to LDL and VLDL (Fig. 10D).

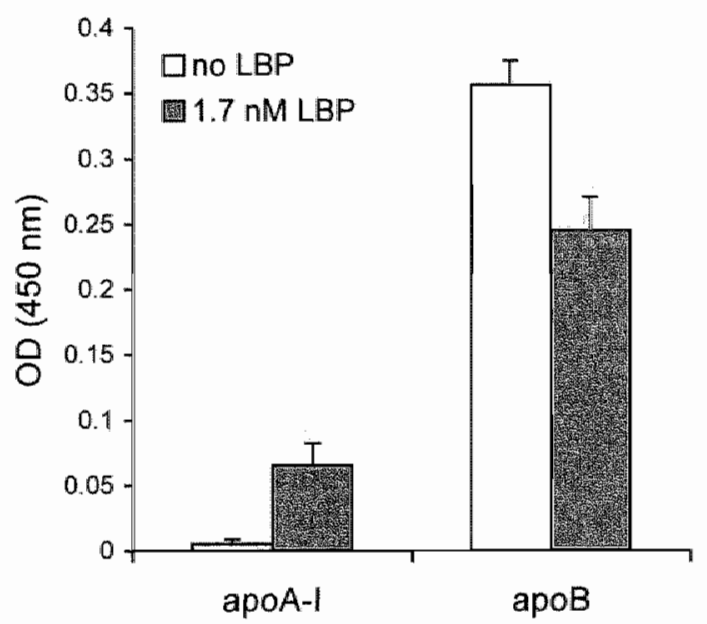

FIGURE 9. LBP enhances binding of LPS to apoA-I and reduces binding of LPS to apoB. Plates were coated with apoA-I (25 nM) or apoB (100 nM). A total of $1.7 \mathrm{nM}$ of LBP was added together with biotinylated LPS, followed by peroxidase-conjugated streptawidin and TMB. Binding of LBP to the apolipoproteins is expressed as mean \pm SD of the OD $450 \mathrm{~nm}$ of four wells after correction for background. The binding of LPS to apoA-I is markedly enhanced by LBP, whereas LBP reduces the binding of LPS to apoB.

\section{Discussion}

The structure and function of LBP is extensively studied, however knowledge concerning the in vivo forms or associations with other serum components and the effect of these associations on the function of LBP is limited. In the present study, we obtained evidence that LBP circulates associated with apoB containing lipoproteins in healthy persons and septic patients. This association is functional, since LBP bound to LDL and VLDL was observed to enhance the LPS binding capacity of these 
lipoproteins, a process known to result in protection from the deleterious effects of LPS-towicity.

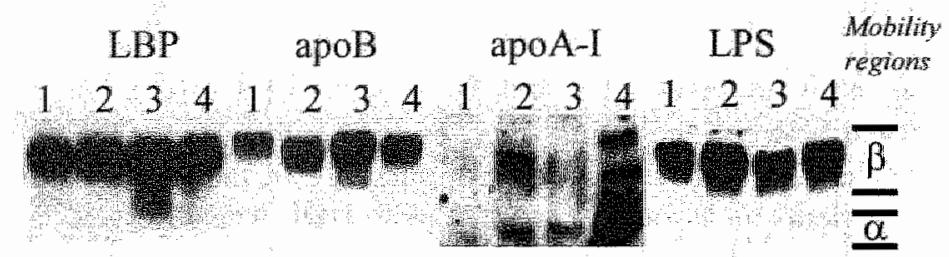

FIGURE 10. Dismbution profile of LBP and LPS in sertm of septic patients. Agarose gel electrophorese of serum from four septic patients (lanes 1-4) was followed by Westem blot analyses using specific Abs for LBP, and apoB. Agarose gel electrophorese of serum from three septic patients (lanes 1 3 ) and a serumpool of healthy persons (lane 4) was followed by Western blot analyses using specilic Abs for apoA-I. LBP predominantly co-localizes with apoB. An additional band compared to normal serum is observed in all subjects between the $\beta$ and $\alpha$ regions, and is most explicit in subject 3 . Preincubation of LPS with the sera followed by Western blot analyses demonstrates the distribution of LPS among lipoproteins during an acute phase response. LPS colocalizes with LBP and apoB in the $\beta$ region under these conditions.

In search for the factors involved in the association of LBP with apoB containing lipoproteins in serum we found that this interaction is at least in part mediated by an interaction of LBP with apoB. Although LBP was not associated with apoA-I or HDL in serum, our experiments demonstrate that LBP does bind to purified apoA-I. Evidence for a specific interaction of LBP with apoA-I is supported by studies by Massamiri et al. who demonstrated that binding of LBP to reconstituted HDL is partially blocked by Abs against apoA-I (23). In the present study we observed a tenfold higher affinity of LBP for apoB compared to apoA-I (Fig. 8C). The amount of apoA-I molecules in serum however, is about thitty times higher then apoB under healthy conditions, and with the present knowledge it is not possible to subscribe the predominant interaction of LBP with LDL and VLDL to the higher affinity of LBP for apoB. It is possible that LBP interacts with domains of apoA-I that are masked by incorporation in native HDL. Furthermore, other constituents then apoB may contribute to the high affinity of LBP for LDL and VLDL and consequently increase the competition for binding of LBP to HDL.

The LBP transporting lipoptoteins LDL and VLDL were also found to be the predominant LPS binding lipoproteins in normal human serum, an observation which is supported by others $(5,24)$. Studies performed in rodents report the preferential binding of LPS to HDL $(4,25,26,27)$. Relative high HDL levels in rodents seem to account for the predominant binding of LPS to HDL, since high LDL levels in Watanabe heritable hyperlipidemic rabbits and high VLDL levels in apoE knockout mice result in the predominant binding of LPS to LDL $(5,28)$ and VLDL (Kuiper personal communication) respectively. In contrast to rodents, the HDL:LDL/VLDL ratio is low in humans, which most likely causes the differences observed for the distribution of LPS among lipoproteins in humans and rodents.

Our data further demonstrate that LBP associated with LDL and VLDL strongly enhances binding of LPS to these lipoproteins in a dose dependent fashion. However, presence of LBP is not required for the interaction of LPS with LDL and VLDL. 
ApoB, present in LDL and VLDL, was demonstrated to have high aftinity for LPS and therefore may account for LPS binding under LBP-free conditions. This interaction of LPS with apoB is inhibited by presence of LBP, implicating competition of LBP and LPS for apoB. It can be hypothesized from these data that apoB functions as an anchor for LBP on LDL and VLDL. This bound LBP may catalyze the binding of LPS to other lipoprotein components and thereby enhance the total LPS binding capacity. Since others found that a lipid-lipid interaction accounts for the association of LPS with lipoproteins (5) and have demonstrated that LBP enhances binding of LPS to phospholipid membranes $(29,30)$, it is likely that LBP linked to apoB enhances intercalation of LPS into the phospholipid membrane of the lipoproteins. Other proteins present in LDL and VLDL may however also contribute to the LPS binding capacity of these lipoproteins. ApoE, present in VLDL, for instance was demonstrated to bind LPS (31). Most interestingly, apoE-deficient mice display increased susceptibility to endotoxemia (32), the latter supporting a possible role for apoE in the scavenging of LPS.

During infection, lipoproteins are proven to be fundamental for the survival of the host $(1,2,9,10,19)$. Under these conditions lipoprotein levels and composition are known to be altered profoundly (33). These changes prompted us to evaluate the interaction of lipoproteins with LBP and endotoxins in septic serum. The changes in lipoprotein composition and the more then tenfold enhanced LBP levels did not significantly affect the distribution profile of LBP. In serum of septic patients LBP is also colocated predominantly with apoB (Fig. 10). These observations indicate that during sepsis approximately tenfold more LBP is associated with LDL and VLDL. This is of particular interest since we observed that the LBP induced up-regulation of LPS binding to these lipoproteins is dose dependent. Only a small fraction of the total LBP in septic sera migrates as free LBP. Whether there is a difference in biologic activity between lipoprotein associated and non-lipoprotein associated LBP in the host response to endotoxin is under current investigation. The predominant incorporation of LPS in LDL and VLDL is also observed in septic serum and does not seem to be influenced by the alterations in lipoprotein composition and the presence of free LBP. Our results which indicate that LPS and LBP both predominantly bind to LDL and VLDL under septic conditions and that apoB forms a binding site for LBP and LPS, is in line with the findings of others (16) that in contrast to apoA-I, apoB levels stay high during infection. The remaining high concentration of apoB in $L D L$ and VLDL seems functional since it may contribute to the enhanced binding of LBP, and as a consequence LPS, to these lipoproteins during infection.

It is firmly established that binding of LPS to lipoproteins reduces LPS toxicity (3). In accordance, hypolipidemia results in enhanced LPS-induced lethality in animals (2) and in human low levels of cholesterol predict an increased risk of death from infection (34), which emphasizes the significance of lipoproteins in protection from bacteria and their toxins. The protective function of lipoproteins is considered to be due to an increase in the clearance of LPS by formation of LPS-lipoprotein complexes and to prevention of its binding to cells. In addition, it was recently demonstrated that lipoproteins, including $\mathrm{LDL}$, also promote the release of cell associated $L P S_{*}$, which was proven to be dependent on LBP (35). This inhibition of endotoxin binding reduces activation of monocytes and thereby the secretion of cytokines $(3,35,36)$. This 
protective property of lipoproteins is not only described for Gram-negative bacteria, also the toxic effects of fragments of Gram positive bacteria are inhibited by LDL, a process catalyzed by the presence of LBP (13). The beneficial role for LDL in the host defense against baeteria is supported by a study, which demonstrates that LDL receptor deficient mice, with elevated circulating LDL concentrations, are protected against lethal endotoxemia and severe infections with Gram-negative micro-organisms (19).

The uptake of LPS into LDL, which we consider beneficial during acute infection, should be considered as potentially harmful during chronic inflammation. Since we studied LPS-binding to LDL and VLDL and not toxicity, we cannot exclude that LPS bind to LDL and VLDL in a manner by which it retains some toxic activity. In the long term these complexes may play a pathogenic role in the development of atherosclerosis. Although LDL protects endothelial cells from acute LPS toxieity by formation of LPS-LDL complexes, these complexes migrate across the endothelium and via unknown pathways increase the secretion of monocyte chemotactic activity by endothelial cells (28). As a consequence transport of LDL-LPS complexes into the artery wall may initiate an inflammatory response and provoke an atherosclerotic reaction.

In conclusion, we found strong evidence for an association of LBP with apoB containing lipoproteins in the circulation of healthy persons. Also in septic patients with extremely high circulating LBP concentrations, LBP is predominantly bound to apoB containing lipoproteins. Most interestingly, LBP associated with $\mathrm{LDL}$ and VLDL enhances the LPS binding capacity of these lipoproteins in a dose dependent manner. Accordingly, in serum from healthy persons and from septic patients LDL and VLDL are the predominant LPS binding lipoproteins. Overall, the data of this study suggest that LBP is a cofactor of circulating LDL and VLDL, which facilitates the uptake of endotoxin by these lipoproteins and imply an important role for LBP/LDL and VLDL complexes in the defense against bacteria and endotoxin.

\section{Acknowledgement}

We thank Dr.M Poeze for the assistance in obtaining the serum of septic patients. This work was supported by a grant of the Dutch Digestive Diseases Foundation, the Netherlands.

\section{References}

1. Read, T.E., H. W. Harris, C. Grunfeld, K. R. Feingold, J. P. Kane, and J.H. Rapp, 1993. The protective effect of serum lipoproteins against bacterial lipopoly saccharide. Eur. Heart J. 14: 125 $12 \%$.

2. Feingold, K. R., J. L. Funk, A. H. Moser, J. K. Shigenaga, J. H. Rapp, and C. Grunfeld. 1995. Role for circulating lipoproteins in protection from endotoxin toxicity. Infect. Imunu. 63: 20412046

3. Flegel, W. A. A. Wölpl, D. N. Mànnel, and H. Northoff. 1989. Inhibition of endotoxin-induced activation of human monocytes by human lipoproteins. Infect. Immun. 57: 2237-2245.

4. Ulevitch, R. J. A. R. Johnston, and D. B. Weinstein. 1979. New function for high density lipoproteins. J. Clin. Jimest. 64: 1516-1524. 
5. Van Lenten, B. J., A. M. Fogelnan, M. E. Haberland, and P. A. Edwards. 1986. The role of lipoproteins and receptor-mediated endocytosis in the transport of bacterial lipopolysaccharide. Proc Natl Acad. Sci USA 83: 2704-2708.

6. Victorov, A. V., N. V. Medvedeva, E. M. Gladkaya, A. D. Morozkin, E. A. Podrez, V. A. Kosykl, and V. A. Yurkiv. 1989. Composition and strueture of lipopolysaccharide-human plasma low density lipoprotein complex. Biochim. Biophys. Acta. 984: 119-127.

7. Netea, M. G., P. N. M. Demacker, B. J. Kullberg, L. E. H. Jacobs, T. J. O. Verver-Jansen, O. C. Boerman, A. F. H. Stalenhoef, and J. W. M. van der Meer. 1998. Bacterial lipopolysaccharide binds and stimulates cytokine producing cells before neutralization by endogenous lipoproteins can occur. Cytokine. 10: 766-772.

8. Read, T. E., C. Grunfeld, Z. Kumwenda, M. C. Caihoun, J. P. Kane, K. R. Feingold, and J. H. Rapp. 1995. Triglyceride-rich lipoproteins improve survival when given after endotoxin in rats. Surgery. 117: 62-67.

9. Harris, H. W., C. Grunfeld, K. R. Feingold, T. E. Read, J, P. Kane, A. L. Jones, E. B. Eichibaum, G. F. Bland, and I. H. Rapp. 1993. Chylomicrons alter the fate of endotxin, decreasing tumor necrosis factor release and preventing death. J. Clin. Inwest 91: 1028-1034

10. Harris, H. W., C. Grunfeld, K. R. Feingold, and J. H. Rapp. 1990. Human very low density lipoproteins and chylomicrons can protect against endotoxin-induced death in mice. $I$. Chin. Invest. 86:696-702.

11. Jack, R.S., X. Fan, M. Bernheiden, G. Rune, M. Ehlers, A. Weber, G. Kirsch, R. Mentel, B. Fürll, M. Freudenberg, G. Schmitz, F. Stelter, and C. Schütt. 1997. Lipopolysaccharide-binding protein is required to combat a murine gram-negative bacterial infection. Nature. 389:742-745.

12. Wurfel, M. M., S. T. Kunitake, H. Lichenstein, J. P. Kane, and S. D. Wright. 1994. Lipopolysaccharide (LPS)-binding protein is carried on lipoproteins and act as a cofactor in the meutralization of LPS. J. Exp. Med. 180: 1025-1035

13. Grunfeld, C., M. Marshall, J. K. Shigenaga, A. H. Moser, P. Tobias, and K. R. Feingold. 1999. Lipoproteins inhibit macrophage activation by lipoteichoic acid. $J$. Lipid Res. 40:245-252.

14. Lamping, N., R. Dettmer, N.W.J. Schröder, D. Pfeil, W. Hallatschek, R. Burger, and R.R. Schumann. $₫ 998$. LPS-binding protein protects mice from septic shock caused by LPS or gramnegative bacteria. J. Clin lnwest. 101:2065-2071.

15. Froon, A. H. M., M. A. Dentener, J. W. M. Greve, G. Ramsay, and W. A. Buuman. 995. Lipopolysaccharide toxicity regulating proteins in bacteremia. J. Infect. Dis. 171: 1250-1257.

16. Sammalkorpi, K., V. Valtonen, Y. Kerttula, E. Nikkila, and M-R. Taskinen. 1988. Changes in serum lipoprotein pattern induced by acute infections. Mefabolism. 37:859-865.

17. Alvarez, C., and A. Ramos. 1986. Lipids, lipoproteins and apoproteins in serum during infection. Clin. Chem. 32: 142-145.

18. Cabana, V. G., J. N. Siegel, and S. M. Sabesin. 1989. Effects of the acute phase response on the concentration and density distribution of plasma lipids and apolipoproteins. J. Lipid Res. 30: 39 . 49.

19. Netea, M. G., P. N. M. Demacker, B. J. Kullberg, O. C. Boerman I. Verschuren, A. F. H. Stalenhoef, and J. W. M. van der Meer. 1996. Low-density lipoprotein receptor deficient mice are protected against lethal endotoxemia and severe gram-negative infections. I. Clim. Imest. 97:1366-1372.

20. Terpstra, A. H. M. C.J.H. Woodward, and F.J. Sanchez-Muniz. 1981 Improved techniques for the seperation of serum lipoproteins by density gradient ultracentrifugation: visualization by prestaining and rapid seperation of serum lipoproteins from small volumes of serum. Anal. Biochem. 111:149-157

21. Vreugdenhil, A.C.E, M.A. Dentener, A.M. Patricia Snoek, J-W. M. Greve, and W. A. Buturman. 1999. Lipopolysaccharide Binding Protein and Senum Amyloid A secretion by human intestinal epithelial cells during the acute phase response. J. Immunol. 163:2792-2798.

22. Kunitake, S.T., C.T. Carilli, K. Lau,A.A.Potter, N. Naya-Vigne, and J.P. Kane. 1994. Identification of proteins associated with apolipoprotein A-I-containing lipoproteins purified by selected-affinity immunosorption. Biochemistry. 33:1988-1993 
23. Massamiri, T., P. S. Tobias, and L. K. Curtiss. 1997. Structural determinants for the interaetion of lipopolysaccharide binding protein with purified high density lipoproteins: role of apolipoprotein A.I. J. Lipid Res. 38:516-525

24. Eggesbo, J. B., T. Lyberg. T. Aspelin, 1. Hjemann, and P. Kierulf. 1996. Different binding of ${ }^{125}$ ILPS to plasma proteins from persons with high or llow HDL. Scand. J. Clin. Lab. Imvest. 56:533543.

25. Tobias, P.S and R.J. Ulevitch. 1983. Control of lipopolysaccharide-high density lipoprotein binding by acute phase protein(s). J. Immunol. 131:1913-1916

26. Muriford, R.S., J.M. Andersen, and J.M.Dietschy. 1981. Sites of tissue binding and uptake in viwo of bacterial lipopolysaccharide-high density lipoprotein complexes. J Cliw. Iwwest. 68:1503-1513.

27. Munford, R.S., C.L. Hall, and J.M. Dietschy. 1981. Binding of Salmonella typhimurium lipopolysaccharides to rat high-density lipoproteins. Infect. Immun. 34:835-843.

28. Navab, M., G. P. Hough, B. J. van Lenten, J. A. Berliner, and A. M. Fogelman. 1988. Low density lipoproteins transfer bacterial lipopolysaccharides across endothelial monolayers in a biologically active form. $J$. Clin. Invest. 81: 601-605.

29. Schromm, A. B., K. Brandenburg, E. T. Rietschel, H-D. Flad, S. F. Caroll, and U. Seidel. 1996. Lipopolysaccharide-binding protein mediates CD14-independent intercalation of lipopolysaccharide into phospholipid nembranes. FEBS. 339: 267-271.

30. Wurfel, M. M., and S. D. Wright. 1997. Lipopolysaccharide-binding protein and soluble CD14 transfer lipopolysaccharide to phospholipid bilayers. I. Immunol. 158:3925-3934.

31. Rensen, P.C.N., M. van Oosten, E. van de Bill, M. van Eck, J. Kuiper, and T.J.C. van Berkel. 1997. Human recombinant apolipoprotein E redirects lipopolysaccharide from kupffer cells to liver parenchymal cells in rats in vivo. J. Clin. Invest. 99:2438-2445.

32. De Bont, N.,M.G. Netea, P.N. Demacker, I. Verschueren, B.J. Kullberg, K.W. van Dijk, J.W. van der Meer, and A.F. Stalenhoef. 1999. Apolipoprotein E knock-out mice are highly susceptible to endotoxemia and Klebsiella pneumoniae infection. J. Lipid Res. 40:680-685.

33. Auerbach, B. J., and J. S. Parks. 1989. Lipoprotein abnormalities associated with lipopolysaccharide-induced lecithin:cholesterol acyltransferase and lipase deficiency. J. Biol. Chem. 264: 10264-10270

34. Jacobs, D., H. Blackburn, M. Higgins, D. Reed, H. Iso, G. McMillan, J. Neaton, J. Nelson, J. Potter, B. Rifkind, J. Rossouw, R. Shekelle, and S. Yususf. 1992. Report of the conference on low blood cholesterol: mortality associations. Circulation. 86: 1046-1060.

35. Kitchens R. L., G. Wolfbauer, J. J. Albers, and R. S. Munford. 1999. Plasma lipoproteins promote the release of bacterial lipopolysaccharide from the monocyte cell surface. $J$. Biol. Chenn. $274: 34116-34122$

36. Cavallon, J-M., C. Fitting, N. Haeffner-Cavaillon, S. J. Kirsch, and H. S. Warren. 1990. Cytokine response by monocytes and macrophages to free and liporotein-bound lipopolysaccharide. Infeet. Innmw. 58: $2375-2382$. 


\section{Chapter 5}

\section{Lipopolysaccharide Binding Protein mediates LPS detoxification by chylomicrons}

Anita C.E. Vreugdenhil*, Corine H. Rousseau*, Thomas Hartung", Jan Willen M. Greve*, Cornelis van 't Veer*, Wim A. Buirman*

Department of General Surgery, Maastricht University, The Netherlands. Department of Biochenical Pharnacology, University of Konstanz, Konstanz Germany.

Published in: J. Immunol. 2003; 170:1399-1405 


\section{Introduction}

Besides a crucial role in the transport of dietary lipids, chylomictons appear to reinfore the host defense against lipopolysaccharide (LPS), a major constituent of the outer membrane of Gram-negative bacteria $(1,2)$. LPS provokes an inflammatory response in the infected host by virtue of its ability to bind membrane factors present on the surface of macrophages and other cells essential to host defense. Once the response to Gram-negative bacteria is initiated, there is a need to inactivate and eliminate LPS to minimize potential deleterious effects of an unregulated response: Circulating chylomicrons were previously demonstrated to be potent inhibitors of LPS activity in vivo and to prevent endotoxin induced mortality $(1,2)$. The metabolic fate of LPS was shown to be strongly affected by complex formation with chylomicrons. Whereas the association of LPS with HDL decreases its clearance from the circulation $(3,4)$, chylomicrons enhance the plasma clearance and hepatic uptake of LPS with shunting of LPS to hepatocytes and away from hepatic macrophages $(2,5)$. Harris et al. recently presented data indicating that both the LDL receptor and LDL receptor related protein (LRP) participate in the rapid internalization of chylomicron-bound LPS by hepatocytes (6). Consequently, LPS is delivered into the bile, where it is inactivated by bile salts (7). Lipoproteins, other then chylomictons, were previously found to prevent a cellular response by binding of LPS (8) and recent studies of Kitchens et al demonstrated that LPS already bound to monocytes is released in response to lipoproteins thereby reducing cytokine secretion (9). Besides an enhanced clearance of LPS from the circulation such mechanisms may also be applicable to chylomicrons and may account for the chylomicron induced increase of survival during endotoxemia. It was demonstrated that plasma constituents other than lipoproteins are required for maximal binding of LPS to lipoproteins (10) and for lipoproteins to achieve maximal prevention of endotoxin-induced death (1), suggesting that a constituent of plasma is required for the binding of endotoxin to lipoproteins.

The acute phase protein LPS Binding Protein (LBP) plays an important role in the reduction of LPS activity by catalyzing the transfer of monomerized LPS from micelles into circulating lipoproteins (11). The enhanced concentration of circulating LBP during an acute phase response was recently demonstrated to be crucial since it diminishes the transfer of LPS to monocytes and reduces cytokine secretion (12). LBP also induces lipoprotein inactivation of lipoteichoic acid (L TA), a component of most Gram-positive bacteria (13). Although initial studies focused on the LPS detoxifying function of HDL (14), later studies demonstrated that in serum LPS predominantly binds to VLDL and LDL, which binding also results in inactivation of LPS (15, 16 , 17). We recently demonstrated that LBP circulates in complex with apoB-containing lipoproteins, i.e., low-density lipoproteins (LDL) and very low-density lipoproteins (VLDL) (18). LBP, complexed with LDL and VLDL strongly enhances the LPS binding to these lipoproteins, which suggests an important role for LBP/lipoprotein complexes in the scavenging of endotoxin present in the circulation (18). The association of LBP with LDL and VLDL appears to result in part from the high affinity of LBP for apoB. This prompted us to study whether LBP also cooperates with the apoB containing chylomicrons in the detoxification of the bacterial toxins LPS and LTA. Consequently, we studied the interaction of LBP with chylomicrons and the effect of this interaction on toxin binding and activity. 


\section{Material \& methods}

\section{Reagents}

LPS from Escherichia coli, serotype 055:B5 was purchased from Sigma (St.Louis, MO). Polyclonal Abs ( $\mathrm{pA}$ b) to human LBP were obtained by immunizing rabbits with purified human LBP. Protein A purified anti-LBP IgG was biotinylated following standard procedures. Anti-human LBP mAb HM14 was obtained by immunizing mice with LBP following classical procedures (18). BSA (containing less than 1 ng LPS/mg) was derived from Sigma. Human TTNF- $\alpha$ was kindly provided by BASF/Knoll Ag (Ludwigshafen, Germany). Since lipoteichoic acid (LTA) preparations available sofar are highly contaminated by LPS (19), we have used a recently introduced preparation method for LTA (20) which allows now to study effects of LPS-free, biologically active LTA. LTA 99\% pure and containing less then $30 \mathrm{pg}$ of LPS/mg LTA, was prepared from Staphylococcus aureus,

\section{Blood samples}

Human venous blood was collected from healthy volunteers after an overnight fast and 2.5 hours postprandially. To prepare serum, blood was allowed to clot for 1 hour at room ternperature. Fresh serum was used for isolation of lipoproteins.

\section{Lipoprotein isolation}

Chylomicrons were isolated from pooled postprandial human serum ( 6 donors) by ultracentrifugation according to Terpstra et al (21). Briefly, dry $\mathrm{KBr}(770 \mathrm{mg})$ and sucrose $(50 \mathrm{mg}$ ) together with $2 \mathrm{ml}$ of serum were placed in the bottoms of ultra clear centrifuge tubes (Beckman Instruments, Brea, CA). These components were carefully mixed with a spatula. A discontinuous gradient was made with the serum mixture of density $1.250 \mathrm{~g} / \mathrm{ml}$, two $\mathrm{KBr}$ solutions with density 1.225 and $1.100 \mathrm{~g} / \mathrm{ml}$ respectively, and on top water density $0.998 \mathrm{~g} / \mathrm{ml}$. The tubes were placed in a SW41 rotor and centrifuged in a Beckman XL-80 ultra-centrifuge (Beckman Instruments) at 30,000 rpm and $20^{\circ} \mathrm{C}$ for 40 minutes. The chylomicrons were collected by aspiration of the top $1 \mathrm{ml}$ fraction and stored at $-80^{\circ} \mathrm{C}$ until use. HDL, LDL and VLDL were isolated from pooled fresh human serum ( 6 healthy donors) by a 22 hours single spin density gradient ultracentrifugation at $40.000 \mathrm{rpm}$ and $17^{\circ} \mathrm{C}$ according to Terpstra et al. (22), using a Beckman XL-80 ultra centrifuge with a SW40 rotor. A discontinuous gradient was constructed from $2 \mathrm{ml}$ serum adjusted to density $1.250 \mathrm{~g} / \mathrm{ml}$ with $\mathrm{KBr}$ and sucrose, two $\mathrm{NaCl} / \mathrm{KBr}$ solutions with density 1.225 and $1.100 \mathrm{~g} / \mathrm{ml}$ respectively, and water density $0.998 \mathrm{~g} / \mathrm{ml}$. All solutions contained $0.1 \mathrm{mg} / \mathrm{ml}$ EDTA. The VLDL, LDL and HDL fractions were collected by aspiration and dialyzed extensively against PBS at $4^{\circ} \mathrm{C}$ and stored at $-80^{\circ} \mathrm{C}$ until use. The lipoprotein fractions used contained less then 4 ng/ml LBP as assessed by LBP specific ELISA (23).

\section{Purification of $L B P$}

LBP was isolated from human plasma by selective affinity immunosorption as described before (18). In short, anti-hLBP mAb HM-14 was cross-linked to CNBractivated Sepharose (Pharmacia) according to the manufacturer's instructions. Normal human plasma kindly provided by the local blood bank was applied to the anti-LBP 
column and unbound proteins were washed out with $0.5 \mathrm{M} \mathrm{MgCl}$. Bound LBP was eluted with $0.1 \mathrm{M}$ Glycine-HCl buffer ( $\mathrm{pH} 2.5$ ).

\section{Preparation of biotin labeled LBP and LPS.}

LPS and LBP were biotinylated using hydrazide-biotin (Pierce) as described before (18). Briefly, LBP and LPS were oxidized with sodium periodate to generate aldehydes from vicinal diols present on saccharide units. The products were then made to react with the hydrazide functionalities present on the biotin, forming stable hydrazone linkages. Linking biotin to the saccharide units in the LBP glycoprotein using hydrazide-biotin did not alter the biologic activity of LBP (data not shown).

\section{Assays for evaluating the association of LBP and LPS to chylomicrons.}

To study binding of LBP and LPS to chylomicrons an in vitro assay was used. 96 well plates were coated with chylomicrons for 2 hours at $37^{\circ} \mathrm{C}$. Non-specific binding sites were blocked by $2 \mathrm{~h}$ incubation with $5 \%$ BSA in PBS. Plates were washed with PBS. A concentration range of biotin labeled LBP diluted in $0.1 \%$ BSA in PBS, was incubated with the immobilized chylomicrons for 1.5 hour at $37^{\circ} \mathrm{C}$. In control experiments $10 \mu \mathrm{g} / \mathrm{ml}$ anti-human LBP pAb or aspecific pAb were added together with LBP. Bound LBP was detected using peroxidase-conjugated streptavidin and tetramethylbenzidine (TMB) (Kirkegaard \& Perry Laboratories Inc., Gaithersburg, MD).

The effect of LBP association with chylomicrons on the capacity of these lipoproteins to interact with LPS was evaluated. To this end, chylomicrons were coated to plates and non-specific binding sites were blocked with 5\% BSA in PBS. A concentration range of LBP was incubated for $1.5 \mathrm{~h}$ and allowed to associate with the chylomicrons at $37^{\circ} \mathrm{C}$. Unbound LBP was washed away and biotin labeled LPS was incubated with the chylomicron-LBP complexes for 1 hour at $37^{\circ} \mathrm{C}$. In control experiments $10 \mu \mathrm{g} / \mathrm{ml}$ anti-human LBP pAb was incubated for 1 hour at $37^{\circ} \mathrm{C}$ with the LBP-chylomicron complexes and biotin labeled LPS was added together with anti-LBP Ab. After washing of plates bound LPS was detected using streptavidin-peroxidase and TMB. The LPS binding capacity of the LBP-chylomicron complexes was compared with that of chylomicrons free of LBP.

\section{Labeling of LPS with BODIPY and measurement of fluorescence}

LPS from Escherichia coli serotype 055:B5 was labeled with the fluorophore BODIPY FL SE (Molecular Probes, Eugene, OR) according to the manufacturer's instructions. Fluorescent labeled LPS can be used to study binding and transfer of LPS in real time (24). Time dependent changes in fluorescence caused by addition of LBP and chylomicrons were measured with a Spectra Max Gemini XS microplate fluorometer (Molecular Devices, Sunnyvale, CA) with emission at $518 \mathrm{~nm}$ and excitation at $485 \mathrm{~nm}$.

\section{Cell isolation and stimulation.}

For experiments designed to determine the effect of chylomicron binding of toxin derived from Gram-negative bacteria as well as from Gram-positive bacteria on their biologic activity, cytokine induction by toxin incubated with chylomicrons in the 
presence or absence of LBP was assessed. PBMC were isolated from buffy coats of healthy volunteers, kindly provided by the local blood bank, by buoyant density centrifugation on Lymphoprep (Nycomed, Oslo, Nonway). Cells were washed five times in HBSS to remove LBP and other plasma proteins and suspended in Macrophage Serum Free Medium (Life Technologies, Paisley, UK) supplemented with $100 \mathrm{U} / \mathrm{ml}$ penicillin $100 \mathrm{ug} / \mathrm{ml}$ streptomycin (Life Technologies). LPS and LTA were pre-incubated with LBP, LBP and lipoproteins or lipoproteins alone as indicated in 96-well llat-bottom tissue culture plates (Costar, Cambridge, MA) for $24 \mathrm{~h}$ or $0.5 \mathrm{~h}$ at $37^{\circ} \mathrm{C}$. Cells were added immediately after isolation at $10^{5}$ cells/well. Control cultures were incubated with medium alone. The cell cultures were incubated for $4 \mathrm{~h}$ at $37^{\circ} \mathrm{C}$ and $5 \% \mathrm{CO}_{2}$. Supernatants were collected and stored at $-20^{\circ} \mathrm{C}$ until use.

\section{TNF- $\alpha$ and II-8 ELISA}

Cytokine concentrations in the cell culture supernatants were determined using sandwich-ELISA for TNF- $\alpha$ (25) and II-8 (26). In short, 96-well immunomaxisorp plates (Nunc, Roskilde, Denmark) were coated overnight at $4^{\circ} \mathrm{C}$ with cytokine-specific $\mathrm{mAb}$. TNF $\alpha$ in the supernatants was detected with polyclonal rabbit anti-human TNF$\alpha$, followed by peroxidase-conjugated goat anti-rabbit IgG (Jackson ImmunoResearch, Westgrove, PA). II-8 was detected by biotinylated polyclonal rabbit anti-human I1-8 followed by peroxidase-conjugated streptavidin. TMB was used as a substrate for peroxidase. Photospectrometry was performed at $450 \mathrm{~nm}$.

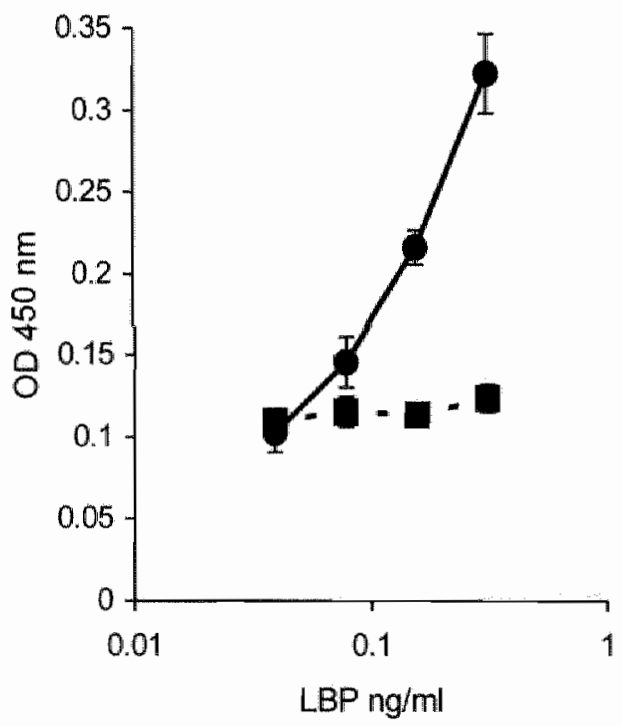

FIGURE 1. LBP associates with chylomicrons. Chylomicrons isolated from postprandial human serum by ultracentrifugation were immobilized to 96 well plates and incubated with biotinylated LBP ( ). As a control a pAb against human LBP was added together with LBP ( $\mathbf{G}$ ). Bound LBP was detected by peroxidase-conjugated streptavidin and TMB. Binding of LBP to the lipoproteins was expressed as mean \pm SD of the OD $450 \mathrm{~nm}$ of four wells of a representative experiment repeated twice after correction for background binding of biotin labeled LBP to coated plates in absence of chylomicrons. A dose-dependent association of LBP with chylomicrons was observed. 


\section{Results}

\section{LBP associates whith chylowicroms}

Recently, LBP was shown to be predominantly complexed with apoB-containing lipoproten particles, 1.e, LDL and VLDL. This interaction was found to be at least in part mediated by an interaction of LBP with apoB (18). These findings prompted us to investigate the interaction of LBP with another triacylglyceride rioh apoB-contaning lipoprotein, i.e. chylomicrons. To study binding of LBP to isolated chylomicrons an in vitro assay was used that revealed a concentration dependent binding of biotinylated LBP to chylomicrons (Fig, 1). Binding of LBP to chylomicrons was completely blocked by a pAb against LBP (Fig. 1), indicating the specificity of this interaction. Addition of aspecific pAb did not affect the results. The data strongly suggest that LBP and chylomicrons form a complex.
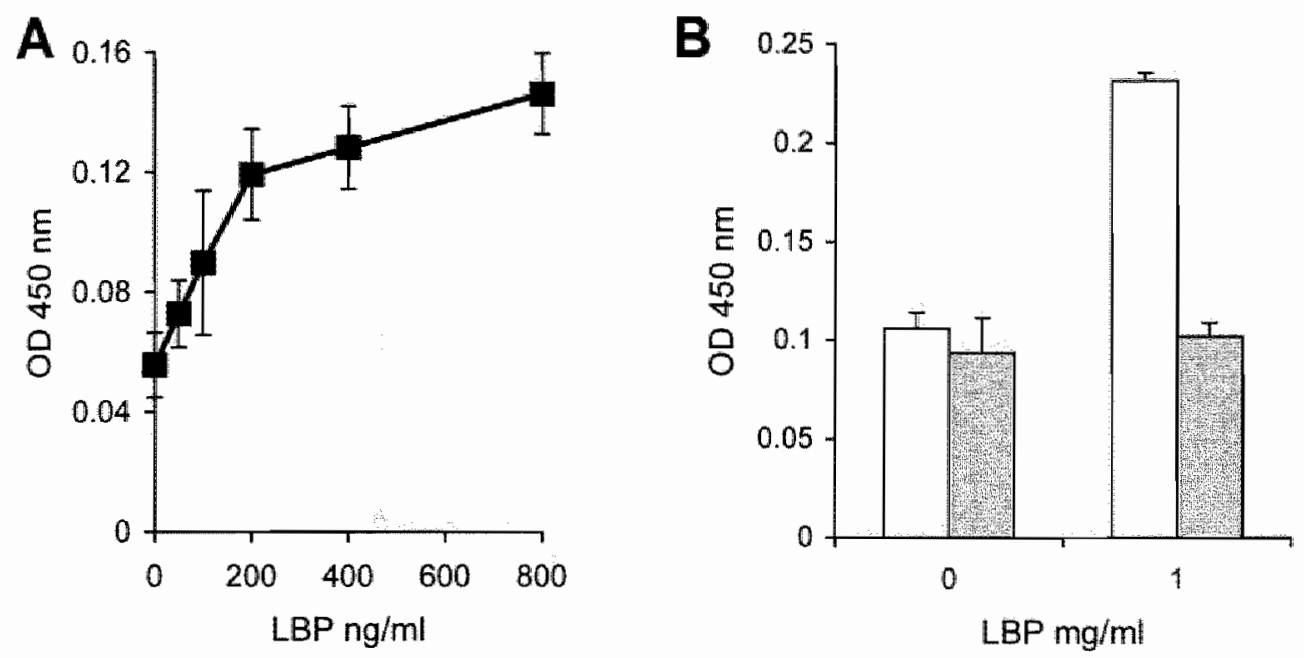

FIGURE 2. LBP associated with chylomicrons enhances the interaction with LPS. A) Immobilized chyllomicrons were preincubated with a concentration range of $L B P$ overnight at $37^{\circ} \mathrm{C}$, unbound $L B P$ was removed by washing the plates, followed by addition of biotinylated LPS to the LBP-chylomicron complexes. Bound LPS was detected using peroxidase-conjugated streptavidin. Binding of LPS to chylomicrons is expressed as mean $\pm \mathrm{SD}$ of the OD $450 \mathrm{~nm}$ of four wells of a representative experiment repeated twice after correction for background binding of biotin labeled LPS to coated plates in absence of chylomicrons. LBP complexed to the chylomicrons enhanced the LPS binding dose-dependently. B) Immobilized chylomicrons were preincubated either with or without $1 \mathrm{Hg} / \mathrm{ml}$ LBP per ml overnight at $37^{\circ} \mathrm{C}$ (open bars). Unbound LBP was removed. In controls $10 \mu \mathrm{g} / \mathrm{ml}$ antihuman LBP $\mathrm{pAb}$ was added for 1 hour (filled bars). Biotinylated LPS was added to the LBPchylomicron complexes. Binding of LPS was assessed and values expressed as in A. The anti-human LBP pAb completely blocked the LBP mediated binding of LPS to chylomicrons.

LBP associated with chylomicrons enhances the LPS binding-capacity of chylomicrons

LBP was demonstrated to transfer LPS into lipoproteins, thereby enlancing its detoxification (11). To elucidate whether LBP complexed to chylomicrons, is able to enhance the LPS binding to chylomicrons, an in vitro assay was used. LPS binding to 


\begin{abstract}
Chylomicrons have been shown to protect against endotoxin-induced lethality. LPS Binding Protein (LBP) is involved in inactivation of bacterial toxim by lipoproteins. The current study examined the interaction between LBP, chylomicrons and bacterial toxin. LBP was demonstrated to associate with chylomicrons and enhance the amount of LPS binding to chylomicrons in a dose dependent fashion. In addition, LBP accelerated LPS binding to chylomicrons. This LBP induced interaction of LPS with chylomicrons prevented endotoxin toxicity as demonstrated by reduced cytokine secretion by PBMC. When postprandial circulating concentrations of chylomicrons were compared with circulating levels of $\mathrm{LDL}, \mathrm{VLDL}$, and HDL, chylomicrons exceeded the other lipoproteins in LPS inactivating capacity. Furthermore, highly purified lipoteichoic acid (LTA), an immunostimulatory component of Gram-positive bacteria, was detoxified by incubation with LBP and chylomicrons. In conclusion, our results indicate that LBP associates with chylomicrons and enables chylomicrons to rapidly bind bacterial toxin, thereby preventing cell activation. Besides a role in the detoxification of bacterial toxin present in the circulation, we consider that LBPchylomicron complexes may be part of a local defense mechanism of the intestine against translocated bacterial toxin.
\end{abstract}


chylomicrons was compared with binding of LPS to LBP-chylomicron complexes. LPS was observed to interact with chylomicrons in the absence of LBP (Fig. 2a). Flowever, LBP associated with chylomicrons strongly enhanced the LPS-binding capacity of chylomicrons (Fig 2a). The LBP induced up-regulation of LPS binding to chylomicrons was found to be dose dependent. This effect of LBP was blocked by $\mathrm{pAb}$ against LBP (Fig $2 \mathrm{~b}$ ). The LPS binding to chylomicrons in the absence of LBP was not affected by the presence of $\mathrm{pAb}$ against LBP, which excludes that this binding Was caused by small amounts of LBP present in the chylomicron fractions. Overall, the data inply that LBP associated with chylomicrons was functionally active in transferring LPS to chylomicrons.

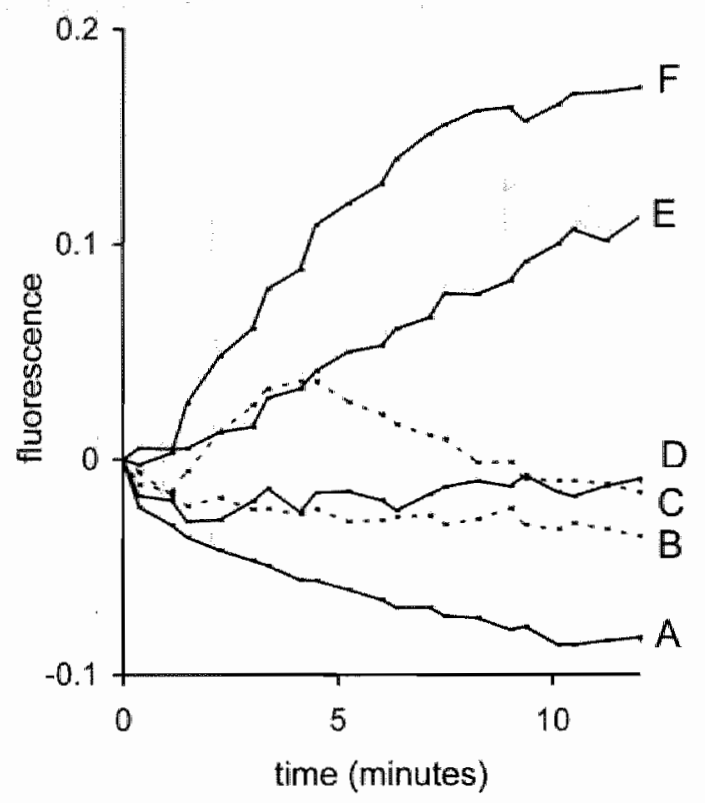

FIGURE 3. $L B P$ accelerates the binding of LPS to chylomicrow BODIPY-LPS was incubated with PBS alone (curve $A$ ), with I and $10 \mu \mathrm{g} \mathrm{LBP/ml}$ (cume $B$ and curve $C$ ), with chylomicrons (Curve $D)$. with chylonicrons and $1 \mu \mathrm{g} \mathrm{LBP} / \mathrm{ml}$ (cume E) and with chylomicrons and $10 \mu \mathrm{g} \mathrm{LBP} / \mathrm{ml}$ (cume F). The fluorescence at $518 \mathrm{~nm}$ was recorded over time. The figure is representative of two separate experiments. LBP was found to dose dependently accelerate the binding of LPS to chylomicrons.

\section{LBP accelerates the transfer of BODIPY-LPS into chylomicrons}

To confirm the ability of LBP to mediate transfer of LPS to chylomicrons and to monitor time kinetics of this interaction we used BODIPY-LPS donor micelles and chylomicrons as acceptor particles. Addition of chylomicrons to BODIPY-LPS in absence of LBP resulted in a dequenching of the fluorescence, indicative for dissociation of LPS from the micelles and binding to chylomicrons. Incubation with LBP together with chylomicrons resulted in a pronounced enhancement of the rate of dequenching of BODIPY-LPS (Fig 3). This acceleration of LPS binding to chylomicrons was found to be LBP dose dependent. These findings are in line with our observations described above and implicate that LBP catalyzes LPS binding to chylomicrons and more importantly accelerate LPS binding to chylomicrons. 

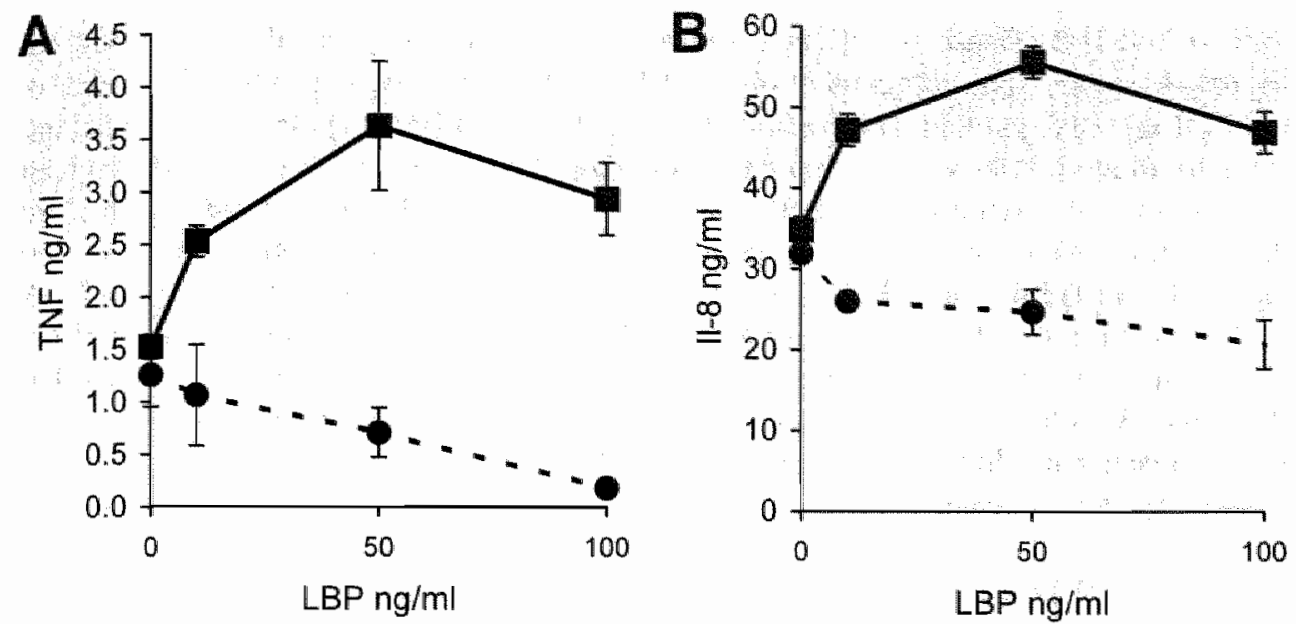

FIGURE 4. Chylonicrons reduce LPS toxicity in an LBP-dose dependem forhiom. LPS $100 \mathrm{ng} / \mathrm{ml}$ was preincubated with $0,10,50$ and $100 \mathrm{ng} / \mathrm{mL}$ LBP in the presence( ) or absence (G) of isolated chylonicrons $\left(12.5 \%\right.$ of circulating levels) for $241 \mathrm{~h}$ at $37{ }^{\circ} \mathrm{C}$. The remaining biological activily of LPS was determined by incubation with PBMC for th and measurement of TNF- $\alpha$ (A) and II-8 (B) secretion in the supernatants. Vialues represent the mean \pm SD of three wells. The experiment shown is representative of three separate experiments. LBP catalyzed the LPS neutralization by chylomicrons.

\section{Chylomicrons detoxify LPS in a LBP dose dependent fashion}

Next, we studied whether the observed enhanced LPS binding to chylomicrons induced by LBP results in abrogation of the bioactivity of LPS. Therefore, we exposed PBMC to LPS preincubated with chylomicrons and different concentrations of LBP.

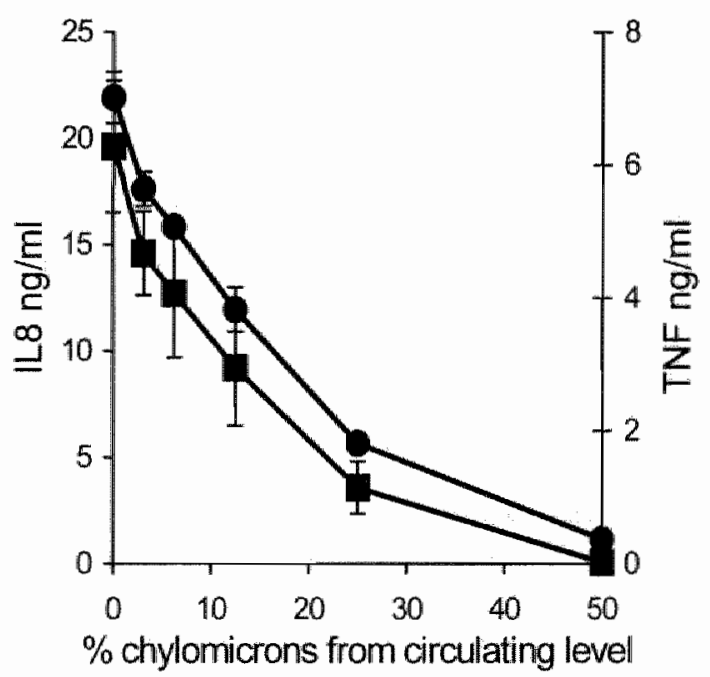

FIGURE 5. Chylowicrons neutralize LPS in a dose-dependent fashion. A range of chylomicron concentrations and $100 \mathrm{ng} / \mathrm{ml}$ LPS were incubated in the presence of $100 \mathrm{ng} / \mathrm{m} 1 \mathrm{LBP}$. The remaining biological activity of LPS was assessed by incubation with PBMC for $4 \mathrm{~h}$ and measurement of II-8 (-) and TNF- $\alpha(\square)$ secretion. Values represent the mean \pm SD of three wells. The experiment shown is representative of three separate experiments. Chylomicrons close-dependently reduced LPS activity in the presence of LBP. 


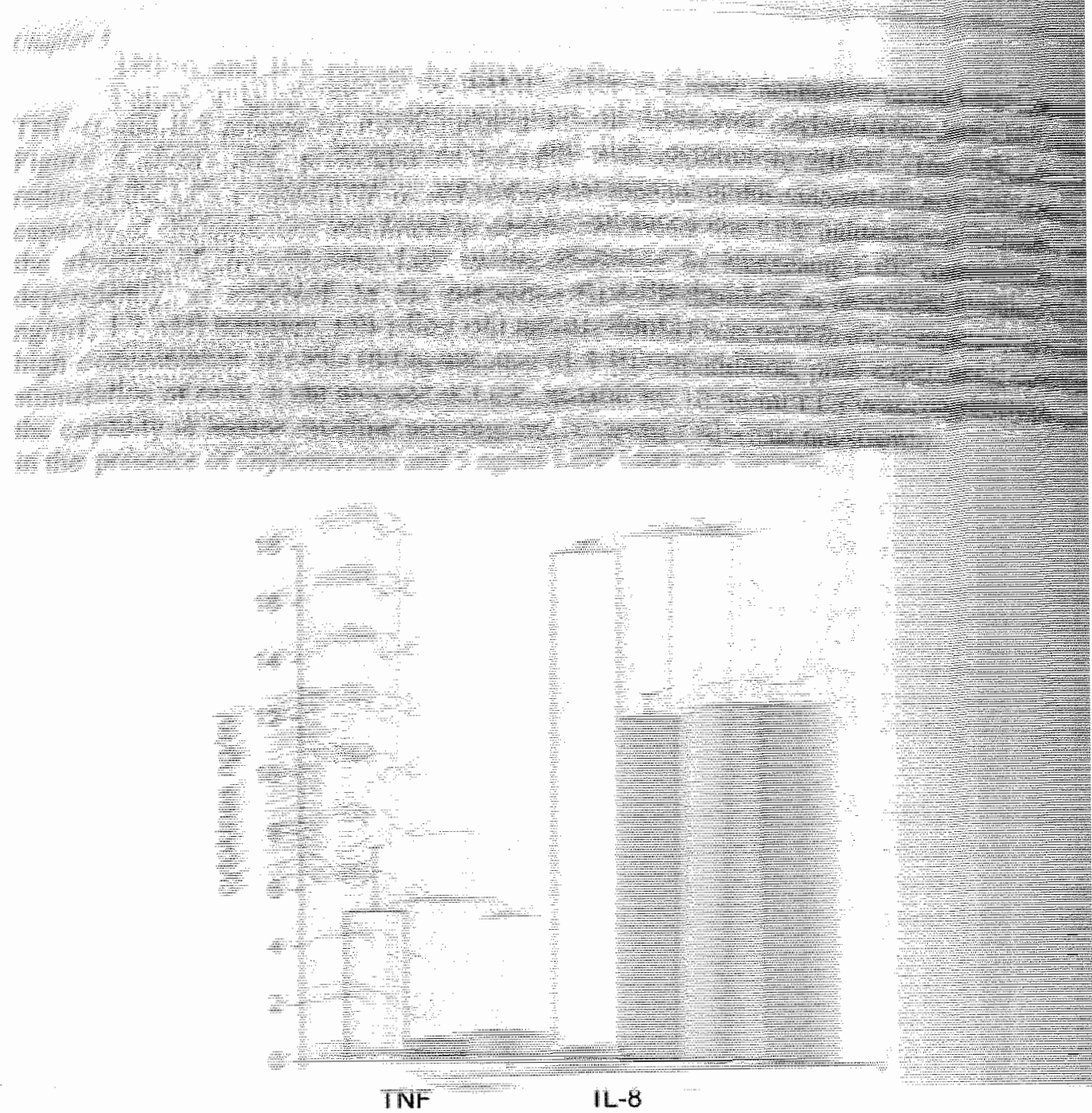

FIGURE 6. LPS is rapidly netwalized by chylonnicron-LBP complexes. LPS $100 \mathrm{ng} / \mathrm{ml}$ was preincubated with (filled bars) or without (open bars) chylomicrons (12.5\% of circulating levels) and $100 \mathrm{ng} / \mathrm{ml}$ of LBP for a $0.5 \mathrm{~h}$ period. Biologically active LPS remaining after $0.5 \mathrm{~h}$ was assessed by addition of PBMC and measuring cytokine secretion. Values represent the mean \pm SD of three wells. The experiment shown is representative of three separate experiments. LPS neutralization by chylomicron-LBP complexes was evident atter $0.5 \mathrm{~h}$ incubation.

To study the effect of the chylomicron concentration on inhibition of LPS-induced cytokine secretion, $100 \mathrm{ng} / \mathrm{ml}$ LPS was preincubated with $100 \mathrm{ng} / \mathrm{ml} \mathrm{LBP}$ and different concentrations of chylomicrons (Fig. 5). The LPS detoxifying function of chylomicrons was found to be concentration dependent. Moreover, $50 \%$ of the postprandial circulating level of chylomicrons abrogated the cytokine response induced by $100 \mathrm{ng} / \mathrm{ml}$ LPS, while a profound reduction of LPS activity was also seen at low chylomicron concentrations.

Prior studies described a maximal endotoxin inactivation by lipoproteins after $24 \mathrm{~h}$ of preincubation (17). However, using BODIPY-LPS dequenching experiments we found 
a rapid binding of LPS to chylomicrons in the presence of LBP (Fig. 3). To study whether this rapid LBP mediated binding of LPS to chylomicrons results in detoxification of LPS, chylomicrons were preincubated with LBP and LPS only for 0.5 hour and PBMC were added. Figure 6 demonstrates that in the presence of LBP chylomicrons are capable of reducing LPS activity within 0.5 hour.

Postprandial chylowicron levels exceed the LPS neutralizing capacity of circulating levels of $H D L, L D L$ and $V L D L$.

It was demonstrated that lipoproteins have the ability to neutralize LPS in a LBP dependent fashion (11). To determine to which extend postprandial chylomicron levels contribute to the LPS neutralization by lipoproteins, the LPS detoxifying capacity of lipoproteins was compared at concentrations equated to their physiologic plasma ratio. For chylomicrons that regards postprandial levels. All lipoproteins were diluted to $12.5 \%$ of their plasma concentration and preincubated with LPS and LBP. The ability of the remaining bioactive LPS to induce TNF- $\alpha$ was determined. In the absence of lipoproteins, $100 \mathrm{ng} / \mathrm{ml}$ LPS together with $50 \mathrm{ng} / \mathrm{ml} \mathrm{LBP}$ led to a strong increase of TNF- $\alpha$ induction (Fig. 7). This TNF- $\alpha$ secretion was reduced by all tested lipoproteins. However, the most pronounced reduction of TNF- $\alpha$ secretion was observed when LPS was incubated with chylomicrons and LBP.

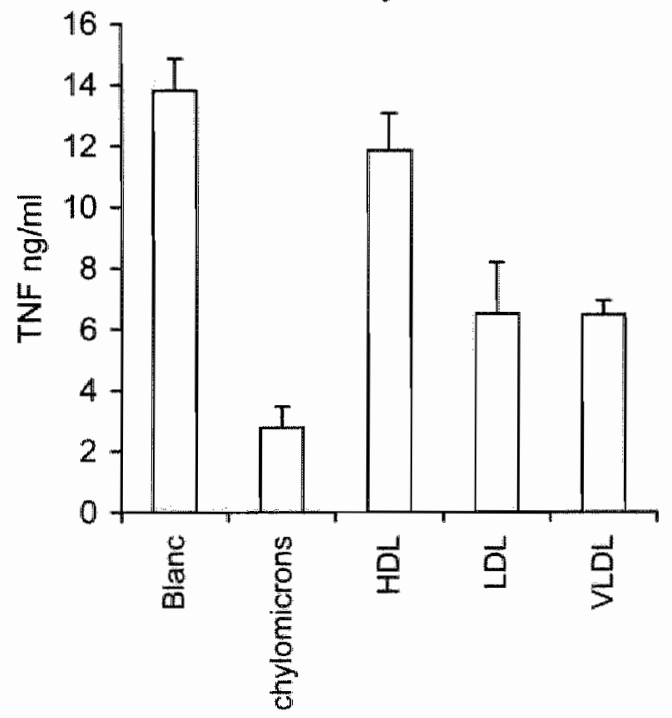

FIGURE 7. LPS newtralizing capacity of chylonicrons conpared to other circulating lipoproteiws. Lipoproteins were isolated from human serum by ultracentrifugation. HDL, LDL, WLDL and chylomicrons were dilluted to $12.5 \%$ of their plasma concentration and incubated with $100 \mathrm{ng} / \mathrm{ml} \mathrm{LPS}$ and $50 \mathrm{ng} / \mathrm{ml} \mathrm{LBP}$ for $24 \mathrm{~h}$ at $37^{\circ} \mathrm{C}$. PBMC were addled and the remaining LPS activity was assessed by measuring the cytokine secretion of the cells after $4 \mathrm{~h}$. Values represent the thean $\pm \mathrm{SD}$ of three wells. The experiment shown is representative of three separate experiments. The LPS neutralizing capacity of the chylomicrons exceeded the capacity of LDL, VLDL and HDL to neutralize LPS. 
Chylomicrons reduce LTA-induced TNF secretion.

The incidence of septic shock caused by Gram-positive bacteria has risen markedlly in the last decade $(28,29)$. LTA, a component of the membrane of Gram-positive bacteria, can elicit the release of proinflammatory cytokines from immune cells (30). We determined whether chylomicrons in cooperation with LBP are also able to inhibit stimulation of PBMC by LTA. Figure 8 demonstrates that LBP also induces detoxification of LTA by chylomicrons dose dependently. These data suggest that besides a role in combating gram-negative bacteria, LBP-chylomicron complexes may also be of importance in the host defense against Gram-positive bacteria.

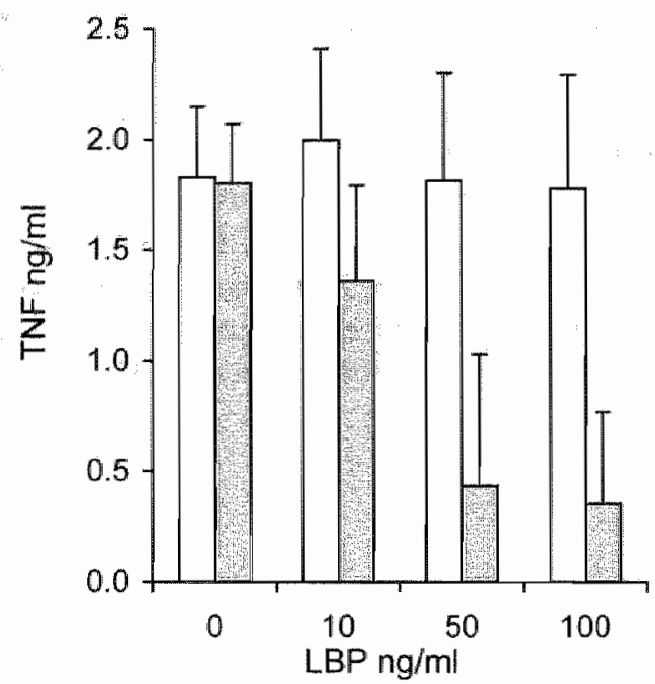

FIGURE 8. LBP induces detoxification of LTA by chylomicrons. LTA $(20 \mu \mathrm{g} / \mathrm{ml})$ was preincubated with (filled bars) or without (open bars) chylomicrons ( $5 \%$ of circulating level) and $0,10,50$ and 100 $\mathrm{ng} / \mathrm{mll}$ LBP for $24 \mathrm{~h}$. Biologically active LTA remaining was assessed by addlition of PBMC and measuring TNF secretion. Values represent the mean \pm SD of three wells. The experiment shown is representative of three separate experiments. LBP and chylomicrons cooperate in detoxification of L'A.

\section{Discussion}

In the present study we obtained evidence for a functional interaction of LBP with chylomicrons. The association of LBP with chylomicrons was shown to enhance the LPS binding capacity of chylomicrons. Most importantly, chylomicrons and LBP cooperate in reducing LPS toxicity resulting in decreased cytokine and chemokine secretion by PBMC Moreover, chylomicron-LBP complexes were demonstrated to prevent cell activation by LTA, a cell wall component of Gram-positive microorganisms. These data imply that LBP is an important co-factor for chylomicrons to execute their function as scavengers of bacterial toxin.

Consistent with others (31), we found that isolated chylomicrons bind LPS in the absence of LBP (Fig 2 and 3). ApoB (18), and apoE (5), present in chylomicrons, were previously demonstrated to bind LPS, and may account for LPS binding to chylomicrons. Binding of LPS to the phospholipids in the membrane of the 
chylomicrons under these conditions is not likely since plasma proteins, such as phospholipid transfer protein (PLTP) (32), cholesteryl ester transfer protein (CETP) and LBP, were demonstrated to be required for intercalation of LPS into phospholipid membranes (33). In line with these findings, plasma factors were reported to be necessary for enhancement of the LPS-binding capacity of chylomicrons and maximal prevention of LPS-induced death by intravenous administrated lipoproteins (1). We now describe that LBP binds to chylomicrons and enhances the LPS-chylomicron interaction dose dependently. Moreover, LBP was observed to accelerate LPS binding to chylomicrons. These data implicate that LBP is an important plasma factor involved in LPS binding to chylomicrons.

Harris et al described that infusion of LPS together with chylomicrons compared to infusion of LPS alone resulted in lower levels of circulating TNF, the cytokine known to mediate much of the LPS toxicity in vivo (2). Moreover they suggested that an enhanced uptake of LPS by hepatocytes and clearance of LPS from the circulation contribute to the reduced cytokine levels in such treated animals. In line with the reduction of TNF levels by chylomicrons observed in vivo by these investigators, we now found evidence for a direct LBP mediated inhibiting effect of chylomicrons on LPS induced cytokine secretion by PBMC in vitro. On the basis of our findings we postulate that LPS-LBP-chylomicron interaction may participate in the reduced TNF levels in vivo by both, enhanced detoxification of LPS and enthanced clearance of LPS complexed to chylomicrons from the circulation. Although in this study we determined the effect of preincubated LPS-chylomicron complexes on cellular activation, the capability of chylomicrons to bind LPS may also enable these lipoproteins to release LPS already bound to monocytes as described for other lipoproteins (9). The finding that infusion of chylomicrons up to $30 \mathrm{~min}$ after the administration of endotoxin improved survival in rodents $(2,34)$ makes such a mechanism plausible.

Thus far, studies on LPS inactivating properties of chylomicrons were focused on circulating chylomicrons and therapeutic application of chylomicrons was performed by systemic infusion of chylomicrons isolated from plasma or lymph $(1,2,5,7)$. Chylomicrons present in the circulation may cooperate with both, hepatic and gut derived LBP and detoxify circulating bacterial toxin. Besides detoxitication of toxin in the circulation by LBP-chylomicron complexes, it can be hypothesized that this mechanism may be part of a local defense mechanism of the intestine against translocated bacterial toxin. Chylomicrons are produced by enterocytes and most interestingly, recent evidence was found for the basolateral secretion of LBP by the intestinal epithelium in response to cytokines (35). It is tempting to speculate from the data presented here that LBP and chylomicrons, both secreted by the intestina] mucosa, cooperate in local neutralization of LPS. Such a mechanism may occur in the subepithelial space or in the lymph and possibly prevents further damage of bacterial toxin to the intestinal epithelial barrier and entrance of biological active toxin into the circulation. A local function is only relevant when LPS detoxification by chylomicronLBP complexes occurs rapidly. The data showed that LBP strongly accelerated the transfer of LPS to chylomicrons (Fig. 3) and in PBMC stimulation experiments we observed that LPS detoxification by chylomicrons was pronounced after $0.5 \mathrm{~h}$ of preincubation (Fig. 6). These observations support the potential relevance of a local role for chylomicrons and LBP in the prevention of LPS induced damage. Such a 
mechanism is of special interest in the intestine since this organ is loaded with high amounts of bacteria and their toxic products that under pathologic conditions are thought to translocate and then play an important role in inflammatory and infectious complications such as multi organ failure and sepsis (36).

Employing highly-purified essentially LPS-free LTA, we show that the phenomenon extends also to Gram-positive bacteria. Noteworthy, LBP was not required for activation of PBMC by $20 \mu \mathrm{g} / \mathrm{ml}$ LTA, although LTA binds to this acute phase protein (37). Our data suggest that LBP and chylomicrons cooperate in the detoxification of LTA.

Enteral feeding is required for chylomicron secretion and our findings may therefore explain at least in part the reported beneficial effects of oral feeding in critically ill patients (38). The physiological advantages of enteral nutrition, as opposed to both starvation and parenteral nutrition, is more and more accepted. Meta analysis have demonstrated that in a large variety of patients, including patients suffering from pancreatitis, ulcerative colitis, Crohn disease, surgery, trauma or multi-organ failure, enteral feeding was associated with a lower risk of infection compared to starvation and parenteral nutrition (38). Early post-operative enteral feeding was found to reduce septic morbidity (39) and hospital stay (40). However, in most centers patients are restricted from early post-operative enteral feeding and from enteral feeding during their stay in the intensive care unit. Such abstinence of enteral feeding may cause a decline in the capacity of the body to detoxify bacterial toxin. We consider that enteral feeding of critically ill patients exploits a physiologic mechanism to enhance the endogenous chylomicron production, potentially leading to an enhanced presence of LPS inactivating LBP-chylomicron complexes in the circulation and possibly more important, in the intestinal subepithelial space and lymph. The chyllomicron levels attained by oral feeding seem to be of relevance, since postprandial levels of chylomicrons are more potent in LPS neutralization then physiologic levels of other lipoprotein fractions (HDL, LDL and VLDL) in vitro. We are not able to conclude from the data whether this greater inhibiting capacity of chylomicrons is due to a higher relative affinity for LPS, higher LBP or LPS binding capacity or a molar excess of circulating chylomicrons as compared to the other lipoprotein classes. Since even low concentrations of chylomicrons exert a significant effect on LPS activity and the fact that postprandial chylomicron levels rise acutely and drop slowly over hours thereafter ( $4 l)$, the effect of feeding is most likely to persist for several hours.

Overall, in this study we obtained evidence for a cooperative function between LBP and chylomicrons in the detoxification of toxin from both Gram-positive and Gramnegative microorganisms. Enhanced binding of LPS to LBP-chylomicron complexes in the circulation may prevent cytokine production and most likelly enhance their clearance from the circulation. We further speculate that production of LBPchylomicron complexes in the gut may represent a natural defense mechanism against endotoxemia of enteric origin. Enteral feeding, and subsequent chylomicron production, may be a preventive or even therapeutic intervention in patients that undergo abdominal surgery or major cardiovascular surgery, since in those patients bacterial translocation across the epithelial barrier of the gut is thought to play an important role in post-operative complications (36). 


\section{Acknowledgement}

This work was supported by a grant of the Dutch Digestive Diseases Foundation, the Netherlands and by Numico Research B.V., Wageningen, the Netherlands.

\section{References}

1. Harris, H. W., C. Grunfeld, K. R. Feingold, and I. H. Rapp. 1990. Human very low density lipoproteins and chylomicrons can protect against endotoxin-induced death in mice. $J$. Clim. Invest. 86:696-702.

2. Harris, H.W., C. Grunfeld, K.R. Feingold, T.E Read, J.P. Kane, A.L Jones, E.B. Eichbaum, G.F. Bland, and J.H. Rapp. 1993. Chylomicrons alter the fate of endotoxin, decreasing tumor necrosis factor release and preventing death. $J$. Clin. lwwest. $91: 1028-1034$

3. Munford, R. S., J.M.Andersen, and I. M. Dietschy. 1981 Sites of tissue binding and uptake in vivo of bacterial lipopolysaccharide-high density lipoprotein complexes. J. Chin. Inest. 68:15031513 .

4. Munford, R. S., C. L. Hall, J. M. Lipton, and J. M. Dietschy. 1982. Biological activity, lipoprotein-binding behavior and in vivo disposition of extracted and native forms of Salmonello typhimurium lipopolysaccharides. $J$. Clin Imest. 70:877-888.

5. Rensen, P.C.N., M. van Oosten, E. van de Bilt, M. van Eck, I. Kuiper, and T.I.C. van Berkel. 1997. Human recombinant apolipoprotein E redirects lipopolysaccharide from kupffer cells to liver parenchymal cells in rats in vivo. $J$. Clin. Invest, $99: 2438-2445$

6. Harris, H. W., S. E. Brady, and J. H. Rapp. 2002. Hepatic endosomal trafficking of lipoproteinbound endotoxin in rats. $J$ Surg. Res. 106:188-195

7. Read, T. E., H.W. Harris, C. Grunfeld, K. R. Feingold, M. C. Cahoun, J. P. Kane, and J. H. Rapp. 1993. Chylomicrons enhance endotoxin excretion in Bile. Infect. Immun. 61:3496-3502

8. Cavaillon, J-M., Fitting C., Haeffner-Cavaillon N., Kirsch S.J, and Warren H.S. 1990. Cytokine response by monocytes and macrophages to free and lipoprotein-bound lipopolysaccharide. Infect. Imm. 58:2375-2382

9. Kitchens, R.L., P. A. Thompson, S. Viriyakosol, G. E. O'Keefe, and R. S. Munford. 2002. Plasma CD14 decreases monocyte responses to LPS by transferring cell-bound LPS to plasma lipoproteins. J. Clin. Invest. 108:485-493.

10. Munford, R. S., C. L. Hall, and J. M. Dietschy. 1981. Binding of Salmonella typhimurium lipopolysaccharides to rat high-density lipoproteins. Infect. Immun. 34:835-843.

11. Wurfel, M.M., and S.D. Wright. 1994. Lipopolysaccharide-binding protein is carried on lipoproteins and acts as a shuttle in the neutralization of LPS by LPS-binding cofactor in the neutralization of LPS. J. Exp. Med. 180:1025

12. Zweigner, J., H. J Gramm, O. C. Singer, K. Wegscheider, and R. R. Schumann 2001. Hight concentrations of lipopolysaccharide-binding protein in serum of patients with severe sepsis on septic shock inhibit the lipopolysaccharide response in human monocytes. Blood. 15:3800-3808.

13. Grunfeld C., M. Marshall, J. K. Shigenaga, A. H. Moser, P. Tobias, and K. R. Feingold, 1999. Lipoproteins inhibit macrophage activation by lipoteichoic acid. L. Lipid Res. 40; 245-252

14. Ulevitch, R. J., A. R. Johnston, and D. B. Weinstein. 1979. New function for high density lipoproteins. J. Clin. Invest. 64: 1516-1524.

15. Van Lenten, B. J., A. M. Fogelman, M. E. Haberland, and P. A. Edwards. 1986. The role of lipoproteins and receptor-mediated endocytosis in the transport of bacterial lipopolysaccharide. Prac. Natl. Acad. Sci. USA. 83: 2704-2708.

16. Victorov, A. V., N. V. Medvedeva, E. M. Gladkaya, A. D. Morozkin, E. A. Podrez, V. A. Kosykh, and V. A. Yurkiv. 1989. Composition and structure of lipopolysaccharide-human plasma low density lipoprotein complex. Biochim. Biophys. Acta. 984: 119-127.

17. Netea, M. G., P. N. M. Demacker, B. J. Kullberg, L. E. H. Jacobs, T. J. G. Verver-Jansen, O. C. Boerman, A. F. H. Stalenhoef, and J. W. M. van der Meer. 1998. Bacterial lipopolysaccharide binds and stimulates cytokine producing cells before neutralization by endogenous lipoptoteins can occur. Cytokine. 10: 766-772. 
18. Vreugdenhil, A. C. E., A. M. P. Snoek, C. van "t Veer, J-W. M. Greve, and W. A. Buuman. 2001 Lipopolysaccharde Binding Protein circulates associated with apoB containing lipoproteins and enhances endotoxin-LDL/VLDL interaction. J. Chw. Imest. 107:225-233

19. Gao, J. J., Q. Xue, E. G. Zuvanich, K. R. Haghi, and D. C. Morrison. 2001. Comercial preparations of lipoteichoic acid contain endotoxin that contributes to activation of mouse macrophages in vitro: Infect. Inmmn. 69:751-757.

20. Morath, S., A. Geyer, and T. Hartung. 2001. Structure-funetion relationship of cytokine induction by lipoteilchoic acid from Staphylococcus aureus. I Exp. Med 193:393-397

21. Terpstra, A. H. M. 1985. Isolation of serum chylomicrons prior to density gradient ultracentrifugation of other serum lipoprotein classes. Anal. Biochem. 150;221-227

22. Terpstra, A. H. M., C.J.H. Woodward, and F.J. Sanchez-Muniz. 1981 Improved techniques for the seperation of serum lipoproteins by density gradient ultracentrifugation: visualization by prestaining and rapid seperation of serum lipoproteins from small volumes of serum. Anal. Biochem. 111:149-157

23. Froon A. H. M., M. A. Dentener, J. W. M. Greve, G. Ramsay, and W. A. Buurman. 1995. LPS toxicity regulating proteins in bacteremia. J. Infect. Dis. 171;1250-1257.

24. Yu B., and S.D. Wright. 1996. Catalytic properties of lipopolysaccharide (LPS) binding protein, transfer of CD 14. J. Biol. Chem. 271;4100-4105

25. Engelberts, 1., A. Moller, G.J.M. Schoen, C.J. van der Linden, and W.A. Buurman. 1991. Evaluation of measurement of human TNF in plasma by ELISA. Lymphokine and Cyrokine Res. 10:69.76

26. Bouma, M. G, R. K. Stad, F. A. J. M van de Wildenberg, and W. A. Buurman. 1994. Differential regulatory effects of adenosine on cytokine release by activated human monocytes. J. Immun. 153:4159-4168

27. Lamping N., R. Dettmer, N. W. J. Schroder, D. Pfeil, W. Hallatschek, R. Burger, and R.R. Schumann. 1998. LPS-Binding protein protects mice from septic shock caused by LPS or Gramnegative bacteria. $J$. Clim. Invest: 101;2065-2071

28. Bone R.C. 1994. Gram-positive organisms and sepsis. Arch. Intern. Med. 154;26-34

29. Nogare A. R., 1991. Southwestern Internal Medicine Conference: septic shock. Am. J. Med. Sci. $302 ; 50-65$

30. Bhakdi S., T. Klonisch, P. Nuber, and W. Fischer. 1991. Stimulation of monokine production by lipoteichoic acids. Infect. Immun. 59;4614-4620

31. Eichbaum E.B., H. W. Harris, J. P. Kane, and J. H. Rapp. 1991. Chylomicrons can inhibit endotoxin activity in vitro. J. Surgical Res. 51:413-416

32. Hailman, E., J. J. Albers, G. Wolfbauer, A. Y. Tu, and S. D. Wright. 1996, Neutralization and transfer of lipopolysaccharide by phospholipid transfer protein. J. Biol. Chem. 24:12 172-12178.

33. Wurfel, M.M, and S.D. Wright. 1997. Lipopolysaccharide-binding protein and soluble CD14 transfer lipopolysaccharide to phospholipid bilayers. In Immum. 158:3925-3934

34. Read T, E., C. Gruntleld, Z. Kumwenda, M. C. Calloun, J. P. Kane, K. R. Feingold, and I. H. T Rapp. 1995. Triglyceride-rich Jipoproteins improve survival when given after endotoxin in rats. Surgery. 117:62-67.

35. Vreugdenhil, A.C.E., M.A. Dentener, A.M.P. Snoek, J-W. Greve, and W.A. Buurman. 1999. Lipopolysacelharide binding protein and serum anyloid A secretion by human intestinal epithelial cells during the acute phase response. J. Immm. 163:2792-2798

36. O'Boyle C.J., J. Maclie, C. J. Mitchell, D. Johnstone, P. M. Sagar, and P. C. Sedman. 1998. Microbiology of bacterial translocation in humans. Gu* 42;29-35

37. Fan, X., F. Stelter, R. Menzel, R. Jack, I. Spreitzer, T. Hartung, and C.Schütt. 1999. Structures in Bacillus subtilis are recognized by CDI4 in a lipopolysaccharide binding protein-dependent reaction. Infect. Immum. 67:2964-2968.

38. Braunschweig C. L., P. Levy, P. M. Sheean, and X. Wang. 2001 Enteral compared with parenteral nutrition: a meta-analysis. Am. J. Clin. Nutr. 74;534-542

39. Moore $\mathbb{E}$. A., E. E. Moore, T. N. Jones, B. L. MeCroskey, and V. M. Peterson. 1989 TEN versus TPN following major abdominal trauma reduced septic morbidity. J. Trawma 29;916-922 
40. Schilder J. M., J. A. Hurteau, K. Y. Look, D. H. Moore, G. Raff, F. B. Stehman, and G. P. Sutton. 1997 A prospective controlled trial of early postoperative oral intake following major abdominal gynecologic surgery. Gynecol. Oncol. $67 ; 235-240$

41. Hugh $P_{n,}$ and $R$. Barett. 1998 Kinetics of triglyceride rich lipoproteins: ellylomicrons and very low density lipoproteins. Atherosclerosis 141. Suppl. 1;S35-S40 


\section{Chapter 6}

Enteral administration of high-fat nutrition before and directly after hemorrhagic shock reduces endotoxemia and bacterial translocation

Misha D.P Luyer*, Jan A Jacobs ${ }^{\dagger}$, Anita C.E. Vreugdenhi1", Mhamed Hadfoune* Cornelis H.C. Dejong*, Wim A. Buurman*, Jan Willein M. Greve*.

Department of General Surgery and Department of Medical Microbiology, Maastricht University, The Netherlands:

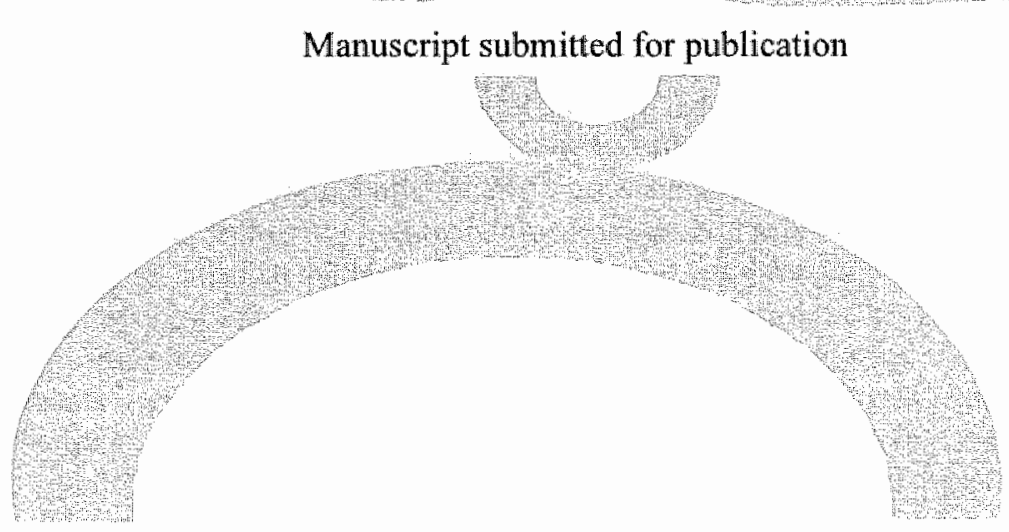




\begin{abstract}
Endotoxin and bacterial translocation due to gut barrier failure are important initiating events in the pathogenesis of sepsis after haemorrhage. Systemic inhibition of endotoxin activity attenuates bacterial translocation and distant organ damage. Triacylglycerol-rich lipoproteins constitute a physiological means of binding and neutralizing endotoxin effectively. We hypothesized that enhancement of triacylglycerol-rich lipoproteins via high-fat enteral nutrition would reduce endotoxemia and prevent bacterial translocation. The objective of this study was to determine whether potential enhancement of endotoxin neutralization via high-fat enteral nutrition affects endotoxemia and bacterial translocation after haemorrhage.

A rat model of non-lethal hemorrhagic shock was used. Hemorrhagic shock (HS) rats were divided into three groups: rats starved overnight (HS-S); rats fed with a low-fat enteral diet (HS-LF) and rats receiving a high-fat enteral diet (HS-HF). Circulating triacylglycerol and apolipoprotein B, reflecting the amount of triacylglycerol-rich lipoproteins, were elevated in HS-HF rats compared with both HS-S rats $(p<0.005$ and $\mathrm{p}<0.05$, respectively) and HS-LF rats $(\mathrm{p}<0.005$ and $\mathrm{p}<0.05)$. Circulating endotoxin was lower in HS-HF rats $(7.2 \pm 10.2 \mathrm{pg} / \mathrm{ml})$ compared with both HS-S rats $(29.1 \pm$ $13.4 \mathrm{pg} / \mathrm{ml}, \mathrm{p} \leq 0.005)$ and HS-LF rats $(29.9 \pm 5.2 \mathrm{pg} / \mathrm{ml}, \mathrm{p}<0.005)$. In line, bacterial translocation was lower in HS-HF rats (incidence $4 / 8$ rats; median 3 (range $0-144$ ) $\mathrm{cfu} / \mathrm{gram})$ compared with both HS-S rats $(8 / 8 ; 212(60-483) \mathrm{cfu} / \mathrm{gram} ; \mathrm{p}=0.006)$ and HS-LF rats $(8 / 8 ; 86(30-209) \mathrm{cfu} / \mathrm{gram} ; \mathrm{p}=0.002)$.

This study is the first to show that high-fat enteral nutrition, leading to increased plasma triacylglycerol and apolipoprotein B levels, significantly decreases endotoxemia and bacterial translocation after haemorrhage.
\end{abstract}




\section{Introduction}

Lipopolysaccharide (LPS) or endotoxin, a constituent of the outer membrane of Gram-negative bacteria, is an important nediator in the pathogenesis of the sepsis syndrome after major trauma, surgery and haemorhage $(1,2)$. The incidence of sepsis has increased over the years and a further increase is expected due to aging of the population and more complex surgery (3). Although the pathogenesis of the (late) sepsis syndrome after haemorrhage is not clear, gut barrier falure is considered to play a key role $(4,5)$. Several animal studies clearly show that hemorrhagic shock results in gut barrier failure leading to translocation of endotoxin and bacteria $(5,6,7$, 8, 9). Bacterial toxins such as endotoxin can lead to local activation of the inflammatory system and subsequent production (locally) of inflammatory cytokines leading to a further deterioration of the gut barrier and bacterial translocation (10). Moreover, an increase of systemic endotoxin levels after haemorthage plays an important role in the development of acute lung injury (8). This vicious circle of endotoxemia and bacterial translocation and subsequent acute lung injury can be interrupted by interventions that neutralize circulating endotoxin $(8,9)$. Several physiological defence mechanisms protect against endotoxemia such as the complement system, the coagulation cascade, the cytokine response and lipoproteins. Lipoproteins bind and incorporate both Gram-positive and Gram-negative bacterial toxins rapidly, a process which is mediated by lipopolysaccharide binding protein (LBP) and apolipoproteins $(11,12)$. Detoxification of endotoxin by lipoproteins prevents endotoxin from initiating an inflammatory response. Triacylglycerol-rich lipoproteins in particular are very potent inhibitors of the bioactivity of endotoxin and protect animals against endotoxin-induced lethality $(13,14,15,16)$. Elevation of triacylglycerol-rich lipoproteins, like chylomicrons and very low density lipoproteins (VLDL) would thus induce an increased capacity to inhibit the bioactivity of endotoxin. Physiological elevation of triacylglycerol levels occurs after a fat meal. Chylomicrons, formed in the gut and transported along mesenteric lymphatics, are present locally in the gut in the early postprandial phase. VLDL circulates systemically and is also elevated after enteral feeding $(17,18)$. Therefore, high-fat enteral nutrition would theoretically be very effective in reducing the bioactivity of enteric derived endotoxin both locally and systemically after disruption of the gut barrier as occurs following hemorrhagic shock in an early stage. Interestingly, fasting is common in surgical patients most at risk for endotoxemia of enteric origin even though a recent meta-analysis indicates that a "nil by mouth" regime is not beneficial in gastro-intestinal surgery (19). In animal studies investigating the pathogenesis of the sepsis syndrome, animals are generally fasted overnight before trauma or haemorthage $(5,6,8)$. Bark et al. (21) reported in rats that brief fasting was associated with significantly increased bacterial translocation following hemorrhagic shock compared with fed animals, indicating the importance of enteral nutrition.

The aim of this study was to induce an increase of triacylglycerol-rich lipoproteins via high-fat enteral nutrition in order to enhance the natural defence mechanism against endotoxin, thereby reducing endotoxemia and bacterial translocation after haemorrhage. In our experiments, we measured circulating triacylglycerol and apoB as indicators of triacylglycerol-rich lipoproteins. Circulating endotoxin and bacterial translocation to mesenteric lymph nodes, spleen and liver were measured as endpoints. 


\section{Material and Methods}

\section{Animals}

The present study was performed according to the guidelines of the Animal Care Committee of the University of Maastricht and this committee approved the protocol. Healthy male Sprague-Dawley rats; weighing $301-410$ grams (average, 342 grams) purchased from Charles River (Maastricht, the Netherlands) were housed under controlled conditions of temperature and humidity. Before the beginning of the experiments, rats were fed water and chow ad libitum.

\section{Experimental Design}

Animals were divided into five groups ( $\mathrm{n}=8$ per group). Control rats (C) were starved for 18 hours and sacrificed to assess the effect of fasting alone. Sham shock (SS) rats were starved and the femoral artery was cannulated, but no shock was induced. The haemorrlagic shock groups were either starved 18 hours before the procedure (HS-S), or enterally fed with a low-fat liquid enteral diet (HS-LF) or a high-fat liquid enteral diet (HS-HF) via oral gavage. The exact set up of the procedure is displayed in Figure 1. Blood and tissue samples were taken at 24 hours after onset of shock. The low-fat diet contained: $6.9 \%$ (energy-percent) proteins, $75.4 \%$ carbohydrates and $16.7 \%$ fat. The amount of fat in the low-fat diet was isocalorical to that present in standard rodent chow. The high-fat liquid enteral diet was isocaloric and isonitrogenous to the low-fat diet, but contained $6.9 \%$ proteins, $40.9 \%$ carbohydrates and $52.2 \%$ fat. The types of carbohydrates and fat used in both diets were identical. The amount of omega- 3 and omega- 6 fatty acids in the high-fat nutrition was less than $5 \%$ of the total fat content.

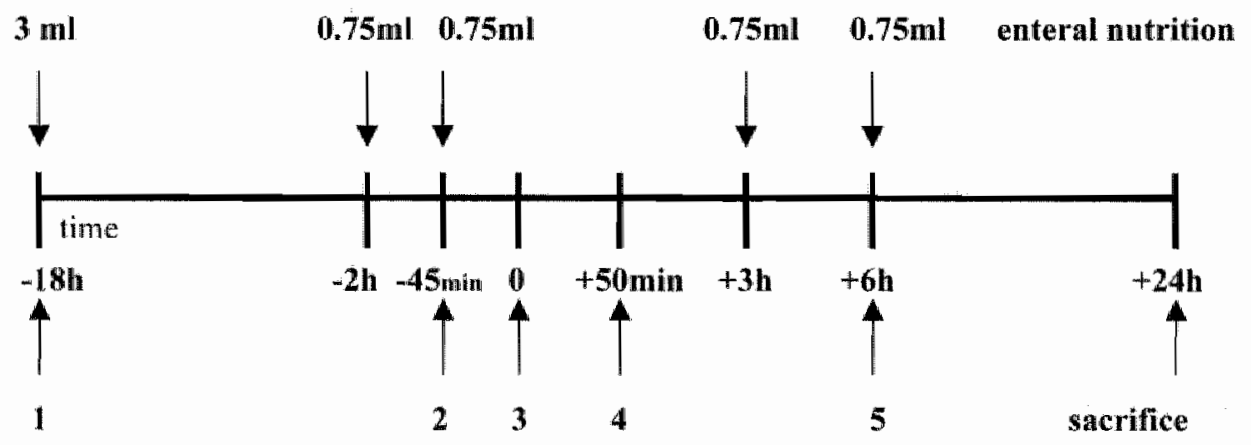

FIGURE 1. Experinchal procedire and feeding schedule. At - 18 hours, rats were starved overnight (1). 45 minutes before withdrawal of blood anaesthesia was given and a femoral artery catheter inserted (2), at $t=0$ hemorrhagic shock was induced (3); after 50 mimutes the fenoral artery catheter was removed and the wound was closed (4); after six hours all shock groups were allowed standard chow ad libitum (5), At 24 hours after (sham) shock ( $t=24$ h) rats were sacrificed (6). A liquid enteral nutrition (low-fat or high-fat) was administered via gavage in the fed groups (HS-LF and HS-HF), at 18 hours $(3 \mathrm{mll}),-2$ hours $(0.75 \mathrm{ml}),-45$ minutes $(0.75 \mathrm{ml}),+3$ hours $(0.75 \mathrm{ml})$ and +6 hours $(0.75 \mathrm{ml})$.

\section{Hemorrhagic shock procedure}

Rats were anaesthetized with intraperitoneally injected sodium pentobarbital (40 $\mathrm{mg} / \mathrm{kg}$ ). The skin over the left femoral area was shaved and disinfected with povidone iodine solution. The animals were placed in the supine position and allowed to breathe 
spontaneously. During surgery and throughout the experiment, body temperature was maintained at $37^{\circ} \mathrm{C}$ with an infrared heating lamp controlled by a thermo analyser system (Hugo Sachs Elektronik, March-Hugstetten, Germany) connected to a rectal probe. The femoral artery was dissected using aseptic technique and cannulated with pollyethylene tubing (PE-10) containing heparinized saline $(10 \mathrm{JU} / \mathrm{ml})$. Arterial blood pressure was continuously measured (Uniflow ${ }^{\text {tm }}$ extemal pressure transducer; BaxterT, Utrecht, the Netherlands) and recorded as Mean Arterial Pressure (MAP). Heart rate (HR) was continuously assessed from the instantaneous pressure signal. To keep the arterial catheter patent, it was constantly perfused with physiological saline $\left(3 \mathrm{ml} / \mathrm{h}\right.$ ) via the Uniflow ${ }^{\text {tm }}$ system; no heparin was used. After an acclimatisation period of 30 minutes, rats were subjected to haemorrhage by withdrawing blood in quantities of $2.1 \mathrm{ml} / 100 \mathrm{gram}$ of body weight (representing approximately $30-40 \%$ of the circulating volume) at a rate of $1 \mathrm{ml} / \mathrm{minute}$. At 50 minutes after the induction of shock, the catheter was removed and the femoral artery ligated. Six hours after haemorrhage, the rats were allowed access to standard chow ad libitum. Rats in the sham-shock group were anaesthetized and the left femoral artery was cannulated. Sham shock rats were monitored simillar as the hemorthagic shock group, however no blood was withdrawn.

Twenty-four hours after induction of shock, the rats were anaesthetized with sodium pentobarbital $(60 \mathrm{mg} / \mathrm{kg})$. The skin over de abdomen was shaved and disinfected with povidone iodine. The abdomen was opened via a midline incision, blood samples were taken and mesenteric lymph nodes, the midsection of the spleen and segment IV of the liver were aseptically removed for bacteriological examination.

\section{Plasma samples}

Arterial blood samples were collected in heparinized pyrogen-free glass tubes at the time of induction of shock $(\mathrm{t}=0)$ and twenty-four hours later. Plasma was separated by centrifugation, frozen immediately and stored $\left(-20^{\circ} \mathrm{C}\right)$ until the time of the assay. Hematocrit values were directly measured at the time of shock $(t=0)$ and twenty-four hours later.

\section{Triacylglycerol and $a p o B$}

Circulating triacylglycerol was determined using a standard enzymatic assay (Sigma Diagnostics, St. Louis, MO). Levels of apoB were determined using Sandwich-ELISA with a pAb against rat apoB, kindly provided by Dr. G. Gibbons, University of Oxford, UK. Briefly, 96-well immunomaxisorp plates (Nunc, Roskilde, Denmark) were coated overnight at $4^{\circ} \mathrm{C}$ with rabbit anti-rat apoB in a concentration of $1 \mu \mathrm{g} / \mathrm{ml}$. ApoB in plasma was detected with biotin-conjugated rabbit anti-rat apoB followed by peroxidase-conjugated streptavidin. TMB was used as substrate for peroxidase. Plates were read in a microplate reader at $450 \mathrm{~nm}$. As no standard was available, apoB levels were expressed as percentage of pooled plasma of normal healthy male SpragueDawley rats with the same weight ( $300-400$ gram).

\section{Endoroxin and Bacterial Translocation}

Total circulating endotoxin was determined by a chromogenic Limulus Amoebocyte Lysate (LAL) assay (Endosafe, Charles River, Charleston, SC). In short, after thawing 
heparinized plasma was directly diluted two-fold in pyrogen-free water and subsequently heated for 5 minutes at $75^{\circ} \mathrm{C}$, to inactivate LPS inhibitors in plasma. LAL-reagent and plasma were incubated for 45 minutes at room temperature. After blocking the reaction with $\mathrm{H}_{2} \mathrm{SO}_{4}$ an endpoint measurement was used. This assay has an effective range from $0.001-1 \mathrm{ng} / \mathrm{ml}$ :

Mesenteric lymph nodes (MLN), the mid-section of the spleen and a segment of the liver were collected aseptically in $2 \mathrm{ml}$ pre-weighed thioglycolate broth tubes (Becton Dickinson (BBL) Microbiology Europe, Maylan, France). After weighing, the tissue specimens were homogenized with sterile grinding rods (Potter S, B.Braun Melsungen, Melsungen, Germany). Subsequently, $500 \mu$ l-volumes were transferred. onto the following agar plates: Columbia III blood agar base supplemented with $5 \%$ voll/vol sheep blood (BBL) (duplicate plates), Chocolate PolyviteX agar (BioMérieux, Marcy L'Etoile, France), and Schaedler Kanamycin-Vancomycin agar supplemented with $5 \%$ sheep blood (BBL). Aliquots were spread over the entire surface of the agar. All agar plates were incubated for $48 \mathrm{~h}$, in a $5 \% \mathrm{CO}_{2}$-enriched atmosphere or under anaerobic conditions (Shaedler agar plates). After incubation, the colonies were counted on the non-selective Columbia sheep blood agar plates. For determination of the number of colony forming units (CFU) per gram tissue, the number of colonies was counted on all aerobic plates and next adjusted to the weight of the grounded tissue. All different colony types were identified to the species level using conventional techniques.

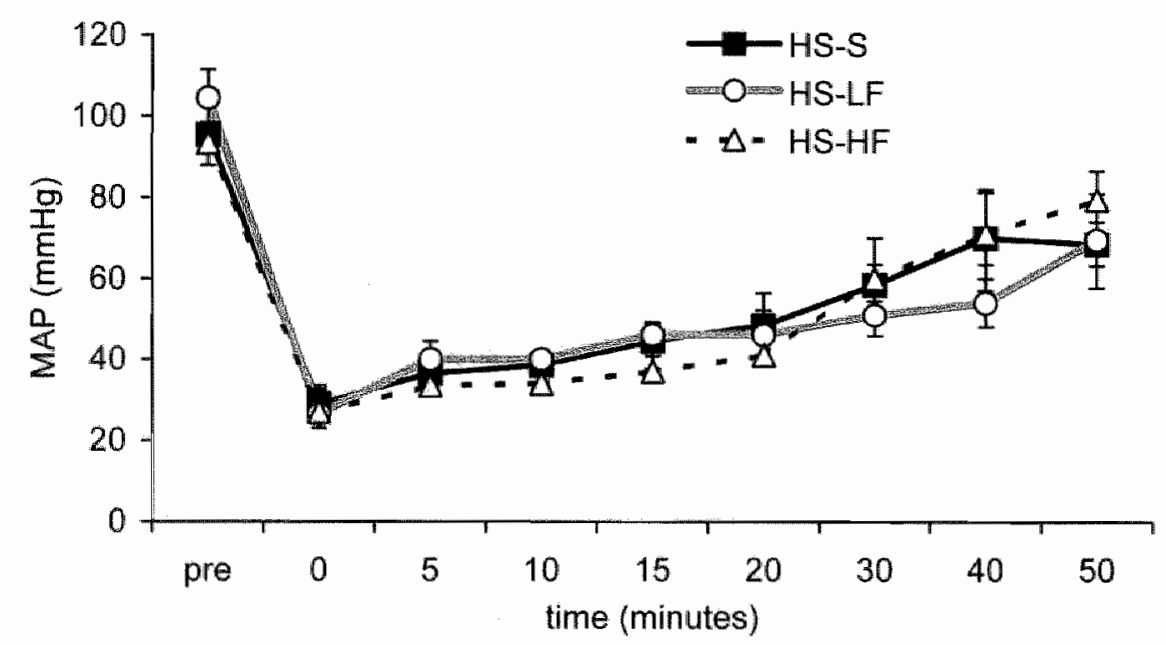

FIGURE 2. Mean Averial Pressure (MAP) of shock rats during the observation period MAP pressure is represented as median with $25^{\text {th }}-75^{\text {th }}$ percentile. MAP pressure before shock (pre) was 100 $(90-110) \mathrm{mmHg}$ and decreased to $26(23-31) \mathrm{mmHg}$ directly after haemorrhage $(t=0)$. There was no significant difference in MAP between the groups during the observation period.

Statistical analysis

Bacterial translocation data are represented as median and range; Mean arterial pressure and heart rate as median with $25^{\text {th }}-75^{\text {th }}$ percentile; other data are represented as mean $\pm \mathrm{SD}$. A Mann-Whitney $\mathrm{U}$ test was used for between-group comparisons. The 
Chi-square test was used to compare incidence of translocation. A non-parametric Spearman correlation test was used for bivariate correlations. $\mathbb{P} \leq 0.05$ was considered statistically significant:
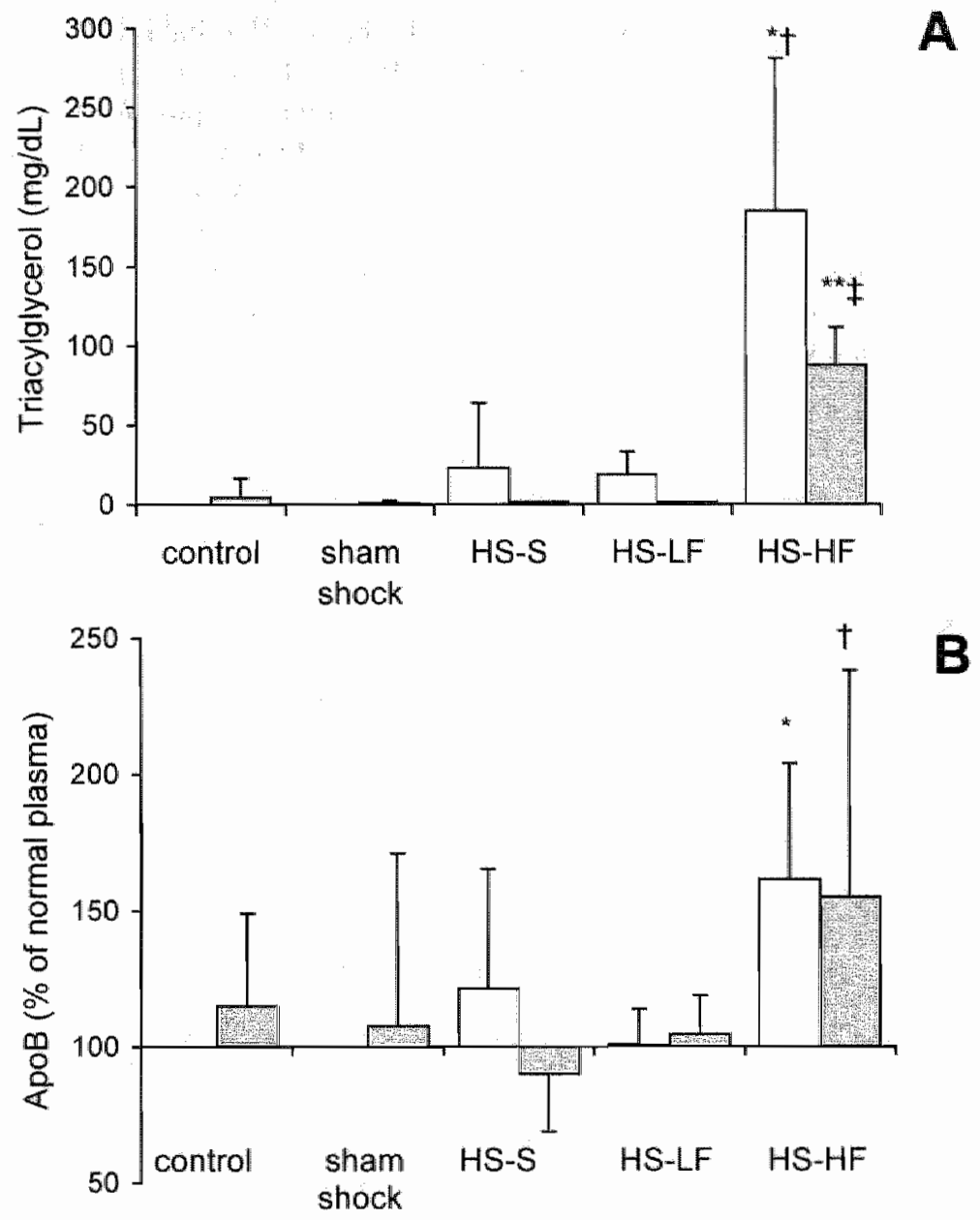

FIGURE 3. High-fat enteral nutrition leads to enhanced triacylglycerol and apoB concentrations. A: Triacylglycerol concentrations in plasma were significantly increased in $\mathrm{HS}-\mathrm{HF}$ rats at both $t=0$ (open bars) and 24 hours later (filled bars) compared with both HS-S and HS-LF groups. Values are expressed as mean $\pm \mathrm{SD}$. ${ }^{*} \mathrm{p}<0.005$ vs HS-S group at $=0 . * * 00001$ vs HS-S group at $t=24$ hours. p $<0.005$ vs HS-LF group at $t=0$. "p<0.001 vs HS-LF group at $t=24$ hours, B: ApoB in the HS-HF grotip at $t=0$ was significantly higher compared with the HS-LF group ${ }^{*} p=0.006$. At $t=24$ hours apoB concentrations in the HS-HF group were significantly higher compared with the HS-S group, $\mathrm{p}=0.036$. Values are expressed as percentage of the apoB concentration in pooled plasma of healthy rats. Concentration of apoB in Control, Sham-Shock, fasted Hemorrhagic Shock (HS) groups and the HS group fed with a low-fat enteral diet did not significantly differ. 


\section{Results}

\section{Hemorrhagic shock procedure}

The severity of the hemorrhagic shock insult as reflected by changes in mean arterial pressure (MAP), heart rate (HR) and hematocrit was similar for all three shock groups, i.e. HS-S, HS-LF and HS-HF (figure 2). Directly after induction of shock $(\mathrm{t}=0)$ mean MAP-values decreased from $100(90-110) \mathrm{mmHg}$ to $26(23-31) \mathrm{mmHg}$ and the HR decreased from $395(369-415)$ beats per minute (bpm) to $200(167-$ 232) bpm in all three shock groups. Hematocrit was reduced from $42 \pm 2.3 \%$ at $t=0$ to $29 \pm 2.3 \%$ at 24 bours after shock ( $t=24$ hours), $\mathrm{p}<0.001$. After 50 minutes both MAP and HR recovered to respectively $68(59-77) \mathrm{mmHg}$ and $339(313-368) \mathrm{bpm}$. All rats recovered spontaneously after the haemorrhage and no deaths occurred. These data are comparable with those reported by other groups using a similar model of nonlethal hemorrhagic shock $(20,22)$.

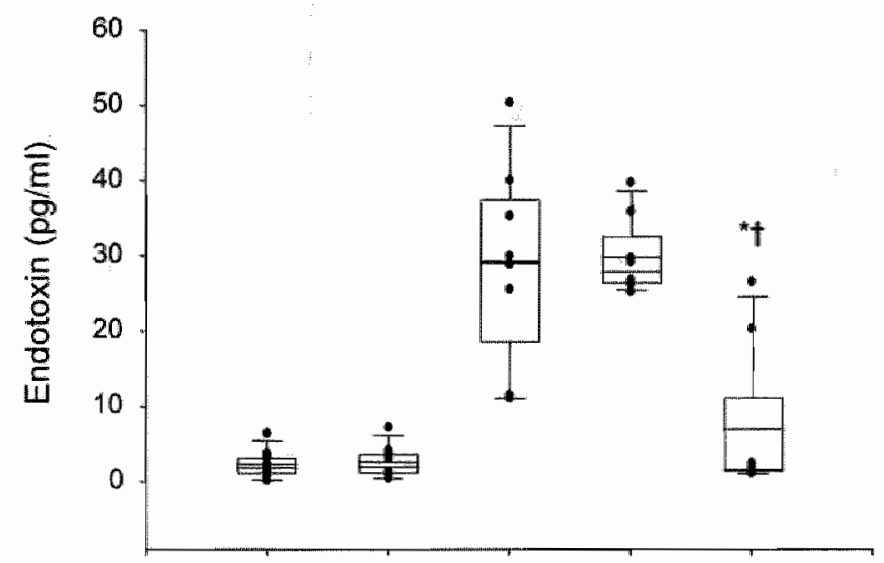

\section{Control Sham HS-S HS-LF HS-HF}

FIGURE 4. Circularing endotoxin at 24 hours after shock. Circulating endotoxin is significantly lower in the HS-HF group compared to both the HS-S group $\left({ }^{*} \mathrm{p}=0.005\right)$ and the HS-LF group $(\psi p=0,002)$. Each individual measurement is presented with the $5^{\text {th }}$ and $95^{\text {th }}$ percentile and mean $\pm S D$.

\section{Triacylglycerol and apoB}

As expected circulating triacylglycerol levels at the time of shock ( $t=0$ ) were significantly higher in HS-HF rats (184.5 $\pm 96.2 \mathrm{mg} / \mathrm{dL}$ ), compared to both HS-LF rats $(18.8 \pm 14.8 \mathrm{mg} / \mathrm{dL}, \mathrm{p}<0.005)$ and HS-S rats $(23 \pm 40.7 \mathrm{mg} / \mathrm{dL}, \mathrm{p}<0.005)$ (Figure $3 \mathrm{~A})$. There was no statistical difference between the HS-S group and the HS-LF group. After 24 hours $(\mathrm{t}=24$ hours) plasma triacylglycerol was still elevated in the HS-HF rats $(87.8 \pm 23.6 \mathrm{mg} / \mathrm{dL})$, whereas plasma triacylglycerol levels were below detection level in both the HS-LF rats $(\mathrm{p}<0.005)$ and the HS-F rats $(\mathrm{p}<0.005)$. As shown in Figure $3 B$, plasma concentrations of apoB in HS-HF rats at $t=0$ were higher compared with both HS-LF and HS-S rats. However, statistical significance was observed only between the HS-HF and HS-LF rats $(\mathrm{p}=0.006)$. After 24 hours circulating apoB levels in plasma were still significantly elevated in the HS-HF group compared with the HS$\mathrm{S}$ group $(\mathrm{p}<0.05)$, but not with the HS-LF group. As expected, circulating 
triacylglycerol and apoB levels were significantly correlated at both $t=0(r=0.471$, $\mathrm{p}<0.01)$ and $\mathrm{t}=24$ hours $(\mathrm{r}=0.314, \mathrm{p}<0.05)$.

Table1. Bacterial translocation at 24 hours after shock

\begin{tabular}{|c|c|c|c|c|c|}
\hline $\begin{array}{r}\text { Groups } \\
(n=8)\end{array}$ & $\begin{array}{c}\text { Translocation } \\
\text { incidence }\end{array}$ & $\begin{array}{c}\text { Mesenteric } \\
\text { tymph nodes } \\
\end{array}$ & Spleen? & Liver" & Total \\
\hline Control & $0 / 8$ & 0 & 0 & 0 & 0 \\
\hline $\begin{array}{l}\text { Sham } \\
\text { Shock }\end{array}$ & $3 / 8$ & $0(0-33)$ & $0(0-17)$ & $0(0-95)$ & 0 \\
\hline HS-S & $8 / 8$ & $212(60-483)$ & $12(0-998)$ & $44(0-249)$ & 327 \\
\hline HS-LF & $8 / 8$ & $86(30-209)$ & $66(7-2543)$ & $28(0-1416)$ & 261 \\
\hline HS-HF & +10 & $3(0-144)$ & $0(0-51)$. & $0(0-11 D)$ & 23 \\
\hline
\end{tabular}

I Number of rats with bacterial iranslocation vs total number of rats in the group. ${ }^{*} p<0.05$ compared with hemorrhagic shock + low-fat enteral diet (HS-LF). 4 p<0.05 compared to the starwed hemorthagic shock group (HS-S).

2 Resulis are presented as median colony forming units (cfi) /gram tissue (range). ${ }^{*} p<0.05, * * p<0.01$ compared to HS-LF. $+p<0.05$, $+p<0.01$ compared to HS-S.

\section{Circulating endotoxin and bacterial translocation}

The induced hypertriglyceridemia would potentially increase capacity to inhibit bacterial toxins such as endotoxin and thus preserve gut barrier function. In the systemic circulation endotoxin levels remained near the detection levels in the control groups (C and SS), Figure 4. Circulating endotoxin after 24 hours in the HS-HF group $(7.2 \pm 10.2 \mathrm{pg} / \mathrm{ml}$ ) was significantly lower compared with both the HS-S group (29.1 $\pm 13.4 \mathrm{pg} / \mathrm{ml}, \mathrm{p}=0.005)$ and the HS-LF group $(29.9 \pm 5.2 \mathrm{pg} / \mathrm{ml}, \mathrm{p}=0.002)$. There was no statistical difference between the HS-S group and the HS-LF group. The bacterial translocation data are represented in Table 1 . As expected, cultures from tissues taken from the control group were sterile. In the sham-shock rats, three animals had positive cultures, with low numbers of bacteria. After hemorthagic shock, bacterial translocation was demonstrated in all animals. The number of bacteria found in mesenteric lymph nodes (MLN), spleen and liver was significantly higher in the HS-S group compared with the sham-shock rats $(p=0.001)$. The median of colony forming units found in MLN of the HS-LF group was not significantly different from the amount of bacteria found in MLN of the HS-S group (212 vs. $86 \mathrm{cfu} / \mathrm{gram}, \mathrm{p}=0.059$ ). In contrast, after high-fat enteral nutrition (HS-HF), sterile cultures were found in $4 / 8$ rats. In addition, the amount of bacteria found in MLN, spleen and liver in the whole group was considerably reduced and significantly lower compared with the HS-S and the HS-LF groups. Overall, the bacteria most frequently found in the cultures were Escherichia coli, Enterococcus faecalis, Staphylococcus aureus. Additionally, Proteus and Lactobacillus spp were sporadically identified. Bacteria were more often found in MLN, than spleen or liver and Enterobacteriacea translocated more frequently than Lactobacillus spp. Both the species of bacteria and the frequency of translocation to the MLN are comparable with other rat studies investigating bacterial translocation 
after hemorrhagic shock $(20,23)$. In line with our hypothesis, levels of circulating triacylglycerol were inversely related with the total bacterial translocation, $r=-0.346$, $p<0.05$ (Figure 5A) and circulating endotoxin levels, $r=-0.598, p \leq 0.01$ (Figure 5B) in each hemorrhagic shock animal.
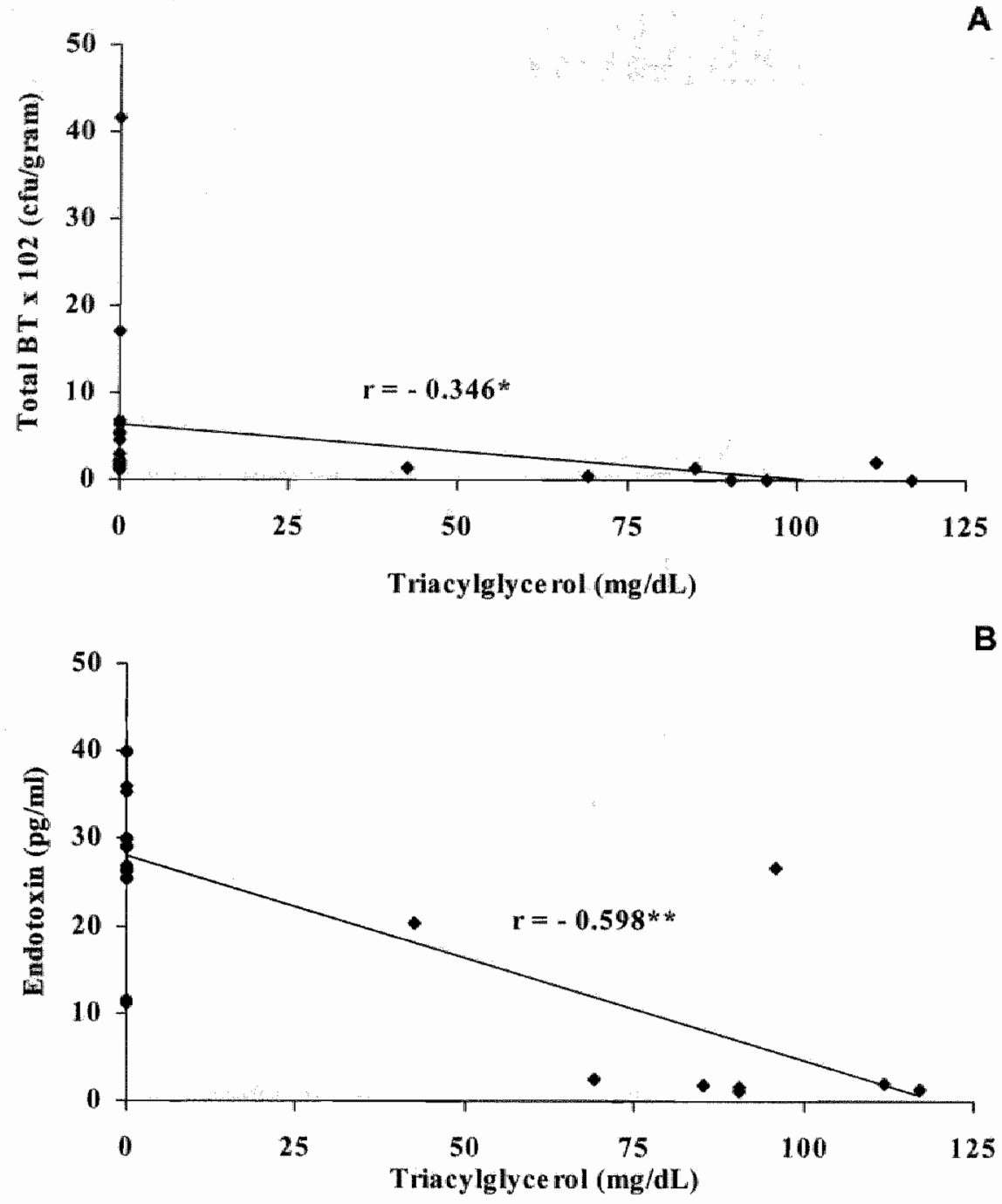

FIGURE 5. Circulating triglycerides are inversely correlated with total bacterial translocation and circulating endotoxin in all hemorrhagic shock rats. A: Circulating triglycerides are inversely correlated with total bacterial translocation. Total bacterial translocation expressed as colony forming units per gram is plotted against circulating triglycerides (mg/dL), $\mathbb{x}=-0.346, * p \leq 0.05$. B: Circulating iriglycerides are inversely correlated with the circulating endotoxin level at $t=24$ hours. Circulating endotoxin (pg/ml) is plotted against circulating triglycerides $(\mathrm{mg} / \mathrm{dL}), \mathrm{r}=-0.598, * 0.01$. 


\section{Discussion}

In the present study, we show that administration of high-fat enteral nutrition before and directly after haemorrhage induces an increase in circulating triacylglycerol and apoB concentrations. Interestingly, this study is the first to show that administration of high-fat enteral nutrition was accompanied by reduced plasma endotoxin levels and bacterial translocation. Ulevitch et al.(24) and Tobias et al. (25) proposed in the early $1980^{\prime}$ 's a possible role for high-density lipoproteins (HDL) to bind and inactivate endotoxin. Later, others discovered that hypertriglyceridemia as a result of de novo synthesis in the liver is part of the early response to low-dose endotoxin (26). This endotoxin-mediated increase in circulating triacylglycerol-rich lipoproteins is considered to have a protective function. Win vifro studies showed that triacylglycerolrich lipoproteins such as VLDL and chylomicrons are potent inhibitors of endotoxin activity $(13,27)$. In addition, in vivo studies showed that preincubation of endotoxin with triacylglycerol-rich lipoproteins or repeated intravenous infusions with chylomicrons protect animals against endoxin-induced death (13, 14). The proposed mechanism for these protective properties of triacylglycerol-rich lipoproteins may be twofold. Firstly, VLDL and chylomicrons can directly inhibit the bioactivity of endotoxin by uptake of endotoxin into these lipoproteins. Secondly, clearance of circulating endotoxin in plasma is enhanced by increased hepatocellular uptake of endotoxin associated with chylomicrons (16). Triacylglycerol-rich lipoproteins shunt endotoxin away from Kupffer cells towards hepatocytes, thereby decreasing cytokine release and TNF-mediated inflammation. Neutralization of the bioactivity of endotoxin by lipoproteins is mediated in part by LBP, apoA-1 and apoB $(12,28,29)$. LBP functions as a lipid transfer molecule, catalyzing the detoxification of endotoxin. $\mathrm{ApoB}$, the main apolipoprotein of triacylglycerol-rich lipoproteins, is considered to function as a binding site for both endotoxin and LBP.

In our study an increase of triacylglycerols was observed only in the HS-HF rats at both $t=0$ and $t=24$ hours. Chylomicrons are primarily triacylglycerol particles and chyllomicron formation is a characteristic property of the enterocytes during the postprandial state (30). Therefore, the majority of triacylglycerol measured at $t=0$ is probably found in chylomicrons. As chylomicrons are rapidly cleared from the circulation ( 31 ), the prolonged hypertriglyceridemia found at $t=24$ hours may be due to elevated VLDL levels. At the same time, also apoB levels in plasma were enhanced in the HS-HF group. Since the apoB concentration in plasma is known to be strongly correlated with circulating triacylglycerol levels (32) we expected a higher apoB concentration in plasma of HS-HF rats compared to that of $\mathrm{HS}-\mathrm{S}$ and HS-LF rats. Statistical significance was obtained with the HS-LF group at $t=0$ and the HS-S group after 24 hours. The absence of a postprandial increase in both triacylglycerols and apoB in the HS-LF group confirms earlier results that the postlipemic response depends on the amount of fat in the administered diet (33). The hypertriglyceridemia and the elevated apoB levels in the HS-HF rats, which reflect an elevation of triacylglycerol-rich lipoproteins, were accompanied with lower circulating endotoxin levels and reduced bacterial translocation. This effect was specific for the high-fat nutrition, since in the HS-LF group both endotoxin Jevels and bacterial translocation to MLN, spleen and liver were not significantly different compared with the HS-S group. 
A transient endotoxemia, attributed to direct endotoxin translocation, has been described in a different model of hemorrhagic shock with a peak concentration at 150 minutes after onset of shock (10). The endotoxemia that we observed at 24 hours after shock may be either the result of direct leakage due to a reduced gut barrier function or derived from translocated bacteria. At this stage, our data do not allow to distinguish between these potential sources of endotoxin. A common hypothesis proposes that endotoxin triggers an inflammatory process locally in the gut resulting in tissue damage, leading to a deterioration of the gut barrier function $(9,10,34,35)$. Neutralization of the bioactivity of endotoxin in an early stage would thus prevent this loss of barrier function. The importance of endotoxin neutralization after hemorrhagic shock in preserving gut barrier integrity is illustrated by animal studies showing that systemically administered endotoxin inhibitors, i.e. recombinant bactericidal/ permeability increasing protein ( $\mathrm{rBP}$ ) and the endotoxin neutralizing monoclonal $\mathrm{Ab}$, WN1 2225 , decrease bacterial invasion into the intestinal wall $(8,9)$. We propose that in our study triacylglycerol-rich lipoproteins play a role in neutralizing endotoxin and that this explains the protective effect of high-fat enteral nutrition regarding bacterial translocation. This is supported by the significant negative correlation between circulating triacylglycerol and both total bacterial translocation and circulating endotoxin levels in all hemorrhagic shock rats. At present, it is unclear whether triacylglycerol-rich lipoproteins funetion locally in the gut or in the systemic circulation. The fact that chylomicrons, apoB and LBP, all essential in endotoxin neutralization, are produced by enterocytes $(12,36,37,38)$, is in favor of local endotoxin neutralization by high-fat enteral nutrition.

Opposed to data found in rodents, there is still controversy about the effect of triacylglycerol-rich lipoproteins on endotoxin responsiveness in humans. Van der Poll et al. (39) showed that the in vivo response to endotoxin in humans is not inhibited by hypertriglyceridemia. However, Harris et al. (40) showed that preincubation of endotoxin with triacylglycerol-rich lipoproteins attenuated the inflammatory response evolving from this toxic compound. Moreover, a recent human study from our group showed that postprandial chylomicrons are very potent in neutralizing both endotoxin and lipoteichoic acid in a lipopolysaccharide binding protein (LBP) depending fashion, resulting in reduced cytokine and chemokine secretion (41). The fact that van der Poll et al. used a bolus injection of endotoxin, creating a sudden increase in endotoxin levels might explain these results, because activation of leukocytes by endotoxin may be more rapid than binding of endotoxin by triacylglycerol-rich lipoproteins $(13,42)$. In contrast, our model creates a situation in which endotoxin gradually translocates from the gut lumen into the systemic circulation, resembling the clinical situation. In this setting, exposure of endotoxin to triacylglycerol-rich lipoproteins leading to neutralization may precede the exposure to leukocytes.

In comparison with studies on triacylglycerol-rich lipoproteins and endotoxin neutralization in humans, data on the inhibitory effect of HDL on endotoxin responsiveness are more apparent (43). As HDL can be up regulated by triacylglycerol-rich lipoproteins via cholesteryl ester transfer protein (CETP) or phospholipid transfer protein (PLTP)(44), triacylglycerol-rich lipoproteins may also indirectly contribute to protection against endotoxin in humans. 
In surgery preoperative fasting is currently still a common routine(45), however a recent meta-analysis of controlled climical trials concludes that there is no clear advantage of keeping patients on a "nil by mouth" regime (19). Shortterm fasting increases the number of coliform bacteria and promotes bacterial adherence to the intestinal mucosa in rats and in a situation of gut barrier failure, these phenomena are thought to promote bacterial translocation(46). Bark et all. (21) already observed that rats receiving enteral nutrition before hemorthagic shock had less bacterial translocation compared with rats which were fasted for 24 hours. Also clinical studies showed the benefit of early postoperative nutrition compared with either fasting (47) or $\operatorname{TPN}(48,49,50,51)$. In addition, certain mutrients such as glutamine, arginine, omega-3 fatty acids and nucleic acids have immune-enhancing effects and reduce wound complication, infection and hospital stay when added to the enteral diet (47, 52). Our data show that a strong additional protective effect can be obtained by perishock administration of an enteral nutrition containing a high concentration of fat.

Taken together our current data are the first to show that a simple and relatively short nutritional intervention just before and directly after haemorrhage with a high-fat diet results in improved gut barrier function as reflected by reduced endotoxemia and bacterial translocation after 24 hours. The observed effects seem to be largely dependent on the amount of fat in the enterally administered diet. Whether this can be attributed to early and local scavenging of endotoxin by chylomicrons, leading to less local inflammation or to the prolonged hypertriglyceridemia, which also results in systemical endotoxin neutralization remains to be investigated. This study indicates that further studies on the potential benefit of high-fat enteral nutrition are needed.

\section{Acknowledgments}

We would like to thank M.G.A. Oude Egbrink from the Physiology Department (University of Maastricht) for facilitating our hemorrhagic shock experiments. We also would like to thank Dr. A. van den Bogaard for his advice. This work was supported by a grant from Numico Research B.V. Wageningen, the Netherlands.

\section{References}

1. Morrison DC, Ryan JL. Endotoxins and disease mechanisms. Arnu Rev Med 1987; 38:417-32,

2. Glauser MP, Zanetti G, Baumgartner JD, et al Septic shock: pathogenesis. Lancet 1991; 338:7326.

3. Angus DC, Linde-Zwirble WT, Lidicker $\boldsymbol{J}$, et al. Epidemiotogy of severe sepsis in the United States: analysis of incidence, outcome, and associated costs of care. Crit Care Med 2001; 29:1303-10.

4. Swank GM, Deitch EA. Role of the gut in multiple organ failure: bacterial translocation and permeability changes. World I Surg 1996;20:411-7.

5. Deitch EA, Morrison I, Berg $R$, et al.. Effect of hemorrhagic shock on bacterial translocation, intestinal morphology, and intestinal permeability in comventional and antibiotic-decontaminated rats. Crit Care Med 1990; 18:529-36.

6. Baker JW, Deitch EA, Li M, et al. Hemorrhagic shock induces bacterial translocation from the gut. J Trauma 1988; 28:896-906.

7. Tani $T$, Fujino M, Hanasawa $K$, et al. Bacterial translocation and tumor necrosis factor-alpha gene expression in experimental hemorthagic shock. Crit Care Med 2000; 28:3705-9.

8. Bahrami $\mathrm{S}$, Yao $\mathrm{YM}$, Leichtfried $\mathrm{G}$, et al. Monoclonal antibody to endotoxin altenuates hemorrhage-induced lung injury and mortality in rats. Crit Care Med 1997; 25:1030 6. 
9. Yo $Y M$, Bahrami $S$, Leichtried $G$, et al. Pathogenesis of hemorhage-induced bacteria/endatoxin translocation in rats. Effects of recombinant bactericidalpermeabilityincreasing protem. Am Surg 1995; 221:398-405.

10. Jiang $J$, Bahrami $\mathrm{s}$, Leichtfried $\mathrm{G}_{2}$ et al. Kinetics of endotoxin and tumor necrosis factor appearance in portal and systemic circulation after hemorrhagic shock in rats. Anm Surg 1995; $221: 100-6$.

11. Rauchliaus $M$. Coats $A J$, Anker SD. The endotoxin-lipoprotein hypothesis. Lancet 2000 ; $356,930 \cdots 3$.

12. Vreugdenhit AC, snoek AM, van "t Veer C, al. LPS binding protein chroulates in association with apoB-containing lipoproteins and enhances endotoxin-LDL/VLDL interaction. I Clin Invest $2001 ; 107: 225-34$.

13. Harris $\mathrm{IW}_{\mathrm{W}}$, Grunfeld $\mathrm{C}$, Feingold $\mathrm{KR}$, et al. Human very low densiry lipoproteins and chylonicrons can protect against endotoxin-induced death in mice. J Clin Invest 1990; 86:696702 .

14. Read TE, Grunfeld $C$, Kumwenda $Z L$, et al. Triglyceride-rich lipoproteins prevent septic death in rats. I Exp Med 1995; 182:267-72.

15. Read TE, Grunfeld C, Kumwenda $Z$, et al. Triglyceride-rich lipoproteins improve survival when given after endotoxin in rats. Surgery $1995 ; 117: 62-7$.

16. Harris $\mathrm{HW}$, Grunfeld C, Feingold KR, et all. Chy lomicrons alter the fate of endotoxin, decreasing tumor necrosis factor release and preventing death. J Clin Invest 1993; $91: 1028-34$.

17. Mero N, Syvanne M, Eliasson B, al. Postprandial elevation of ApoB-48-containing triglyceride-rich particles and retinyl esters in nomolipemic males who smoke. Arterioscler Thromb Vase Biol 1997; 17:2096-102.

18. Orth $\mathrm{M}$, Wahl $\mathrm{S}_{\mathrm{s}}$ Henisch $\mathrm{M}$, et al. Clearance of postprandial lipoproteins in normolipemics: role of the apolipoprotein E phenotype. Biochim Biophys Acta 1996; 1303:22-30.

19. Lewis SJ, Egger M, Sylvester PA, et al. Early enteral feeding versus "thil by mouth" after gastrointestinal surgery: systematic review and meta-analysis of controlled trials. Bmj 2001 ; $323: 773-6$.

20. Bark $T$, Katouli $M$, Ljungqvist $O$, et al. Bacterial translocation after non-lethal hemorrhage in the rat. Circ Shock $1993 ; 41: 60-5$.

21. Bark T, Katouli M, Svenberg T, et al. Food deprivation increases bacterial translocation after non-lethal haemorrhage in rats. Eur J Surg 1995; 161:67-71.

22. Agalar F, Iskit AB, Agalar C, et al. The effects of G-CSF treatment and starvation on bacterial translocation in hemorrhagic shock. J Surg Res 1998; 78:143-7.

23. Reed LL, Manglano R, Martin M, et al. The effect of hypertonic saline resuscitation on bacterial translocation after hemorrhagic shock in rats. Surgery 1991; 110:685-8; discussion 688-90.

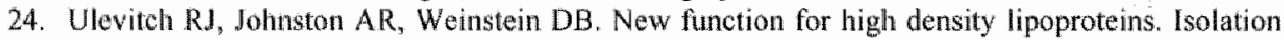
and characterization of a bacterial lipopolysaccharide-high density lipoprotein complex formed in rabbit plasma. I Clin Invest $1981 ; 67: 827-37$.

25. Tobias PS, McAdam KP, Soldau K, et al. Control of lipopolysaccharide-high-density lipoprotein interactions by an acute-phase reactant in human serum. Infect Immun 1985; 50:73-6.

26. Feingold $K R$, Staprans $I_{\text {, Menon }} R A$, et al. Fendotoxin rapidly induces changes in lipid metabolism that produce hypertriglyceridemia: low doses stimulate hepatic triglyceride production while high doses inhibit clearance. J Lipid Res 1992; 33:1765-76.

27. Harris $\mathrm{HW}$, Eichbaum EB, Kane JP, et al. Detection of endotoxin in triglyceriderich lipoproteins in vitro. J Lab Clin Med 1991; I 18:186-93.

28. Emancipator $K$. Csako $G$, Elin R. In vitro inactivation of bacterial endotoxin by human lipoproteins and apolipoproteins. Lufect Immun 1992; 60:596-601.

29. Wurfel MM, Kunitake ST, Lichenstein H, et al. Lipopolysaccharide (LPS)-binding protein is carried on lipoproteins and acts as a cofactor in the neutralization of LPS. J Exp Med 1994; 180:1025-35.

30. Hussain MM. A proposed model for the assembly of chylomicrons. Atheroselerosis $2000 ; 148: 1$ 15.

31. Martins IJ, Mortimer BC, Miller J, et al. Effects of particle size and number on the plasma clearance of chylomicrons and remmants. J Lipid Res 1996; 37:2696-705. 
32. Schneeman BO, Kotite L, Todd KM, et al. Relationships between the responses of triglyceridizrich lipoproteins in blood plasma containing apollpoproteins B-48 and B-100 to a fat-containing meal in normolipidemic thumans. Proc Natl Acad Soi U S A 1993; 90:2069-73.

33. Dubois $C$, Armand $M$, Azais-Braesco $V$, et al. Effects of moderate amounts of emulsiffed dietary fat on postprandial lipemia and lipoproteins in normolipidemis adults. Am J Clin Nutr 1994: $60: 374-82$.

34. Magnotti LJ, Upperman JS, Xu DZ, et al Gut-derived mesenteric lymph but not portal blood increases endothelial cell permeability and promotes lung injury after hemomhagic shock. Ann Surg 1998; 228:518-27.

35. Haimovitz-Friedman $A_{*}$ Cordon-Cardo $C$, Bayoumy $S$, et al. Lipopolysacoharide induses disseminated endothelial apoptosis requiring ceramide generation. I Exp Med 1997; 186:183:-41.

36. Vreugdenhil AC, Snoek AM, Greve JW, et al Lipopolysaccharide-binding protein is vectorially secreted and transported by cultured intestinal epithelial cells and is present in the intestinal mucus of mice. J Immunol 2000; 165:4561-6.

37. Cartwright $U$, Plonne $D$, Higgins $J A_{n}$ Intracellular events in the assembly of chylomicrons in rabbit enterocytes. J Lipid Res 2000; 41:1728-39.

38. Cartwright 1J, Higgins. JA. Direct evidence for a two-step assembly of ApoB48-containing lipoproteins in the lumen of the smooth endoplasmic reticulum of rabbit enterocytes. J Biol Chem $2001 ; 276: 48048-57$.

39. van der Poll $\mathrm{T}$, Braxton $\mathrm{CC}$, Coyle $\mathrm{SM}$, et al. Effect of hypertriglyceridemia on endotoxin responsiveness in humans. Infect Immun 1995; 63:3396-400.

40. Harris HW, Johnson JA, Wigmore SJ. Endogenous lipoproteins impact the response to endotoxin in humans. Crit Care Med 2002; 30:23-31.

41. Vreugdenhil $A C$, Rousseau $C H$, Hartung $T$, at al LPS Binding protein mediates LPS detoxification by chylomicrons; a potential defense mechanism of the intestine against bacterial toxin. J Immunol 2003; in press.

42. Netea $\mathrm{MG}$, Demacker $\mathrm{PN}$, Kullberg $\mathrm{BJ}$, et al. Bacterial lipopolysaccharide binds and stimulates cytokine-producing cells before neutralization by endogenous lipoproteins can occur. Cytokine $1998 ; 10: 766-72$.

43. Pajkrt D, Doran JE, Koster F, et al. Antinflammatory effects of reconstituted high-density lipoprotein during human endotoxemia. J Exp Med 1996; 184:1601-8.

44. Hunskonen J, Olkkonen VM, Jauhiainen $\mathrm{M}$, et al. The impact of phospholipid transfer protein (PLTP) on HDL metabolism. Atherosclerosis 2001; 155:269-81.

45. Crenshaw JT, Winslow EH. Original Research: Preoperative Fasting: Old Habits Die Hard: Research and published guidelines no longer support the routine use of 'NPO safter midnight,' but the practice persists. Am I Nurs 2002; 102:36-44.

46. Nettelbladt $C G$, Katouli M, Volpe A, et al. Starvation increases the number of coliform bacteria in the caecum and induces bacterial adherence to caecal epithelium in rats. Eur J Surg 1997; $163: 135-42$.

47. Kudsk KA, Minard G, Croce MA, et al. A randomized trial of isonitrogenous enteral diets after severe trauma. An immune-enhancing diet reduces septic complications. Ann Sturg 1996; $224: 531-40$

48. Beier-Holgersen $R$, Boesby $S$. Influence of postoperative enteral nutrition on postsurgical infections. Gut $1996 ; 39: 833-5$.

49. Moore EE, Jones TN. Benefits of immediate jejunostomy feeding after major abdominal trauma-a prospective, randomized study. J Trauma 1986;26:874-81.

50. Kudsk KA, Croce MA, Fabian TC, et al. Enteral versus parenteral feeding. Effects on septic morbidity after blunt and penetrating abdominal trauma. Ann Surg 1992;215;503-11.

51. Moore FA, Moore EE, lones TN, et al. TEN versus TPN following major abdominal traumareduced septic morbidity. I Trauma 1989;29:916-22.

52. Galban $\mathrm{C}$, Montejo JC, Mesejo $\mathrm{A}$, ell al. An immune-enhancing enterall diet reduces mortality rate and episodes of bacteremia in septic intensive care unit patients. Crit Care Med 2000; 28:643.8. 


\section{Chapter 7}

\section{Phosphatidylcholine enhances apolipoprotein secretion}

\section{by enterocytes during the acute phase response}

Anita C.E. Vreùgdenhil, A.M. Patricia Snoek, Erik F. Engelen, Jan Willem M. Greve, Win

A. Buurman

Department of General Sungery, Maastricht University, The Netherlands.

Manuscript submitted for publication

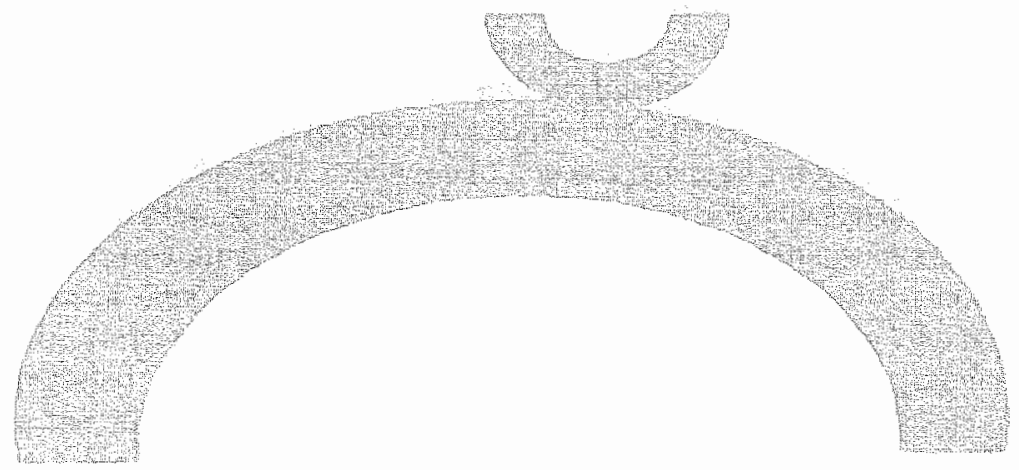




\begin{abstract}
Translocated enteric bacteria and their toxins cause local damage to the intestine and systemic pathology. Direct detoxification of these bacterial toxins after invading the interior of the host is vital. Intestinal lipoproteins were demonstrated to effectively prevent the detrimental effects of bacterial toxin. In this study we explored conditions for enhancement of intestinal lipoprotein secretion during the acute phase response. Since phosphatidylcholine $(\mathrm{PC})$ is thought to be essential in intestinal lipoprotein assembly and secretion, we studied the effect of PC on apolipoprotein secretion by enterocytes under normal and acute phase conditions. The data show that apical presence of L-PC enhances apolipoprotein secretion by enterocytes in vitro. Accordingly, instillation of $\mathrm{PC}$ in healthy rats significantly enhanced circulating apoB levels. $\mathrm{PC}$ in combination with other nutritional. compounds had an additional effect on the upregulation of intestinal apolipoprotein synthesis. Most interestingly, PC administered to enterocytes under acute phase conditions abrogated the cytokineinduced reduction of apolipoprotein secretion and even enhanced the secretion of apolipoproteins to the same levels as under non-acute phase conditions. The data of this study imply that enteral supplementation of PC enhances intestinal lipoprotein secretion during infection. Administration of $\mathrm{PC}$ may in particular be effective since the presence of dietary and biliary $P C$ is lacking in the intestinal lumen during inflammatory conditions. We speculate that $\mathrm{PC}$ induced secretion of lipoproteins by enterocytes may promote detoxification of bacterial toxins at the site of translocation and prevent the local damage and systemic pathology induced by these toxins.
\end{abstract}




\section{Introduction}

Physiologic levels of lipoproteins have been shown to protect against the deleterious effects of bacterial toxins $(11,13,14,20)$. Toxins incorporated into lipoproteins are not able to activate cells and thereby prevent the release of a cascade of cytokines (3, $13,14)$. The liver and the intestine are the organs that contribute the majority of circulating lipoproteins. Liver derived lipoproteins i.e. very low-density lipoproteins (VLDL) and low-density lipoproteins (LDL) were found to be the lipoproteins that predominantly bind and inactivate LPS in fasting healthy and septic subjects $(32,42$, 43, 47). Chylomicrons, the very large triacylglycerol-rich lipoproteins produced by the intestime upon feeding, were also demonstrated to prevent endotoxin-induced mortality in vivo $(18,19)$.

The intestine is a potential port of entrance for bacteria and their toxins $(5,24,34)$. Translocated enteric bacteria and toxins are thought to cause local damage to the intestinal barrier $(6,28)$ as well as systemic pathology $(5,24,34)$. Consequently, there is a strong need for immediate detoxification of bacterial toxins after passage of the intestinal epithelium. Hypothetically intestinal lipoproteins are able to inactivate these toxins locally in the gut. LBP a protein that strongly catalyzes the detoxification of bacterial toxins by lipoproteins was recently found to be produced by enterocytes $\left(45_{*}\right.$ 46), and may assist in direct lipoprotein mediated detoxification of toxins in the intestine. However, during infection the conditions for secretion of intestinal lipoproteins are poor. Cytokines, released in response to bacterial toxins, interact with enterocytes and diminish the secretion of intestinal lipoproteins; TNF- $\alpha$ and Il-6 were demonstrated to reduce the synthesis of apoB and apoA-I and the secretion of lipids and lipoproteins by intestinal epithelial cells $(16,26,31)$. An additional effect of these circulating cytokines is anorexia (reviewed in reference 37 ). Hence, the main trigger for intestinal lipoprotein production, i.e. the presence of intraluminal nutrients, is strongly impaired. Moreover, critically ill patients admitted to an intensive care unit are in general initially starved or given total parenteral nutrition (TPN). Another factor, impeding intestinal lipoprotein secretion, is a profound decrement in bile flow and biliary phospholipid concentrations during critical illness and lack of enteral nutrition (7). Presence of phospholipids in the intestinal lumen however, is required for secretion of lipoproteins by enterocytes $(12,25,33,44)$

In search for therapeutic strategies to combat bacterial infection several investigators increased circulating lipoprotein concentrations artificially by infusion of exogenous lipoproteins in animal models of infection $(18,19,38)$. Modest increases in circulating chylomicron concentrations profoundly enhanced resistance to endotoxemia in vivo $(18,19)$. Next to these studies using exogenous lipoproteins, Harris et al. recently demonstrated that also endogenous lipoproteins, produced in response to feeding, reduce the toxic effects of bacterial toxins in human $(20)$. In the present study we explored conditions for enhancement of the endogenous production of lipoproteins by the intestine, during normal and acute phase conditions. Since intestinal lipoprotein secretion is thought to depend on presence of phosphatidylcholine (PC) in the intestinal lumen, which is dramatically impaired during infectious conditions, we investigated in the present study whether PC enhances intestinal lipoprotein secretion during the acute phase response. In vitro differentiated human colonic adenocarcinoma (Caco-2) cells were used as a model of normal human intestinal 
epithelial cells. This cell line was chosen as an experimental model, in view of its well-established ability to differentiate into funetional enterocytes with the capacity for lipid and apolipoprotein assembly, secretion and metabolism (22). In addition we examined the capacity of chylomicrons, the lipoprotein mainly secreted by enterocytes, to attenuate the cellular cytokine response to LPS in vitro. The results derived by the in vitro experiments were extended in in wivo experiments in which the effect of oral administration of PC to rats on endogenous lipoprotein secretion was evaluated.

\section{Material \& methods}

\section{Reagents.}

Human rTNF- $\alpha$ was kindly provided by BASF/Knoll (Ludwigshafen; Germany); human recombinant interleukin (IL)-6 by Prof. W. Sebald (Physiologisch-Chemisches Institut der Universität Würzburg, Germany); human $r I L-1 \beta$ was a gift from Immunex, Seattle, WA. Lyso-phosphatidylcholine (L-PC) and LPS from Escherichia coli, serotype 055:B5 was purchased from Sigma (St.Louis, MO). Intralipid was derived from Kabivitrum (Stockholm, Sweden). The human apoA-I immunoassay was a gift from Dr. Gavilondo, Center for Genetic Engineering and Biotechnology (Havana, Cuba). Phosphatidylcholine (Phospholipon 90) was a kind gift of Nattermann, Köln, Germany. Polyclonal rabbit anti-rat apoB Abs were kindly provided by Dr.G. Gibbons, University of Oxford, UK. Polyclonal and monoclonal Ab against human apoB (2B4) were derived from Calbiochem (La Jolla, CA) and ICN (Irvine, CA) respectively. Goat anti-rabbit $\mathrm{IgG}$ was purchased from Jackson ImmunoResearch (Westgrove, PA).

\section{Chylomicron isolation}

Chylomicrons were isolated from pooled postprandial human serum ( 6 donors) by ultracentrifugation according to Terpstra et al. (41). Briefly, dry $\mathrm{KBr}(770 \mathrm{mg})$ and sucrose $(50 \mathrm{mg})$ together with $2 \mathrm{ml}$ of serum were placed in the bottom of ultra clear centrifuge tubes (Beckman Instruments, Brea, CA). The components were carefully mixed with a spatula. A discontinuous gradient was made with the serum mixture of density $1.250 \mathrm{~g} / \mathrm{ml}$, two $\mathrm{KBr}$ solutions with density 1.225 and $1.100 \mathrm{~g} / \mathrm{ml}$ respectively, and on top water density $0.998 \mathrm{~g} / \mathrm{ml}$. The tubes were placed in a $S W 41$ rotor and centrifuged in a Beckman XL-80 ultra-centrifuge (Beckman Instruments) at 30,000 $\mathrm{rpm}$ and $20^{\circ} \mathrm{C}$ for 40 minutes. The chylomicrons were collected by aspiration of the top $1 \mathrm{ml}$ fraction and stored at $-80^{\circ} \mathrm{C}$ until use.

\section{Cell isolation and stimulation.}

PBMC were isolated from buffy coats of healthy volunteers, kindly provided by the local blood bank, by buoyant density centrifugation on Lymphoprep (Nycomed, Oslo, Norway). Cells were washed five times in HBSS to remove LBP and other plasma proteins and suspended in Macrophage Serum Free Medium (Life Technologies, Paisley, UK) supplemented with $100 \mathrm{U} / \mathrm{ml}$ penicillin and $100 \mu \mathrm{g} / \mathrm{ml}$ streptomycin (Life Technologies). LPS was pre-incubated with chylomicrons ( $50 \%$ of postprandial circulating levels) in 96-well flat-bottom tissue culture plates (Costar, Cambridge, 
MA) for $24 \mathrm{~h}$ at $37^{\circ} \mathrm{C}$. Cells were added immediately after isolation at $10^{5} \mathrm{cells} / \mathrm{wel}$. Control cultures were incubated with medium alone. The cell cultures were incubated for $4 \mathrm{~h}$ at $37^{\circ} \mathrm{C}$ and $5 \% \mathrm{CO}_{2}$. Supernatants were collected and stored at $-20^{\circ} \mathrm{C}$ until use.

\section{Immunoasscrys.}

ApoA-I release by Caco-2 cells was evaluated using sandwich ELISA. PIates (NuncImmuno Plate Maxisorp, Roskilde, Denmark) were coated with specific monoclonal Abs for human apoA-I. A peroxidase labeled monoclonal Ab was used for detection of immobilized apoA-I. Peroxidase activity was determined by addition of tetramethylbenzidine (TMB) substrate (Kirkegaard \& Perry Laboratories Inc., Gaithersburg, MD).

For evaluation of human apoB concentrations plates were coated with monoclonal $\mathrm{Ab}$ against human apoB. Polyclonal $\mathrm{Ab}$ against apoB followed by a peroxidaseconjugated goat anti-rabbit IgG were used for detection of apoB.

ApoB concentrations in the sera of rats were evaluated using sandwich ELISA. Plates were coated with polyclonal rabbit $\mathrm{Ab}$ against rat apoB. For detection of apoB, biotin labeled polyclonal $\mathrm{Ab}$ against rat apoB, followed by peroxidase-conjugated streptavidin, was used. Values of $A p o B$ are expressed as percentage of normal plasma, since a standard was not available.

Cytokine concentrations in the cell culture supernatants were determined using sandwich-ELISA for "TNF- $\alpha$ (9) and 11-8 (1). In short, 96-well immunomaxisorp plates (Nunc, Roskilde, Denmark) were coated overnight at $4^{\circ} \mathrm{C}$ with cytokine-specific mAb. TNF- $\alpha$ in the supernatants was detected with polyclonal rabbit anti-human TNF- $\alpha$, followed by peroxidase-conjugated goat anti-rabbit IgG (Jackson). 11-8 was detected by biotinylated polyclonal rabbit anti-human I1-8 followed by peroxidase-conjugated streptavidin.

\section{Culture and stimulation of Caco-2 cells}

In vitro differentiated human colonic adenocarcinoma (Caco-2) cells were used as a model of normal human intestinal epithelial cells. Caco-2 cells were obtained from the American Type Culture Collection (Rockville, MD; ATCC HTB 37). Caco-2 cells were cultured at $37^{\circ} \mathrm{C}$ with $5 \% \mathrm{CO}_{2}$ in Dulbecco's modified Eagle medium (DMEM) (Life Technologies, Paisley, UK), supplemented with $10 \%$ fetal calf serum (Hyclone, Logan, UT) $1.0 \mathrm{mM}$ sodium pyruvate (Life Technologies), $0.1 \mathrm{mM}$ non-essential amino acids (Life Technologies), $100 \mathrm{NU}$ penicillin/ml and $100 \mu \mathrm{g}$ streptomycin/ml (Life Technologies). Cells were maintained in $25 \mathrm{~cm}^{2}$ or $75 \mathrm{~cm}^{2}$ lasks (Costar, Cambridge, MA). Cultures were split when they reached $80 \%$ confluence.

For experiments, $5 \times 10^{5} \mathrm{Caco-2} \mathrm{cells} / \mathrm{cm}^{2}$ were seeded onto $1 \mathrm{~cm}^{2}$ collagen-coated membranes (3.0 $\mu \mathrm{m}$ pore size) inserted in Transwells (Costar, Cambridge, MA). Cells were cultured in the complete medium as described above. The medium was changed $48 \mathrm{~h}$ after seeding and further every other day. After two weeks, Caco-2 monolayers display functional properties similar to those found in normal enterocytes (21) and they form a polarized monolayer with tight junctions and brush border microvilli at their apical surfaces (36). Therefore, in this study all experiments were conducted between 14 and 17 days after seeding of the cells. The formation and maintenance of a 
sealed monolayer of Caco-2 cells was monitored by measurement of the passage of the permeability probe phenol red (500 Dalton). Monolayers permeable for phenol red were not used.

Experiments designed to study the effect of L-PC on apoA-I and apoB secretion by Caco-2 cells were performed in the absence of serum. Caco-2 monolayers were washed extensively before experiments and fresh medium was added basollateral. Medium supplemented with different concentrations of L-PC (L-PC) or supplemented with $200 \mu \mathrm{M}$ L-PC together with a 6-fold dilution of parenteral nutrition containing $16 \%$ intralipid- $20 \%$ (containing $1.2 \%$ phospholipids), $40 \%$ aminoacids $-10 \%$ and $26 \%$ glucose $-50 \%$, was added apical. Every 2.5 hour the apical medium was removed and fresh medium with L-PC or L-PC plus parenteral nutrition was added. After incubation for 10 hours, basolateral medium was removed and apolipoprotein concentrations in the medium were determined by ELISA.

To study the effect of L-PC on apolipoprotein secretion during the acute phase response, IL-1 $\beta(5 \mathrm{ng} / \mathrm{ml}), \mathrm{IL}-6(100 \mathrm{ng} / \mathrm{ml})$ and TNF- $\alpha(100 \mathrm{ng} / \mathrm{mll})$, were added to the apical and basolateral medium 48 hours and 24 hours before the start of experiments. These settings were based on pilot experiments, which demonstrated the induction of an acute phase response under these conditions. Monolayers were washed and medium with or without cytokines and containing 0 or $200 \mu \mathrm{M} \mathrm{L-PC}$ was added to the apical compartments. Apical medium was refreshed every 2.5 hours. ApoA-I and apoB concentrations in the basolateral medium were determined after an incubation period of 10 hours.

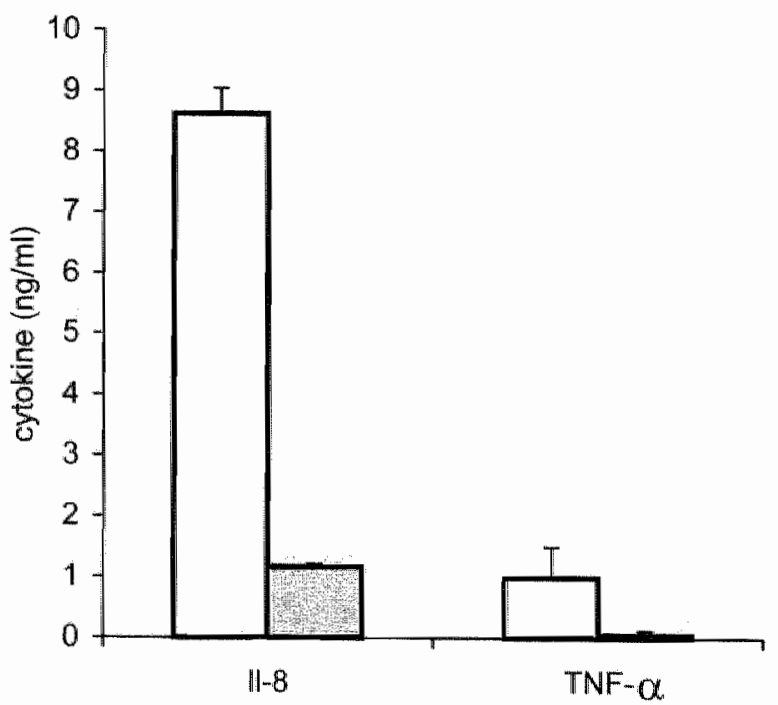

FIGURE 1. Chylomicrons reduce LPS toxicity. LPS $100 \mathrm{ng} / \mathrm{ml}$ was preincubated with (filled bars) or without (open bars) isolated chylomicrons (50\% of postprandial circulating levels) for $24 \mathrm{~h}$ at $37^{\circ} \mathrm{C}$. The remaining biological activity of LPS was determined by incubation with PBMC for $4 \mathrm{~h}$ and metsurement of TNF- $\alpha$ and II-8 secretion in the supernatants. Values represent the mean \pm SD of 3 wells. 


\section{Animal study}

$15 \mathrm{mg}$ PC (Nattermann) diluted in physiologic saline (n=10) or physiologic saline Without $\mathrm{PC}(\mathrm{n}=10)$ was administerd by oral gavage to 10 weeks old male Whistar rats every 2 hours for 8 hours on the first day of the experiment. On the second day of the experiment phospholipids or physiologic saline was again administered by oral gavage every 2 hours for 8 hours. During the experiment food was withdrawn, while drinking water was provided ad libitum. At the end of the experiment, arterial blood was collected and the apoB concentration in the serum was evaluated by ELISA.

\section{Results}

Chylomicrons reduce LPS activity.

To determine whether chylomicrons, the lipoproteins in particular produced by the intestine, reduce the bioactivity of LPS in vitro we exposed PBMC to LPS preincubated with chylomicrons. TNF- $\alpha$ and $11-8$ release by PBMC after a 4 hour incubation period were measured. Figure 1 shows that, preincubation of LPS with chylomicrons (50\% of postprandial circulating levels), clearly reduced the LPS evoked TNF- $\alpha$ and $11-8$ secretion by PBMC.

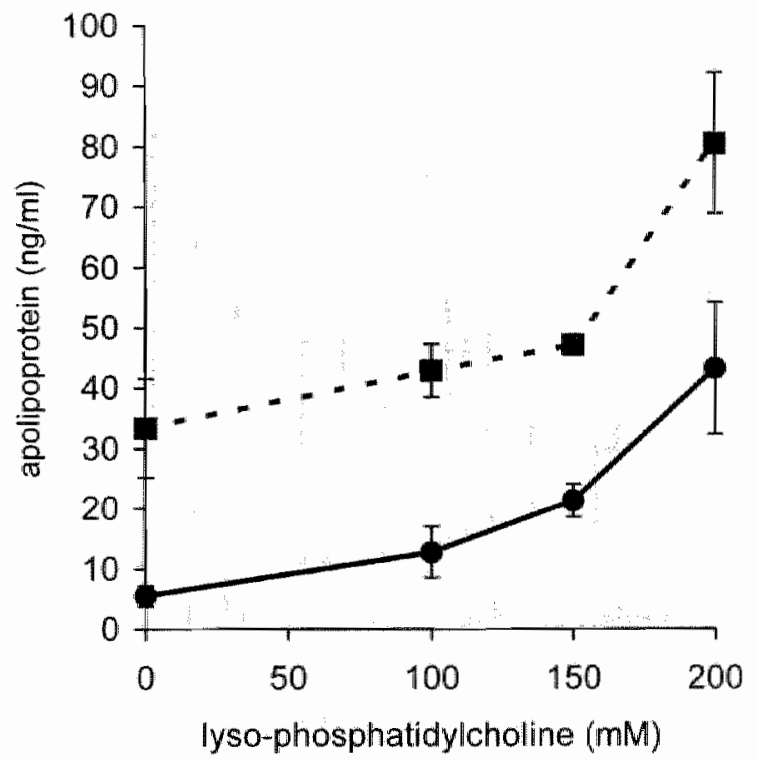

FIGURE 2. Lyso-phosphatidy/choline enhances apolipoprotein secretion by enterocyres dose dependently. Caco-2 cells were grown on Transwell-Col ${ }^{\mathrm{Th}}$. Maintenance medium was removed, cells were washed and serum free medium containing $0,100,150$ and $200 \mu \mathrm{M} \mathrm{L}-\mathrm{PC}$ was added apically every 2.5 hour. The effect of L-PC on basolateral apoA-1 ( ) and apoB (W) secretion after $10-\mathrm{h}$ incubation was determined by ELISA. Values represent the mean \pm SD of 4 wells.

Lyso-phosphatidylcholine enhances apoA-I and apoB secretion by Caco-2 cells.

Next, we studied whether apical presence of PC affects apo $A-I$ and apoB secretion by Caco-2 cells. Others have demonstrated the coordinated induction of triacylglycerol and apoB in $C$ aco- 2 cells suggesting that the regulation of lipoproteins and apoB is a 
coordinated process (4). In the intestine, most PC is hydrolysed by phospholipase derived from the pancreas. Since Caco-2 cells lack the ability to hydrolyse and release fatty acids from $P C$, L-PC was added to mimic more closely the form of $\mathrm{PC}$ available for intestinal cells. L-PC was added to the apical serum free medium of Caco-2 cells, cultured on semiperneable filters. Since L-PC is efficiently absorbed by enterocytes, the apical medium containing L-PC was refreshed every $2.5 \mathrm{~h}$ in order to accomplish continuous presence of L-PC at the apical cell surface. After $10 \mathrm{~h}$ incubation the amount of apo $\mathrm{A}-\mathrm{I}$ and $\mathrm{apoB}$ in the basolateral medium was determined. Figure 2 shows that L-PC enhanced apoA-I and apoB secretion dose- dependently. Addition of $200 \mu \mathrm{M} L-P C$ to the apical medium caused an 8 and 2.5 -fold increase in the amount of respectively apo $\mathrm{A}-\mathrm{I}$ and apoB secreted by the $\mathrm{Caco}-2$ cells. When apical medium was not refreshed every $2.5 \mathrm{~h}$ the upregulation of apolipoprotein secretion was much lower (data not shown), which underlines the importance of continuous presence of $\mathrm{PC}$ at the apical surface of enterocytes. Concentrations of L-PC above $200 \mu \mathrm{M}$ resulted in disturbances of the integrity of the Caco- 2 monolayers and were therefore not further studied.

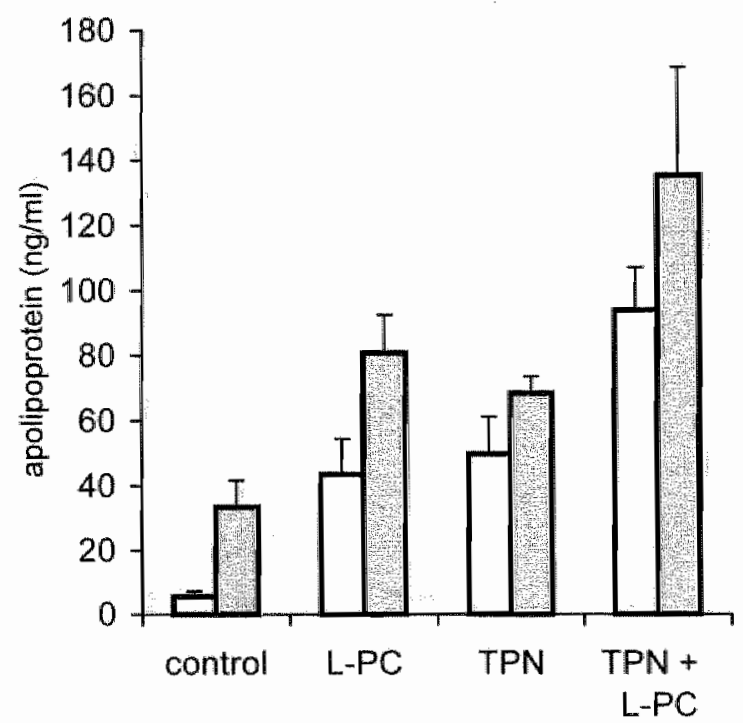

FIGURE 3. Additionat ettect of lyso-phosphatidylcholine stpplewented to mutrition on apoliporotein secretion by enterocytes. Caco-2 cells were grown on Transwell-Col ${ }^{\text {Twl }}$. Maintenance medium was removed, cells were washed, and only serum free medium, serum free medium with $200 \mu \mathrm{M} \mathrm{L}_{\mathrm{u}}-\mathrm{PC}_{\mathrm{s}}$ or serum free medium containing parenteral nutrition (1:6) with or without $200 \mu \mathrm{M}$ L-PC was added apically every 2.5 hour. The effect of supplementation of $L-P C$ to nutrition on basolateral apoA-I (open bars) and apoB (filled bars) secretion after 10-h incubation was determined by ELISA.Values represent the mean $\pm S D$ of 4 wells.

It has been proposed that phosphatidylcholine enhances the intestinal absorption of dietary fat (33). In search for conditions to further enhance the lipoprotein secretion by enterocytes, we studied whether the combination of L-PC with other nutritional compounds resulted in a further upregulation of the apoA-I and ApoB secretion. Since Caco-2 cells do not secrete all enzymes necessary for digestion of enteral nutrition, 
parenteral nutrition supplemented with L-PC was added to the apical side of Caco-2 cells. Figure 3 demonstrates that the parenteral nutrition containing aminoacids, glucose and lipids, amongst which low eoncentrations of phospholipids, induced apoA-I and apoB secretion by $\mathrm{Caco-2}$ cells. This apolipoprotein secretion was additionally enhanced by presence of L-PC.

\section{Enteral infusion of phosphatidylcholine enhances circulating concentrations of apoB} in rats

The results derived by the in vitro experiments were extended in an in wivo study in which the effect of enteral administration of PC to rats on endogenous lipoprotein secretion was evaluated. To this end rats were fed $\mathrm{PC}$ or physiologic saline repetitively during the 32 hours before blood sampling. The concentration of circulating apoB in the rats fed with $\mathrm{PC}$ was $53 \%$ higher $(\mathrm{p}<0.05$, Mann-Whitney $\mathrm{U}$ test) as compared to control rats (Fig. 4), clearly indicating that enteral administration of PC enhances endogenous lipoprotein secretion.

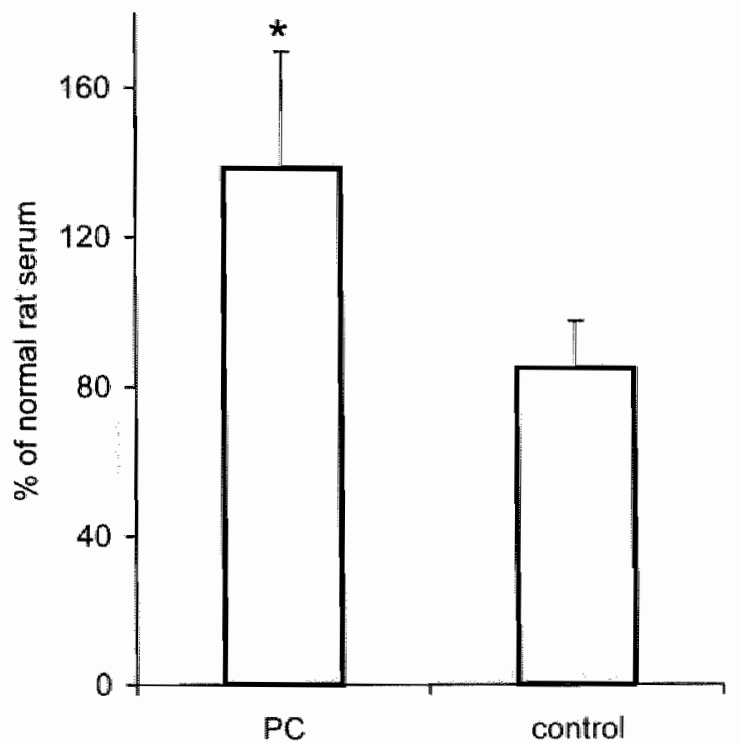

FIGURE 4. Enteral infusion of phosphatidylcholine enhances circulaing concentrations of apoB in rats. 10 weeks old male Whistar rats were instilled $15 \mathrm{mg}$ PC diluted in physiologic saline (nim 10 ) or physiologic saline without PC $(n=10)$ every 2 hours for 8 hours on the first day of the experiment. The second day $\mathrm{PC}$ or physiologic saline was instilled again every 2 hours for 8 hours. During the experiment food was withdrawn, while drinking was provided ad libitum. At the end of the experiment, arterial blood was collected and apoB in the serum was evaluated by ELISA. Values of $A$ poB are expressed as percentage of normal plasma. Values represent the mean $\pm S D$ of 10 rats. A Mann-Whitney $U$ test was used for between-group comparisons. $\mathrm{P}<0.05$ was considered to be statistically significant. * The circulating apoB concentration in the rats fed with PC was significantly higher as compared to control rats. 
Lyso-phosphatidylcholine enhances the lipoprotein secretion by Caco-2 cells during the acute phase response

Cytokines have been shown to affect lipoprotein metabolism during infection (16). TNF induces a dose related inhibition of apoA-I and apoB secretion in both, hepatocytes and enterocytes $(10,16,26,31)$. Our prior studies demonstrated that a mixture of TNF- $\alpha, 11-6$ and $I-1 \beta$ induced a more pronounced acute phase response in Caco-2 cells, resulting in a strong upregulation of positive acute phase proteins accompanied by a reduction of the negative acute phase protein apoA-I (46). The next experiment was performed to study whether L-PC is able to prevent the decreased apoA-I and apoB secretion during the acute phase response. To this end, $\mathrm{Caco}-2$ cells were cultured for $48 \mathrm{~h}$ in the presence of cytokines before L-PC was

added to the apical cell surface. The apical culture medium containing L-PC and cytokines was refreshed every 2.5 hour. After a $10 \mathrm{~h}$ incubation period the amount of apoA-I in the basolateral culture medium was measured. Figure 5 shows that also in the presence of high concentrations of pro-inflammatory cytokines, L-PC enhanced the apoA-I secretion in intestinal epithelial cells. In conclusion, $\mathrm{PC}$ administered to intestinal epithelial cells during the acute phase response abrogates the cytokine induced inhibition of apolipoprotein secretion and even enhances the secretion of apolipoproteins to the same levels as under non-acute phase conditions.

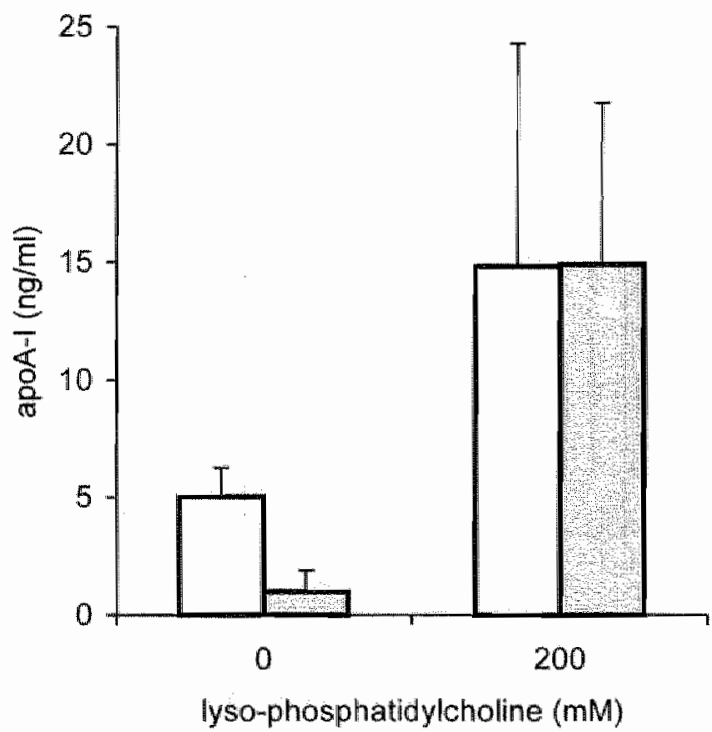

FIGURE 5. Lyso-phosphatidy/choline enhances apolipoprotein secretion by enterocytes during the acute phase response. An acute phase response was induced in Caco-2 cells, grown on TranswellCol ${ }^{\mathrm{m}}$, by incubation of the cells with $\mathrm{LL}-1 \mathrm{~B}(5 \mathrm{ng} / \mathrm{ml}), \mathrm{LL}-6(100 \mathrm{ng} / \mathrm{ml})$, TNF-a $(100 \mathrm{ng} / \mathrm{ml})$ for 48 hours (filled bars). In controls no cytokines were added (open bars). At the end of the incubation,

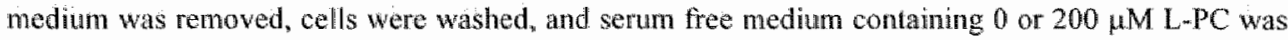
added apically every 2.5 hour. The effect of apical presence of L-PC on basolateral apoA-l secretion under these acute phase conditions was evaluated after 10 -h incubation. Values represent the mean \pm SD of 4 wells. 


\section{Discussion}

Gut barrier failure and subsequent bacterial translocation is considered to be a cause for infection and sepsis $(5,24,34)$. Translocated bacterial toxins can cause further intestinal damage, either directly or via the induced toxic agents, such as cytokines and free radicals $(6,28)$. There is a strong need for direct neutralization of these translocated bacterial toxins in order to prevent further gut barrier dysfunction and to diminish the deleterious systemic effects. Chylomicrons, the predominant lipoproteins produced by the intestine in response to feeding, were found to be effective in neutralization of bacterial toxins in vitro (Fig. 1) and in vivo $(18,19)$. Chylomicrons, not only neutralize bacterial toxins, they also alter their metabolic fate by shunting toxins to hepatocytes and away from hepatic macrophages $(19,40)$. Consequently, toxins are delivered into the bile, where they are inactivated by bile salts (39). A relative small increase in the circulating concentration of chylomicrons was observed to reduce mortality caused by endotoxemia $(18,19)$. In line with these observations, Harris et al. demonstrated recently that endogenous lipoproteins produced in response to feeding could ameliorate the effects of bacterial toxins in human (20). During severe infection however, conditions for endogenous intestinal lipoprotein secretion are poor; the presence of cytokines and the absence of biliary and dietary phospholipids most likely reduces the absorption of lipids and the secretion of lipoproteins by enterocytes. Strategies that increase endogenous lipoprotein production have the potential to combat bacterial infection. Therefore, in this study we searched for conditions to enhance the endogenous intestinal lipoprotein secretion during the acute phase response.

Here we established that apoA-I and apoB secretion by enterocytes under non-acute phase conditions were dose dependently enhanced by addition of L-PC to the apical surface (Fig.2). These in vitro observations were supported by an animal study, which demonstrated that repetitive enteral administration of $\mathrm{PC}$ enhanced circulating concentrations of apoB (Fig. 4). These results are in agreement with earlier observations demonstrating that phospholipids enhance the intestinal secretion of triacylglycerol-rich lipoproteins $(23,25,33,44)$. PC was earlier demonstrated not to affect apoB mRNA levels, suggesting that $\mathrm{PC}$ increases newly synthesized apoB probably by modification of posttranscriptional processes (25).

Cytokines are known to alter protein metabolism resulting in an increase or decrease of the positive or negative acute phase proteins, respectively. Pro-inflammatory cytokines strongly reduce apolipoprotein secretion by enterocytes, as demonstrated in this study (Fig. 5). Consistent with our findings, cytokines were demonstrated to decrease apoB, apoA-I, lipid and lipoprotein secretion in human intestinal epithelial cells $(26,31)$. We have now shown that also under these acute phase conditions $L-P C$ present at the apical surface of the enterocytes enhanced basolateral apolipoprotein secretion (Fig.5). Administration of L-PC to the enterocytes during the acute phase response not only reverted the cytokine effect on apolipoprotein secretion; it even enhanced the secretion of apolipoproteins to the same level as under non-acute phase conditions. These data might suggest that endogenous intestinal lipoprotein production can be enhanced during infection and inflammation by enteral administration of PC. In search for an intervention to further enhance the intestinal lipoprotein secretion induced by $\mathrm{PC}$, it was found that L-PC in combination with other nutrients had an 
additional effect on apoA-I and apoB secretion by enterocytes as compared to administration of L-PC alone (Fig.3). For this additional effect at least two explanations can be given. At first, $\mathrm{PC}$ is thought to improve the absorption and transport of dietary fats by enterocytes $(23,33)$. Secondly, PC may induce increased intestinal lipoprotein secretion by a mechanism independent of enhanced lipid absorption. This second assumption is strengthened by both our in vivo and in vitro studies that indicate that himinal presence of other nutritional compounds is not a prerequisite for $\mathrm{PC}$ to enhance intestinal apoliporotein secretion. In rats, even after 32 hours of lasting, $\mathrm{PC}$ still resulted in increased levels of apoB in the circulation. $A$ similar phenomenon was observed in the in vitro study; when L-PC was added apical and basolateral medium was refreshed each 2.5 hour during a total period of 10 hours, even in the fourth 2.5 hour interval L-PC enhanced the apolipoprotein concentration in the basolateral eulture medium of Caco-2 cells whilst other nutrients were absent at the apical cell surface (data not shown). These data imply that the PC induced apolipoprotein secretion is not exclusively caused by a rapid release of accumulated intracellular lipids and apolipoproteins or enhanced absorption of other lipids, but may involve enhanced de novo synthesis of lipoproteins. Consistently, L-PC was earlier demonstrated to enhance cholesterol (30) and triacylglycerol synthesis by enterocytes (25). These findings may have clinical importance since they suggest that the effect of enteral supplementation with $\mathrm{PC}$ is not restricted to a rapid short-term release of preexisting intracellular lipoproteins, but instead, that $\mathrm{PC}$ have a prolonged effect on intestinal lipoprotein synthesis and secretion.

Enhancement of intestinal lipoprotein secretion by PC or PC-enriched nutrition hypothetically reinforces a biological defense mechanism of the intestine against bacterial toxins by enhanced neutralization and clearance of bacterial toxins from the circulation and possibly, even more important, by direct neutralization of bacterial toxins translocated across a compromised intestinal mucosa. Harris et al found that preincubation of LPS with postprandial blood was required for attenuation of the immune response by the endogenous lipoproteins secreted in response to feeding (20). We hypothesize that the endogenous lipoproteins secreted by the intestine have the opportunity to interact and neutralize bacterial toxins already in the intestinal submucosa and lymphatic ducts, hence before active toxins reach the blood stream.

Prior studies found direct and indirect evidence for a role of enteral administered phospholipids in the host defense against bacterial infection. The absence of bile in the gastrointestinal tract in patients with obstructive jaundice is accompanied by translocation of bacteria and their toxins $(27,35)$. The incidence of post-operative infections in patients suffering from biliary obstruction is markedly enhanced compared to patients without biliary obstruction (8). Other evidence for a beneficial role of presence of phospholipids in the intestinal lumen was found in studies that demonstrated that enteral administration of phospholipids protected against the reduction of intestinal and mucosal weight and bacterial translocation $(15,48)$. In addition, supplementation of preterm formula with phospholipids, mainly $\mathrm{PC}$, lowered the incidence of necrotizing enterocolitis in preterm neonates (2). Also in this disorder, an impaired barrier function is thought to be crucial in the etiology. Although the authors of these studies speculate about the possible mechanisms underlying these positive effects of enteral phospholipids, including surfactant 
activity, alteration of mucus solubility and charge and enhanced repair of the injured intestinal epithelium, evidence for such mechanisms was not found. Enhanced intestinal lipoprotein secretion and concomitant detoxification of bacterial toxins, thereby preventing further damage to the intestinal epithelium, may also have accounted for the protective effects of enteral phospholipids found in these studics.

In conclusion, in this study we demonstrated that merely $\mathrm{PC}$ and $\mathrm{PC}$ in combination with other nutrients increase the apolipoprotein secretion by intestinal epithelial cells. Most interestingly, this effect of PC was also pronounced in the presence of proinflammatory cytokines, which in enterocytes reduce apolipoprotein secretion. Further studies are required to establish the clinical relevance of early post-operative feeding with $\mathrm{PC}$ or $\mathrm{PC}$ enriched enteral nutrition in patients undergoing abdominal surgery or complex cardiovascular surgery since bacterial translocation across an injured intestinal mucosa is thought to cause inlectious complications in these patients. In patients with biliary obstruction, severely lacking luminal endogenous $\mathrm{PC}$, enteral supplementation of PC may in particular be beneficial for improvement of intestinal lipoprotein secretion and subsequent improvement of the intestinal defense against bacterial toxins.

\section{Acknowledgements}

This work was supported by grants of the Dutch Digestive Diseases Foundation, the Netherlands and Numico Research, Wageningen, the Netherlands.

\section{References}

1. Bouma, M. G., R. K. Stad, F. A. J. M van de Wildenberg, and W. A. Buurman. 1994. Differential regulatory effects of adenosine on cytokine release by activated human monocytes. $\mathrm{J}$. Immun. 153:4159-4168.

2. Carlson, S. E., M. B. Montalto, D. L. Ponder, S. H. Werkman, and S. B. Korones. 1998. Lower incidence of necrotizing enterocolitis in infants fed a preterm formula with egg phospholipids. Pediatr. Res. 44:491-498.

3. Cavaillon, J-M., Fitting C., Haeffner-Cavaillon N., Kirsch S.J., and Warren H.S. 1990. Cytokine response by monocytes and macrophages to firee and lipoprotein-bound lipopolysacchatide. Infect. Imm. 58:2375-2382.

4. Dashti, N., E. A. Sinith, and P. Alaupovic. 1990. Increased production of apolipoprotein B and its lipoproteins by olleic acid in Caco-2 cells. J. Lipid Res. 31:113-123.

5. Deitch, E. A. 1990. Bacterial translocation of the gut flora. J. Trauna. 30:S184-S189,

6. Deitch, E. A., R. Berg, and R. Specian. 1987. Endotoxin promotes the translocation of bacteria from the gut. Arch. Surg. 122:185-190.

7. De Vree, J. M. L. , J. A. Romijn, K. S. Mok, L. M. H. Mathus-Vliegen, C. P. Stoutenbeek, 1. D Ostrow, G. N. J. Tytgat, H. P. Sauerwein, R. P. J. Oude Elferink, and A. K. Groen. 1999. Laclis of enteral nutrition during critical illness is associated with profound decrements in biliary lipid concentrations. Am. J. Clin. Nutr. 70;70-77.

8. Dixon, J. M., C. P. Armstrong, S. W. Duffy, and G. C. Davies. 1983. Factors affecting morbidity and mortality after surgery for obstructive jaundice: a review of 373 patients. Gut. $24: 845-852$.

9. Engelberts, L., A. Moller, G.J.M. Schoen, C.J. van der Jinden, and W.A. Buurnan. 1991 Evaluation of measurement of human TNF in plasma by ELISA. Lymphokine and Cylokine Res 10:69-76.

10. Ethinger, W. H., V. K. Varma, M. Sorci-Thomas, J. S. Parks, R. C. Sigmon, T. K. Smith, and R. B. Verdery. 1994. Cytokines decrease apolipoprotein accumulation in medium from Hep $G 2$ cells. Arterioscler. Thromb. 14:8-13. 
11. Feingold, K. R, J. L. Funk, A. H. Moser, J. K. Shigenaga, J. H. Rapp, and C. Grunfeld 1995. Role for circulating lipoproteins in protection from endotoxin toxicity. Infect. Immun. 63: 20412046.

12. Field, I. J, E. Borm, H, Chen, S. Murthy, and S. N. Mathur. 1994. Regulation of apolipoprotein B secretion by biliary lipids in Caco-2 cells. J. Lipid Res. $35 ; 749-762$.

13. Flegel, W. A. A. Wolpl, D. N. Mannel, and H. Northoff. 1989. Inhibition of enclotoxin-induced activation of human monocytes by human lipoproteins. Infect. lmmun $57.2237-2245$.

14. Gruifeld C., M. Marshall, J. K. Shigenaga, A. H. Moser, P. Tobias, and K. R Feingold 1999. Lipoproteins inhibit macrophage activation by lipoteichoic acid. J. Lipid Res. 40;245-252

15. Guo, W, R Andersson, A. Ljungh, H. Pärsson, K. Johansson, and S. Bengmark. 1994. Orally Administered phospholipids inhibit abdominal rubber-drain-induced bacterial translocation in the rat. Digestion, $55: 417-424$.

16. Hardardottir, I., I. Sipe, A. H. Moser, C. J. Fielding, K. R. Feingold, and C. Grunfeld. 1997. LPS and cytoknes regulate extra hepatie mRNA levels of apolipoproteins during the acute phase response in Syrian hansters. Biochem. Biophys. Acta $1344: 210-220$.

17. Hardardottir II., C. Grunfeld, and K. R. Feingold. 1994. Effects of endotoxin and cytokines on lipid metabolism. Curr. Opin. Lipidol. 5:207-215.

18. Harris, H. W., C. Grunfeld, K. R. Feingold, and J. H. Rapp. 1990. Human very low density lipoprotens and chylomicrons can protect against endotoxin-induced death in mice. J. Clin. Invest. 86:696-702.

19. Harris, H. W., C. Grunfeld, K. R. Feingold, T. E Read, J. P. Kane, A. L. Jones, E. B. Eichbaum, G. F. Bland, and J. H. Rapp. 1993. Chylomicrons alter the fate of endotoxin, decreasing tumor necrosis factor release and preventing death. J. Clin. Invest. 91 : 1028-1034

20. Harris, H. W., J. A. Johnson, and S. I. Wigmore. 2002. Endogenous lipoproteins impact the response to endotoxin in humans. Crit. Care Med. 30:23-31.

21. Hidalgo IJ, Raub TI, Borchardt RT. 1989. Characterization of the human colon carcinoma cell line (Caco-2) as a model system for intestinal epithellial permeability. Gastroenterology 96:736749.

22. Levy, E., M. Melran, and E. Seidman. 1995. Caco-2 cells as a model for intestinal lipoprotein synthesis and secretion. FASEB J. 9;626-635.

23. Mansbach, C. M. A. Arnold, and M. A. Cox. 1985. Factors influencing triacylglycerol delivery into mesenteric lymph. Am. J. Physiol.249; G642-648.

24. Marshall, J. C., N. V. Christou, R. Horn, and J. L. Meakins. 1988. The microbiology of multiple organ failure. Arch. Surg. 123:309-315.

25. Mathur, S. N., E. Born, S. Murthy, and F. J. Field. 1996. Phosphatidylcholine increases the secretion of triacylglycerol-rich lipoproteins by Caco-2 cells. Biochem. J. 314;569-575.

26. Meliran, M., E. Seidman, R. Marchand, C. Gurbindo, and E. Lewy. 1995. Tumor necrosis factor- $\alpha$ inhibits lipid and lipoprotein transport by Caco-2 cells. Am. J. Physiol. 269:0953-G960.

27. Mentes, B, B., E. Tatlicioglu, G. Akyol, O. Uluoglu, N. Sultan, E. Yilmaz, M. Cellebi, F. Taneri, and 2 . Ferahkose. 1996 Intestinal endotoxins as co-factors of liver injury in obstructive jaundice. HPB Surg. 9:61-69.

28. Mercer, D. W., G. S. Smith, J. M. Cross, D. H. Russell, L. Chang, and J. Cacioppo. 1996. Effects of lipopolysaccharide on intestinal injury; potential role of nitric oxide and lipid peroxidation. I Surg Res. 63:185-92.

29. Muir, L. V., E. Born, S. N. Mathur, and F. J. Field. 1996. Lysophosphatidy leholine increases 3. hydroxy-3-methylglutaryl-coenzyme A reductase gene expression in Caco-2 cells. Gastroenterology. 110:1068-1076.

30. Murthy, S., S. N. Mathur, F. J. Field. 2000. Tumor necrosis factor-alpha and interleukin-Ibeta inhibit apolipoprotein B secretion in Caco-2 cells via the epidermal growth factor receptor signaling pathway. J. Biol. Chem. 275:9222-9229.

31. Murthy, S., S. N. Mathur, G. Varilek, W. Bishop, and F. J. Field, 1996. Cytokines regulate apolipoprotein B secretion by Caco-2 cells. Am. J. Physiol. 270; G94-102.

32. Netea, M. G., P. N. M. Demacker, B. J. Kullberg, L. E. H. Jacobs, T. J. G. Verver-Jansen, O. C. Boerman, A. F. H. Stalenhoef, and J. W. M. van der Meer. 1998. Bacterial lipopolysaccharide 
binds and stimulates cytokine producing cells before neutralization by andogenoins lipoproteins can occur. Cytokine. 10: 766-772.

33. Noh, S. K, and S. I. Koo. 2001 . Enteral infusion of phosphatidy/choline increases the lymphatic absorption of fat, but lowers alpha-tocopherol absorption in rat fed a low zinc diet. I. Nutr. Biochem. 12:330-337.

34. O'Boyle, C.J., J. MacFie, C. J. Mitchell, D. Johnstone, P. M. Sagar, and P. C Sedman. 1998. Microbiology of bacterial translocation in humans. Gut $42 ; 29-35$.

35. Parks, R.W., C. H. Stuart Cameron, C. D. Gannon, C. Pope, T. Diamond, and B. J. Rowlands. 2000. Changes in gastrointestinal morphology associated with obstructive jaundice. J. Pathol. $192: 526-532$

36. Pinto, M., S. Robine-leon, M. Appay, M. Kedinger, N. Triadou, E. Dussaulx, B. Lacroix, P. Simon-assmann, K. Haffen, J. Fogh, A. Zweibaum. 1983. Enterocyte-like differentiation and polarization of the human colon carcinoma cell line Caco-2 in culture. Biol.Cell. $47: 323-330$.

37. Plata-Salaman C. R. 2001. Cytokines and feeding. Int. J. Obes. Metab. Disord. $25: \mathrm{S} 48-52$.

38. Read, T. E., C. Grunfeld, Z. Kumwenda, M. C. Calhoun, J. P. Kane, K. R. Feingold, and J. H. Rapp. 1995. Triglyceride-rich lipoprotens improve survival when given after endotoxin in rats. Surgery. 117;62-67.

39. Read, T. E., H.W. Harris, C. Grunfeld, K. R. Feingold, M. C. Calhoun, J. P. Kane, and J. H. Rapp. 1993. Chylomicrons enhance endotoxin excretion in Bile. Infect. Inmun. 61:3496-3502.

40. Rensen, P.C.N., M. van Oosten, E. van de Bilt, M. van Eck, J. Kuiper, and T.J.C. van Berkel. 1997. Human recombinant apolipoprotein E redirects lipopolysaccharide from kuplfer cells to liver parenchymal cells in rats in vivo. J. Clin. Invest, 99:2438-2445.

41. Terpstra, A. H. M. 1985. Isolation of serum chylomicrons prior to density gradient ultracentrifugation of other serum lipoprotein classes. Anal. Biochem. 150:221-227.

42. Van Lenten, B. J., A. M. Fogelman, M. E. Haberland, and P. A. Edwards. 1986. The role of lipoproteins and receptor-mediated endocytosis in the transport of bacterial lipopolysaccharide. Proc. Natl. Acad. Sci. USA. 83:2704-2708.

43. Victorov, A. V., N. V. Medvedeva, E. M. Gladkaya, A. D. Morozkin, E. A. Podrez, V. A. Kosykh, and V. A. Yurkiv. 1989. Composition and structure of lipopolysaccharide-human plasma low density lipoprotein conplex. Biochim. Biophys. Acta. 984: 119-127.

44. Voshol, P. J., D. M. Minich, R. Havinga, R. P. Elferink, H. J. Verkade, A. K. Groen, F. Kuipers, 2000. Postprandial chylomicron formation and fat absorption in multidrug resistance gene $2 \mathrm{P}$. glycoprotein-deficient mice. Gastroenterolgy 118:173-182.

45. Vreugdenhill, A.C.E., M.A. Dentener, A.M.P. Snoek, J-W. Greve, and W.A. Buurman. 1999. Lipopolysaccharide binding protein and serum amyloid A secretion by human intestinal epithelial cells during the acute phase response. J. Immum. 163:2792-2798.

46. Vreugdenhil, A. C. E. A.M.P. Snoek, J-W. Greve, W.A. Burman. 2000 Lipopolysaccharide. binding protein is vectorially secreted and transported by cultured intestimal epithelial cells and is present in the intestinal mucus of mice. J. Immun. 165:4561-4566

47. Vreugdenhil, A. C. E., A. M. P. Snoek, C. van "t Veer, J-W. M. Greve, and W. A. Burrman. 2001 Lipopolysaccharide Binding Protein circulates associated with alpoB containing lipoproteins and enhances endotoxin-LDL/VLDL interaction. J. Clin. Invest. 107:225-233.

48. Wang, X. D., R. Andersson, V. Soltesz, W. Q. Wang, A. Ar"Rajab, and S. Bengmark. 1994. Thospholipids prevent enteric bacterial translocation in the earlier stage of experimental acute liver failure in the rat. Scand. J. Gastroenterol. 29:1117-1121. 


\section{Chapter 8}

\section{Summary and discussion/}

Samenvatting en discussie

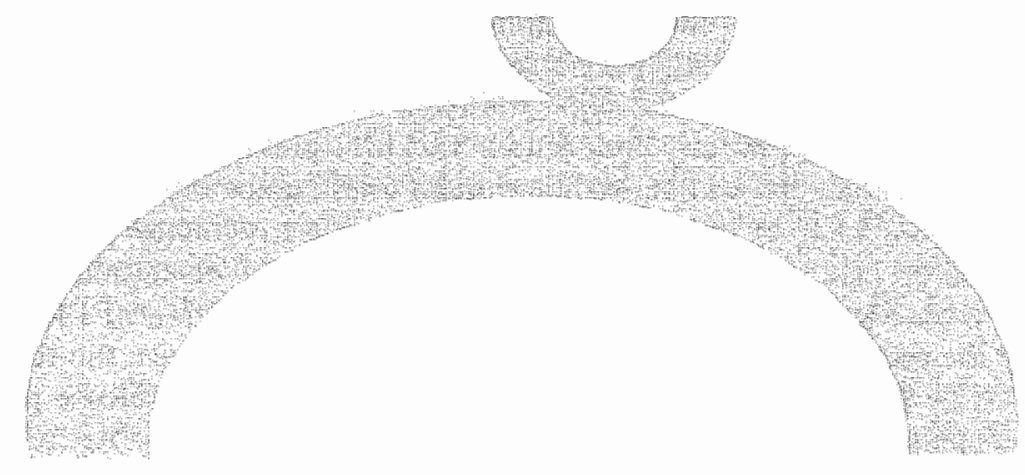




\section{Summary and discussion}

The gastrointestinal tract forms an enormous surface continuously exposed to high concentrations of bacteria and their toxic metabolites. Under pathologic conditions, such as hemorrhagic shock, severe burns, major trauma or complex surgical procedures, the intestinal barrier function fails, which is thought to cause translocation of bacteria and toxins that induce and perpetuate sepsis $(1,2)$. Although the intestinal barrier does not withstand these extreme conditions, under healthy or less extreme conditions the intestinal mucosa limits translocation of enteric bacteria and toxins and is capable of coping with small amounts of bacterial toxin that enter the host. For this function it has an extensive defense system at its disposal comprising of a mechanical barrier, a cellular and an immunological component.

Whereas, insights in the functioning and failure of the intestinal barrier are increasing, much of the complex mechanisms underlying this extensive natural line of defense have yet to be unravelled. New knowledge may form a guide in the development of treatment strategies intended to prevent gut derived bacterial infection and its detrimental effects. The aim of this thesis was to further explore the natural intestinal defense against bacterial toxins and find conditions to optimise this defense.

In the systemic response to bacterial toxins, LPS binding protein (LBP), an acute phase protein, has an important modulating dual role. Cell activation by endotoxin is enhanced by low concentrations of LBP, whereas high concentrations reduce the toxicity (3). In addition LBP enhances the detoxification of bacterial toxin by lipoproteins (3). The results of studies of Jack et al, which demonstrate enhanced mortality and uncontrolled multiplication and spread of bacteria in LBP knockout mice, indicate that LBP is essential for the resistance to bacteria (4). The liver was long thought to be the main organ responsible for LBP production. Hypothetically, local LBP secretion at a site of bacterial inwasion would provide a direct local response to bacteria and their toxins. Since the gastrointestinal tract is considered to be a route of entry for bacteria and toxins, we studied whether LBP is produced in the intestinal epithelium (Chapter 2). Human intestinal epithelial cells were demonstrated to synthesize and release LBP. In this study we also investigated the production of serum amyloid A (SAA) by intestinal epithelial cells. Although the primary function of SAA in the acute phase response is not fully understood, SAA was previously demonstrated to be involved in the routing and binding of lipoproteins to inflammatory cells (5). The secretion of LBP and SAA by intestinal epithelial cells was demonstrated to be strongly enhanced by the proinflammatory cytokines, TNF- $\alpha, I L-6$ and $I L-1 \beta$. Glucocorticoids were found to enhance the cytokine mediated induction of LBP and SAA release by the epithelial cells. Endotoxins were shown not to induce the release of LBP and SAA by intestinal epithelial cells, indicating that cytokine release in the proximity of the epithelial cells is necessary for the induction of LBP and SAA release by these cells. The capability of intestinal epithelial cells to release LBP and SAA suggests a role for the intestinal epithelium in the acute phase response and in the local defense of the gut against bacteria and endotoxin.

Next, we explored the polarity of LBP secretion by intestinal epithelial cells (Chapter 3). Constitutively, LBP was found to be secreted unipolar from the apical cell surface. This apical secretion of LBP was markedly enhanced when cells were exposed to proinflammatory cytokines at their apical surface. However, bioactive LBP was 
secreted from both cell surfaces after basolateral stimulation of cells. Cytokines also enhanced the secretion of SAA from both surfaces of Caco-2 cells, whereas the secretion of apoA-I and apoB was strongly decreased in the presence of cytokines. Further, it was demonstrated that LBP was transponted exclusively from the basolateral towards the apical cell surface. In line with these in who data, the presence of LEBP in intestinal mucus was strongly enhanced in mice after an intraperitoneally challenge with endotoxin. The results indicate that LBP is present at the mucosal surface of the intestine, a phenomenon for which secretion and transport of LBP by intestinal epithelial cells may be responsible. In addition, LBP is secreted towards the basolateral surface of the intestinal epithelium during an acute phase response.

Several lines of evidence indicate that LBP and serum lipoproteins cooperate in reducing the toxic properties of bacterial toxins. Others found evidence for an association of LBP with apoA-I containing lipoproteins in plasma from healthy persons (6). This physical association of LBP with lipoproteins may be important for the cooperation of LBP and lipoproteins in the detoxification of bacteriall toxins. However, the strong reduction of apoA-I and HDL levels $(7,8)$ which coincides with the raise in LBP levels during endotoxemia seems in contrast with this cooperative function. It is firmly established that LDL and VLDL are critical in the survival of bacterial infection (9) and that circulating levels of these lipoproteins are relatively high during unflammation compared to HDL levels. Therefore, we studied interactions of LBP with LDL and VLDL (Chapter 4). By separation of lipoprotein classes under the mild conditions of agarose electrophoresis followed by Westem blot analysis of LBP and apoproteins, we clearly demonstrate that LBP in serum is associated with apoB containing lipoproteins. In contrast, no association of LBP with HDL or apoA-I was found in serum. Consistently, we observed that LPS incubated with serum co-migrates with LBP and apoB, indicating that both LBP and, if present, LPS circulate predominantly associated with LDL and VLDL. Quantitative studies on LBP. lipoprotein interaction further demonstrated a strong interaction of LBP with isolated LDL and VLDL. Most interestingly, we observed that LBP bound to LDL and VLDL enhances the LPS binding capacity of these lipoproteins.

LBP induced binding of LPS to lipoproteins is of utmost importance during infection. Therefore, the association of LBP and LPS with lipoproteins was also studied in serum from septic patients. In septic serum containing high $L B P$ levels and a markedly altered lipoprotein spectrum, most of the LBP is associated with LDL and VLDL, although some LBP appeared to circulate free from lipoproteins. In line with these findings, we observed that also LPS predominanty binds to LDL and VLDL in serum from septic patients.

ApoB was found to account at least in part for the LBP binding capacity of LDL and VLDL. Although apoA-I also interacts with $L B P$, the affinity of LBP for apoB was found to be tenfold higher than for apoA-I, which is in accordance with the predominant association of LBP with LDL and VLDL in human serum.

Our results imply that LBP circulates as a complex with LDL and VLDL. ApoB functions as a binding site for $\angle B P$ on $L D L$ and VLDL, which interaction entances the rate of LPS binding. Overall these results emphasize a crucial role for LBP-LDL/VLDI complexes in the scavenging of endotoxin present in the circulation. 
Our observations that LBP is secreted by intestinal epithelial cells, together with our finding that circulating LBP is associated with apoB containing lipoproteins thereby enhancing its LPS binding capacity, prompted us to study whether LBP also cooperates with the apoB containing intestine derived chylomicrons in LPS binding and inactivation. Chylomicrons have previously been shown to prevent endotoxininduced inflammation and to improve survival when given in a murine endotoxemia model $(10,11)$. LBP was demonstrated to associate with chylomicrons and to enhance the amount of LPS binding to chylomicrons in a dose dependent fashion (Chapter 5). This LBP induced interaction of LPS with chylomicrons prevented endotoxin activity as demonstrated by reduced cytokine secretion by PBMC. When postprandial circulating concentrations of chylomicrons were compared with circulating levels of LDL, VLDL, and HDL, chylomicrons exceeded the other lipoproteins in LPS inactivating capacity. Furthermore, in presence of LBP chyllomicrons inhibited also the ability of LTA, a fragment of gram-positive bacteria, to stimulate cytokine secretion by PBMC.

Recently it was demonstrated that the intestinal epithelium takes up circulating endotoxin followed by secretion of endotoxin into the intestinal lumen (12). These data suggest that intestinal epithelial cells contribute to the clearance of endotoxin. We asked whether the binding of LPS to LBP-chylomicron complexes at the basolateral site of the intestinal epithelium influences the clearance of LPS by enterocytes. The transport of LPS from the basolateral towards the apical surface of Caco-2 cells was found to be markedly enhanced by basolateral presence of chylomicrons and further augmented by presence of both chyllomicrons and LBP (Figure 5, Chapter 1). These data imply that besides a function for LBP-chylomicron complexes in the detoxification of LPS, these complexes also contribute to the clearance of LPS by the intestinal epithelium.

In conclusion, our results indicate that LBP binds to chylomicrons and enables chylomicrons to rapidly bind high amounts of bacterial toxin, thereby preventing cell activation and increasing the clearance of toxin. We consider systemic clearance of bacterial toxin and inactivation of bacterial toxins by LBP-chylomicron complexes in the circulation of significance. In addition, we hypothesize that this is also part of a local defense mechanism of the intestine against translocated bacterial toxins, since LBP and chylomicrons are both synthesized by enterocytes. This may implicate that enteral feeding is a possible physiologic route to enhance the presence of toxin neutralizing and clearing chylomicrons in the circulation and probably more important, in the intestinal submucosa and lymphatics.

A high fat diet is known to increase chylomicron secretion in an early postprandial phase as well as hepatic secretion of VLDL in a later phase. Hypothetically postprandial enthancement of these lipoproteins increases the host's capacity to inactivate bacterial toxin either locally in the intestine or in the circulation. This inactivation will prevent the secretion of inflammatory mediators and damage to the intestinal barrier caused by these mediators or toxin themselves. To evaluate this hypothesis the effect of a high-fat enteral nutrition on endotoxemia and bacterial translocation was studied in a rat model of non-lethal hemorrhagic shock (Chapter 6). Most interestingly, the enhanced concentrations of circulating triacylglycerol and apolipoprotein $B$ were accompanied by reduced levels of circulating endotoxin and 
bacterial translocation. The data described are the first to show that a simple and relatively short nutritional intervention just before and direetly after haemorrhage with a high-fat diet results in improved gut barrier function.

In search for conditions to further enhance intestinal lipoprotein secretion during the acute phase response, we studied the effect of phosphatidylcholine (PC) on apolipoprotein secretion by enterocytes under normal and inflammatory conditions (Chapter 7), since PC is thought to be essential in intestinal lipoprotein assembly and secretion $(13,14,15)$. The data show that apical presence of lyso-phosphatidyllcholine (L-PC) enhances apolipoprotein secretion by enterocytes in vitro. Accordingly, enteral instillation of $\mathrm{PC}$ in healthy rats significantly enlanced circulating apoB levels. $\mathrm{PC}$ in combination with other nutritional compounds had an additional effect on the upregulation of intestinal apolipoprotein synthesis in vitro. Most interestingly, PC administered to enterocytes under acute phase conditions abrogated the cytokineinduced reduction of apolipoprotein secretion and even enhanced the secretion of apolipoproteins to the same levels as under non-acute phase conditions. The data of this study implies that enteral supplementation of PC enhances intestinal lipoprotein secretion during infection. Administration of $\mathrm{PC}$ may in particular be effective since the presence of dietary and biliary PC is strongly reduced in the intestinal lumen of critically ill patients (16). We speculate that PC induced secretion of lipoproteins by enterocytes may promote detoxification of bacterial toxins on the site of translocation and may prevent the local damage and systemic pathology induced by these toxins.

\section{General discussion}

In this thesis, the secretion of LBP by intestinal epithelial cells in vitro and in animal studies is described. This secretion is markedly enhanced under acute phase conditions. LBP can be secreted towards both, the apical and the basolateral surface of the intestinal epithelium. Inflammatory processes are known to take place at both sites of the intestinal mucosa. Several functions of LBP have been described, which can be applicable to processes taking place at the apical surface of normal and diseased epithelium. The secreted LBP may regulate the function of other cells in the local micro-environment. In addition, evidence for a role for LBP in the sequestration of Gram-negative bacteria was supported by at recent study, which demonstrated that intraperitoneal administration of bacteria is tolerated by wild type mice, whereas it results in an uncontrolled multiplication and spread of bacteria in LBP knockout mice (4). Moreover, i.p injection of LBP can reduce mortality mediated by endotoxin and bacteria in mice (3). In view of these functions apical secreted LBP may contribute to the intestinal barrier against bacteria and their toxin by increasing the ability of mucus to prevent bacterial translocation.

Basolaterally secreted LBP may contribute to the handling of endotoxins that have penetrated into the subepithelium during conditions in which a disturbed mucosal integrity results in enhanced permeability. First of all, this handling possibly concerns clearance of bacterial toxins from the submucosa. LBP was demonstrated to enhance the transport of LPS from the basolateral towards the apical surface in the presence of chylomicrons. Although further studies are necessary to investigate this phenomenon, we hypothesize that co-transport of LPS associated with LBP-chylomicron complexes 
across the intestinal epithelium may provide a mechanism of LPS clearance via the gutit.

In addition LBP produced by the intestine may contribute to the neutralization of endotoxin by lipoproteins. Intestinal LBP may cooperate with circulating lipoproteins, in particular LDL and VLDL, in the detoxification of bacterial toxin. Most interestingly however we demonstrated that LBP also associates with chylomicrons in vitro thereby enhancing the capacity of chylomicrons to inactivate bacterial toxin. In the light of this function it is plausible that intestinal LBP interacts with chylomicrons, which may provide a local mechanism for detoxification of bacterial toxin.

Although we hypothesize that the local production of LBP in the intestine might be part of the natural defense of the intestine against damage induced by bacterial toxin, we cannot exclude that LBP secreted by the intestinal epithelium can also sensitize the intestinal epithelium for bacterial toxin. In particular, under inflammatory conditions, in which the receptors for bacterial toxin expressed on the intestinal epithelium, i.e. TLRs and CD14, are increased $(17,18)$, and the secretion of intestinal lipoproteins is decreased, the presence of LBP may as well enhance cell activation by bacterial toxins and contribute to the damaging effects of an excessive proinflammatory response. Further studies, for instance in LBP-knock out mice or by instillation of LBP blocking antibodies into the intestinal lumen, are needed to define the function of LBP in the intestine. In addition, LBP production and secretion by the healthy and inflamed human gut still has to be substantiated.

On the basis of our findings we speculate that LBP-lipoprotein complexes may be essential in the detoxification and clearance of bacterial toxin that crossed the intestinall barrier in an early stage. Harris et al found that preincubation of LPS with postprandial blood was required for attenuation of the immune response by the endogenous lipoproteins secreted in response to feeding (19). We speculate that the endogenous lipoproteins secreted by the intestine have the opportumity to interact and neutralize bacterial toxins in the intestinal submucosa and lymphatics, hence before active toxins reach the blood stream. Preservation of the structure and function of the intestinal mucosa is essential for execution of this defense mechanism. Under conditions during which bacterial translocation may occur however, one of the most important factors necessary to maintain mucosal integrity and chylomicron production, namely enteral nutrition, is often lacking. In addition, as a result of fasting or TPN, mucosal mass decreases leaving fewer cells for LBP and chylomicron secretion. In this thesis, higl fat enteral mutrition was demonstrated to reduce endotoxemia and bacterial translocation under these kind of circumstances. Moreover, we found evidence that enteral administration of $\mathrm{PC}$ may be effective in enhancing intestinal lipoprotein secretion under inflammatory conditions.

The secretion of LBP by the intestine and its cooperation with chylomicrons in inactivating bacterial toxin, as described in this thesis, illuminates a possible natural defense mechanism of the host. The results may give implications for new therapentic strategies in the prevention of sepsis in for instance patients undergoing complex surgical procedures. Since the results clearly underline the importance of enteral feeding to maintain the proposed defense system, a new light is shed on the "nil by mouth" therapy in patients undergoing extensive surgery, in critically ill neonates, and in the acute phase of for instance meningococcal sepsis. 


\section{Samenvatting em discussie}

Het oppervlak van het maggdarmkanaal wordt continu blootgesteld atin grote hoeveelheden bacterièn en de gifstoffen die zij produceren, toxinen genoemd. Pathologische omstandigheden zoals een hemorrhagische shock, ernstige brandwonden, ernstig trauma of complexe chirurgische ingrepen, verstoren de integriteit van de darmbarrière, hetgeen verondersteld wordt translocatie van bacteriën en toxinen te induceren en daarmee sepsis in gang te zetten en in stand te houden ( 1 , 2). Hoewel de darmbarrière niet bestand is tegen deze extreme omstandigheden, beperkt de darm onder gezonde en minder extreme pathologische omstandigheden het binnendringen van bacteriën en toxinen in het lichaam, en is tevens in staat kleine hoeveelheden getransloceerde bacteriën te doden, de toxinen te inactiveren en te klaren waardoor een schadelijke ontstekingsreactie voorkomen wordt. Hiertoe beschikt de darm over een uitgebreid afweersysteem, bestaande uit een mechanische barrière, een cellulaire en een humorale afweer.

Hoewel de inzichten in het functioneren en falen van de darmbarrière toenemen, zijn veel van de ingewikkelde mechanismen die ten grondslag liggen aan dit uitgebreide afweersysteem nog onbegrepen. Nieuwe inzichten in de naturlijke afweer van de darm tegen bacteriën en toxinen kunnen een belangrijke basis vormen voor de ontwikkeling van behandelingsstrategieen die tot doel hebben infecties, ge ̈̈nitieerd vanuit de darm, te voorkomen en de schadelijke effecten ervan te beperken. Het doel van het onderzoek beschreven in dit proefschrift was het natuurlijke afweersysteem van de darm tegen bacteriële toxinen verder te onderzoeken en aangrijpingspunten te vinden voor interventies die de verdedigingsmechanismen van de darm tegen bacteriële toxinen optimaliseren.

In de systemische reactie van het lichaam op bacteriële toxinen speelt het acute fase eiwit LPS bindend eiwit (LBP), een essentiële rol. De activatie van cellen van het immuunsysteem door bacteriële toxinen neemt sterk toe in aanwezigheid van een lage concentratie LBP, terwijl een hoge concentratie LBP deze celactivatie remt (3). Bovendien katalyseert LBP de binding van bacteriële toxinen aan lipoproteïnen, waardoor toxinen niet meer in staat zijn cellen te activeren (3). De resultaten van een studie van Jack e.a. tonen aan dat de mortaliteit ten gevolge van een bacteriële infectie in LBP knock-out muizen sterk is toegenomen ten opzichte van wild type muizen. In LBP knock-out muizen vond een ongecontroleerde vermenigvuldiging en verspreiding van bacteriën plaats (4). Deze studie impliceert dat aanwezigheid van LBP essentieel is in de verdediging van het lichaam tegen bacteriën.

Lang is verondersteld dat circulerend LBP afkomstig is van de lever. Hypothetisch, zou locale productie van LBP, op plaatsen waar het lichaam wordt blootgesteld aan bacteriën, een meer directe en locale reactie op bacteriële toxinen kurnen induceren. Het maagdarmkanaal vormt bij uitstek een plaats waar het lichaam wordt blootgesteld aan bacteriën, die, onder pathologische omstandigheden, het lichaam binnendringen. Dit heeft ons ertoe gebracht de locale productie van LBP in de darm te bestuderen (Hoofdstuk 2). Humane darmepitheelcellen bleken LBP te produceren en uit te scheiden. In deze studie onderzochten we tevens de productie van het acute fase eiwit, serum amyloid A (SAA), door darmepitheelcellen. Hoewel de primaire functic van SAA nog grotendeels onbegrepen is, bleek uit voorgaand onderzoek dat SAA betrokken is bij het sturen van lipoproteinnen naar cellen van het immuunsysteem en 
daarmee naar de locatie van ontsteking (5). De uitscheiding van LBP en SAA door damepitheelcellen bleek sterk toe te nemen in aanwezigheid van de proinflammatoire cytokinen TWF- $\alpha$; 11-6 en 11-1 $\beta$. Deze door cytokinen gemedieerde uitscheiding wan LBP en SAA nam verder toe onder invloed van glucocorticoiden. Geconstateerd werd dat endotoxinen zelf geen effect hebben op de uitscheiding van LBP en SAA door darmepitheelcellen. De capaciteit van darmepitheel om LBP en SAA uit te scheiden suggereert een belangrijke rol voor deze cellen in de acute fase response en in de locale verdediging van de darm tegen bacteriële toxinen.

Vervolgens, hebben we de polariteit van de LBP uitscheiding door darmepitheelcellen bestudeerd (Hoofdstuk 3). Ongestimuleerde cellen bleken LBP uitshitend naar de apicale zijde uit te scheiden. Deze apicale uitscheiding van LBP nam duidelijk toe indien het apicale celoppervlak werd blootgesteld aan pro-inflammatoire cytokinen. Indien de cellen echter aan de basolaterale zijde werden blootgesteld aan cytokinen, werd biologisch actief LBP uitgescheiden naar zowel de apicale als de basolaterale zijde. De aanwezigheid van cytokinen verhoogde eveneens de uitscheiding van SAA naar beide celpolen, terwijl de uitscheiding van de negatieve acute fase eiwitten apoAI en apoB sterk werd gereduceerd. In deze studie toonden we bovendien aan dat LBP uitsluitend van de basolaterale zijde naar de apicale zijde van darmepitheelcellen wordt getransporteerd. Overeenkomstig deze in vitro resultaten, bleek de aanwezigheid van LBP in de darmmucus van muizen sterk toe te nemen na intraperitoneale toediening van endotoxinen. Tesamen impliceren deze gegevens dat LBP aanwezig is op het apicale oppervlak van de darmmucosa, waarvoor zowel uitscheiding van door darmepitheel geproduceerd LBP als transport van LBP door het darmepitheel verantwoordelijk kunnen zijn. Daarnaast toont deze studie dat tijdens een acute fase response LBP eveneens naar de basolaterale zijde van het epitheel wordt uitgescheiden.

Er zijn diverse studies beschreven in de literatuur die aantonen dat LBP en lipoproteinen een gezamenlijke functie vervullen in het verminderen van de schadelijke effecten van bacteriële toxinen. Een van deze studies beschrijft de binding van LBP aan apoA-I bevattende lipoproteinen in het plasma van gezonde personen (6). Een dergelijke associatie van LBP met lipoproteinen zou een rol kunnen spelen in het onschadelijk maken van bacterièle toxinen. Echter, de enorme afname van apoA-I en HDL concentraties $(7,8)$ die vergezeld gaat met een sterke toename van de LBP concentratie tijdens endotoxinemie lijkt in tegenspraak met een dergelijke coöperatieve functie. Er zijn sterke aanwijzingen dat LDL en VLDL, waarvan de circulerende concentraties in vergelijking met HDL relatief hoog blijven tijdens een ontstekingsreactie, een essentiële rol vervullen bij de overleving van bacteriele infecties (9). Dit heeft ons ertoe gebracht de interactie tussen LBP en LDL en VLDL te bestuderen (Hoofdstuk 4). Door lipoproteïnen te scheiden middels agarose electroforese, gevolgd door Western blot analyse van LBP en apolipoproteinen, vonden we sterke aanwijzingen voor de binding van LBP aan apoB bevattende lipoproteinen in de circulatie. Binding van LBP aan apoA-I danwel apoA-I bevattende lipoproteinen was daarentegen niet aantoonbaar in serum. In overeenstemming met deze bevindingen, bleek dat LPS, na incubatie met serum, co-lokaliseert met LBP en apoB, hetgeen impliceert dat zowel LBP als LPS, indien aanwezig, in de circulatie voornamelijk gebonden zijn aan LDL en VLDL. Ook kwantitatieve experimenten 
toonden een sterke interactie tussen LBP en geìsoleerd LDL en VLDL. Bovendien bleek uit deze studie dat de binding van LBP aan LDL en VLDL resulteert in een sterk toegenomen LPS bindingscapaciteit van deze lipoproteïnen.

Deze LBP gemedieerde binding van LPS aan lipoproteinen is met name van belang tijdens een infectie. Daarom hebben we de associatie van LBP en LPS met lipoproteïnen bestudeerd in het serum van septische patiënten. Ook in dit septische serum, met hoge concentraties LBP en een sterk veranderd lipoproteȟnen spectrum, was LBP voornamelijk gebonden an LDL en VLDL. Een geringe hoeveetheid LBP bleek echter niet gebonden aan lipoproteinen te circuleren. In overeenstemming met deze resultaten constateerden we dat ook LPS voornamelijk gebonden is aan LDL en VLDL in het serum van septische patiënten

$A p o B$ bleek een component van LDL en VLDL te zijn met een hoge affiniteit voor LBP. Hoewel LBP eveneens kan binden aan apoA-I, is de affiniteit van LBP voor apoB tien keer hoger dan voor apoA-I.

De resultaten van deze studies impliceren dat LBP als een complex met LDL en VLDL circuleert. ApoB functioneert daarbij als bindingsplaats voor LBP op LDL en VLDL, van waaruit LBP de binding van LPS aan deze lipoproteînen verhoogt. Deze resultaten benadrukken bovendien een belangrijke rol voor LBP-LDL/VLDL complexen in het wegvangen van toxinen in de circulatie.

De observatie dat LBP wordt uitgescheiden door darmepitheel, tesamen met de observatie dat LBP in de circulatie bindt aan de apoB bevattende lipoproteinnen VLDL, en LDL en daarmee de LPS bindingscapaciteit van deze lipoproteìnen verhoogd, heeft ons er toe gebracht te bestuderen of er een soortgelijke interactie is tussen L.BP en chylomicronen. Chylomicronen bevatten eveneens apoB en worden postprandiaal uitgescheiden door de darm. Voorgaande studies toonden aan dat chylomicronen beschermen tegen ontstekingsreacties geïnduceerd door endotoxinen en dat daardoor de overleving van endotoxinemie toeneemt in muizen $(10,11)$. Uit onze studie bleek LBP te binden aan chylomicronen, hetgeen een dosisafhankelijke toename van de binding van LPS aan chylomicronen tot gevolg had (Hoofdstuk 5). Bovendien toonden we aan dat deze LBP gemedieerde binding van LPS aan chylomicronen de activiteit van toxinen remt, blijkens verminderde cytokinen secretie door PBMC. Indien de postprandiale concentratie chylomicronen werd vergeleken met circulerende concentraties LDL, VLDL en HDL, bleek de LPS inactiverende capaciteit van chylomicronen groter te zijn dan die van de andere lipoproteïnen. Bovendien bleken chylomicronen in aanwezigheid van LBP eveneens in staat LTA, afkomstig van grampositieve bacteriên, te inactiveren.

Recent onderzoek toonde aan dat darmepitheel endotoxinen opneemt uit de circulatie en uitscheidt in het darmlumen (12). Deze gegevens suggereren dat darmepitheel betrokken is bij de klaring van bacteriële toxinen. Naar aanleiding van deze studie en onze voorgaande resultaten hebben we bestudeerd of de binding van LPS aan LBPchylomicron complexen aan de basolaterale zijde van het darmepitheel van invloed is op de klaring van LPS door deze cellen. Het transport van LPS van de basolaterale naar de apicale zijde van Caco-2 cellen bleek duidelijk verhoogd te worden door de aanwezigheid van chylomicronen. Dit transport werd verder verhoogd indien naast chylomicronen eveneens LBP aanwezig was aan de basolaterale zijde (Figuur 5, Hoofdstuk 1). Deze resultaten impliceren dat naast een mogelijke rol voor LBP- 
chylomicton complexen in de inactivatie van bacteriële toxinen, deze complexen tevens a rol kunnen spelen in de klaring van bacteriele toxinen door het darmepitheel.

Samenvattend toonden de resultaten van de studies, tot dusver beschreven, dat LBP aan chylomicionen bindt en daarmee chylomicronen in staat stelt snel en grote hoeverheden bacteriele toxinen te binden, te inactiveren en te klaren. Wij veronderstellen dat een dergelijke functie van LBP-chylomicron complexen een rol van betekenis kan zijn in de systemische crirulatie. Daamaast hypothetiseren wij dat deze functie van LBP-chylomicron complexen eveneens deel kan uitmaken van de locale verdedigingsmechanismen van de darm tegen getransloceerde bacteriele toxinen, gezien het feit beide, LBP en chylomicronen, worden uitgescheiden door het darmepitheel. Een dergelijk mechanisme impliceert dat toediening van orale voeding een natuurlijke manier is om de aanwezigheid van toxinen neutraliserende en klarende chylomicronen te verhogen in de circulatie en belangrijker nog, in de submucosa en Jymfevaten van de darm.

Het is bekend dat een vetrijke voeding de secretie van chylomicronen in een vroege postprandiale fase verhoogt en, in een latere fase, de secretie van VLDL door de lever verhoogt. Hypothetisch zou de postprandiale toename van deze lipoproteïnen de capaciteit van het lichasm om bacteriële toxinen te inactiveren en te klaren verhogen. Inactivatie van toxinen voorkomt het vrijkomen van onstekingsmediatoren en daarmee schade an de darmbarrière door deze mediatoren of de toxinen zelf. Deze hypothese hebben we geëvalueerd door het effect van een vetrijke voeding op endotoxinemie en bacteriële translocatie te bestuderen in een proefdier model waarin ratten een nietlethale hemorrhagische shock ondergaan (Hoofstuk 6). De toegenomen concentratie triacylglycerol en apo $\mathrm{B}$ in de circulatie geinduceerd door deze vetrijke voeding, bleek in dit model gepaard te gaan met een verminderde concentratie circullerende endotoxinen en minder bacteriële translocatie. Concluderend, toont deze studie aan dat een eenvoudige en korte voedingsinterventie vlak voor en na een hemorrhagische shock, resulteert in een verbeterde darmbarrière functie.

Vervolgens hebben we naar condities gezocht die de uitscheiding van lipoproteinnen door de darn verder kunnen verhogen tijdens een acute fase response. Omdat verondersteld wordt dat fosfatidylcholine (PC) van essentieel belang is voor de productie en uitscheiding van lipoproteïnen door de darm $(13,14,15)$, hebben we het effect van PC op de apolipoproteïnen secretie door enterocyten bestudeerd, onder normale en inflammatoire omstandigheden (Hoofdstuk 7). De resultaten van deze studie tonen dat de apicale aanwezigheid wan lyso-fosfatidylcholine $(\mathrm{L}-\mathrm{PC})$ de apolipoproteünen secretie in vitro verhoogd. Ook in vivo, resulteerde de orale toediening van PC aan gezonde ratten in een significante toename van de circulerende concentratie apoB. Toevoeging van $\mathrm{PC}$ aan een samenstelling van andere voedingscomponenten had een additief effect op de uitscheiding van apolipoproteinen door darmepitheelcellen in vitro. Cytokinen hebben een sterk remmend effect op de secretie van apolipoproteünen door enterocyten. Toediening van PC deed dit remmende effect van cytokinen volledig teniet en verhoogde de apolipoproteinen secretie door de darm onder deze acute fase condities zelfs tot gelijke hoeveelheden als uitgescheiden in afwezigheid van cytokinen. De resultaten verkregen uit deze studie suggereren dat enterale toediening van $\mathrm{PC}$ de intestinale lipoproteinen secretie 
verhoogd tijdens infecties. De aanwezigheid van fosfolipiden in thet darmlumen afkomstig uit de gal en uit de voeding is sterk gereduceerd bij ernstig ziek patiènten (16), hetgeen de effectiviteit van orale toediening van $\mathrm{PC}$ onder deze omstandigheden waarschijnlijk maakt. Wij veronderstellen dat PC genedieerde secretie van lipoproteïnen door enterocyten de detoxificatie van bacteriële toxinen zal verhogen op een plek waar bacteriën het lichaam binnendringen en dat daardoor de locale schade aan de darm en de systemische pathologische gevolgen van deze bacterièn en hun toxinen beperkt worden.

\section{Discussie}

In dit proefschrift wordt de uitscheiding van LBP door darmepitheelcellen beschreven. Deze uitscheiding is duidelijk toegenomen tijdens een acute fase reactie. LBP kan zowel naar de basolaterale als naar de apicale zijde van het darmepitheel worden uitgescheiden. Ontstekingsprocessen spelen zich aan beide polen van het darmepitheel af. Er zijn diverse functies van LBP beschreven in de literatuur, die toepasbaar zijn op processen die zich afspelen aan de apicale zijde van het darmepitheel onder zowel gezonde als pathologische omstandigheden. Apicaal uitgescheiden LBP reguleet mogelijk de functie van andere cellen in de omgeving van het darmepitheel. Bovendien volgde uit een recente studie sterke aanwijzingen voor een rol voor LBP in de sequestratie van gram-negatieve bacteriën. In deze studie werd geconstateerd dat intraperitoneale toediening van bacteriën goed getolereerd word door wild type muizen, terwijl dit in LBP knock-out muizen een ongecontroleerde vermenigvuldiging en verspreiding van bacteriën tot gevolg had (4). Bovendien, reduceert intraperitoneale toediening van LBP de mortaliteit geinduceerd door endotoxinen en bacterièn in muizen (3). In het licht van deze capaciteiten van LBP, is het mogelijk dat apicaal uitgescheiden LBP bijdraagt aan de barrière functie van de darm tegen bacteriën en toxinen door een vermindering van bacteriële translocatie.

Basolateraal uitgescheiden LBP speelt mogelijk een rol in de afweer tegen endotoxinen die aanwezig zijn in de subepitheliale ruimte onder omstandigheden waarin een verstoorde integriteit van de darmmucosa resulteert in een toegenomen permeabiliteit. Deze afweer bestaat mogelijk uit een toename van de klaring van bacteriêle toxinen uit de subepitheliale ruimte, gezien de resultaten van onze studie die aantonen dat LBP het transport van LPS van de basolaterale naar de apicale zijde van darmepitheel verhoogd in aanwezigheid van chylomicronen. Alhoewel vervolgstudies nodig zijn om dit fenomeen te bestuderen, hypothetiseren wij dat co-transport van LPS gebonden aan LBP-chylomicron complexen door het darmepitheel een mogelijk mechanisme is voor LPS klaring door de darm.

Daarnaast draagt basolateraal uitgescheiden LBP mogelijk bij aan de inactivatie van endotoxinen door lipoproteïnen. LBP uitgescheiden door de darm werkt daarbij mogelijk samen met circulerende lipoproteïnen, in het bijzonder LDL en VLDL. LBP is echter eveneens in staat te binden aan chylomicronen, waardoor de LPS inactiverende capaciteit van chylomicronen sterk toeneemt. In dit kader lijkt het mogelijk dat LBP, geproduceerd door de darm, samenwerkt met chylomicronen, en daarmee een lokaal verdedigingsmechanisme van de darm vormt tegen bacteriẻle toxinen. 
Hoewel we hypothetiseren dat de locale productie van LBP in de darm onderdeel uitmaakt van de natuurlijke verdediging van de darm tegen schade geïnduceerd door bacteriêle toxinen, is het op basis wan de in dit proefschrift beschreven studies niet mogelijk uit te sluiten dat LBP, uitgescheiden door de darm, cellen in de omgeving gevoeliger maakt voor bacteriële toxinen. Met name tijdens een ontstekingsreactie, wanneer de expressie van receptoren voor bacteriële toxinen, TLR en CD14, door darmepitheel en cellen van het immuinsysteem verhoogd is $(17,18)$ en bovendien de uitscheiding van intestinale lipoproteïnen verlaagd is, bestaat de mogelijkheid dat de aanwezigheid van LBP resulteert in een toegenomen cel activatie en daarmee bijdraagt aan de schade die het gevolg is van een overmatige pro-inflammatoire reactie. Om de precieze functie van LBP in de darm te definiëren, zijn vervolgstudies vereist, bijvoorbeeld studies waarin gebruik gemaakt wordt van LBP knock-out muizen of door toediening van LBP blokkerende factoren in het darmlumen. Bovendien, dient de LBP secretie door de gezonde en zieke humane darm nog te worden vastgesteld.

Op basis van onze bevindingen speculeren wij dat complexen van LBP en lipoproteĭnen essentieel zijn voor een snelle inactivatie en klaring van bacteriële toxinen die door een falende darmbarrière naar binnen zijn gelekt. Harris e.a. constateerden dat preincubatie van LPS met postprandiaal bloed essentieel is voor inhibitie van de afweerreactie door endogene lipoproteïnen geproduceerd in respons op voeding (19). Wij veronderstellen echter dat endogene lipoproteïnen uitgescheiden door de darm de mogelijkheid hebben een interactie aan te gaan met bacteriële toxinen in de submucosa van de darm en in de lymfevaten, en daarmee voorkomen dat actieve toxinen de circulatie bereiken. Het behoud van functie en structuur van de darmmucosa is essentieel om een dergelijke afweer functie te bewerkstelligen. Onder de pathologische omstandigheden waarbij bacteriële toxinen naar binnen lekken ontbreekt vaak echter de factor die essentieel is voor handhaving van de mucosale integriteit en secretie van chylomicronen, namelijk orale voeding. Bovendien resulteert vasten en TPN in een afname van de mucosa massa, waardoor er minder cellen zijn die LBP en chylomicronen kunnen produceren. In dit proefschrift wordt beschreven dat een vetrijke enterale voeding endotoxemie en bacteriële translocatie onder deze pathologische omstandigheden reduceert. Bovendien vonden we sterke aanwijzingen dat PC de secretie van lipoproteïnen door de darm verhoogd onder pro-inflammatoire omstandigheden.

De secretie van LBP door de darm en de samenwerking tussen LBP en chylomicronen in de inactivatie van bacteriêle toxinen, zoals beschreven in dit proefschrift, vertegenwoordigt een potentieel natuurlijk afweer mechanisme van het lichaam. De resultaten van de beschreven studies kunnen als basis dienen voor de ontwikkeling van nieuwe therapeutische strategieën die tot doel hebben sepsis te voorkomen, bijvoorbeeld bij patiënten die complexe chirurgische ingrepen moeten ondergaan. De resultaten benadrukken het belang van toediening van enterale voeding voor het behoud van dit potentiele verdedigingsmechanisme en schept daarmee een nieuw licht op het huidige nog wijd toegepaste 'niets per os" beleid bij patiënten die complexe chirurgische ingrepen ondergaan, bij ernstig zieke neonaten en in de acute fase van meningococcen sepsis. 


\section{References}

1. MacFie J, $\mathrm{O}^{\prime}$ Boyle $\mathrm{C}$, Mitchell $\mathrm{Cl}$, et al. Gut origin of sepsis: a prospective study investigating associations between bacterial translocation, gastric microflora, and septic morbidity. Gut $1999,45: 223-228$.

2. Woodcock NP, Sudheer V, El-Barghouti $\mathrm{N}_{\text {, }}$ et al. Bacterial translocation in pativents undergoing abdominal aortic aneurysm repair. Br I Surg 2000; 87:439-442.

3. Lamping $N$, Dettmer $\mathrm{R}$. Schröder NMI, et al. LPS-binding protein protects mice from septic shock caused by LPS or gram-negative bacteria. J Clin Invest 1998; 101:2065-2071.

4. Jack RS, Fan $X$, Bernheiden $M$, et al. Lipopolysaccharide-binding protein is required to combat a murine Gam-negative bacterial infection. Nature 1997;389:742.

5. Kisilevsky R, Subrahmanyan L. Serum amyloid A changes high density lipoprotein's cellular affinity. Lab Invest 1992; 66:778.

6. Wurfel MM, Kunitake ST, Lichenstein $\mathrm{H}$, et al. Lipopolysaccharide (LPS)-binding protein is carried on lipoproteins and act as a cofactor in the neutralization of LPS. J Exp Med 1994;180: $1025-1035$.

7. Sammalkorpi $K$, Valtonen $V$, Kerttula $Y$, et al. Changes in serum lipoprotein pattern induced by acute infections. Metabolism 1988;37:859-865.

8. Cabana VG, Siegel JN, Sabesin SM, et al. Effects of the acute phase response on the concentration and density distribution of plasma lipids and apolipoproteins. I Lipid Res $1989 ; 30$ : $39-49$.

9. Netea MG, Demacker PNM, Kullberg BJ, et al. Low-density lipoprotein receptor deficient mice are protected against lethal endotoxemia and severe gran-negative infections. J Clin Invest $1996 ; 97: 1366-1372$.

10. Harris HW, Grunfeld C, Feingold KR, et al. Chylomicrons alter the fate of endotoxin, decreasing tumor necrosis factor release and preventing death. J Clin Invest 1993;91:1028-1034.

11. Read TE, Grunfeld C, Kumwenda $Z$, et al. Triglyceride-rich lipoproteins improve survival when given after endotoxin in rats. Surgery 1995;117;62-67.

12. Ge Y, Ezzell RM, Warren HS. Localization of endotoxin in the rat intestinal epithelium. J Infect Dis 2000;182:873-881

13. Field $\mathrm{FJ}$, Born $\mathrm{E}$, Chen $\mathrm{H}$, et al. Regulation of apolipoprotein $\mathrm{B}$ secretion by biliary lipids in Caco-2 cells. J Lipid Res 1994;35:749-762.

14. Mathur SN, Born $E$, Murthy $S$, et al. Phosphatidylcholine increases the secretion of triacylglycerol-rich lipoproteins by Caco-2 cells. Biochem. J 1996;314:569-575.

15. Voshol PJ, Minich DM, Havinga R, et all. Postprandial chylomicron formation and fat absorption in multidrug resistance gene 2 P-glycoprotein-deficient mice. Gastroenterolgy $2000 ; 118: 173-182$.

16. De Vree JML, Romijn JA, Mok KS, et al. Lack of enteral nutrition during critical illness is associated with profound decrements in biliary lipid concentrations. Am J Clin Nutr $1999,70: 70$ 77.

17. Cario $\mathbb{E}$, Podolsky DK. Differential alteration in intestinal epithelial cell expression of toll-like receptor 3 (TLR3) and TLR4 in inflammatory bowel disease. Infect Immun 2000;68:7010 070 77

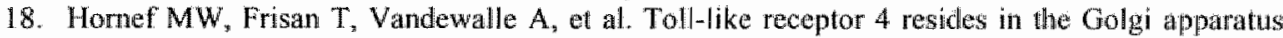
and colocalizes with internalized lipopolysaccharide in intestinal epithelial cells. J Exp Med 2002 $; 195: 559-570$

19. Harris HW, Johson JA, Wigmore SI. Endogenous lipoproteins impact the response to endotoxin in humans. Crit Care Med 2002;30:248-249 


\section{Dankwoord}

Velen hebben bijgedragen aan de totstandkoming van dit proefschrift.

Ten eerste mijn promoter, Prof. W.A. Buurman. Beste Wim, de brainstorms met jouw, soms uitmondend in de meest fantasierijke experimenten, soms onmogelijk en soms briljant, vormen de basis voor dit proefschrift en mijn interesse voor wetenschappelijk onderzoek. Jij stuurde mij op pad in de wereld van LBP, LPS, en verder, en waar nodig wees je de weg. Ik heb veel van je geleerd, onder andere het verkopen van bananen (ook de wat minder rijpe). Jij bood mij de kans om mijn studie met promotieonderzoek te combineren, ook daarin ben je een pioneer. Dank je wel voor het vertrouwen dat jij vanaf het eerste moment in me had, ik heb veel aan je te danken.

Mijn co-promotor, Dr. J.W.M. Greve. Beste Jan Willem, ook jouw ben ik erkentelijk voor je ondersteuning, de precisie waarmee je mijn artikelen corrigeerde, en je inzichten in de aansluiting tussen fundamenteel onderzoek en patientgerichte problematiek.

I would like to thank Prof. dr. E.F.M. Wouters, Prof. dr. R. Donckerwolcke, Prof. dr. R-J. M. Brummer, Prof. dr. J. Verhoef, and Prof. dr. C. Grunfeld, for their critical evaluation of this thesis.

Graag wil ik in het bijzonder Gaby, Joris, Patricia en Corine bedanken voor de enorme inzet waarmee zij vele experimenten, essentieel voor de totstandkoming van dit proefschrift, tot een goed einde hebben gebracht. Gaby, jij maakte mij wegwijs op het lab. Je weet hoe jammer ik het vind dat onze samenwerking te kort durde. Joris, ook jij kwam en ging, maar pas nadat je een belangrijk deel van het PCR werk had verricht. Patricia, hoewel het strippen van zo'n veel te dunne lipogel onmogelijk leek, slaagde jij erin en lukte het om samen met jou kunde en ervaring met Western blotting eindelijk aan te tonen dat LBP gebonden is aan apoB bevattende lipoproteinen. $\mathrm{Na} 3$ jaar frustraties en gepruts met andere technieken mijnerzijds, begrijp je hoe blij ik met jou impuls was. Ook ons uitstapje naar New York (seen that, done that), waar we en passant ook de isolatie van darmepitheelcellen leerden, is voor mij gedenkwaardig. Corine, het was zeer plezierig samenwerken en ook jouw enorme inzet en perfectionisme hebben geresulteerd in mooie resultaten.

Ik heb met zeer veel plezier samengewerkt met mijn collega's van de Algemene Heelkunde. Naast de geweldige werksfeer, waren de labuitjes en frequente borrels buitengewoon gezellig. Vincent, Francois, Nicole, Bart, Trudi, Mieke, Maarten, Danielle, Marloes, Erik, Mohammed, Kiyoko, Isabel, Annemarie, Jessica, Judith, Mehmet, Misha, Juanita, Marc, Mart-Jan, Marjan, Mickey, Brigitte en Kim bedankt voor de hulp daar waar nodig en de fijne werkplek. Kees, jij in het bijzonder bedankt voor je adviezen. Al vond ik je kritische noten niet altijd leuk op het moment dat ik net dacht dat het bewijs geleverd en het manuscript klaar was, maar uiteindelijk heb ik veel van je geleerd. 
Ook ben ik Sabine Neirynck en Hans Wolfgang van de Afdeling Moleculaire Biologie van de Universiteit Gent erkentelijk voor de mogelijkheid die zij mij hebben geboden om LBP in darmmucus van $11-10$ knock-out muizen te bestuderen. I would also like to thank Dr. L. Mayer and his colleagues at the Department of Medicine (The Mount Sinai Hospital, New York) for teaching me the isolation of intestinal epithelial cells. The isolation of hepatocytes I learned at the Department of Clinical and Surgical Sciences (Royal Infirmary of Edinburgh) and I would like to thank Dr. K.C. Fearon and his nice colleagues for their hospitality.

Ook mijn nieuwe collega's bij de Afdeling Kindergeneeskunde in het Maaslandziekenhuis Sittard en het Academisch Ziekenhuis Maastricht wil ik bedanken voor hun getoonde belangstelling en de ruimte die ze mij hebben geboden om het schrijven van dit proefschrift te voltooien.

Mijn paranimfen wil ik bedanken voor hun steun, nu en door de jaren heen. Lieve Inge, ook al zien we elkaar door de grote afstand niet vaak meer, het is steeds weer een kunst hoe jij mij in de spaarzame (maar lange) telefoongesprekken met het leven confronteerd en me hierin terug plaatst. Lieve Monique, één van de goede dingen die is voortgekomen uit het werken bij de Heelkunde is mijn vriendschap met jouw en natuurlijk met Erik. Ondanks de te veel onbeantwoorde e-mail (betere tijden breken aan), volhardt jij in het contact en zorgt altijd weer voor een gezellig onder ons.

Lieve Pap en Mam, dit proefschrift draag ik op aan julie, de'genen' die mij het doorzettingsvermogen en de creatieve geest meegaven om dit 'klusje' te kunnen klaren. Ik ben julie dankbaar voor julie sturende hand, later coachend vanaf de zijlijn, altijd motiverend, soms mee protesterend en daar waar nodig kritisch.

Lieve Jogchum, in onbeschrijvelijk veel opzichten heb jij me geholpen en gesteund bij het bereiken van mijn doelen, waaronder deze mijlpaal, dit proefschrift. Al mijn halve leven deel je mijn enthousiasme voor de studies en het onderzoek die mij tot dit punt hebben gebracht. Je gaf mij mijn enthousiasme terug na minder hoopvolle resultaten en wist in een hoofd vol chaos altijd weer orde te scheppen. Maar vooral, jij bent er altijd, thuis, geduldig wachtend op de dag dat mijn strijd tegen de klok gewonnen is. Onze proefschriften af, ons droomhuis van ons, ons gezinnetje... is het nu dan toch zover?

Lieve Stijn. Sinds jouw geboorte is de vordering van dit proefschrift grotendeels afhankelijk van de duur van jou middagdutjes. Je houdt niet erg van slapen, en dus moest je mijn aandacht vaak delen met de computer. 'Mamma op de computer', was een van je eerste 4- woorden zinnen. Vanaf nu kunnen we op 'mamma-dagen' samen zwemmen, tekenen, voetballen en al die andere dingen doen die jij zo leuk vind. Dank je wel voor al je geduld. 


\section{Curriculum Vitae}

Anita Vreugdenhil was born on September $4^{\text {th }}, 1971$ in Delft, The Netherlands. In 1990 she finished secondary school at the "Rijksscholengemeenschap de Springborn" in Epe. Starting in 1991, she studied Food and Dietetics at the Hanzehogeschool Groningen, and graduated in 1994. The internship of this study was performed at the departments of Clinical Nutrition of the Sahl-Grenska hospital in Göteborg, Sweden. In 1994 she started to study Biological Health Science at the Faculty of Health Sciences, Maastricht University. Her internship was spent at the Department of General Surgery, Maastricht University, in which she developed monoclonal antibodies against LBP and she started studying the function of LBP. She graduated Cum Laude in 1996.

From 1992 until 1993 she attended Medical School at the University of Groningen, which study was continued at the Maastricht University from 1994 until 1997. During her medical training at the Maastricht University, she worked as a research assistant at the Department of General Surgery under guidance of Prof. Dr. W.A. Butrman. This research was continued during her PhD-Project, which started in 1997. During this period she also performed her clinical rotations. She received her Medical Degree in September 2001. From January until October 2002 she worked as AGNIO at the Pediatric Department of the Maasland Ziekenhuis Sittard, and started her pediatric training in the Academic Hospital Maastricht in October 2002. 


\section{Publications}

A.C.E. Vreugdenhil, M.A. Dentener, A.M.P. Snoek, J.W.M. Greve, W.A. Buturman. Lipopolysaccharide Binding Protein and Serum Amyloid A secretion by human intestinal epithelial cells during the acute phase response. J. Immunol. 1999;163:27922798

A.C.E. Vreugdenhil, A.M.P. Snoek, J.W.M. Greve, W.A. Buurman. Lipopolysaccharide-Binding Protein is vectorially secreted and transported by cultured intestinal epithelial cells and is present in the intestinal mucus of mice. J. Immunol. $2000 ; 165: 4561-4566$

M.G. Scott, A.C.E. Vreugdenhil, W.A. Buurman, R.E.W. Hamcock, M.R. Gold. Cationic antimicrobial peptides block the binding of lipopolysaccharide (LPS) to LPS Binding Protein. I.Immunol. 2000;164:549-553

M.A. Dentener, A.C.E. Vreugdenhil, P.H.M. Hoet, J.H.J. Vernooy, F.H.M. Nieman, D. Heumann, Y.M.W. Janssen, W.A. Buurman, E.F.M. Wouters. Production of the acute-phase protein Lipopolysaccharide-Binding Protein by respiratory type II epithelial cells. Am. J. Resp. Cell. Mol. Biol. 2000; 23:146-153

A.C.E. Vreugdenhil, A.M.P. Snoek, C. van 't Veer, J.W.M. Greve, W.A. Buurman. LPS-Binding Protein circulates in association with apoB-containing lipoproteins and enhances endotoxin-LDL/VLDL interaction. $J$. Clin. Invest. 2001; 107:225-234

A.C.E. Vreugdenhil, C.H. Rousseau, T. Hartung, J.W.M. Greve, C. van 't Veer, W.A. Buurman. Lipopolysaccharide (LPS)-Binding Protein mediates LPS detoxification by chylomicrons. J. Immunol. 2003; 170:1399-1405

A.C.E. Vreugdenhil, J.W.M. Greve, W.A. Buurman The natural defense of the intestine against infection; a compass for future strategies in the battle against sepsis. Submitted.

A.C.E. Vreugdenhil, A.M. Patricia Snoek, E.F. Engelen, J.W.M. Greve, W.A. Buurman. Phosphatidylcholine enhances apolipoprotein secretion by enterocytes during the acute phase response. Submitted.

M.D.P. Luyer, J.A. Jacobs, A.C.E. Vreugdenhil, M. Hadfoune, C.H.C. Dejong, W.A. Buurman, J.W.M. Greve. Enteral administration of high-fat nutrition before and directly after hemorrhagic shock reduces endotoxemia and bacterial translocation. Submitted. 